Aus der Klinik für Dermatologie, Venerologie und Allergologie

(Prof. Dr. med. M. P. Schön)

im Zentrum Arbeits-, Sozial-, Umweltmedizin und Dermatologie der Medizinischen Fakultät der Universität Göttingen

\title{
Die anti-tumorale Wirkung des neuen Phosphoinositid-3- Kinase-Inhibitors BAY 80-6946 auf humane Myelom-Zellen
}

\section{INAUGURAL - DISSERTATION}

zur Erlangung des Doktorgrades

der Medizinischen Fakultät der

Georg-August-Universität zu Göttingen

vorgelegt von

Janina Hensen (geb. Glauer)

aus

Langenhagen

Göttingen 2014 
Dekan: Prof. Dr. rer. nat. H. K. Kroemer

I. Berichterstatter: Prof. Dr. med. M. P. Schön

II. Berichterstatter: Prof. Dr. rer.nat. H. Bastians

III. Berichterstatter: Prof. Dr. med. M. Oppermann

Tag der mündlichen Prüfung: 20. Januar 2015

Die Inhalte der vorliegenden Arbeit wurden unter folgendem Titel: „A novel selective small-molecule PI3K inhibitor is effective against human multiple myeloma in vitro and in vivo"veröffentlicht (Glauer et al. 2013). 


\section{Inhaltsverzeichnis}

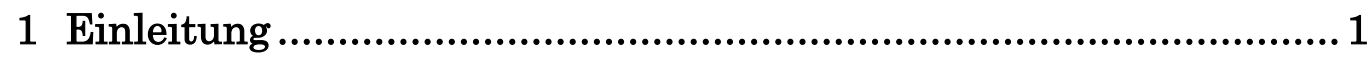

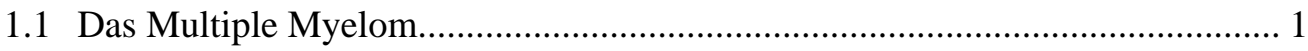

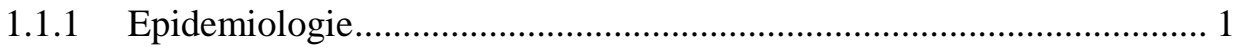

1.1.2 Symptomatik des Multiplen Myeloms ................................................ 2

1.1.3 Klassifikation und Stadieneinteilung .................................................. 3

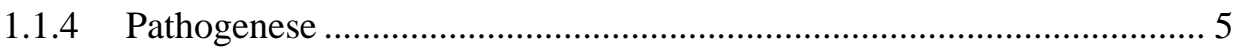

1.1.5 Das Mikromilieu im Knochenmark ………...................................... 7

1.1.6 IGF-1: Ein wesentlicher Wachstumsfaktor.......................................... 8

1.1.7 Therapieprinzipien und Prognosefaktoren .............................................. 9

1.1.8 Medikamentenresistenz .................................................................. 11

1.1.9 Targeted therapy als neue Behandlungsmöglichkeit.......................... 12

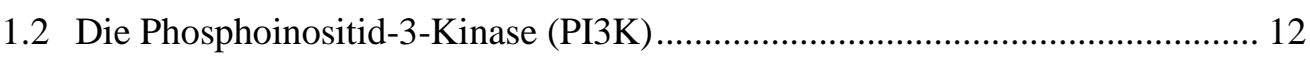

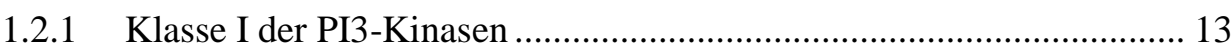

1.2.2 Signaltransduktion der PI3K und ihre Wirkungen .............................. 14

1.2.3 Expression und Tumorgenese der PI3K ….......................................... 17

1.2.4 Inhibitoren des PI3K-Akt-Signalweges ............................................ 18

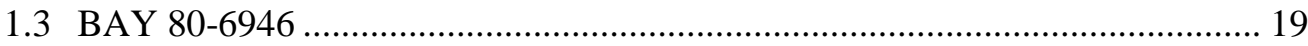

1.4 Zielsetzung und Fragestellung der Arbeit ........................................................ 20

2 Material und Methoden ......................................................... 22

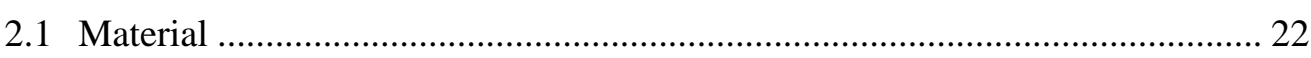

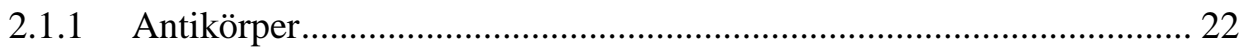

2.1.2 Materialien und Chemikalien ........................................................ 23

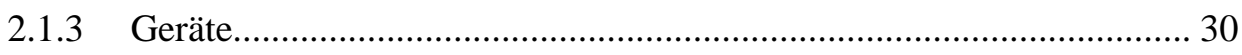

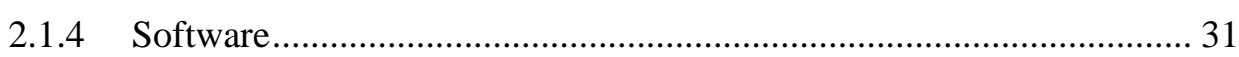

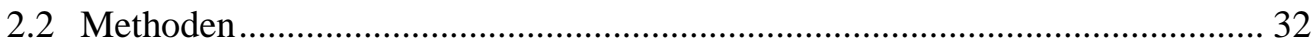

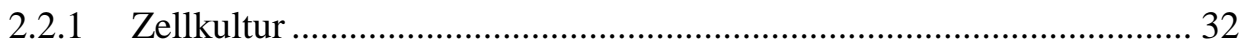

2.2.2 Zellpassage und Zählen der Zellen .................................................... 32

2.2.3 Behandlung mit BAY 80-6946 …...................................................... 33

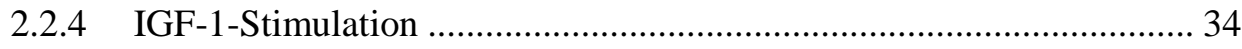

2.2.5 Proteingewinnung durch SDS-Lysate.............................................. 35

2.2.6 Photometrische Proteinkonzentrationsbestimmung............................ 35

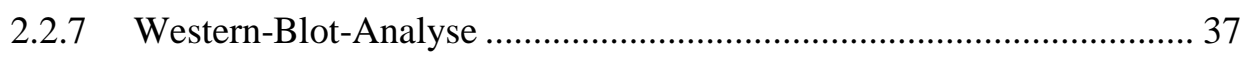

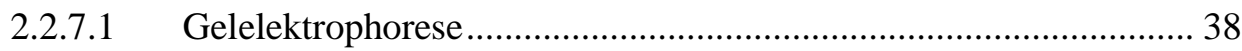

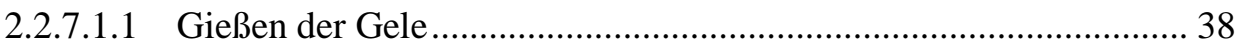

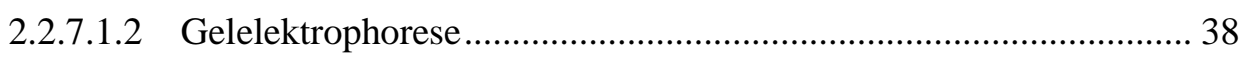


2.2.7.2 Blotten der Membran..................................................................... 39

2.2.7.3 Hinzugabe der Antikörper ........................................................... 39

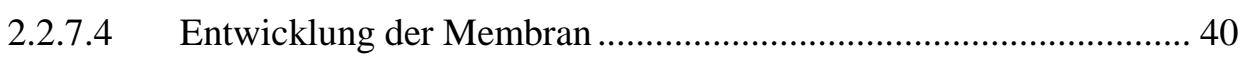

2.2.7.5 Auswertung der Ergebnisse ....................................................... 40

2.2.7.6 Western-Blot-Analyse mit WesternBreeze ${ }^{\circledR}$................................. 41

2.2.7.7 Stripping der Membran............................................................... 42

2.2.8 Durchflusszytometrie zur Bestimmung der p-Akt-Expression............. 42

2.2.8.1 Fixierung der Zellen ............................................................... 43

2.2.8.2 Permeabilisierung der Zellen....................................................... 43

2.2.8.3 Färbung der Zellen ................................................................... 43

2.2.8.4 Analyse mit dem Durchflusszytometer ........................................ 44

2.2.8.5 Statistische Auswertung der Daten................................................. 45

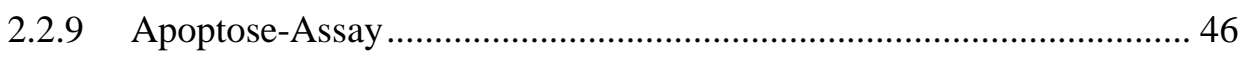

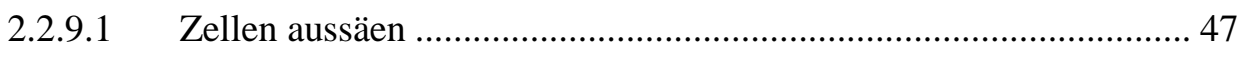

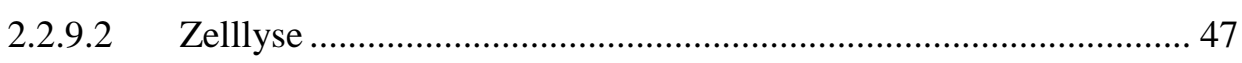

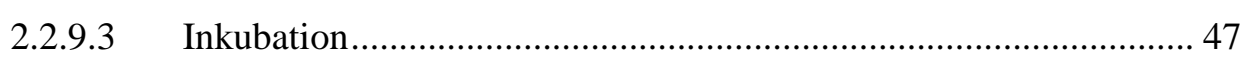

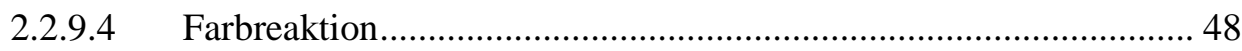

2.2.9.5 Auswertung und statistische Analyse der Ergebnisse .................... 48

2.2.10 Proliferations-Assay ...................................................................... 48

2.2.10.1 Durchführung der Proliferations-Assay-Analyse .......................... 49

2.2.10.2 Auswertung und statistische Analyse der Ergebnisse .................... 49

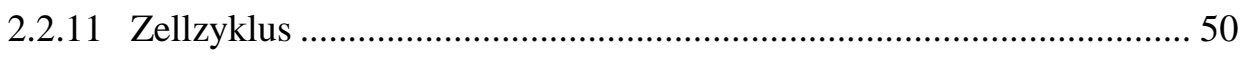

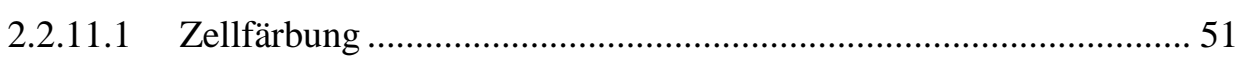

2.2.11.2 Durchflusszytometrische Analyse ................................................ 51

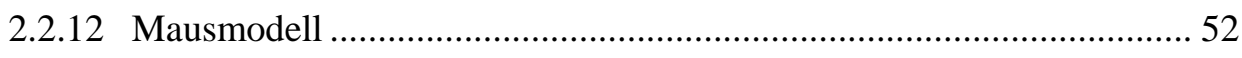

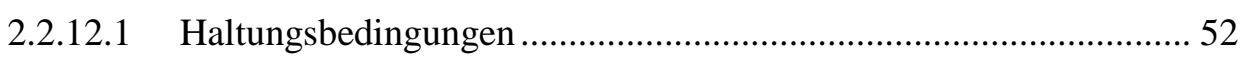

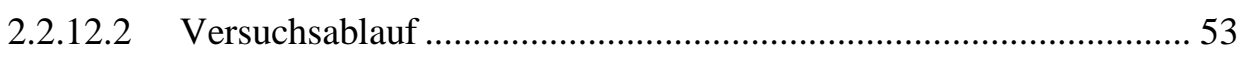

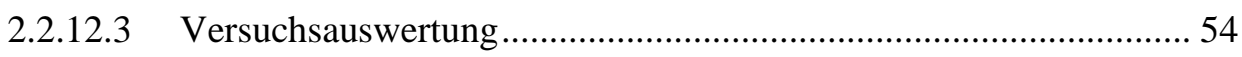

2.2.12.3.1 Bauchspülung .......................................................................... 54

2.2.12.3.2 Milz und Femurknochen........................................................... 55

2.2.12.3.3 Auswertung und statistische Analyse der Ergebnisse ................... 55

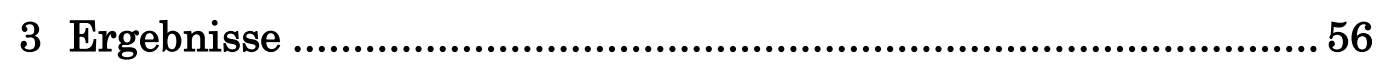

3.1 Der PI3K-Akt-Signalweg ist in Multiplen Myelom-Zellen konstitutiv aktiviert56

3.2 BAY 80-6946 hemmt die Aktivierung von Akt .............................................. 59

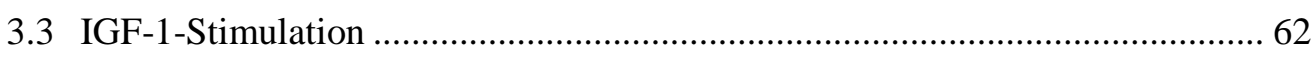

3.4 BAY 80-6946 hemmt die IGF-1-stimulierte Aktivierung von Akt ................... 65

3.5 Die Hemmung der PI3K erhöht die Apoptoseraten in Myelom-Zellen.............. 72

3.6 BAY 80-6946 hemmt die Proliferation von Myelom-Zellen ............................ 74

3.7 BAY 80-6946 beeinflusst den Zellzyklus von Myelom-Zellen ......................... 76 


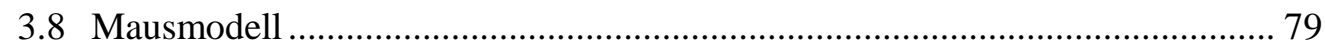

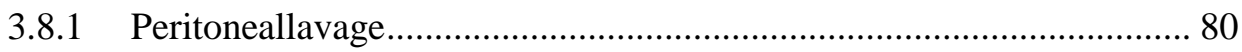

3.8.2 Milz und Femurknochen ............................................................. 83

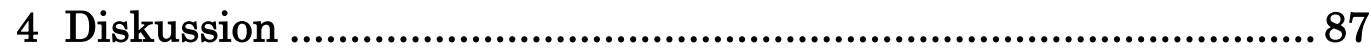

4.1 Konstitutive Aktivierung von Akt in Multiplen Myelom-Zellen ...................... 87

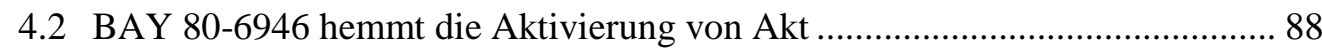

4.3 Der Einfluss von BAY 80-6946 auf Apoptose, Proliferation und Zellzyklus .. 89

4.4 BAY 80-6946 hemmt die IGF-1-stimulierte Aktivierung von Akt ................... 91

4.5 Einsatz von BAY 80-6946 im murinen Xenotransplantations-Modell ............ 92

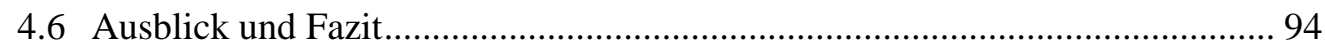

5 Zusammenfassung ...................................................... 97

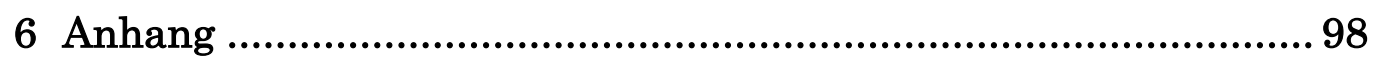

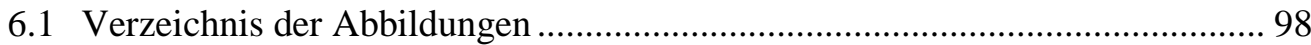

6.2 Verzeichnis der Tabellen ............................................................................ 100

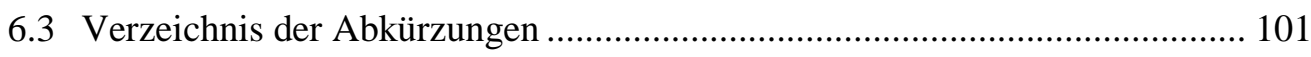

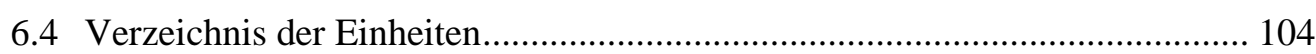

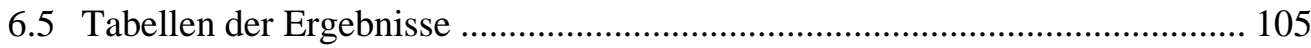

7 Literaturverzeichnis ................................................... 112 


\section{$1 \quad$ Einleitung}

\subsection{Das Multiple Myelom}

Das Multiple Myelom ist eine Erkrankung aus der Gruppe der niedrig malignen B-Zell-NonHodgkin-Lymphome, die sich durch klonale Expansion von malignen, terminal differenzierten B-Zellen (Plasmazellen) im Knochenmark auszeichnet. Charakterisiert wird das Multiple Myelom durch sein destruktives Wachstum im Knochen und die vermehrte Bildung von funktionslosen monoklonalen Antikörpern und Antikörperbruchstücken (Paraprotein). Die Folgen sind Osteolysen, Nierenschädigung und die Entwicklung einer sekundären Immundefizienz (Raab et al. 2009).

Das Multiple Myelom gilt bis heute als unheilbar (Hideshima et al. 2007). Insbesondere die Entwicklung von Medikamentenresistenzen verhindert immer wieder eine effektive Therapie (Hideshima und Anderson 2002). Doch neue onkogenetische Studien helfen, die molekulare Pathogenese des Multiplen Myeloms im Mikromilieu des Knochenmarkes besser zu verstehen und legen damit den Grundstein für die Entwicklung neuer Behandlungsmethoden (Hideshima et al. 2007).

\subsubsection{Epidemiologie}

Das Multiple Myelom stellt die zweithäufigste hämatologische Neoplasie in den USA dar. 1\% aller Krebserkrankungen sind dort durch das Multiple Myelom verursacht (Raab et al. 2009). Den Daten der SEER Cancer Statistics von 2004-2008 zufolge liegt die mittlere jährliche altersjustierte Inzidenzrate in den USA bei 5,7/100.000, wobei diese bei Männern mit 7,2/100.000 und bei Frauen mit 4,6/100.000 angegeben wird (Howlander et al. 2011). Menschen asiatischer Ethnien sind deutlich seltener, Schwarzafrikaner hingegen deutlich häufiger betroffen als hellhäutige Bevölkerungsgruppen (Sirohi und Powles 2004).

Die Inzidenzrate steigt zudem stark mit dem Alter an. Das Multiple Myelom gehört zu den Erkrankungen des höheren Lebensalters. Das mediane Alter bei Diagnosestellung liegt bei 70 Jahren, wobei $37 \%$ der Patienten sogar 75 Jahre oder älter sind (Palumbo und Anderson 2011). 


\subsubsection{Symptomatik des Multiplen Myeloms}

$\mathrm{Zu}$ Beginn der Erkrankung dominieren uncharakteristische Symptome wie Knochenschmerzen, Abgeschlagenheitsgefühl oder sekundäre Infektionen. Im weiteren Krankheitsverlauf zeigen sich vielgestaltige Symptome, die sich zumeist auf das infiltrative Wachstum der Multiplen Myelom-Zellen selbst oder deren Produktion monoklonaler Antikörper oder Bruchstücke derselben (Paraprotein) zurückführen lassen (Jagannath 2008).

Das Paraprotein kann mit dem diagnostischen Verfahren der Serumelektrophorese als pathologischer „Peak“ (M-Gradient) innerhalb der Immunglobulinfraktion abgebildet werden. Die sezernierten Immunglobuline sind zu 52 \% Immunglobuline der Klasse G, zu $21 \%$ der Klasse A und zu $2 \%$ der Klasse D. In $16 \%$ der Fälle werden ausschließlich deren Leichtketten ( $\lambda$ oder $\mathrm{K}$ ) sezerniert und nur in seltenen Fällen (7 \%) ist das Multiple Myelom asekretorisch. Zu $2 \%$ treten biklonale Zellen auf (Kyle et al. 2003).

Besonders kennzeichnend für das Multiple Myelom sind neben der Paraproteinsekretion das verdrängende Wachstum im Knochenmark und die Interaktion der malignen Zellen mit dem Mikromilieu vor Ort. Die Folge ist eine übermäßige Aktivierung des Knochenabbaus durch Osteoklasten. Sie führt bei den Patienten zu Knochenläsionen, diffusen Knochenschmerzen sowie Hyperkalzämie (Jagannath 2008). Die in der Folge erhöhte Kalziumbelastung im Serum zusammen mit den hohen Mengen an Paraprotein, darunter insbesondere die Leichtketten (Bence-Jones-Protein), belasten die Nieren und können eine Niereninsuffizienz hervorrufen. Im Krankheitsverlauf zeigen zwischen 20 und $40 \%$ der Patienten Beeinträchtigungen der Nierenfunktion (Eleutherakis-Papaiakovou et al. 2007).

Durch die maligne Proliferation im Knochenmark werden zudem die Zellen der Hämatopoese verdrängt. Der resultierende Mangel an Erythrozyten ruft bei $97 \%$ aller Patienten im Laufe der Erkrankung Anämien (zumeist normochrom, normozytär) hervor (Kyle et al. 2003). Die resultierende Thrombozytopenie führt zusätzlich zu Gerinnungsstörungen. Es kann jedoch auch zu einer Hyperkoagulabilität kommen, da große Mengen des Paraproteins die Viskosität des Blutes wiederum erhöhen (Kyle et al. 2003; Jagannath 2008).

Eine schwerwiegende Komplikation bei Myelom-Erkrankten stellt auch die Entwicklung einer Immunschwäche mit erhöhter Infektanfälligkeit dar. Die Ursache hierfür ist insbesondere eine funktionelle Hypogammaglobulinämie durch Mangel an funktionsfähigen Antikörpern. Aber auch Veränderungen in der Anzahl und der Funktion anderer Immunzellen wie der Dendritischen Zellen, T-Zellen und Natürlichen Killerzellen spielen eine wichtige 
Rolle. Die Entwicklung sekundärer Infektionen stellt die häufigste Todesursache für Patienten mit Multiplem Myelom dar (Nucci und Anaissie 2009).

\subsubsection{Klassifikation und Stadieneinteilung}

Um bei einem Patienten die Diagnose eines Multiplen Myeloms stellen zu können, müssen folgende Diagnosekriterien erfüllt sein: Zunächst muss die Paraprotein-Konzentration im Serum des Patienten über $3 \mathrm{~g}$ pro 100 Milliliter betragen. Zudem sollte der Anteil der monoklonalen Plasmazellen im Knochenmark über $10 \%$ liegen. Zusätzlich entscheidend für die Diagnose des Multiplen Myeloms ist jedoch auch das Auftreten von Endorganschäden. Zur klinischen Manifestation spezifischer Endorganschäden zählen Hyperkalzämie, Niereninsuffizienz, Anämie sowie Knochenläsionen. Die International Myeloma Working Group (IMWG) hat diese Endorganschäden aufgrund ihrer klinischen Relevanz als sogenannte CRAB-Kriterien (C: hypercalcemia, R: renal insufficiency, A: anemia, B: bone lesions) zusammengefasst. Das Vorhandensein eines dieser Kriterien reicht demnach aus, um die Indikation zur Therapie zu stellen (The International Myeloma Working Group 2003).

Dem klinisch manifesten Multiplen Myelom geht meist eine sogenannte „monoklonale Gammopathie unbestimmter Signifikanz“ (MGUS) voraus, die bei $3 \%$ der Menschen über 50 Jahren auftritt (Rajkumar et al. 2010; Kyle und Rajkumar 2007). Klinisch entscheidend ist, dass die Patienten in diesem prämalignen Zustand ein Risiko von $1 \%$ pro Jahr haben, am Multiplen Myelom zu erkranken (Rajkumar et al. 2010; Kyle und Rajkumar 2007). Eine prospektive Studie, die 77.000 Patienten einschloss, zeigte, dass alle neu am Multiplen Myelom Erkrankten im Vorfeld schon mit MGUS diagnostiziert worden waren (Landgren et al. 2009).

Die Diagnose der MGUS ist nach folgenden Kriterien zu stellen: Im Unterschied zum Multiplen Myelom werden beim MGUS-Patienten keine Endorganschäden durch die monoklonale Gammopathie verursacht (Kyle und Rajkumar 2009; Anderson und Carrasco 2011). Zudem liegt die Paraprotein-Konzentration im Serum unter 3 g pro 100 Milliliter sowie der Anteil monoklonaler Plasmazellen im Knochenmark beträgt weniger als $10 \%$. (Kyle und Rajkumar 2009; Anderson und Carrasco 2011).

Die asymptomatische Form des Multiplen Myeloms, die jedoch die Kriterien der erhöhten Paraprotein-Konzentration und des Vorhandenseins monoklonaler Plasmazellen im Knochenmark erfüllt, dabei aber noch keine Endorganschädigung aufweist, wird als sogenanntes Smouldering Myeloma bezeichnet (Jagannath 2008). Das Smouldering Myeloma 
stellt somit eine Übergangsform zwischen MGUS und der eigentlichen Myelom-Erkrankung dar, die jedoch nicht zwangsläufig bei jedem Patienten nachweisbar sein muss (Jagannath 2008).

Um Aussagen hinsichtlich der individuellen Prognose eines Patienten mit Multiplem Myelom treffen zu können, teilt man die Erkrankung in verschiedene Stadien ein. Bis zum Jahr 2005 war die Einteilung nach den Durie-Salmon-Kriterien in drei verschiedene Kategorien (Stadium I, II, III) weit verbreitet (Durie und Salmon 1975). Maßgebend für die Kategorisierung waren der Hämoglobinwert, der Serumkalziumspiegel, die Menge des sezernierten Paraproteins sowie die Anzahl der vorhandenen Knochenläsionen (Raab et al. 2009). Abhängig vom Vorhandensein einer Nierenfunktionsstörung unterteilte man die drei Stadien zusätzlich in Subklasse A oder B, wobei Subklasse A einer relativ normalen Nierenfunktion und Subklasse B einer eingeschränkten Nierenfunktion entsprach (Jagannath 2008).

Heute nutzt man zur Stadieneinteilung vermehrt das ,,International-Staging-System “ (ISS). Es wurde durch die Auswertung von 10.750 Patientendaten weltweit entwickelt (Greipp et al. 2005). Hiernach werden die Patienten ausschließlich ausgehend von ihrem Serumalbuminspiegel sowie Beta 2 -Mikroglobulinwert in drei Stadien eingeteilt. Diese beiden klinischen Faktoren gelten als leicht reproduzierbar und sollen zudem eine hohe prognostische Aussagekraft aufweisen (Jagannath 2008; Raab et al. 2009; Kyle und Rajkumar 2009). Tabelle 1 zeigt vergleichend die Kriterien nach Durie-Salmon und dem „InternationalStaging-System “.

Tabelle 1: Stadieneinteilung des Multiplen Myeloms: Durie-Salmon-Kriterien und ISS-Kriterien. Darstellung modifiziert nach Jagannath 2008; Daten der Multiple Myeloma Research Foundation (Orlowski 2006)

\begin{tabular}{|clll|}
\hline Stadium & \multicolumn{1}{c}{ I } & \multicolumn{1}{c|}{ II } & III \\
Durie- & Alle folgenden Kriterien zutreffend: & weder Stadium I & mind. 1 der folgenden Kriterien trifft zu: \\
Salmon- & - Hämoglobin $>10 \mathrm{~g} / \mathrm{dl}$ & noch III & - Hämoglobin $<8,5 \mathrm{~g} / \mathrm{dl}$ \\
Kriterien & - Serumkalzium $<12 \mathrm{mg} / \mathrm{dl}$ & & - Serumkalzium $>12 \mathrm{mg} / \mathrm{dl}$ \\
& - maximal solitäre Knochenläsion & & -3 oder mehr Knochenläsionen \\
& - niedrige Paraprotein-Produktionsrate & - hohe Paraprotein-Produktionsrate \\
& (IgG $<5 \mathrm{~g} / \mathrm{dl}$; IgA $<3 \mathrm{~g} / \mathrm{dl})$ & (IgG $>7 \mathrm{~g} / \mathrm{dl}$; IgA $>5 \mathrm{~g} / \mathrm{dl})$ \\
& Bence-Jones-Protein $<3 \mathrm{~g} / 24 \mathrm{~h}$ & Bence-Jones-Protein $>12 \mathrm{~g} / 24 \mathrm{~h}$ \\
Zusätzliche Kriterien: & \\
A & Serumkreatinin $<2 \mathrm{mg} / \mathrm{dl}$ & \\
B & Serumkreatinin $>$ oder $=2 \mathrm{mg} / \mathrm{dl}$ & \\
\end{tabular}




$\begin{array}{llll}\text { ISS } & \beta_{2} \text {-Mikroglobulin }<3.5 \mathrm{mg} / \mathrm{dL} \text { und } & \text { weder Stadium I } & \beta_{2} \text {-Mikroglobulin } \geq 5.5 \mathrm{mg} / \mathrm{dl} \\ & \text { Albumin } \geq 3.5 \mathrm{~g} / \mathrm{dl} & \text { noch III } & \end{array}$

Klassischerweise ist das Multiple Myelom im Knochenmark lokalisiert, dabei nimmt das dort ansässige Mikromilieu eine herausragende Rolle in der Pathogenese ein (Hideshima et al. 2007). Es kommen jedoch auch extramedulläre Manifestationen vor (The International Myeloma Working Group 2003). Im Progress der Erkrankung kann es ebenso zur Ausschwemmung der Plasmazellen in das periphere Blut kommen. Man spricht dann von der so genannten Plasmazellleukämie (Anderson und Carrasco 2011).

\subsubsection{Pathogenese}

Die Pathogenese des Multiplen Myeloms ist ein mehrstufiger Prozess. Ausgangspunkt ist ein maligne transformierter Zellklon einer postgerminalen Plasmazelle. Zahlreiche onkogene Ereignisse und Umwelteinflüsse spielen eine wichtige Rolle bei der malignen Transformation zur Myelomzelle (Kuehl und Bergsagel 2002).

Es ist davon auszugehen, dass der Prozess im prämalignen Stadium der MGUS (Monoklonale Gammopathie unklarer Signifikanz) beginnt, über die asymptomatische Stufe des Smouldering Myeloma verläuft und letztlich zum symptomatischen Multiplen Myelom führt (Palumbo und Anderson 2011). Zahlreiche genetische Veränderungen spielen bei dieser Entwicklung zur Multiplen Myelomzelle eine wichtige Rolle (vergleiche Abbildung 1).

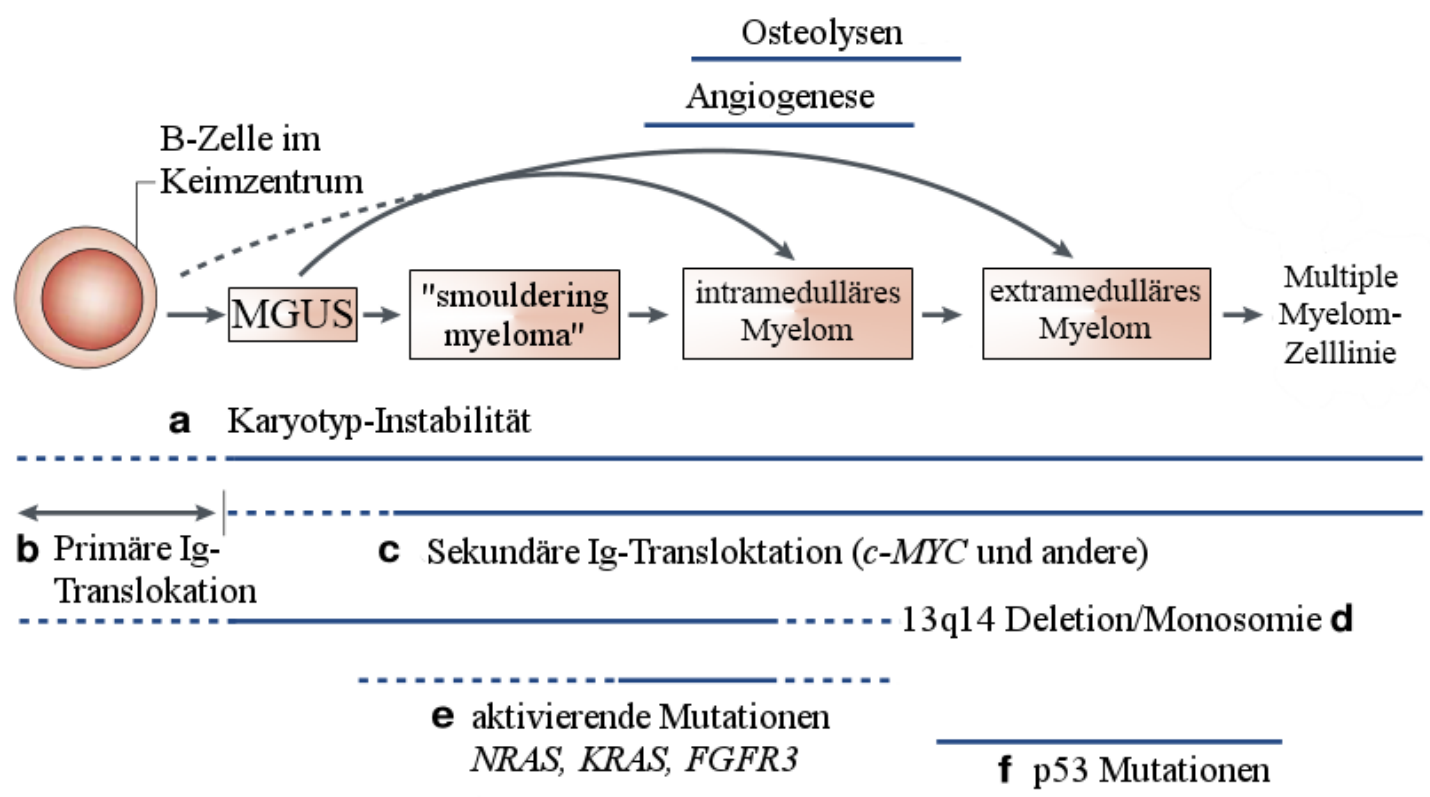


Abbildung 1: Die Pathogenese des Multiplen Myeloms; Die Abbildung wurde mit freundlicher Genehmigung dem Artikel „Multiple myeloma: Evolving genetic events and host interactions“ entnommen und übersetzt, Originaltitel der Abbildung: „Molecular pathogenesis of myeloma“ (Kuehl und Bergsagel 2002). Die Abbildung zeigt schematisch verschiedene malignitätsfördernde genetische Veränderungen in der Pathogenese des Multiplen Myeloms: a) Instabilität des Karyotyps; b) primäre Chromosomentranslokationen treten im Keimzentrum des Lymphknotens auf und führen zur Überexpression von wachstumsfördernden Genen; c) sekundäre Translokationen (c-MYC) (zelluläres Myelocytomatose-Onkogen); d) Deletion des Chromosoms 13q; e) aktivierende Mutationen von NRAS, KRAS, FGFR3; f) spät auftretende Mutationen wie die von p53

Früh in der Pathogenese treten reziproke Chromosomentranslokationen auf, durch die Onkogene unter die Kontrolle eines Immunglobulin-Transkriptionsverstärkers (Enhancer) gelangen und folglich überexprimiert werden (Kuehl und Bergsagel 2002). Die reziproken Chromosomentranslokationen erfolgen zumeist durch einen Fehler der Rekombination der schweren Kette oder der somatischen Hypermutation, die im Rahmen der Affinitätsreifung und des Isotypenwechsels einer B-Zelle nach Antigenkontakt ablaufen (Anderson und Carrasco 2011). Diese Translokationen bewirken die Überexpression von wachstumsfördernden Genen wie zum Beispiel Cyclinen der Klasse D, MMSET (Multiple Myeloma SET Domain) oder der onkogene Tyrosinkinase FGFR3 (Fibroblast growth factor receptor 3) und tragen damit wahrscheinlich zur Entstehung der immortalisierten MGUSZelle bei (Kuehl und Bergsagel 2002).

Die Überexpression von Cyclin D1 (Translokation $t(11,14)$ ) tritt in $15-20 \%$ der Erkrankungen auf und scheint eine große Rolle in der Pathogenese des Multiplen Myeloms zu spielen (Bergsagel et al. 2005; Hideshima et al. 2007).

Später im Krankheitsverlauf auftretende sekundäre Translokationen, die unter anderem zur Dysregulation des $M Y C$-Gens führen, tragen zur Weiterentwicklung der MGUS-Zelle zur Multiplen Myelomzelle bei (Kuehl und Bergsagel 2002).

Zusätzlich tritt in der Pathogenese des Multiplen Myeloms eine zunehmende Instabilität des Karyotyps auf. Im Gegensatz zu anderen hämatologischen Neoplasien haben Myelom-Zellen einen äußerst komplexen und heterogenen Karyotyp, der eher dem Karyotyp epithelialer Tumoren ähnelt (Anderson und Carrasco 2011). Auf dieser Grundlage werden die MyelomZellen in 2 Gruppen aufgeteilt: 55-60\% besitzen einen hyperdiploiden Karyotyp (48-74 Chromosomen), der restliche Anteil dagegen weist einen Karyotyp mit weniger als 48 oder mehr als 74 Chromosomen auf (Anderson und Carrasco 2011).

Die Diagnostik des Karyotyps ist auch entscheidend für die Prognose der Patienten. Studien haben ergeben, dass Patienten mit einem nicht-hyperdiploiden Karyotyp eine deutlich 
schlechtere Prognose aufweisen (Jagannath 2008). Weitere Mutationen wie die des Onkogens p53 können zu vom Knochenmarkstroma unabhängigen Wachstum der Multiplen MyelomZellen führen (Kuehl und Bergsagel 2002; Anderson und Carrasco 2011).

In neueren Studien verdichten sich die Hinweise, dass nicht alle Zellklone gleichermaßen für die Pathogenese des Multiplen Myeloms verantwortlich sind. Vielmehr geht man davon aus, dass eine kleine Subpopulation der sogenannten Krebsstammzellen existiert (Ghosh und Matsui 2009; Anderson und Carrasco 2011).

\subsubsection{Das Mikromilieu im Knochenmark}

Neben den onkogenen Ereignissen spielt das Mikromilieu des Knochenmarks eine herausragende Rolle in der Pathogenese des Multiplen Myeloms. Es setzt sich zusammen aus extrazellulären Matrixproteinen wie Fibronektin oder Kollagen und zellulären Bestandteilen wie den hämatopoetischen Stammzellen, Knochenmarkstromazellen (BMSC; Bone marrow stromal cell), Osteoklasten und Osteoblasten (Hideshima et al. 2007).

Die Migration der Multiplen Myelom-Zellen ins Knochenmarkstroma (Homing) wird durch das Chemokin SDF1 $\alpha$ (Stromal Derived Factor $1 \alpha$ ) über Bindung an den CXCR4-Rezeptor (CXC-Motiv-Chemokinrezeptor 4) auf den Myelom-Zellen vermittelt (Hideshima et al. 2007). Der Kontakt zum Knochenmarkstroma wird über Adhäsionsmoleküle auf der Oberfläche von extrazellulären Matrixproteinen oder Knochenmarkstromazellen hergestellt (Hideshima und Anderson 2002).

Die Interaktion der Multiplen Myelom-Zellen mit den ortsständigen Zellen im Mikromilieu des Knochenmarks läuft über direkten Kontakt sowie indirekt vermittelt über diverse Zytokine. Wichtige Zytokine in der Interaktion, die sowohl von den Knochenmarkstromazellen als auch den Myelom-Zellen selbst sezerniert werden, stellen der Insulin-ähnliche Wachstumsfaktor I (Insulin-like-Growth-Factor-1; IGF-1), Interleukin-6 (IL6), der vaskulär-endotheliale Wachstumsfaktor (VEGF) oder der Tumornekrosefaktor $\alpha$ (TNF $\alpha$ ) dar (Anderson und Carrasco 2011).

Die Ausschüttung der Zytokine führt zur Aktivierung zahlreicher Signalkaskaden wie dem Phosphatidylinositolkinase (PI3K)/Akt-Signalweg, dem NF-кB (Nuclear Factor 'kappa-lightchain-enhancer' of activated B-cells)-vermittelten Signalweg, dem MAP-Kinase (MitogenActivated Protein-Kinase)-Weg und dem JAK-STAT (Januskinase-Signal Transducers and Activators of Transcription-Kinase)-Signalweg (Lentzsch et al. 2004; van de Donk et al. 
2005). In der Folge werden nachgeschaltete Signalproteine aktiviert, die letztendlich zur Hochregulation von Regulationsproteinen des Zellzyklus wie Cyclinen der Klasse D und von anti-apoptotischen Proteinen wie BCL-X $\mathrm{L}_{\mathrm{L}}$ (B-cell lymphoma-extra large), MCL1 and Caspasen-Inhibitoren führen (Hideshima et al. 2007).

Die Folgen sind eine verstärkte Proliferation und Migration sowie eine Erhöhung des Gesamtüberlebens der Myelom-Zellen. Zudem führen die Aktivierungen der Signalkaskaden zu Medikamentenresistenz sowie verstärkter Angiogenese (Mitsiades et al. 2006; Hideshima et al. 2007; Anderson und Carrasco 2011).

Die Multiplen Myelom-Zellen greifen zudem in die Homöostase des Knochenaufbaus ein. Im gesunden Knochen regulieren Osteoblasten, die knochenaufbauenden Zellen, und die Knochenmarkstromazellen den Knochenabbau der Osteoklasten durch Bildung zweier regulierender Faktoren: dem sogenannten Rezeptor Aktivator des NF- $\kappa B$ Liganden (RANKL) und Osteoprotegerin (OPG). RANKL bindet an den RANK-Rezeptor auf Osteoklasten und stimuliert damit deren Differenzierung. OPG dagegen kann diese Interaktion durch eigene Bindung an RANKL verhindern. Die Multiple Myelomzelle vermag durch Bindung an die Knochenmarkstromazellen die Bildung von OPG zu vermindern sowie die Menge an RANKL $\mathrm{zu}$ erhöhen, sodass das physiologische Verhältnis von RANKL und OPG gestört wird (Mitsiades et al. 2006; Hideshima et al. 2007; Roodman 2010). Die Folge sind die für das Multiple Myelom so charakteristischen Osteolyseherde.

\subsubsection{IGF-1: Ein wesentlicher Wachstumsfaktor}

Das Polypeptid Insulin-like-Growth-factor-1 (IGF-1) stellt einen der bedeutendsten Wachstumsfaktoren für die Myelomzelle innerhalb des Mikromilieus des Knochenmarks dar und spielt deshalb auch eine wichtige Rolle in der Pathogenese des Multiplen Myeloms (Sprynski et al. 2009). Im Mikromilieu des Knochenmarks führt die Freisetzung von IGF-1 unter anderem insbesondere zu einer direkten Aktivierung der Phosphatidylinositol-3-Kinase (Anderson und Carrasco 2011).

Der IGF-1-Rezeptor stellt einen Transmembranrezeptor mit intrinsischer TyrosinkinaseAktivität dar (Qiang et al. 2002). Die Bindung von IGF-1 führt über Autophosphorylierung zu einer Potenzierung seiner Aktivität sowie über die Phosphorylierung von Adaptermolekülen wie IRS-1 (Insulin-Rezeptor-Substrat-1) und IRS-2 (Insulin-Rezeptor-Substrat-2) zur Aktivierung von Signalkaskaden wie dem PI3-Kinase-Akt-Signalweg oder dem MAPKSignalweg (Laviola et al. 2007). 
Über die Aktivierung des PI3K-Akt-Signalweges bietet IGF-1 den Zellen vor Ort einen umfassenden Schutz vor Glukokortikoid-induzierter Apoptose (Sprynski et al. 2009). Beide Signalkaskaden induzieren darüber hinaus Zellwachstum, Proliferation, Angiogenese, Resistenzentwicklung und Metastasierung der malignen Zellen (Anderson und Carrasco 2011).

\subsubsection{Therapieprinzipien und Prognosefaktoren}

Das Multiple Myelom ist nach wie vor meist eine unheilbare Erkrankung (Hideshima et al. 2007). Dennoch konnten durch die intensive Auseinandersetzung mit der Pathologie des Multiplen Myeloms neue Therapieverfahren entwickelt und Erfolge erzielt werden. Studien zeigen, dass sich die Überlebenswahrscheinlichkeit innerhalb der letzten Dekade stetig verbessert hat (Kumar et al. 2008; Brenner et al. 2008; Kastritis et al. 2009).

Einen großen Fortschritt in der Therapie stellte neben der Einführung der autologen Stammzelltransplantation - kombiniert mit Hochdosischemotherapie (Attal et al. 1996) insbesondere die Etablierung neuer Substanzen wie des Proteasomeninhibitors Bortezomib sowie der immunmodulatorischen Medikamente (Immunmodulatory Drugs; IMiDs®) Thalidomid und Lenalidomid dar (Richardson et al. 2007; Kumar et al. 2008). Zahlreiche Studien belegen die gute Wirksamkeit der drei neuen Substanzen in der Myelomtherapie (Raab et al. 2009). Diese könnten bald sogar die Chemotherapie als Standardtherapie bei Patienten, für die keine Stammzelltransplantation geeignet ist, ersetzen (Brenner et al. 2008).

Dieser Erfolg schlägt sich in der durchschnittlichen fünf-Jahresüberlebensrate nieder, die in den Jahren 1990 bis 2004 von 28,8 auf 34,7 \% angehoben werden konnte. Bei jüngeren Patienten unter 50 Jahren ließ sich sogar eine fünf-Jahresüberlebensrate von 56,7 \% erreichen (Brenner et al. 2008).

Konkret unterscheidet die aktuelle Therapie nach den Leitlinien der Deutschen Gesellschaft für Hämatologie und Onkologie (DGHO) zwischen Patienten über und unter 65 bzw. 70 Jahren. Patienten unter 65-70 Jahren erhalten derzeit eine Induktionschemotherapie, gefolgt von einer Hochdosis-Chemotherapie mit Melphalan, kombiniert mit einer autologen Stammzelltransplantation (Kortüm et al. 2010). Studien konnten zeigen, dass die zusätzliche Gabe von neuen Substanzen wie Bortezomib zur Induktionschemotherapie die Ansprechraten verbessern kann (Harousseau et al. 2010; Kumar et al. 2008). Grundsätzlich besteht auch die Möglichkeit einer allogenen Stammzelltransplantation. Aufgrund hoher Mortalität der vorangehenden hochdosierten myeloablativen Therapie wird diese Option jedoch eher bei 
jungen Patienten mit refraktärer Erkrankung angewandt. Bei diesen Patienten kann der „Graft-Versus-Myeloma-Effect“ das Rückfallrisiko verringern (Van de Donk et al. 2011). Die Durchführung einer anschließenden Erhaltungstherapie wird aktuell in Studien überprüft (Kortüm et al. 2010).

Der klinische Standard für Patienten über 65 Jahre besteht aus intermittierenden Zyklen von Melphalan und Prednison in Kombination mit Thalidomid oder Bortezomib (Facon et al. 2007; Venon et al. 2009). Studien zeigen jedoch, dass auch bei älteren Patienten das Konzept aus Induktionschemotherapie, Hochdosis-Chemotherapie kombiniert mit Melphalan und einer anschließenden autologen Stammzelltransplantation genutzt werden kann (Jantunen et al. 2006).

Neben der Therapie der Grunderkrankung ist auch die supportive Behandlung der vielfältigen Begleiterscheinungen entscheidend. Insbesondere fällt hierunter die Gabe von Bisphosphonaten, um pathologische Wirbelkörperfrakturen zu vermeiden (Kumar et al. 2011). Darüber hinaus kann die Therapie mit Bisphosphonaten zudem die Proliferation der Myelom-Zellen inhibieren (Raab et al. 2009; Richardson et al. 2011a). Ebenso sind die spezifischen Nebenwirkungsspektren der Therapeutika zu beachten. So erfordert, den Leitlinien entsprechend, die Thalidomidtherapie eine zusätzliche Thrombembolieprophylaxe und die Bortezomibtherapie eine Herpes-Zoster-Prophylaxe (Kortüm et al. 2010).

Das Multiple Myelom ist sowohl im Hinblick auf die klinische Symptomatik als auch auf die Genetik und Pathogenese eine äußerst heterogene Erkrankung. Diese Tatsache äußert sich darin, dass das Therapieansprechen sowie das Überleben der einzelnen Patienten von wenigen Monaten bis hin zu 10 Jahren äußerst stark differieren kann (Rajkumar und Buadi 2007; Badros 2010). Aus diesem Grund wird zunehmend eine Therapie gefordert, die sich an der individuellen Prognose orientiert. Dieses Vorgehen erfordert zunächst die Definition von Parametern, die eine möglichst objektive Abschätzung der individuellen Prognose möglich machen. Grundsätzlich hängt die Prognose des Patienten von Konstanten wie dem Alter, dem Gesundheitsstatus, Komorbidität und Krankheitsstadium, Aggressivität der Erkrankung sowie dem Therapieansprechen ab (Russell und Rajkumar 2011; Rajkumar 2012).

Darüber hinaus stellt die Stadieneinteilung nach dem ISS-Score eine Möglichkeit dar, die individuelle Klinik des Patienten $\mathrm{zu}$ beurteilen. Um eine Entscheidung über die Therapiestrategie zu treffen, hat sich der Nachweis zytogenetischer und molekulargenetischer Marker als prognostisch wegweisend herausgestellt (Rajkumar 2012). So gehören zum 
Beispiel Patienten mit einer Deletion an Chromosom 17 (17p) oder einer Translokation t(14;16)/t(14;20) zur Hochrisikogruppe (Badros 2010; Rajkumar 2012).

\subsubsection{Medikamentenresistenz}

Ungeachtet der zahlreichen therapeutischen Fortschritte ist eine Heilung der Patienten mit Multiplem Myelom weiterhin nicht möglich. Obwohl konventionelle Therapieregime ein langfristiges Therapieansprechen erreichen können, scheint das Krankheitsrezidiv früher oder später unausweichlich zu sein (Hideshima et al. 2007). Therapielimitierend sind insbesondere die häufig auftretenden Medikamentenresistenzen im Mikromilieu des Knochenmarks (Hideshima et al. 2007; Anderson et al. 2011). Für diese sind verschiedene Mechanismen verantwortlich.

Die Bindung der Multiplen Myelom-Zellen an extrazelluläre Matrixproteine vermittelt die sogenannte zelladhäsionsvermittelte Medikamentenresistenz (cell-adhesion-mediated drug resistance; CAMDR) (Hazlehurst et al. 2000; Landowski et al. 2003). Zusätzlich wird über die Bindung der Multiplen Myelomzelle an die ortsständigen Zellen die Ausschüttung zahlreicher Zytokine wie des insulinähnlichen Wachstumsfaktors 1 (IGF-1) (Ferlin et al. 2000; Sprynski et al. 2009), des Interleukin-6 (IL-6) (Zhang et al. 1992), des vaskulär-endothelialen Wachstumsfaktors (VEGF) (Dankbar et al. 2000) und des Tumornekrosefaktors (TNF) (Jourdan et al. 1999; Hideshima et al. 2001a) initiiert (Hideshima et al. 2007). Diese im Mikromilieu des Knochenmarks sowohl von den Multiplen Myelom-Zellen selbst als auch von den Knochenmarkstromazellen sezernierten Zytokine aktivieren verschiedene spezifische Signalkaskaden, unten denen der Phosphoinositid-3-Kinase(PI3K)-Signalweg eine der bedeutsamsten Signalkaskaden darstellt (Pene et al. 2002; Younes et al. 2007). Aktiviert durch IGF-1 unterstützt die PI3K das Überleben der Multiplen Myelom-Zellen durch Erhöhung der Proliferationsraten und Senkung der Apoptoseraten (Datta et al. 1999; van de Donk et al. 2005; Sprynski et al. 2009). Die Aktivierung des PI3K-Akt-Signalwegs führt zu Medikamentenresistenz, verstärkter Angiogenese, Proliferation und Migration sowie Erhöhung des Gesamtüberlebens der Myelom-Zellen (Mitsiades et al. 2006; Hideshima et al. 2007; Anderson und Carrasco 2011).

Darüber hinaus kann die Behandlung der Myelom-Zellen mit Chemotherapie den Erwerb von Resistenzen unterstuitzen. Die Exposition der Multiplen Myelom-Zellen mit Chemotherapeutika wie Alkylanzien oder Anthrazyklinen ruft Multiresistenzen durch Überexpression des MDR-Gens und P-Glykoproteins in den Myelom-Zellen hervor (Salmon 
et al. 1991; Covelli 1999; Schwarzenbach 2002). Darüber hinaus konnten zahlreiche Studien zeigen, dass der Einsatz von Dexamethason, Doxorubicin oder Bortezomib wiederum die Aktivierung von Akt induzieren kann und folglich auch über diesen Weg Medikamentenresistenzen hervorruft (Hideshima et al. 2006; Hideshima et al. 2001b; Mitsiades et al. 2002).

Weiterhin können Mutationen wie die des p53-Gens zu intrinsischen genetischen Mechanismen der Medikamentenresistenz führen (Hideshima et al. 2007).

\subsubsection{Targeted therapy als neue Behandlungsmöglichkeit}

Ziel der aktuellen Myelomforschung ist weiterhin die Suche nach neuen Substanzen und Kombinationsschemata zur Überwindung oder Verzögerung der Resistenzmechanismen. Die Auseinandersetzung mit der Pathogenese des Multiplen Myeloms, insbesondere die Interaktion im Mikromilieu des Knochenmarks, hat neben einem verbesserten Verständnis der Erkrankung auch neue Therapiemöglichkeiten hervorgebracht (Hideshima et al. 2007). Der Begriff der sogenannten targeted therapy verspricht der Übersetzung nach eine gezielte Therapie. Das Ziel ist hierbei, eine Therapie zu entwickeln, die gezielt auf ein Molekül in den Tumorzellen wirkt, das eine zentrale Rolle in der Karzinogenese spielt (Thundimadathil 2012). Im Unterschied dazu wirken altbewährte Chemotherapeutika meist allgemein auf schnell proliferierende Zellen und machen so keinen Unterschied zwischen Tumorzellen und nicht-maligen Zellen (Thundimadathil 2012).

Die Einführungen von Thalidomid, Lenalidomid und Bortezomib als targeted therapy haben die Therapie des Multiplen Myeloms revolutioniert. Dennoch kommt es in den meisten Fällen früher oder später zu einem Rezidiv der Erkrankung (Hideshima et al. 2007).

Folglich ist es notwendig, sich weiterhin mit den pathophysiologischen Mechanismen des Multiplen Myeloms auseinanderzusetzen, um weitere therapeutische Angriffsziele (targets) zu definieren, mit dem Ziel, Medikamentenresistenzen zu vermeiden und die Überlebenszeit der am Multiplen Myelom Erkrankten zu verlängern (Raab et al. 2009).

\subsection{Die Phosphoinositid-3-Kinase (PI3K)}

Die Phosphoinositid-3-Kinasen bilden eine Familie intrazellulärer Lipidkinasen, die in nahezu allen eukaryotischen Zellen exprimiert werden. PI3-Kinasen sind verantwortlich für die Bildung von Phospholipid-Second-Messenger-Molekülen, indem sie die Phosphorylierung der 
3'-OH-Position am Inositolring von Inositolphospholipiden katalysieren. Die Bindung der Second-Messenger-Moleküle an Signaltransduktionsmoleküle wie die Proteinkinase B/Akt ist verantwortlich für zahlreiche Schlüsselfunktionen wie Zellüberleben, Zellwachstum, Proliferation, Migration, Zelldifferenzierung und Zelladhäsion. Man unterscheidet verschiedene Isoformen der PI3-Kinasen, die basierend auf ihrer Primärstruktur, dem jeweiligen Aktivierungsmechanismus und der in vitro Substratspezifität in drei Hauptklassen Klasse I, II und III eingeteilt werden (Vanhaesebroeck et al. 1997).

Die Klasse I der PI3-Kinasen wurde umfassend erforscht und steht nach heutigen Studienergebnissen eindeutig im Zusammenhang mit Krebserkrankungen (Yuan und Cantley 2008; Brachmann et al. 2009; Courtney et al. 2010; Vogt et al. 2010). Aus diesem Grund beschränkt sich die folgende Arbeit auf diese Klasse der PI3-Kinasen. Im Folgenden wird vereinfachend die Bezeichnung PI3-Kinasen für die Klasse I der PI3-Kinasen verwendet.

\subsubsection{Klasse I der PI3-Kinasen}

Die Hauptklasse I der PI3K besteht aus heterodimeren Enzymen, die sich aus einer katalytischen p110 (110 kDa) und einer konstitutiv assoziierten regulatorischen Untereinheit (meist 85 kDa, als Splice-Varianten 55 kDa und 50 kDa) zusammensetzen.

\begin{tabular}{|c|c|c|c|c|c|}
\hline \multirow[t]{3}{*}{ Klasse Ia } & \multirow{2}{*}{\multicolumn{4}{|c|}{$\begin{array}{c}\text { Bindungs } \\
\text { domäne }\end{array}$ Ras $-\mathrm{C} 2-\mathrm{PIK}-$ Katalytische Domäne }} & \multirow{3}{*}{$\mathbf{p 1 1 0}, \alpha, \beta, \delta$} \\
\hline & & & & & \\
\hline & \multicolumn{4}{|c|}{$\mathrm{SH} 3-\mathrm{P}-\mathrm{BH}-\mathrm{P}-\mathrm{SH} 2-\mathrm{SH} 2$} & \\
\hline \multirow[t]{3}{*}{ Klasse Ib } & 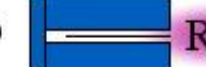 & \multicolumn{3}{|c|}{ Ras - C2 - PIK - Katalytische Domäne } & $\mathbf{p} 110 \gamma$ \\
\hline & katalytische & regulatorische & Regulation & Substrate & Gewebeverteilung \\
\hline & Untereinheit & Untereinheit & & (in vivo) & \\
\hline \multirow[t]{3}{*}{ Klasse Ia } & $\mathrm{p} 110 \alpha, \beta, \delta$ & $\mathrm{p} 85 \alpha, \mathrm{p} 85 \beta$ & Tyrosinkinasen & PtdIns(4,5- & $\alpha, \beta$-ubiquitär \\
\hline & & $\mathrm{p} 55 \gamma$ & Ras & $\mathrm{P} 2$ & $\delta$-Leukozyten \\
\hline & & $\mathrm{p} 50 \alpha, \mathrm{p} 55 \alpha$ & $\mathrm{G} \beta \gamma$ für $110 \beta$ & & \\
\hline \multirow[t]{2}{*}{ Klasse Ib } & $\mathrm{p} 110 \gamma$ & P101 & $\mathrm{G} \beta \gamma$ & & myeloid \\
\hline & & & Ras & & \\
\hline
\end{tabular}


Abbildung 2: Die Familie der PI3-Kinasen; Abbildung modifiziert nach Anderson und Jackson 2003. Die Abbildung zeigt eine schematische Darstellung der Struktur der katalytischen und regulatorischen Untereinheiten von Klasse Ia und Ib der PI3-Kinasen sowie die Art der Regulation, die Gewebeverteilung und Substratspezifität der Isoformen an. HR: homologe Region, P: prolinreiche Region, Ras: Ras-bindende Domäne, PIK: PI-Kinase Domäne, SH3: SH3-Domäne, SH2: SH2Domäne, PtdIns(4,5)P2: Phosphatidylinositol 4,5-bisphosphat. Abbildung erstellt mit der Software GIMP.

Es sind vier Isoformen $(\alpha-\delta)$ der katalytischen p110 Untereinheit (Vogt et al. 2010) und auch verschiedene regulatorische Untereinheiten (p85a, p55a, p50a, p85b, p55g) (Yuan und Cantley 2008) bekannt. Die katalytische Untereinheit setzt sich aus verschiedenen Domänen zusammen. Meist findet man folgende homologe Regionen: eine katalytische Lipid-KinaseDomäne, eine Phosphoinositol-Kinase-Domäne, eine C2-phospholipidbindende Domäne, eine Ras-bindende Domäne und zusätzlich eine N-terminale Domäne, mithilfe derer die PI3K mit der regulatorischen Untereinheit interagiert (Anderson und Jackson 2003).

Die regulatorischen Untereinheiten verfügen über verschiedene Domänen, wie zwei terminale SH2 (src homology 2) Domänen und eine beide trennende zusätzliche SH2 Domäne, die eine Interaktion von Proteinen ermöglicht (Anderson und Jackson 2003). Die beide trennende SH2 Domäne vermittelt die feste Bindung an die katalytische Einheit und spielt eine entscheidende Rolle bei der Aktivierung der PI3-Kinasen (Anderson und Jackson 2003).

Anhand struktureller Merkmale und ihrer Aktivierungsform werden die Klasse I PI3-Kinasen nochmals in Klasse IA und IB unterteilt. Die $\alpha, \beta$, and $\delta$ Isoformen der katalytischen p110 Untereinheit treten am häufigsten in Verbindung mit der regulatorischen Untereinheit p85 auf. Sie werden zur Klasse IA zusammengefasst. Die $\gamma$ Isoform ist dagegen meist mit der regulatorischen Untereinheit p101 verbunden (Vogt et al. 2010). Sie bildet das bisher einzige Mitglied der Klasse IB der PI3-Kinasen. Die Klasse I-PI3-Kinasen treten in der Zelle obligat als Dimer auf (Geering et al. 2007).

\subsubsection{Signaltransduktion der PI3K und ihre Wirkungen}

Die Klasse I-PI3-Kinasen werden hauptsächlich über Rezeptoren mit intrinsischer Tyrosinkinasenaktivität oder Nicht-Rezeptor-Tyrosinkinasen reguliert (Anderson und Jackson 2003; Zhao und Vogt 2008). Wie Abbildung 3 schematisch veranschaulicht, erfolgt der Aktivierungsmechanismus durch Ligandenbindung an den jeweiligen Rezeptor. 


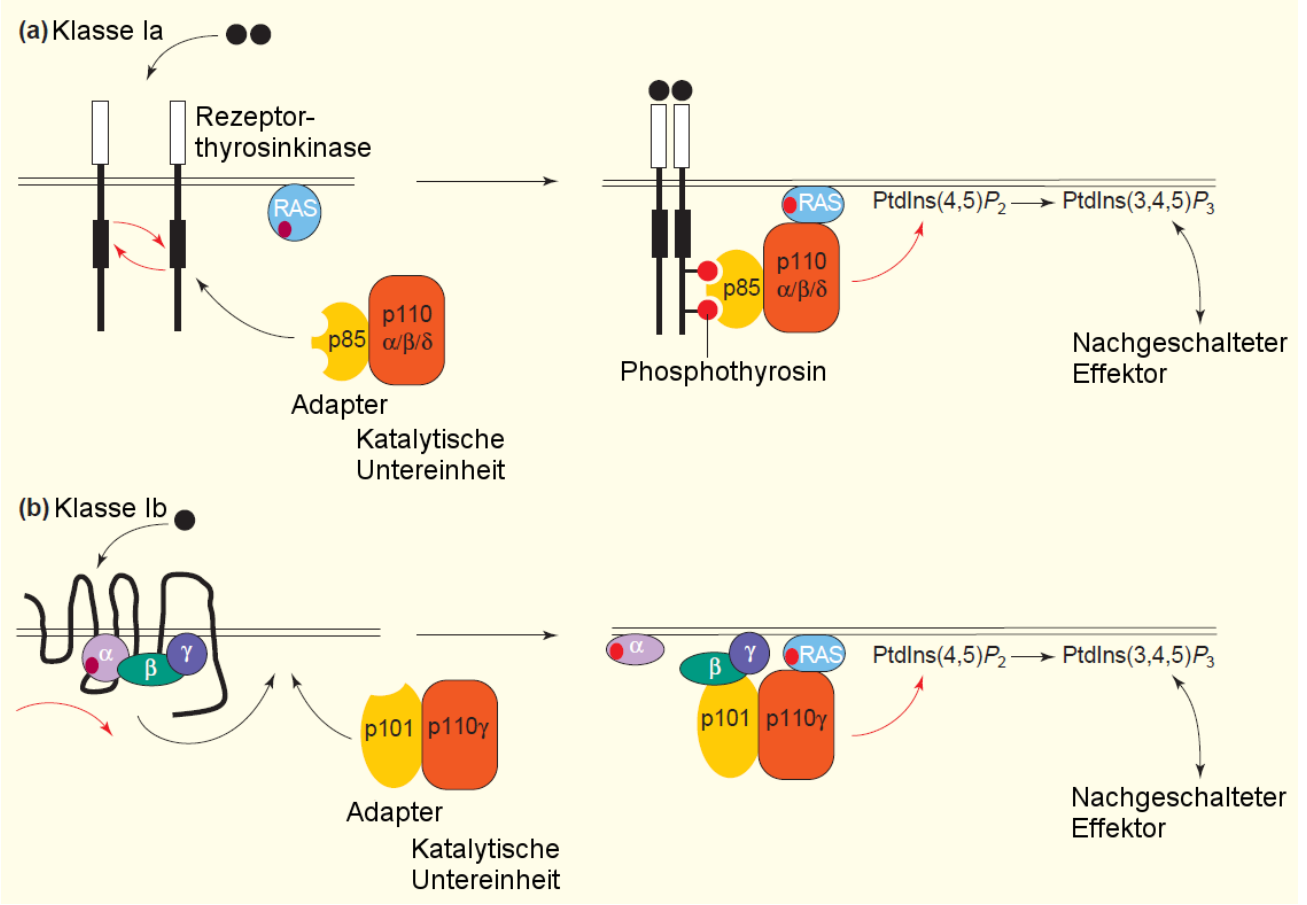

\begin{abstract}
Abbildung 3: Aktivierungsmechanismus der Klasse I PI3-Kinasen. Die Abbildung wurde mit freundlicher Genehmigung dem Artikel „PI3-kinase inhibition: a target for drug development? “ entnommen und übersetzt. Originaltitel der Abbildung: "Class I PI3-kinase activation" (Stein und Waterfield 2000); a) Aktivierung der Klasse Ia der PI3-Kinasen durch Bindung der SH2-Domäne der regulatorischen Untereinheit p85 an Phosphotyrosinreste. Die Bindung von Liganden wie VEGF führt zur Dimerisierung des Rezeptors und Transphosphorylierung der zytoplasmatischen Tyrosinreste des Rezeptors, wodurch die Bindungsstelle für die SH2-Domäne geschaffen wird. b) Aktivierung der Klasse Ib der PI3-Kinasen durch Bindung der regulatorischen Untereinheit p101 an die G $\beta \gamma$-Untereinheit des G-Proteins gekoppelte Rezeptoren. Die Ligandenbindung führt zur Trennung des heterotrimeren G-Proteins vom Rezeptor und zur Dissoziation des G-Proteins selbst. Das an der G $\alpha$ Untereinheit gebundene GDP wird durch GTP ersetzt. Die Bindung der PI3-Kinase an die G $\beta \gamma$-Untereinheit über die p101 Untereinheit führt zur Aktivierung (Stein und Waterfield 2000)
\end{abstract}

Die Bindung der SH2 Domänen der regulatorischen Untereinheit p85 an spezifische zytoplasmatische Phosphotyrosinreste des Rezeptors führt zur Aktivierung der PI3-Kinase (Carpenter et al. 1993). Entsprechend kann die Klasse IA auch durch GTP-gebundenes Ras stimuliert und die Klasse IB direkt über ein heterotrimeres G-Protein aktiviert werden (Vanhaesebroeck et al. 2001; Anderson und Jackson 2003).

Die Aktivierung veranlasst die Rekrutierung der PI3-Kinase aus dem Zytosol zur Plasmamembran, wo die PI3-Kinase ihr physiologisches Substrat vorfindet (Zhao und Vogt 2008). Die Klasse I der PI3-Kinasen katalysiert die Phosphorylierung der 3'-OH-Position am Inositolring. In vitro können sie Phosphatidylinositol (PI), Phosphatidylinositol-4-phosphat (PI-4-P) und Phosphatidylinositol-4,5-bisphosphat (PI-4,5-P2) als Substrate nutzen, dagegen scheinen sie in vivo PI-4,5-P2 (PIP2) zu präferieren (Carpenter et al. 1990). 
Die Phosphatase PTEN (Phosphatase and Tensin homolog) vermag PIP3 zu PIP2 zu dephosphorylieren und stellt somit den Gegenspieler der PI3-Kinase dar (Li et al. 1997; Maehama und Dixon 1998; Dahia 2000; Maehama 2007). Das gebildete Phosphatidylinositol3,4,5-trisphosphat (PIP3) fungiert als wichtigster sekundärer Botenstoff (second messenger) und aktiviert als Mediator der PI3K- Aktivität wiederum zahlreiche weitere Signalmoleküle durch direkte Bindung an deren PH-(Pleckstrin-Homologie)-Domäne (Toker und Cantley 1997).

Ein sehr bedeutendes Signalmolekül stellt hierbei die Serin-Threonin-Kinase Akt (Proteinkinase B) dar. Die PI3K geleitet Akt zur inneren Plasmamembran, wo Akt sowohl am Threoninrest an Position 308, wie auch am Serinrest an Position 473 phosphoryliert und damit aktiviert wird (Kandel und Hay 1999; Vanhaesebroeck und Alessi 2000). Die Aktivierung von Akt führt wiederum zur Aktivierung nachgeschalteter Signalkaskaden, die insbesondere an der Regulation des Zellzyklus und Verhinderung der Apoptose beteiligt sind (Franke et al. 2003).

Für die Apoptoseregulation ist Akt unter anderem direkt für die Phosphorylierung des proapoptotischen Proteins BAD (Bcl-2-Antagonist of Cell Death) (Datta et al. 1997), der proapoptotischen Caspase 9 (Franke et al. 2003; Downward 2004) und von FKHR (forkhead related transcription factor), einem Mitglied der Forkhead-Box-Protein-Familie, der zur Inhibierung von Bim (Bcl-2 interacting mediator of cell death) und Fas-Ligand (CD95Ligand) führt (Ghobrial et al. 2005), verantwortlich. Außerdem ist Akt mit Wirkung auf NF$\kappa B$ und p53 indirekt beteiligt an der Regulation zweier zentraler Regulatoren des Zelltods (Scheid und Woodgett 2001; Downward 2004).

Über die apoptosehemmende Wirkung hinaus hat Akt einen proliferations- und wachstumsfördernden Effekt auf die Zellen. Akt ist involviert in die Zellzyklusregulation durch seinen Einfluss auf Cyclin D1, das eine wichtige Rolle für die G1/S-Phasen-Progression einnimmt. Durch Phosphorylierung und folglich Hemmung der Glycogen-Synthase-Kinase-3 (GSK-3), die selber die Expression von Cyclin D1 senkt, führt die Aktivierung von Akt zu einer beschleunigten Progression des Zellzyklus (Cross et al. 1995; Diehl et al. 1998). Zusätzlich ist Akt für die Aktivierung der Serin-Threonin-Kinase mTOR (mammalian target of rapamycin) zuständig, die mit verantwortlich für die nährstoffabhängige Regulation der Proteinsynthese und indirekt Verstärkter der Translation ist (Pene et al. 2002; Younes et al. 2007). 


\subsubsection{Expression und Tumorgenese der PI3K}

Bedenkt man, welche Schlüsselrolle die PI3-Kinase in der Signaltransduktion jeder Zelle einnimmt, erscheint es folgerichtig anzunehmen, dass sie auch eine wichtige Rolle in der Tumorgenese spielt. So steht die Klasse I der PI3-Kinasen schon lange im Mittelpunkt des Interesses zahlreicher Krebsforschungen. Heute weiß man, dass Veränderungen des PI3Kinase-Signalweges in der Tat eine äußerst häufige Veränderung in Krebszellen darstellen (Zhao und Vogt 2008; Yuan und Cantley 2008).

Zahlreiche Studien konnten zeigen, dass die PI3-Kinase auch in der Genese des Multiplen Myeloms eine wichtige Funktion hat (Pene et al. 2002). Die Wachstumsfaktoren IL-6 und IGF-1 wirken über eine Aktivierung des PI3-Kinase-Akt-Signalweges stimulierend auf Wachstum und Überleben der Multiplen Myelom-Zellen (Hideshima et al. 2001b; Lentzsch et al. 2004; van de Donk et al. 2005; Sprynski et al. 2009; Pollak 2012).

Konstitutive Aktivierungen des PI3-Kinase-Akt-Signalwegs konnten auch in vielen weiteren Krebsarten wie dem Mammakarzinom, Ovarialkarzinom oder Magenkarzinom nachgewiesen werden (O'Brian et al. 1989; Philp et al. 2001; Roy et al. 2002). Mechanismen, die zu einer konstitutiven Aktivierung von Akt in Tumorzellen führen, beinhalten insbesondere den Verlust der Funktion des Tumorsuppressors und Gegenspielers von Akt PTEN, Amplifikationen oder Mutationen der PI3-Kinase oder der Wachstumsfaktor-Rezeptoren (Li et al. 1997; Jimenez et al. 1998; Tu et al. 2000; Shaw und Cantley 2006; Maehama 2007). Genamplifikationen der p110 sowie p85 Untereinheit konnten in Ovarialkarzinomen gezeigt werden. In Ovarialkarzinomen, Mammakarzinomen und Magenkarzinomen fand man ebenso Amplifikationen von Akt (Vivanco und Sawyers 2002). In dem für die p110 Untereinheit codierenden Gen PIK3CA konnten darüber hinaus in einigen Tumoren Mutationen nachgewiesen werden, die mit einer Häufigkeit von 5 bis $25 \%$ anzutreffen waren (Samuels und Velculescu 2004). Mutationen von PTEN, die zu dessen Funktionsverlust als Tumorsuppressor führen, sind ebenso sehr häufig in zahlreichen Krebsarten anzufinden (Luo et al. 2003).

Die verbindende Eigenschaft dieser Mutationsmechanismen ist, dass sie alle zu einer deutlich erhöhten Aktivität des PI3-Kinase-Akt-Signalweges führen. Zudem sind sie alle unabhängig von stimulierenden Wachstumsfaktoren. Diese konstitutive Aktivierung der Zellen konnten Vogt et al. durch Nachweis der Phosphorylierung von Akt (T308 und S473) belegen (Vogt et al. 2010). Im Tiermodell konnte zudem gezeigt werden, dass Zellen mit einer Mutation der p110 Untereinheit Tumoren auslösen können (Bader et al. 2006). Die konstitutive Aktivierung 
des PI3-Kinase-Akt-Signalweges korreliert mit einer schlechten Prognose und verkürzter Überlebenszeit (Saal et al. 2007).

\subsubsection{Inhibitoren des PI3K-Akt-Signalweges}

Aufgrund seiner Bedeutung für Proliferations- und Apoptoseregulation ist der PI3Kinasen/Akt-Signalweg ein Erfolg versprechendes Angriffsziel in der Krebsbehandlung.

Zahlreiche Studien haben bestätigt, dass die Hemmung des PI3-Kinase-Akt-Signalweges die Proliferationsraten senken und Apoptoseraten steigern kann (Luo et al. 2003; Crabbe et al. 2007; Courtney et al. 2010). Es konnte gezeigt werden, dass Inhibition der PI3K in XenograftMausmodellen das Tumorwachstum von hämatologischen Tumoren, Kolon-Karzinomen und Lungen-Karzinomen zu hemmen vermag (Dean et al. 1996). Auch beim Multiplen Myelom konnten bereits einige Inhibitoren des PI3-Kinase-Akt-Signalweges erfolgreich eingesetzt werden (Younes et al. 2007).

Die PI3-Kinase-Inhibitoren lassen sich in direkte und indirekte Hemmer unterscheiden. Direkt hemmend auf den PI3-Kinase-Akt-Signalweg wirken PI3-Kinase-Inhibitoren, AktInhibitoren, Inhibitoren der Proteinkinase C (PKC) und mTOR-Inhibitoren (Younes et al. 2007). Alle bisher bekannten PI3-Kinase-Inhibitoren wirken durch kompetitive Bindung an der ATP-Bindungsstelle der katalytischen Untereinheit der PI3-Kinasen. Man unterscheidet pan-PI3-Kinase-Inhibitoren und selektive PI3-Kinase-Inhibitoren, deren Entwicklung aufgrund der hoch konservierten ATP-Bindungsstelle schwierig ist (Walker et al. 1999).

Beim Einsatz von pan-PI3-Kinase-Inhibitoren muss mit toxischen Nebeneffekten gerechnet werden, da die PI3-Kinasen in zahlreichen physiologischen Prozessen wie dem GlukoseMetabolismus und der Immunantwort eine wichtige Funktion haben. Das Risiko dieser Nebenwirkungen muss gegen den erwarteten Nutzen in der Tumortherapie abgewogen werden. Isoform-spezifische Inhibitoren mit weniger unerwünschten Wirkungen könnten eine sinnvolle Alternative in der Therapie chronischer Erkrankungen sein (Crabbe et al. 2007).

Die chemischen Verbindungen Wortmannin und LY294002 stellen die ältesten bekannten PI3-Kinase-Inhibitoren dar. Ihr Verlust an Spezifität für PI3-Kinasen in höheren Konzentrationen und weitere chemische Eigenschaften machen ihren therapeutischen Einsatz jedoch schwierig (Stein und Waterfield 2000). Das Alkylphospholipid Perifosin ist ein oraler Akt-Inhibitor, der eine signifikante Zytotoxizität gegenüber Multiplen Myelom-Zellen, sowohl in vitro als auch in vivo, zeigt. Perifosin weist diese Zytotoxizität ebenfalls in 
Gegenwart von Knochenmarkstromazellen, die Medikamentenresistenzen induzieren können, auf.

Darüber hinaus konnte gezeigt werden, dass Perifosin die antitumorale Wirkung von Bortezomib und Dexamethason in einer Kombinationstherapie erhöhen kann (Hideshima et al. 2006). Phase-I- und II-Studien mit Perifosin sind erfolgsversprechend verlaufen (Ghobrial et al. 2007). Aktuell läuft eine Phase-III-Studie, die eine Kombinationstherapie mit Perifosin, Bortezomib und Dexamethason mit der bisher üblichen Bortezomib und DexamethasonKombinationstherapie vergleicht (Richardson et al. 2011b).

Neben dem Akt-Inhibitor Perifosin zeigen PKC-Inhibitoren Erfolg versprechende Ergebnisse in der Myelomtherapie. Der selektive PKC-Inhibitor Enzastaurin hemmt ebenfalls den PI3Kinase-Akt-Signalweg und reduziert folglich das Tumorzellüberleben und die Proliferation ebenfalls in vitro und in vivo. Ebenso vermag Enzastaurin Zelladhäsion, VEGF- und IGF-1stimulierte Migration sowie Angiogenese beim Multiplen Myelom zu unterbinden (Moreau et al. 2007; Podar et al. 2007; Neri et al. 2008).

$\mathrm{Zu}$ den indirekten Hemmern des PI3-Kinase-Akt-Signalweges zählen IL-6- und IGF-1Inhibitoren sowie Hemmer des Heat shock protein 90 (Hsp90). Insbesondere die Erfahrungen mit Perifosin und Enzastaurin verdeutlichen, dass der PI3-Kinasen-Akt-Signalweg ein Erfolg versprechendes Angriffsziel in der Therapie des Multiplen Myeloms darstellt.

\subsection{BAY 80-6946}

BAY 80-6946 (5-amino-N-[7-methoxy-8-(3-morpholin-4-ylpropoxy)]-2,3-dihydroimidazo [1,2-c]quinazolin) ist ein neuer hoch spezifischer pan-Klasse I-PI3-Kinasen-Inhibitor mit der folgenden Strukturformel:

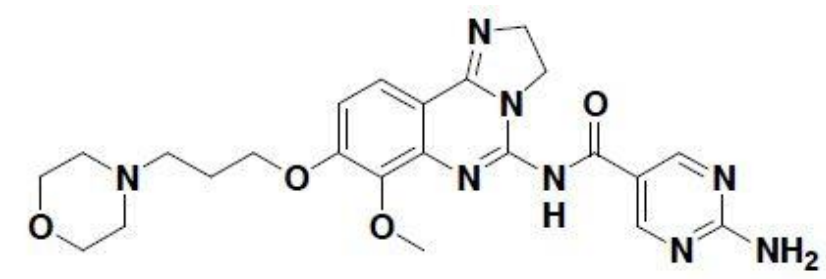

Abbildung 4: Strukturformel BAY 80-6946 (Liu und Ziegelbauer, nicht veröffentlicht)

Um die biochemische Aktivität zu ermitteln, wurde in vorangehenden Versuchen in den Laboren von BayerHealthCare ein Kinase-Assay durchgeführt (Liu und Ziegelbauer, nicht veröffentlicht). Die hierbei gemessenen $\mathrm{IC}_{50}$-Werte sind in Tabelle 2 abgebildet. 
Tabelle 2: Biochemische Aktivität von BAY 80-6946; Ergebnisse eines Kinase-Assays (Liu und Ziegelbauer, nicht veröffentlicht); Dieser zellfreie Assay zeigt die biochemische Aktivität unter Angabe des $\mathrm{IC}_{50^{-}}$Wertes von BAY 80-6946 auf die verschiedenen Untereinheiten der PI3K sowie auf mTOR.

\begin{tabular}{|lr|}
\hline \multicolumn{2}{|c|}{ Biochemische Aktivität } \\
PI3K- $\alpha \mathrm{IC}_{50}$ & $0,5 \mathrm{nM}$ \\
PI3K- $\beta \mathrm{IC}_{50}$ & $3,7 \mathrm{nM}$ \\
PI3K-ү $\mathrm{IC}_{50}$ & $6,4 \mathrm{nM}$ \\
PI3K-ס IC & $0,7 \mathrm{nM}$ \\
mTOR IC $_{50}$ & $45 \mathrm{nM}$ \\
\hline
\end{tabular}

Hieraus wird ersichtlich, dass BAY 80-6946 auf sämtliche Untereinheiten der PI3K wirkt, also ein pan-Klasse I-PI3K-Inhibitor ist. Im Unterschied dazu zeigt BAY 80-6946 auf die zur Kontrolle ebenfalls untersuchte Serin-Threonin-Kinase $m T O R$, die ebenfalls von Akt aktiviert wird (Pene et al. 2002; Younes et al. 2007), erst bei deutlich höheren Konzentrationen eine biochemische Aktivität. Zusammenfassend kann man BAY 80-6946 somit als spezifischen pan-Klasse I-PI3K-Inhibitor bezeichnen.

\subsection{Zielsetzung und Fragestellung der Arbeit}

Das Ziel der vorliegenden Arbeit war, die Wirkung des neuen spezifischen pan-Klasse I-PI3Kinasen-Inhibitors BAY 80-6946 auf vier verschiedene Multiple Myelom-Zelllinien zu untersuchen. Die einzelnen Ziele sollen im Folgenden benannt werden:

- Darstellung der konstitutiven Aktivierung des PI3-Kinase-Akt-Signalweges in den vier Multiplen Myelom-Zelllinien AMO-1, KMS-12-BM, MOLP-8, U-266.

- Untersuchung der Wirkung von BAY 80-6946 auf die Phosphorylierung (Aktivierung) des PI3-Kinase-Akt-Signalweges in den Multiplen Myelom-Zelllinien.

- Stimulierung der Aktivierung des PI3-Kinase-Akt-Signalweges mit Hilfe von IGF-1 in den Multiplen Myelom-Zelllinien.

- Untersuchung der Wirkung von BAY 80-6946 auf die durch IGF-1-stimulierte Aktivierung des PI3-Kinase-Akt-Signalweges in den Multiplen Myelom-Zelllinien.

- Prüfung des Einflusses von BAY 80-6946 auf die funktionellen zellulären Parameter Apoptose, Proliferation und Zellzyklus der Multiplen Myelom-Zelllinien. 
- Bestätigung der in vitro gezeigten Wirkung von BAY 80-6946 auf die beiden Multiplen Myelom-Zelllinien AMO-1 und MOLP-8 in einem Xenograft-Mausmodell in vivo

Hierfür wurden folgende vier humane Myelom-Suspensionszelllinien AMO-1 (Shimizu et al. 1993), KMS-12-BM (Ohtsuki et al. 1989), MOLP-8 (Matsuo et al. 2004) und U-266 (Schwab et al. 1991), die freundlicherweise von Herrn Dr. Thorsten Stühmer aus der Abteilung Hämatologie und Onkologie der Universitätsklinik Würzburg zur Verfügung gestellt wurden, ausgewählt. Zunächst wurden die vier Zelllinien hinsichtlich ihrer konstitutiven Aktivierung von Akt untersucht. Als Marker für die konstitutive Aktivierung diente der Nachweis der Phosphorylierung von Akt am Serinrest an Position 473. Dazu wurden sowohl Western-BlotAnalysen als auch FACS-Analysen durchgeführt.

Anschließend wurde die Hemmung dieser Aktivierung (Phosphorylierung) von Akt durch BAY 80-6946 in drei verschiedenen Wirkstoffkonzentrationen ebenfalls mit Hilfe von Western-Blot-Analysen und FACS-Analysen untersucht.

Im nächsten Schritt wurden die Zellen mit IGF-1 stimuliert. Multiple Myelom-Zellen stehen in ihrer Umgebung dem Mikromilieu des Knochenmarkes unter dem ständigen Einfluss von zahlreichen Wachstumsfaktoren (siehe auch 1.1.5: "Das Mikromilieu im Knochenmark"). Der insulinähnliche Wachstumsfaktor IGF-1 stellt einen der bedeutendsten Wachstumsfaktoren für das Multiple Myelom dar (Sprynski et al. 2009). Die Stimulation mit IGF-1 kann die Aktivierung von Akt erheblich verstärken (Ferlin et al. 2000; Qiang et al. 2002; Tai et al. 2003; Sprynski et al. 2009). Aus diesen Gründen wurde IGF-1 für die Stimulation der Myelom-Zellen in den folgenden Versuchen ausgewählt und anschließend der Einfluss von BAY 80-6946 auf die stimulierte Aktivierung von Akt untersucht.

Der hemmende Einfluss von BAY 80-6946 auf die funktionellen Parameter Apoptose, Proliferation und Zellzyklus wurde mit Hilfe von Proliferations- und Apoptose-Experimenten überprüft.

Abschließend wurden zwei Multiple Myelom-Zelllinien ausgewählt (AMO-1, MOLP-8) und die in-vivo-Wirkung von BAY 80-6946 in einem Xenograft-Mausmodell untersucht. 


\section{Material und Methoden}

\subsection{Material}

\subsubsection{Antikörper}

\begin{tabular}{|c|c|c|}
\hline $\begin{array}{l}\text { Antikörper } \\
\text { (Konzentration) }\end{array}$ & Herkunft & Firma \\
\hline \multicolumn{3}{|l|}{ Western-Blot-Analyse } \\
\hline \multicolumn{3}{|l|}{ Primärantikörper } \\
\hline $\begin{array}{l}\text { Beta-Aktin }(1: 10.000) \\
\text { Klon C4 }\end{array}$ & Maus (monoklonal) & Millipore, Temecula, USA \\
\hline Akt (1:2.000) & Kaninchen (polyklonal) & $\begin{array}{l}\text { Cell Signaling Technology, } \\
\text { Danvers, USA }\end{array}$ \\
\hline $\begin{array}{l}\text { Phospho-Akt (1:500) } \\
\text { Ser473 }\end{array}$ & Kaninchen (polyklonal) & $\begin{array}{l}\text { Cell Signaling Technology, } \\
\text { Danvers, USA }\end{array}$ \\
\hline Erk & Maus (monoklonal) & $\begin{array}{l}\text { Cell Signaling Technology, } \\
\text { Danvers, USA }\end{array}$ \\
\hline Phospho-Erk & Maus (monoklonal) & $\begin{array}{l}\text { Cell Signaling Technology, } \\
\text { Danvers, USA }\end{array}$ \\
\hline \multicolumn{3}{|l|}{ Sekundärantikörper } \\
\hline $\begin{array}{l}\text { Anti-Maus-IgG }(1: 2.500) \\
\text { HRP Konjugat }\end{array}$ & & $\begin{array}{l}\text { Promega } \\
\text { Madison, USA }\end{array}$ \\
\hline $\begin{array}{l}\text { Anti-Kaninchen- } \\
\operatorname{IgG}(1: 2.500) \\
\text { HRP Konjugat }\end{array}$ & & $\begin{array}{l}\text { Promega Corporation, } \\
\text { Madison, USA }\end{array}$ \\
\hline \multicolumn{3}{|l|}{$F A C S$} \\
\hline $\begin{array}{l}\text { Phospho-Akt (1:50) } \\
\text { Alexa fluor } 647 \text { Konjugat }\end{array}$ & & $\begin{array}{l}\text { Cell Signaling Technology, } \\
\text { Danvers, USA }\end{array}$ \\
\hline
\end{tabular}




\begin{tabular}{|l|l|l|}
\hline $\begin{array}{l}\text { Kaninchen IgG Isotyp } \\
\text { Kontrolle }\end{array}$ & $\begin{array}{l}\text { Cell Signaling Technology, } \\
\text { Danvers, USA }\end{array}$ \\
\hline CD $138(20 \mu$ l pro Test $)$ & $\begin{array}{l}\text { Becton Dickinson, Franklin } \\
\text { Lakes, USA }\end{array}$ \\
\hline$H L A-A B C(10 \mu$ l pro Test $)$ & $\begin{array}{l}\text { Becton Dickinson, Franklin } \\
\text { Lakes, USA }\end{array}$ \\
\hline Maus IgG Isotyp Kontrolle & $\begin{array}{l}\text { Becton Dickinson, Franklin } \\
\text { Lakes, USA }\end{array}$ \\
\hline
\end{tabular}

\subsubsection{Materialien und Chemikalien}

\begin{tabular}{|l|l|}
\hline Name & Hersteller/Zusammensetzung \\
\hline AB-Serum human & PAA Laboratories, Pasching, Österreich \\
\hline $\begin{array}{l}\text { Acrylamide 30\%: N,N-methylene-bis- } \\
\text { Bis Solution 37.5:1 (2,6\% C) }\end{array}$ & $\begin{array}{l}\text { Bio-RAD Laboratories GmbH, Hercules, } \\
\text { USA }\end{array}$ \\
\hline AEC+ Lösung & Biomol GmbH, Hamburg, Deutschland \\
\hline BAY 80-6946 & $\begin{array}{l}\text { Summenformel: (5-amino-N-[7-methoxy-8- } \\
\text { (3-morpholin-4-ylpropoxy)]-2,3-dihydro- } \\
\text { imidazo [1,2-c] quinazolin } \\
\text { gelöst in 5 mM TFA in DMSO }\end{array}$ \\
\hline Blockmilch 5\% & $\begin{array}{l}\text { TBS Tween Pufferlösung } \\
5 \% \text { Blockmilchpulver }\end{array}$ \\
\hline Blockmilchpulver & $\begin{array}{l}\text { Bio-RAD Laboratories GmbH, Hercules, } \\
\text { USA }\end{array}$ \\
\hline Bradford-Reagenz-Protein-Assay & $\begin{array}{l}\text { Bio-RAD Laboratories GmbH, Hercules, } \\
\text { DSA }\end{array}$ \\
\hline
\end{tabular}




\begin{tabular}{|c|c|c|}
\hline & \multicolumn{2}{|c|}{ 5\% BSA-Pulver } \\
\hline BSA-Pulver & \multicolumn{2}{|c|}{$\begin{array}{l}\text { Carl Roth GMBH + CO. KG, Karlsruhe, } \\
\text { Deutschland }\end{array}$} \\
\hline $\begin{array}{l}\text { Cell Death Detection ELISA Plus } \\
\text { Immunoreagenz }\end{array}$ & \multicolumn{2}{|c|}{$\begin{array}{ll}400 \mu 1 & \text { Anti-DNS-Antikörper } \\
400 \mu 1 & \text { Anti-Histon-Antikörper } \\
7200 \mu 1 & \text { Inkubationspuffer }\end{array}$} \\
\hline Cell Death Detection ELISA Plus, 10x Kit & \multicolumn{2}{|c|}{$\begin{array}{l}\text { Roche Diagnostics GmbH, Indianapolis, } \\
\text { USA }\end{array}$} \\
\hline $\begin{array}{l}\text { Cell Titer } 96 \mathrm{Aq}_{\text {ueous }} \text { One Solution Cell } \\
\text { Proliferation-Assay }\end{array}$ & \multicolumn{2}{|c|}{ Promega Corporatio, Madison, USA } \\
\hline $\begin{array}{l}\text { Cell Titer } 96 \text { Non-radioactive Cell } \\
\text { Proliferation-Assay (MTT) }\end{array}$ & \multicolumn{2}{|c|}{ Promega Corporation, Madison, USA } \\
\hline $\begin{array}{l}\text { Complete Mini - } \\
\text { 7x Complete Stock Lsg. Protease Inhibitor } \\
\text { Cocktail Tablets }\end{array}$ & \multicolumn{2}{|c|}{$\begin{array}{l}\text { Roche Diagnostics GmbH, Indianapolis, } \\
\text { USA }\end{array}$} \\
\hline $\begin{array}{l}\text { Deckglas } \\
\text { Glassplate Mini Protean } 3 \text { System }\end{array}$ & \multicolumn{2}{|c|}{$\begin{array}{l}\text { Bio-RAD Laboratories GmbH, Hercules, } \\
\text { USA }\end{array}$} \\
\hline Dimethylsulfoxid (DMSO) & \multicolumn{2}{|c|}{$\begin{array}{l}\text { Carl Roth GMBH + CO. KG, Karlsruhe, } \\
\text { Deutschland }\end{array}$} \\
\hline ECL-Lösung 1 & \multicolumn{2}{|c|}{$\begin{array}{ll}9 \mathrm{ml} & \mathrm{dH}_{2} \mathrm{O} \\
1 \mathrm{ml} & 1 \mathrm{M} \text { Tris-HCl, pH 8,5 } \\
45 \mu \mathrm{l} & \text { p-Cumarsäure Stammlösung } \\
100 \mu \mathrm{l} & \text { Luminol Stammlösung }\end{array}$} \\
\hline ECL-Lösung 2 & $\begin{array}{l}9 \mathrm{ml} \\
1 \mathrm{ml} \\
6 \mu \mathrm{l}\end{array}$ & $\begin{array}{l}\mathrm{dH}_{2} \mathrm{O} \\
1 \mathrm{M} \text { Tris-HCl, pH } 8,5 \\
\text { Hydrogenperoxid, } 30 \%\end{array}$ \\
\hline Eichlösung FACS; CST Beads & \multicolumn{2}{|c|}{ Becton Dickinson, Franklin Lakes, USA } \\
\hline Eppendorf Reaktionsgefäß 1,5 ml & \multicolumn{2}{|c|}{ Eppendorf AG, Hamburg, Deutschland } \\
\hline Eppendorf Reaktionsgefäß $2 \mathrm{ml}$ & \multicolumn{2}{|c|}{ Eppendorf AG, Hamburg, Deutschland } \\
\hline
\end{tabular}




\begin{tabular}{|c|c|}
\hline Ethanol $100 \%$ & AppliChem GmbH, Darmstadt, Deutschland \\
\hline $\begin{array}{l}\text { FACS Röhrchen } 5 \mathrm{ml} \\
\text { Polystyrene Round-Bottom-Tube }\end{array}$ & Becton Dickinson, Franklin Lakes, USA \\
\hline Falcon $15 \mathrm{ml}$ & $\begin{array}{l}\text { Greiner Bio-One International AG, } \\
\text { Kremsmünster, Österreich }\end{array}$ \\
\hline Falcon $50 \mathrm{ml}$ & $\begin{array}{l}\text { Greiner Bio-One International AG, } \\
\text { Kremsmünster, Österreich }\end{array}$ \\
\hline Fetales Kälberserum (Fetal-Calf-Serum) & PAA Laboratories, Pasching, Österreich \\
\hline Gefriermedium Kryo SFM & Promo Cell, Heidelberg, Deutschland \\
\hline Gelgießkammersystem; Protean III Minigel & $\begin{array}{l}\text { Bio-RAD Laboratories GmbH, Hercules, } \\
\text { USA }\end{array}$ \\
\hline $\begin{array}{l}\text { Gelplatte } \\
\text { Short Plates Mini Protean } 3 \text { System }\end{array}$ & $\begin{array}{l}\text { Bio-RAD Laboratories GmbH, Hercules, } \\
\text { USA }\end{array}$ \\
\hline Glycerol & $\begin{array}{l}\text { Carl Roth GMBH + CO. KG, Karlsruhe, } \\
\text { Deutschland }\end{array}$ \\
\hline Glycin & $\begin{array}{l}\text { Carl Roth GMBH + CO. KG, Karlsruhe, } \\
\text { Deutschland }\end{array}$ \\
\hline Hydrogenperoxid $30 \%$ & $\begin{array}{l}\text { Carl Roth GMBH + CO. KG, Karlsruhe, } \\
\text { Deutschland }\end{array}$ \\
\hline IGF-1 & Immunotools GmbH, Friesoythe; Germany \\
\hline Inkubationspuffer Durchflusszytometrie & $\begin{array}{ll}500 \mathrm{ml} & \text { PBS } \\
2,5 \mathrm{~g} & \text { BSA-Pulver }\end{array}$ \\
\hline $\begin{array}{l}\text { Isopropranol-Container; } 5100 \text { Cryo } 1{ }^{\circ} \mathrm{C} \\
\text { Freezing Container, "Mr. Frosty" }\end{array}$ & $\begin{array}{l}\text { Nalgene®Labware, Thermo Fisher Scientific } \\
\text { Inc., Waltham, Massachusetts, USA }\end{array}$ \\
\hline Kämme 0,75 & $\begin{array}{l}\text { Bio-RAD Laboratories GmbH, Hercules, } \\
\text { USA }\end{array}$ \\
\hline $\begin{array}{l}\text { Kanüle, Microlance TM, 30,9 mm x 40mm, } \\
20 \text { G1 1/2 }\end{array}$ & Becton Dickinson, Franklin Lakes, USA \\
\hline
\end{tabular}




\begin{tabular}{|c|c|}
\hline Küvetten 3,5 ml & $\begin{array}{l}\text { Bio-RAD Laboratories GmbH, Hercules, } \\
\text { USA }\end{array}$ \\
\hline $\begin{array}{l}\text { Kulturmedium Zelllinien AMO-1, KMS-12- } \\
\text { BM, MOLP-8 }\end{array}$ & $\begin{array}{ll}500 \mathrm{ml} & \text { RPMI 1640-Medium } \\
100 \mathrm{ml} & \text { FCS (20\%) } \\
1 \% & \text { Penicillin } \\
1 \% & \text { Streptomycin }\end{array}$ \\
\hline Kulturmedium Zelllinien U-266 & $\begin{array}{ll}500 \mathrm{ml} & \text { RPMI 1640-Medium } \\
50 \mathrm{ml} & \text { FCS (10\%) } \\
1 \% & \text { Penicillin } \\
1 \% & \text { Streptomycin }\end{array}$ \\
\hline Laufpuffer 10x & $\begin{array}{l}288 \mathrm{~g} \quad \text { Glycin } \\
60 \mathrm{~g} \quad 1 \mathrm{M} \text { Tris-HCl, } \mathrm{pH} 8,5 \\
100 \mathrm{ml} \quad 10 \% \text { SDS-Lsg, } \\
\text { mit Aqua bidest. auf 2 Liter auffüllen } \\
\text { (für Laufpuffer } 100 \mathrm{ml} \text { 10x Laufpuffer mit } \\
900 \mathrm{ml} \text { Aqua bidest. verdünnen) }\end{array}$ \\
\hline Laufpuffer 10x & $\begin{array}{ll}288 \mathrm{~g} & \text { Glycin } \\
60 \mathrm{~g} & \text { Tris } \\
10 \% & \text { SDS-Lösung } \\
\text { Mit Aqua bidest. auf 2 Liter auffüllen }\end{array}$ \\
\hline Luminol (3-Aminophthalydrazide) & $\begin{array}{l}\text { Sigma-Aldrich Corporation, St. Louis, } \\
\text { Missouri, USA }\end{array}$ \\
\hline Luminol Stammlösung (250mM) & $\begin{array}{ll}0,44 \mathrm{~g} & \text { Luminol } \\
10 \mathrm{ml} & \mathrm{DMSO}\end{array}$ \\
\hline Methanol & AppliChem GmbH, Darmstadt, Deutschland \\
\hline Methanol 90\% & $\begin{array}{l}90 \% \text { Methanol } \\
10 \% \text { PBS }\end{array}$ \\
\hline Nitrozellulosemembran & $\begin{array}{l}\text { Bio-RAD Laboratories GmbH, Hercules, } \\
\text { USA }\end{array}$ \\
\hline Paraformaldehyd Pulver (PFA) & Sigma-Aldrich Corporation, St. Louis, \\
\hline
\end{tabular}




\begin{tabular}{|c|c|}
\hline & Missouri, USA \\
\hline $\begin{array}{l}\text { PBS, Dulbeccós Phosphate buffered saline; } \\
\text { phosphatgepufferte Salzlösung }\end{array}$ & Biochrom AG, Berlin, Deutschland \\
\hline p-Cumarsäure & $\begin{array}{l}\text { Sigma-Aldrich Corporation, St. Louis, } \\
\text { Missouri, USA }\end{array}$ \\
\hline p-Cumarsäure Stammlösung (90mM) & $\begin{array}{cr}0,15 \mathrm{~g} & \mathrm{p} \text {-Cumarsäure } \\
10 \mathrm{ml} & \text { DMSO }\end{array}$ \\
\hline Penicillin/Streptomycin & Biochrom AG, Berlin, Deutschlan \\
\hline PFA 4\% & $\begin{array}{l}\text { BSA } \\
4 \% \text { Paraformaldehyd Pulver }\end{array}$ \\
\hline Pipette (steril) $10 \mathrm{ml}$ & $\begin{array}{l}\text { Sarstedt Serological Pipette, Nümbrecht, } \\
\text { Deutschland }\end{array}$ \\
\hline Pipette (steril) $25 \mathrm{ml}$ & $\begin{array}{l}\text { Sarstedt Serological Pipette, Nümbrecht, } \\
\text { Deutschland }\end{array}$ \\
\hline Pipette (steril) $5 \mathrm{ml}$ & $\begin{array}{l}\text { Sarstedt Serological Pipette, Nümbrecht, } \\
\text { Deutschland }\end{array}$ \\
\hline Propidiumjodid & $\begin{array}{l}\text { Sigma-Aldrich Corporation, St. Louis, } \\
\text { Missouri, USA }\end{array}$ \\
\hline $\begin{array}{l}\text { Proteinstandard, Page Ruler prestained } \\
\text { Protein ladder }\end{array}$ & FERMENTAS INC, Glen Burnie, Maryland \\
\hline Reinigungslösung $F A C S$ & Becton Dickinson, Franklin Lakes, USA \\
\hline Ribonuklease A (RNAse 1) & $\begin{array}{l}\text { Sigma-Aldrich Corporation, St. Louis, } \\
\text { Missouri, USA }\end{array}$ \\
\hline RPMI Medium-1640 & PAA Laboratories, Pasching, Österreich \\
\hline Sammelgel (SDS Gel) & $\begin{array}{ll}2,1 \mathrm{ml} & \text { Aqua bidest. } \\
0,5 \mathrm{ml} & 30 \% \text { Acrylamid } \\
0,38 \mathrm{ml} & 1 \mathrm{M} \text { Tris } \mathrm{HCl} \text { ph } 6,8 \\
0,03 \mathrm{ml} & 10 \% \mathrm{SDS} \\
0,03 \mathrm{ml} & 10 \% \text { APS }\end{array}$ \\
\hline
\end{tabular}




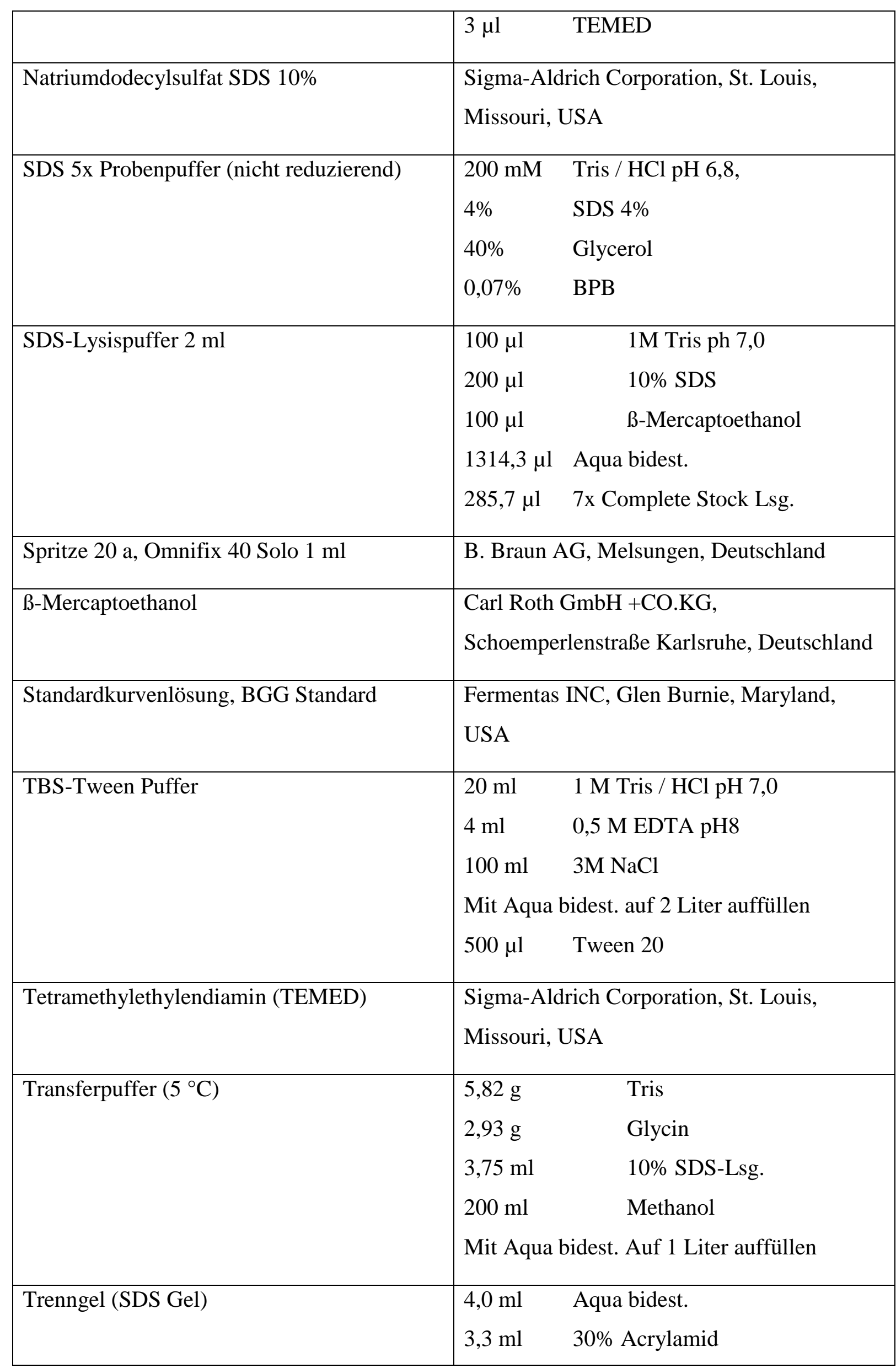




\begin{tabular}{|c|c|}
\hline & $\begin{array}{ll}2,5 \mathrm{ml} & 1,5 \mathrm{M} \text { Tris } \mathrm{HCl} \text { ph } 8,8 \\
0,1 \mathrm{ml} & 10 \% \text { SDS } \\
0,1 \mathrm{ml} & 10 \% \text { APS } \\
15 \mu \mathrm{l} & \text { TEMED }\end{array}$ \\
\hline Trifluoressigsäure (TFA) & $\begin{array}{l}\text { Sigma-Aldrich Corporation, St. Louis, } \\
\text { Missouri, USA }\end{array}$ \\
\hline Tris HCL $1,0 \mathrm{M}$ & $\begin{array}{l}\text { 121,1 g Tris, } \mathrm{pH} \text {-Einstellung mit HCL, mit } \\
\text { Aqua bidest. auf } 1 \mathrm{~L} \text { auffüllen }\end{array}$ \\
\hline Tris $\mathrm{HCl} 1,5 \mathrm{M}$ ph 8,8 & $\begin{array}{l}\text { 18,15g Tris, } \mathrm{pH} \text {-Einstellung mit HCL, mit } \\
\text { Aqua bidest. auf } 100 \mathrm{ml} \text { auffüllen }\end{array}$ \\
\hline Tris(hydroxymethyl)-aminomethan (Tris) & $\begin{array}{l}\text { Carl Roth GMBH + CO. KG, Karlsruhe, } \\
\text { Deutschland }\end{array}$ \\
\hline Trypanblau & $\begin{array}{l}\text { Sigma-Aldrich Chemie GmbH, München, } \\
\text { Deutschland }\end{array}$ \\
\hline Tween 20 & $\begin{array}{l}\text { Carl Roth GmbH +CO.KG, } \\
\text { Schoemperlenstraße, Karlsruhe, Deutschland }\end{array}$ \\
\hline Vehikel & $5 \mathrm{mM}$ TFA in DMSO \\
\hline Kulturplatte (6 well) & $\begin{array}{l}\text { Greiner Bio-One International AG, } \\
\text { Kremsmünster, Österreich }\end{array}$ \\
\hline Kulturplatte (96 well) & $\begin{array}{l}\text { Greiner Bio-One International AG, } \\
\text { Kremsmünster, Österreich }\end{array}$ \\
\hline $\begin{array}{l}\text { WesternBreeze® Chemiluminescent Kit- } \\
\text { Anti-Rabbit }\end{array}$ & Invitrogen, Carlsbad, Kalifornien, USA \\
\hline Reinigungslösung $F A C S$ & Becton Dickinson, Franklin Lakes, USA \\
\hline Zellkulturflaschen $75 \mathrm{~cm}^{2}$ & $\begin{array}{l}\text { Greiner Bio-One International AG, } \\
\text { Kremsmünster, Österreich }\end{array}$ \\
\hline Zelllinien & AMO-1, KMS-12-BM, MOLP-8 und U-266 \\
\hline Zellschaber & SARSTEDT AG \& Co, Nümbrecht, \\
\hline
\end{tabular}




\begin{tabular}{|l|l|}
\hline & Deutschland \\
\hline Stripping-Puffer & Für $100 \mathrm{ml}: 0.76 \mathrm{~g}$ Tris, $2 \mathrm{~g}$ SDS und $700 \mu 1$ \\
& $\beta$-Mercaptoethanol. Mit Aqua bidest. auf 100 \\
& ml auffüllen. $\mathrm{pH}$ mit HCL auf 6,8 einstellen. \\
\hline
\end{tabular}

\subsubsection{Geräte}

\begin{tabular}{|c|c|}
\hline Name & Hersteller \\
\hline $\begin{array}{l}\text { Blot Gerät, Trans Blot SD, } \\
\text { Semi Dry Transfer Cell }\end{array}$ & $\begin{array}{l}\text { Bio-RAD Laboratories GmbH, Hercules, } \\
\text { USA }\end{array}$ \\
\hline $\begin{array}{l}\text { Entwicklungsgerät } \\
\text { Luminescent Image Analyzer LAS-4000 }\end{array}$ & Fujifilm, Tokio, Japan \\
\hline FACS-Gerät FACS Canto II & Becton Dickinson, Franklin Lakes, USA \\
\hline Kocher, Thermo Stat plus & Eppendorf AG, Hamburg, Deutschland \\
\hline Kühlzentrifuge, Centrifuge 5417R & Eppendorf AG, Hamburg, Deutschland \\
\hline Laufkammer, Mini Protean Tetra Cell & $\begin{array}{l}\text { Bio-RAD Laboratories GmbH, Hercules, } \\
\text { USA }\end{array}$ \\
\hline Mikroplattenlesegerät, Appliskan & $\begin{array}{l}\text { Thermo Fisher Scientific Inc., Waltham, } \\
\text { Massachusetts, USA }\end{array}$ \\
\hline Mikroskop Zellkultur, Axiovert $40 \mathrm{C}$ & Carl Zeiss AG, Oberkochen, Deutschland \\
\hline $\begin{array}{l}\text { Netzgerät, Electrophoresis Power Supply } \\
\text { EPS } 1001\end{array}$ & Amersham Biosciences, Uppsala, Sweden \\
\hline Neubauer-Zählkammer & $\begin{array}{l}\text { Glaswarenfabrik Karl Hecht GmbH\&Co KG, } \\
\text { Sondheim, Deutschland }\end{array}$ \\
\hline Photometer, Genesys 10 Bio & $\begin{array}{l}\text { Thermo Fisher Scientific Inc., Waltham, } \\
\text { Massachusetts, USA }\end{array}$ \\
\hline Pipettierhilfe, Pipet Boy acu & $\begin{array}{l}\text { Integra Biosciences GmbH, Fernwald, } \\
\text { Deutschland }\end{array}$ \\
\hline Reinstwassersystem Arium & Sartorius Stedim Biotech S.A., Aubagne, \\
\hline
\end{tabular}




\begin{tabular}{|l|l|}
\hline & Frankreich \\
\hline Schüttler- und Mischgerät, LABINCO L46 & Labinco B.V., Breda, Niederlande \\
\hline Schüttler- und Mischgerät, PMR-30 & $\begin{array}{l}\text { Grant Instruments, Cambridgeshire, } \\
\text { Großbritannien }\end{array}$ \\
\hline Transferpipetten & Eppendorf AG, Hamburg, Deutschland \\
\hline Zentrifuge, Multifuge 1S-R Heraeus & $\begin{array}{l}\text { Thermo Fisher Scientific Inc., Waltham, } \\
\text { Massachusetts, USA }\end{array}$ \\
\hline
\end{tabular}

\subsubsection{Software}

\begin{tabular}{|l|l|}
\hline Name & Firma \\
\hline Adobe Acrobat Reader 9 & $\begin{array}{l}\text { Adobe Systems Incorporated, San Jose, } \\
\text { California, USA }\end{array}$ \\
\hline BD FACS Diva & Becton Dickinson, Franklin Lakes, USA \\
\hline Citavi & Swiss Academic Software, Swiss \\
\hline Fujifilm Las 4000 Image Reader & Fujifilm, Tokio, Japan \\
\hline GIMP Version 2.8.10 & $\begin{array}{l}\text { Open source Software verwendet unter der } \\
\text { Linzenz LGPLv3+ und GPLv3+ }\end{array}$ \\
\hline GraphPad Prism V 5 & $\begin{array}{l}\text { GraphPad Software, Inc., La Jolla, } \\
\text { California, USA }\end{array}$ \\
\hline Image J Software & $\begin{array}{l}\text { National Institute of Health, Bethesda, } \\
\text { Maryland, USA }\end{array}$ \\
\hline Microsoft Office 2007 & $\begin{array}{l}\text { Microsoft Corporation, Redmond, } \\
\text { Washington, USA }\end{array}$ \\
\hline Pixelmator 3.1 Marble & \begin{tabular}{l} 
Fixelmator Team Ltd., Litauen \\
\hline
\end{tabular} \\
\hline
\end{tabular}




\subsection{Methoden}

\subsubsection{Zellkultur}

Die humanen Multiple Myelom-Suspensionszelllinien AMO-1 (Shimizu et al. 1993), KMS12-BM (Ohtsuki et al. 1989), MOLP-8 (Matsuo et al. 2004) und U-266 (Schwab et al. 1991) wurden bei einer Zelldichte von $0,3 \times 10^{6}$ bis $1,5 \times 10^{6}$ Zellen/ml in $75 \mathrm{~cm}^{2}$ großen Zellkulturflaschen, gefüllt mit $20 \mathrm{ml}$ des jeweiligen Mediums, kultiviert Die Zelllinien AMO1, KMS-12-BM und MOLP-8 wurden in RPMI 1640-Medium, versetzt mit $20 \%$ FCS (Fetal Calf Serum), $1 \%$ Penicillin und $1 \%$ Streptomycin, gehalten. Die Zelllinie U-266 erhielt RPMI 1640-Medium, das mit $10 \%$ FCS, $1 \%$ Penicillin und $1 \%$ Streptomycin versetzt war.

Die Zellen wurden bei einer Temperatur von $37^{\circ} \mathrm{C}$ und einer $\mathrm{CO}_{2}$-Sättigung von $5 \% \mathrm{im}$ Inkubator kultiviert. Alle folgenden Arbeiten mit den Zelllinien wurden unter einer Sterilbank durchgeführt. In regelmäßigen Abständen wurden alle Zelllinien auf MykoplasmenInfektionen untersucht.

Zwischen den Experimenten wurden die Zellen in flüssigem Stickstoff aufbewahrt. Hierzu wurden 3-5 x $10^{6}$ Myelom-Zellen in Zellsuspension in ein Zentrifugierröhrchen (Falcon) überführt und für 5 Minuten bei $200 \mathrm{G}$ zentrifugiert. Das Zellpellet wurde in $1 \mathrm{ml}$ speziellem Gefriermedium (Kryo SFM) resuspendiert und in ein Kryoröhrchen überführt. Dieses wurde zunächst, um ein zellschonendes Einfrieren zu gewährleisten, in einem vorgekühlten Isopropanol-Container für eine Nacht in den $-80{ }^{\circ} \mathrm{C}$ kalten Gefrierschrank gestellt und anschließend im Stickstoffstank konserviert. Zum Auftauen wurde das Kryoröhrchen auf Eis gelegt und die Zellsuspension in $10 \mathrm{ml} 37{ }^{\circ} \mathrm{C}$ warmes Medium überführt. Danach wurde die Zellsuspension für 5 Minuten bei $200 \mathrm{G}$ zentrifugiert und das Zellpellet in $20 \mathrm{ml}$ Medium resuspendiert und wie gewohnt kultiviert.

\subsubsection{Zellpassage und Zählen der Zellen}

Abhängig von der Zelldichte wurden das Kulturmedium der Suspensionszelllinien ausgetauscht und die Zellen neu ausgesät. Für die Zellpassage wurde die Zellsuspension aus den $75 \mathrm{~cm}^{2}$ großen Zellkulturflaschen mit Hilfe einer Pipette in ein steriles $50 \mathrm{ml}$ fassendes Falcon überführt und durch mehrfaches vorsichtiges Auf- und Abpipettieren eine homogene Zellsuspension hergestellt. Für die Zellzählung wurden $50 \mu$ l dieser Zellsuspension als Aliquot in ein steriles Eppendorfgefäß $(0,5 \mathrm{ml})$ pipettiert und zunächst beiseitegestellt. Die im 
Falcon verbliebene Zellsuspension wurde nun in die Zentrifuge verbracht und bei $4{ }^{\circ} \mathrm{C}$ für 5 Minuten bei $200 \mathrm{G}$ zentrifugiert.

Zwischenzeitlich konnte die Zellsuspension mit Hilfe einer Zählkammer nach Neubauer ausgezählt werden. Hierzu wurden $50 \mu 1$ Trypanblau zu den $50 \mu 1$ Zellsuspension pipettiert und die Lösung mit Hilfe des Schüttelgerätes vermischt. Bei aufgelegtem Deckglas wurden $10 \mu 1$ der Lösung seitlich an der Zählkammer aufpipettiert. Durch die Kapillarkraft wurde die Zellsuspension in den 0,1 mm breiten Raum zwischen Zählkammer und Deckglas gesaugt. Anschließend wurden die Zellen unter dem Mikroskop mäanderförmig ausgezählt. Nach dem Prinzip der Neubauer-Zählkammer wurden vier Quadranten à 16 Kleinquadrate ausgezählt.

Durch die Trypanblaufärbung konnte dabei zwischen lebenden und toten Zellen unterschieden werden. Tote Zellen wurden im Gegensatz zu lebenden Zellen blau angefärbt, da sie eine veränderte Membrandurchlässigkeit haben. Anhand folgender Formel wurde die Zellzahl pro Milliliter bestimmt:

Zellzahl $/ \mathrm{ml}=\frac{Z * V^{*} K}{Q}$

$\mathrm{Z}=$ Zellzahl vital

V= Verdünnungsfaktor Trypanblau $=2$

$\mathrm{K}=1 \times 10^{4}=$ Konstante der Zählkammer

$\mathrm{Q}=$ Anzahl gezählter Quadranten = 4

\subsubsection{Behandlung mit BAY 80-6946}

Der neue Phosphoinositid-3-Kinase (PI3K)-Inhibitor BAY 80-6946 wurde freundlicherweise von der Arbeitsgruppe um Ningshu Liu und Karl Ziegelbauer aus dem Labor der BayerHealthCare zur Verfügung gestellt. Durch Verdünnung von BAY 80-6946 in Vehikellösung (5 mM TFA in DMSO) wurde eine 100-mikromolare Stammlösung hergestellt und die Aliquote derselben bei $-20{ }^{\circ} \mathrm{C}$ im Gefrierschrank aufbewahrt.

Die Myelom-Zellen wurden wie oben beschrieben in RPMI 1640-Medium, versetzt mit 10 oder $20 \%$ FCS und je $1 \%$ Penicillin sowie Streptomycin, kultiviert. Für die Behandlung mit BAY 80-6946 wurde die gewünschte Zellzahl $\left(0,5-1,5 \times 10^{6} / \mathrm{ml}\right)$ in frischem Medium ausgesät. Von jeder Zelllinie wurden folgende 5 Versuchsansätze angesetzt: eine Konzentrationsreihe 
von drei verschiedenen BAY 80-6946 Konzentrationen (10 nM, $50 \mathrm{nM}, 100 \mathrm{nM})$, eine Kontrolle ohne Wirkstoff und eine Vehikelkontrolle (Tabelle 3). Für die Vehikelkontrolle wurde eine 100 nM-Lösung des Vehikels verwendet. Dies entspricht der Vehikelkonzentration in Ansatz 5 (100 nM BAY 80-6946).

Tabelle 3: Behandlungsschema BAY 80-6946 unstimuliert; Die Myelom-Zellen wurden jeweils gezählt, in frischem Medium ausgesät und anschließend nach dem Behandlungsschema die entsprechende Menge an BAY 80-6946 oder Vehikellösung hinzugegeben.

\begin{tabular}{|lccccc|}
\hline & Ansatz 1 & Ansatz 2 & Ansatz 3 & Ansatz 4 & Ansatz 5 \\
BAY 80-6946 & - & - & $10 \mathrm{nM}$ & $50 \mathrm{nM}$ & $100 \mathrm{nM}$ \\
Vehikel & - & $100 \mathrm{nM}$ & - & - & - \\
\hline
\end{tabular}

Für die verschiedenen Konzentrationsansätze wurde BAY 80-6946 mit der jeweils entsprechenden Menge an Vehikellösung verdünnt. Die Behandlungszeit mit BAY 80-6946 betrug bei allen Konzentrationen $16 \mathrm{~h}$. Anschließend wurde das BAY 80-6946-haltige Medium ausgetauscht und die Zellen abhängig vom jeweiligen Experiment vorbereitet (siehe Western-Blot-Analyse, Durchflusszytometrie, Apoptose-Assay, Proliferations-Assay, Zellzyklus).

\subsubsection{IGF-1-Stimulation}

Als Vorbereitung auf die Stimulation wurden die Myelom-Zellen zunächst $16 \mathrm{~h}$ in FCSfreiem Medium kultiviert. Um zu untersuchen, welchen Einfluss BAY 80-6946 auf die Wirkung der IGF-1-Stimulation bei Multiplen Myelom-Zellen nehmen kann, wurden die Zellen zunächst mit BAY 80-6946 in FCS-freiem Medium für $16 \mathrm{~h}$ behandelt und anschließend mit 100 ng/ml IGF-1 für 20 Minuten stimuliert.

Hierbei wurden, entsprechend der Vorversuche mit den unstimulierten Myelom-Zellen, ebenfalls 5 Versuchsansätze mit drei verschiedenen Konzentrationen von BAY 80-6946 gewählt. Hinzu kamen zwei Kontrollen: ein Ansatz ohne Behandlung mit BAY 80-6946 und eine Vehikel-behandelte Kontrolle (Tabelle 4). 
Tabelle 4: Behandlungsschema BAY 80-6946, IGF-1 stimuliert; Die Myelom-Zellen wurden jeweils gezählt und in FCSfreiem Medium ausgesät. Nach dem Behandlungsschema wurde die entsprechende Menge an BAY 80-6946 oder Vehikellösung hinzugegeben und die Zellen $16 \mathrm{~h}$ behandelt. Anschließend wurden die Zellen mit 100ng/ml IGF-1 für 20 Minuten stimuliert und anschließend $16 \mathrm{~h}$ kultiviert.

\begin{tabular}{|lccccc|}
\hline & Ansatz 1 & Ansatz 2 & Ansatz 3 & Ansatz 4 & Ansatz 5 \\
IGF-1 & $100 \mathrm{ng} / \mathrm{ml}$ & $100 \mathrm{ng} / \mathrm{ml}$ & $100 \mathrm{ng} / \mathrm{ml}$ & $100 \mathrm{ng} / \mathrm{ml}$ & $100 \mathrm{ng} / \mathrm{ml}$ \\
BAY 80-6946 & - & - & $10 \mathrm{nM}$ & $50 \mathrm{nM}$ & $100 \mathrm{nM}$ \\
Vehikel & - & $100 \mathrm{nM}$ & - & - & - \\
\hline
\end{tabular}

\subsubsection{Proteingewinnung durch SDS-Lysate}

Um die Proteine der Myelom-Zellen quantitativ zu untersuchen, mussten die Zellen zunächst lysiert werden. Dies geschah durch SDS (Natriumdodecylsulfat)-Lyse. Im Anschluss an die Behandlung mit BAY 80-6946 wurde hierzu zunächst die Zellsuspensionen in ReagenzRöhrchen überführt und bei $900 \mathrm{G}$ für 5 Minuten bei $4{ }^{\circ} \mathrm{C}$ zentrifugiert. Dann wurde das Medium vorsichtig abgesaugt, die Zellen in PBS (phosphate buffered saline) $\left(4{ }^{\circ} \mathrm{C}\right)$ resuspendiert, erneut zentrifugiert, der Überstand entfernt und schließlich die Zellen in $1 \mathrm{ml}$ $\operatorname{PBS}\left(4^{\circ} \mathrm{C}\right)$ resuspendiert.

Die Zellsuspension wurde in ein Reaktionsgefäß $(1,5 \mathrm{ml})$ überführt und auf Eis gestellt. Anschließend wurde für 10 Minuten bei $800 \mathrm{G}$ und $4{ }^{\circ} \mathrm{C}$ erneut zentrifugiert und der Überstand abgenommen. Das Zellpellet wurde in $200 \mu$ l SDS-Lysispuffer resuspendiert und für 5 Minuten auf $95{ }^{\circ} \mathrm{C}$ erhitzt. Die Zelllysate wurden homogenisiert, indem sie 5 Mal durch eine Spritze mit 20 Gauge-Kanüle gezogen wurden. Abschließend wurde für 10 Minuten in der Eppendorf-Zentrifuge bei Höchstgeschwindigkeit (14.000 U/min) und $4{ }^{\circ} \mathrm{C}$ zentrifugiert. Der Überstand stellt das SDS-Lysat der Proteine dar. Dieses wurde bei $-80{ }^{\circ} \mathrm{C}$ aufbewahrt.

\subsubsection{Photometrische Proteinkonzentrationsbestimmung}

Die Proteinkonzentrationsbestimmung wurde mit dem Farbstoffbindungs-Assay von BioRAD (Bradford-Reagenz-Protein-Assay) durchgeführt. Dieser stellt eine photometrische Methode zur quantitativen Bestimmung der Proteinkonzentration dar. Das Verfahren nach Bradford beruht auf dem Prinzip, dass sich das Absorptionsmaximum des Triphenylmethanfarbstoffes Coomassie-Brilliant-Blau G-250 (CBBG) bei Proteinbindung verschiebt (Bradford 1976). CBBG bildet in saurer Lösung Komplexe mit kationischen und unpolaren Seitenketten der Proteine. Die ungebundene Form von CBBG (rote Form des 
Farbstoffes) hat im Absorptionsspektrum ein Maximum bei $465 \mathrm{~nm}$, die gebundene Form von CBBG (blaue Form des Farbstoffes) dagegen ein Maximum bei 595 nm. Die Zunahme der Absorption bei $595 \mathrm{~nm}$ kann photometrisch gemessen werden und stellt ein Maß für die Proteinkonzentration der jeweiligen Probe dar (Bio-Rad o. J.). Da die Farbreaktion abhängig vom jeweiligen Protein ist, wird eine zusätzliche Kalibrierung mit Standardproteinen nötig. Tabelle 5 zeigt das Pipettierschema für den Bradford-Protein-Assay.

Tabelle 5: Pipettierschema Bradford-Protein-Assay; $1 \mu 1$ der zu bestimmenden Proteinprobe wurde in ein Reaktionsgefäß, in dem $800 \mu \mathrm{l}$ Aqua bidest. vorgelegt waren, pipettiert. Für die Nullprobe wurde $1 \mu 1$ des SDS-Lysispuffers verwendet. Für die Standardkurve wurden 6 Reaktionsgefäße mit jeweils $800 \mu$ l Aqua bidest. vorbereitet und anschließend $10 \mu 1$ der jeweiligen Standardkurvenlösung sowie $1 \mu 1$ des SDS-Lysispuffers pipettiert. Abschließend wurden in alle 8 Reaktionsgefäße $200 \mu 1$ Bradford-Reagenz hinzugegeben.

\begin{tabular}{|c|c|c|c|c|c|c|c|c|}
\hline \multirow[b]{4}{*}{ Aqua bidest. } & \multicolumn{8}{|c|}{ Reaktionsgefäß } \\
\hline & \multirow{3}{*}{$\begin{array}{c}1 \\
\text { Probe } \\
800 \mu \mathrm{l}\end{array}$} & \multirow{3}{*}{$\begin{array}{c}2 \\
\text { Nullprobe } \\
800 \mu \mathrm{l}\end{array}$} & \multirow[t]{2}{*}{3} & \multirow[t]{2}{*}{4} & \multirow[b]{2}{*}{ Stanc } & \multirow[b]{2}{*}{ dkurve } & \multirow[t]{2}{*}{7} & \multirow[t]{2}{*}{8} \\
\hline & & & & & & & & \\
\hline & & & $800 \mu \mathrm{l}$ & $800 \mu \mathrm{l}$ & $800 \mu 1$ & $800 \mu 1$ & $800 \mu \mathrm{l}$ & $800 \mu 1$ \\
\hline Standard- & - & - & 125 & 250 & 500 & 1000 & 1500 & 2000 \\
\hline $\begin{array}{l}\text { kurvenlösung } \\
(\mu \mathrm{g} / \mathrm{ml})\end{array}$ & & & $10 \mu 1$ & $10 \mu 1$ & $10 \mu 1$ & $10 \mu 1$ & $10 \mu 1$ & $10 \mu 1$ \\
\hline SDS-Lysispuffer & - & $1 \mu 1$ & $1 \mu 1$ & $1 \mu 1$ & $1 \mu 1$ & $1 \mu \mathrm{l}$ & $1 \mu 1$ & $1 \mu 1$ \\
\hline Proteinprobe & $1 \mu 1$ & - & - & - & - & - & - & - \\
\hline $\begin{array}{l}\text { Bradford- } \\
\text { Reagenz }\end{array}$ & $200 \mu 1$ & $200 \mu \mathrm{l}$ & $200 \mu 1$ & $200 \mu 1$ & $200 \mu 1$ & $200 \mu 1$ & $200 \mu 1$ & $200 \mu 1$ \\
\hline
\end{tabular}

Von der zu bestimmenden Proteinprobe wurde $1 \mu \mathrm{l}$ in $800 \mu$ l Aqua bidest. verdünnt. Zur Erstellung der Standardkurve wurden den Herstelleranweisungen folgend sieben Reaktionsgefäße mit ansteigenden Proteinkonzentrationen von $125 \mu \mathrm{g} / \mathrm{ml}$ bis $2000 \mu \mathrm{g} / \mathrm{ml}$ aus den Standardkurvenlösungen erstellt. Hierzu wurden zunächst $800 \mu 1$ Aqua bidest. vorgelegt und $10 \mu \mathrm{l}$ der jeweiligen Standardkurvenlösung hinzupipettiert. Um einen Messfehler durch den SDS-Lysispuffer in der zu untersuchenden Probe auszuschließen, wurde jeweils $1 \mu 1$ des SDS-Lysispuffers in die Standardkurvenproben (Probe 3-8) und die Nullprobe pipettiert. Abschließend wurde allen Proben $200 \mu$ l Bradford-Reagenz hinzugefügt. Nach dreiminütiger Wartezeit und anschließendem Mischen auf dem Schüttler wurden die Proben in Küvetten überführt und bei $595 \mathrm{~nm}$ photometrisch ausgewertet. Das Photometer zeigte als Ergebnis den Proteingehalt der Probe in $\mu \mathrm{g} / \mathrm{ml}$ an. Anschließend konnten die Proben für die Western-Blot- 
Analyse vorbereitet werden. Grundsätzlich wurden pro Probe $40 \mu$ g Protein in $15 \mu 1$ gelöst verwendet. Hierzu wurden $100 \mu \mathrm{l}$ Stammlösung der jeweiligen Proteinprobe angemischt. Mit Hilfe des folgenden Dreisatzes wurde berechnet, dass die Stammlösung 266, $\overline{6} \mu \mathrm{g}$ Protein enthalten muss:

$$
\begin{aligned}
& \frac{40 \mu g}{15 \mu l}=\frac{x \mu g}{100 \mu l} \\
& x \mu g=\frac{40 \mu g}{15 \mu l} * 100 \mu l=266, \overline{6} \mu g
\end{aligned}
$$

Wiederum mit Hilfe des Dreisatzes konnte nun, abhängig von der jeweiligen Proteinkonzentration, errechnet werden, wie viele Mikroliter der jeweiligen Proteinprobe entnommen werden mussten, um diese Stammlösung herzustellen:

$$
\begin{aligned}
& \frac{x \mu g(P k b)}{1 \mu l}=\frac{266, \overline{6} \mu g}{x \mu l} \\
& x \mu l=\frac{266, \overline{6} \mu g}{x \mu g(P k b)} * 1 \mu l
\end{aligned}
$$

$\mathrm{Pkb}=$ Proteinkonzentrationsbestimmung

$\mathrm{Zu}$ der errechneten Mikroliterzahl der Proteinprobe wurden jeweils $20 \mu$ SDS-Puffer (5x SDS) gegeben. Das Gemisch wurde mit Aqua bidest. auf $100 \mu 1$ Gesamtvolumen aufgefüllt. Die fertigen Proben wurden für 5 Minuten auf $95{ }^{\circ} \mathrm{C}$ erhitzt, auf dem Schüttler gemischt und 1 Minute zentrifugiert. Durch das Erhitzen der Proben wurden Wasserstoffbrïcken und folglich die Sekundär- und Tertiärstruktur der Proteine aufgebrochen. Anschließend konnte mit der Western-Blot-Analyse begonnen werden.

\subsubsection{Western-Blot-Analyse}

Die Western-Blot-Analyse ist ein Verfahren zum semiquantitativen Nachweis von Proteinen. $\mathrm{Zu}$ diesem Zweck werden zunächst mit Hilfe der Gelelektrophorese die zu untersuchenden Proteine in einem Polyacrylamidgel nach Größe aufgetrennt. Durch das Blotting-Verfahren werden die Proteinbanden auf eine Trägermembran (Nitrozellulose) übertragen. Anschließend können die Proteinbanden mit spezifischen Antikörpern detektiert werden (Towbin et al. 1979; Burnette 1981). 


\subsubsection{Gelelektrophorese}

Die Gelelektrophorese ist eine Methode, durch welche Proteingemische aufgetrennt werden können. Für die Gelelektrophorese wurden Gele auf Polyacrylamidbasis (10\% Polyacrylamid) mit Natriumdodecylsulfat (SDS) verwendet. Das Polyacrylamidgel bildet ein feinmaschiges Netz. Unter Einfluss eines elektrischen Feldes wandern die Proteine abhängig von Ladung und Größe unterschiedlich schnell durch das Polyacrylamidgel. Kleine, negativ geladene Moleküle wandern am schnellsten in Richtung Anode, kleine positiv geladene Moleküle dagegen in Richtung Kathode. Durch die Zugabe von SDS, einem anionischen Tensid (Detergenz), werden die Eigenladungen der Proteine ,überdeckt“. Nach Bindung an das SDS weisen alle Proteine eine negative Ladung auf. Folglich ist nun hauptsächlich die Größe der Proteine entscheidend für die Wanderungsgeschwindigkeit durch das Polyacrylamidgel. Kleine Moleküle wandern weiter durch das feinmaschige Netz als die größeren (Towbin et al. 1979; Burnette 1981).

\subsection{Gießen der Gele}

Die Gele wurden mit Hilfe des Gelgießkammersystems Protean III Minigel von BioRAD gegossen. Die Grundsubstanz der Gele wurde jeweils zwischen eine Gelplatte und ein Deckglas gegossen. Die Gele bestanden aus einem Trenn- und einem Sammelgel, die nacheinander gegossen wurden. Zunächst wurde das Trenngel angerührt, gegossen und mit Ethanol überschichtet, um ein Austrocknen zu verhindern. Nach der Polymerisationszeit von $1 \mathrm{~h}$ konnte das überschüssige Ethanol abgegossen werden. Das Sammelgel wurde angerührt und über das bereits polymerisierte Trenngel gegossen. Zur Ausformung der neun Ladetaschen wurde ein Kamm in das Sammelgel gedrückt. Nach einer weiteren Polymerisationszeit von 30 Minuten konnte der Kamm entfernt werden.

\subsection{Gelelektrophorese}

Für die Gelelektrophorese wurde das Gel zunächst in die Laufkammer eingespannt und die Kammer mit Laufpuffer gefüllt. Anschließend konnten jeweils $15 \mu$ Probe in die Ladetaschen des Sammelgels pipettiert werden. Zudem wurde die erste Ladetasche mit $5 \mu$ l eines dreifarbigen Proteinstandards (Page ruler prestained protein ladder) beladen, der 10 Proteine mit definierten Größen von 10 bis 170 Kilo-Dalton enthält. Diese bewegen sich unter Einfluss des elektrischen Feldes mit im Polyacrylamidgel und dienen somit als Referenzgröße für die 
zu untersuchenden Proteine. Bei der anschließenden Gelelektrophorese wurde zunächst eine Spannung von $60 \mathrm{~V}$ angelegt. Sobald die Proben das Trenngel erreicht hatten, wurde diese auf 200 V erhöht. Die Laufzeit betrug insgesamt 80 Minuten

\subsubsection{Blotten der Membran}

Der Vorgang des „Blotten“ beschreibt die Übertragung der Proteine auf eine Nitrozellulosemembran. Durch Anlegen eines senkrecht zum Polyacrylamidgel gerichteten elektrischen Feldes werden die Proteine aus dem Gel auf die Nitrozellulosemembran übertragen. Das Muster der elektrophoretischen Auftrennung (Größe der Proteine) bleibt dabei erhalten.

Hierzu wurde das Polyacrylamidgel auf eine Nitrozellulosemembran gelegt. Diese wurde wiederum zwischen zwei in Transferpuffer getränkten Filterpapieren in die Kammer des Blotgerätes verbracht und für 40 Minuten bei einer Stromstärke von 150 mA geblottet.

\subsubsection{Hinzugabe der Antikörper}

Die auf die Nitrozellulosemembran übertragenen Proteinbanden konnten mit Hilfe spezifischer Antikörperbindung detektiert werden. Hierfür wurden Primär- und Sekundärantikörper verwendet. Die Primärantikörper binden spezifisch ein Epitop (monoklonal) oder verschiedene Epitope (polyklonal) eines Proteins. Die Sekundärantikörper sind Enzym-Antikörper-Konjugate und binden an die Fc-Teile der Primärantikörper. Der FcTeil ist Spezies-spezifisch gemäß der Herkunft der Primärantikörper (hier Kaninchen oder Maus). Das ebenfalls an den Antikörper gebundene Enzym katalysiert bei erfolgreicher Bindung eine Farbreaktion und bewirkt zudem eine Signalverstärkung. Diese nutzt man bei der Entwicklung des Western-Blots, um die spezifische Bindung der Antikörper an die Antigene sichtbar zu machen. Vor Zugabe des Antikörpers müssen jedoch die freien Bindungsstellen auf der Membran mit Hilfe von Blockmilch geblockt werden. Ansonsten würde das unspezifische Binden der Antikörper an diese Bindungsstellen einen spezifischen Nachweis von Antigenen unmöglich machen.

Die Membran wurde in $5 \%$ iger Blockmilch $1 \mathrm{~h}$ auf das Schüttelgerät gestellt und in der Zwischenzeit die jeweilige Primärantikörperlösung (Verdünnung in $5 \% \mathrm{BSA}$ ) in den folgenden Konzentrationen angemischt. 
Tabelle 6: Antikörperkonzentrationen Western-Blot-Analyse

\begin{tabular}{|cc|}
\hline Antikörper & Konzentration \\
Beta-Aktin & $1: 10.000$ \\
Akt & $1: 2.000$ \\
p-Akt & $1: 500$ \\
Erk & $1: 1000$ \\
p-Erk & $1: 2000$ \\
\hline
\end{tabular}

Die Membran wurde in $5 \mathrm{ml}$ der Primärantikörperlösung über Nacht bei $4{ }^{\circ} \mathrm{C}$ auf dem Schüttler inkubiert. Am nächsten Morgen wurde die Antikörperlösung verworfen und die Membran dreimal jeweils 15 Minuten in TBS-Tween-Pufferlösung auf dem Schüttler gewaschen. Anschließend wurde der jeweilige Sekundärantikörper (anti-Kaninchen für Akt, p-Akt, Erk und p-Erk; anti-Maus für B-Aktin) in 1\%iger Blockmilch im Verhältnis 1:2.500 verdünnt, die Membran für $1 \mathrm{~h}$ in der Sekundärantikörperlösung auf dem Schüttler inkubiert und anschließend die Membran erneut dreimal jeweils 15 Minuten in TBS-Tween Pufferlösung auf dem Schüttler gewaschen.

\subsubsection{Entwicklung der Membran}

Um die spezifische Bindung der Antikörper auf der Membran sichtbar zu machen, wurde die luminolhaltige Entwicklerlösung aus ihren zwei Komponenten (ECL1+2) eins zu eins zusammengemischt und $1 \mathrm{ml}$ der Gesamtlösung auf die Membran pipettiert. Das Enzym, das an den Sekundärantikörper gebunden ist (horseradish peroxidase, HRP) katalysiert die Farbreaktion von Luminol in seine oxidierte Form. Die dabei frei werdende Chemilumineszenz kann von dem Entwicklungsgerät detektiert und somit sichtbar gemacht werden. Die Entwicklerlösung wurde für 2 Minuten auf der Membran belassen. Anschließend wurde die Membran im Luminescent Image Analyzer LAS-4000 entwickelt.

\subsubsection{Auswertung der Ergebnisse}

Um statistisch signifikante Aussagen über die Protein-Analysen treffen zu können, wurde jede Western-Blot-Analyse dreimal in voneinander unabhängigen Versuchen durchgeführt. Mit dem Programm MultiGauge von Fujifilm konnten die entwickelten Western-Blots als JPEG (Joint Photographic Experts Group)-Bild exportiert werden. Das JPEG der Western-Blot- 
Analyse wurde anschließend mit dem Programm ImageJ geöffnet und der Anleitung Analyzing gels and western blots with ImageJ folgend ausgewertet (Miller 2010). Das Ergebnis dieser Analyse waren Integrationsdichtewerte der Western-Blot-Analyse-Banden. Der Integrationsdichtewert der jeweiligen Ladekontrolle (Beta-Aktin-Blot) wurde als Referenz herangezogen, um die bei diesem Verfahren gewonnenen Integrationsdichtewerte untereinander vergleichbar $\mathrm{zu}$ machen. Hierzu wurde der Quotient aus dem Integrationsdichtewert des spezifischen Antikörpers (Akt, p-Akt) und dem Integrationsdichtewert des zugehörigen Beta-Aktin-Blots gebildet. Die Darstellung der Daten erfolge mit Hilfe eines Balkendiagramms.

\subsubsection{Western-Blot-Analyse mit WesternBreeze ${ }^{\circledR}$}

Die Western-Blot-Analysen, die in Abbildung 16 und 18 des Ergebnisteils abgebildet sind, wurden mit dem WesternBreeze ${ }^{\circledR}$ Chemiluminescent Western Blot Immunodetection Kit von Invitrogen durchgeführt (Invitrogen 2003). Hierzu wurden die Proteinproben mit Hilfe von SDS-Lysaten gewonnen und die Gelelektrophorese sowie das Blotten der Membran wie oben beschrieben durchgeführt. Anschließend wurde die Membran zweimal mit jeweils $20 \mathrm{ml}$ Aqua bidest. gewaschen, um Gel- und Transferpufferrückstände zu entfernen.

In der Zwischenzeit wurden alle im „Kit“ enthaltenen Lösungen, wie in der Anleitung beschrieben, vorbereitet. Die Membranen wurden mit jeweils $10 \mathrm{ml}$ Blocklösung für 30 Minuten auf dem Schüttler geblockt. Die Blocklösung wurde verworfen und die Membranen zweimal für jeweils 5 Minuten mit Aqua bidest. gespült. Dann wurden die Membranen mit 10 $\mathrm{ml}$ des jeweiligen Primärantikörpers in den oben genannten Konzentrationen für $1 \mathrm{~h}$ auf dem Schüttler inkubiert.

Anschließend wurde die Antikörperlösung verworfen und die Membranen dreimal für je 5 Minuten mit jeweils $20 \mathrm{ml}$ Waschlösung gewaschen, um die Antikörperrückstände zu entfernen. Je nach Primärantikörper wurden $10 \mathrm{ml}$ der anti-Kaninchen- bzw. anti-MausSekundärantikörperlösung auf die Membranen gegeben. Die Lösung wirkte über einen Zeitraum von 30 Minuten ebenfalls auf dem Schüttler auf die Membranen ein. Im Anschluss wurde die Antikörperlösung verworfen und die Membranen dreimal über 5 Minuten mit jeweils $20 \mathrm{ml}$ der Waschlösung gewaschen. Zusätzlich wurden die Membranen zweimal für jeweils 2 Minuten mit Aqua bidest. gespült. Abschließend wurden die Membranen auf eine Folie gelegt und 2,5 $\mathrm{ml}$ der Chemolumineszenz-Entwicklerlösung hinzugegeben. Nach einer 
Einwirkzeit von 5 Minuten konnten die Membranen ebenfalls mit Hilfe des Luminescent Image Analyzer LAS-4000 entwickelt werden.

\subsubsection{Stripping der Membran}

Um die Membranen der Western-Blot-Analyse nacheinander mit mehreren Antikörpern entwickeln zu können, wurde das sogenannte Stripping-Verfahren angewandt. Hierzu wurden die Membranen nach der Entwicklung zunächst dreimal 20 Minuten mit TBS-TweenPufferlösung auf dem Schüttler gewaschen. Währenddessen wurde der Stripping-Puffer angesetzt, mithilfe dessen die vorhandenen Antikörper von der Membran entfernt werden können. Die Membran wurde in eine Plastikschale gegeben, $10 \mathrm{ml}$ der Strippinglösung hinzugegeben und fest mit Folie verschlossen. Es folgte eine Inkubationszeit von 30 Minuten bei $50{ }^{\circ} \mathrm{C}$ unter Schütteln. Anschließend wurde die Membran dreimal jeweils 20 Minuten mit TBS-Tween Pufferlösung unter Schütteln gespült. Vor der erneuten Durchführung einer weiteren Antikörperfärbung musste erneut geblockt werden.

\subsubsection{Durchflusszytometrie zur Bestimmung der p-Akt-Expression}

Die Durchflusszytometrie (fluorescence activated cell sorting, FACS) ist ein Verfahren zur Untersuchung der Morphologie, Größe und Antigen-Expression von Zellen. Die Zellen werden durch eine Kapillare eingesaugt und passieren einzeln einen Laserstrahl. Dabei wird ein Teil des Lichts gestreut. Dieses wird mit Hilfe von Detektoren erfasst. Die Streuung ist abhängig von Größe, Komplexität und Färbung der Zellen. So zeigt das Vorwärtsstreulicht (Forward scatter, FSC) die Beugung des Lichtes im flachen Winkel und korreliert mit dem Volumen der Zelle. Das Seitwärtsstreulicht (Sidewards Scatter, SSC) dagegen gibt die Brechung des Lichts im rechten Winkel an und korreliert mit der Granularität der Zelle. Zusätzlich kann man in der Durchflusszytometrie auch Fluoreszenzfarben messen.

Die Multiplen Myelom-Zellen wurden mit einem Antikörper gefärbt, der spezifisch an phosphoryliertes Akt bindet (Ser 473) und zudem direkt an den Fluoreszenzfarbstoff gekoppelt ist. Somit ließ sich im FACS in einer Suspension von Myelom-Zellen der relative Anteil der Zellen bestimmen, bei dem Akt phosphoryliert ist. Da Akt intrazellulär liegt, mussten die Zellen vor der Färbung fixiert und permeabilisiert werden. Die Fixierung, Permeabilisierung und Färbung wurde nach dem Protokoll Flow Cytometry Protocol von Cell Signaling Technology® durchgeführt (Cell Signaling Technology® 2009). 


\subsubsection{Fixierung der Zellen}

Die Zellen wurden 5 Minuten bei $200 \mathrm{G}$ zentrifugiert und das überschüssige Medium abgesaugt. Anschließend wurden die Zellen in $4 \%$ Paraformaldehyd (PFA) in Falconröhrchen resuspendiert und für die Fixierung 10 Minuten bei $37{ }^{\circ} \mathrm{C}$ stehen gelassen. Danach wurden die Reagenzröhrchen für 1 Minute auf Eis gestellt.

\subsubsection{Permeabilisierung der Zellen}

Die Reagenzröhrchen wurden erneut 5 Minuten bei 200 G zentrifugiert. Zur Permeabilisierung wurde das Zellpellet in $90 \%$ Methanol resuspendiert und die Falconröhrchen für 30 Minuten auf Eis inkubiert.

\subsubsection{Färbung der Zellen}

Für die Färbung wurde ein Aliquot der fixierten und permeabilisierten Zellen ausgezählt und $10^{6}$ Zellen pro Probe wurden in ein FACS-Röhrchen pipettiert. $2 \mathrm{ml}$ des Inkubationspuffers wurden hinzugegeben und die Zellsuspension erneut für 5 Minuten bei $200 \mathrm{G}$ zentrifugiert. Dieser Waschvorgang wurde ein weiteres Mal wiederholt. Das überschüssige Medium wurde vorsichtig abgesaugt und das Zellpellet in $100 \mu 1$ resuspendiert. Anschließend wurden $15 \mu 1$ AB-Serum (antikörperfreies, humanes Serum der Blutgruppe AB) zur Blockierung der FCFragmente hinzugegeben. Dies soll unspezifischen Bindungen des Antikörpers vorbeugen. Nach 10 Minuten Inkubation bei Raumtemperatur wurden erneut $2 \mathrm{ml}$ Inkubationspuffer hinzugegeben, 5 Minuten bei $200 \mathrm{G}$ zentrifugiert und das Zellpellet in $100 \mu \mathrm{l}$ PBS resuspendiert. Der p-Akt-Antikörper wurde in einer 1:10-Verdünnung hinzugegeben $(10 \mu \mathrm{L}$ pro Probe). Eine Probe wurde jeweils ungefärbt belassen, um eine Aussage über die Autofluoreszenz der Zellen zu erhalten. Zudem wurde eine Probe mit einer Isotypkontrolle in entsprechender Konzentration gefärbt. Der Isotyp hat den gleichen Subtyp wie der spezifische Antikörper, kann aber nicht spezifisch das Epitop erkennen. Somit zeigen Bindungen des Isotyp-Kontroll-Antikörpers unspezifische Bindungen des Antikörpers an. Die Isotypkontrolle wurde in der gleichen Konzentration wie der Antikörper hinzupipettiert. Nach einer Inkubationszeit von 30 Minuten bei Raumtemperatur wurden die Proben erneut mit $2 \mathrm{ml}$ Inkubationspuffer gewaschen und zentrifugiert. Das Zellpellet wurde in $500 \mathrm{ml}$ PBS aufgenommen. 


\subsubsection{Analyse mit dem Durchflusszytometer}

Die Analyse der gefärbten Proben wurde mit dem „FACS Canto II“ Gerät durchgeführt. Zuvor wurde das Gerät mit dem Reinigungsmodus gespült und einmal in der Woche mit der Eichlösung geeicht. Die Proben wurden jeweils direkt vor dem Messen auf dem Schüttlergerät durchmischt. Pro Messung wurden 10.000 Zellen einer Probe gezählt. Die Ausgabe der Messdaten geschah mit Hilfe der Software BD FACS Diva. Bei der Messung der Proben wurden das Vorwärtsstreulicht (FSC) und das Seitwärtsstreulicht (SSC) bestimmt, um Aussagen über die Größe und Granularität der Zellen treffen zu können. Jeder Zelltyp, so auch die Multiple Myelomzelle, hat eine charakteristische Größe und Granularität. Somit erlaubt die Bestimmung dieser beiden Parameter eine Aussage über die in der zu messenden Zellsuspension enthaltende Zellart.

Die Ergebnisse wurden in einem Streulicht-Dot-Plot abgebildet. Zum anderen wurde das APC-A Mean, das heißt die mittlere Fluoreszenzintensität (Mean Fluorescence Intensity; MFI) im APC-A-Kanal des Durchflusszytometers, bestimmt. Diese ist eine Referenz für den prozentualen Anteil der fluoreszierenden Zellen. Die Messungen wurden jeweils an einer ungefärbten Probe (Eigenfluoreszenz), der Isotypkontrolle (unspezifische Bindungen) und der p-Akt gefärbten Probe durchgeführt. Diese Ergebnisse werden in einem Histogramm dargestellt. Die Abbildung 5 stellt die Streulicht-Dot-Plots und Histogramme einer durchflusszytometrischen Messung der Zelllinie AMO-1 beispielhaft dar.

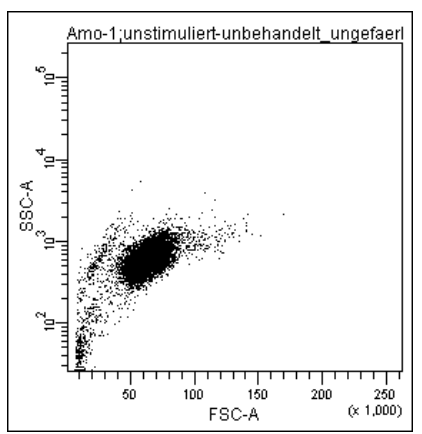

Streulicht-Dot-Plot ungefärbte Probe

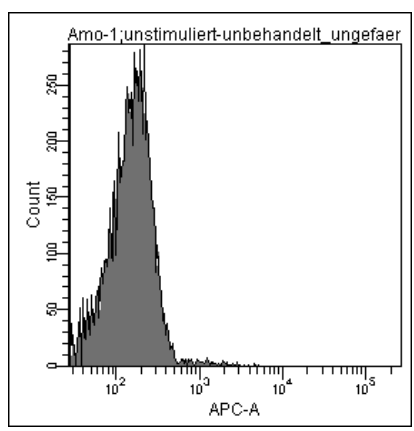

Histogramm ungefärbe Probe 


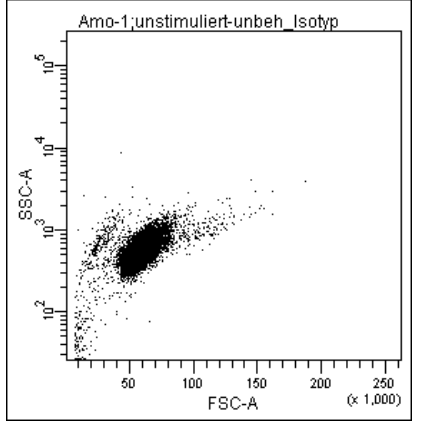

Streulicht-Dot-Plot Isotyp Färbung

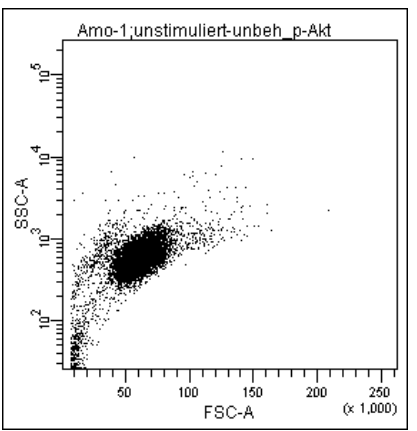

Streulicht-Dot-Plot Phospho-Akt Färbung

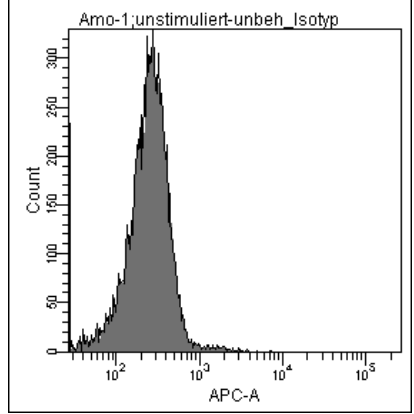

Histogramm Isotyp Färbung

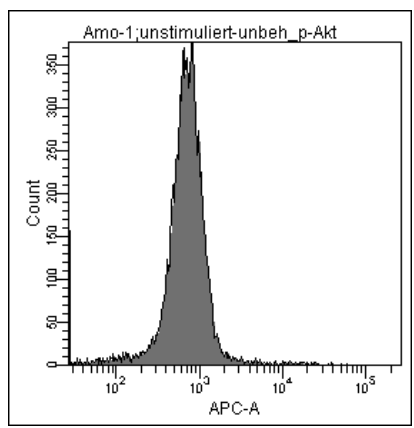

Histogramm Phospho-Akt Färbung

Abbildung 5: Durchflusszytometrische Analyse der konstitutiven Aktivierung von Akt (Zelllinie Amo-1); abgebildet sind die Streulicht-Dot-Plots (Y-Achse: Seitwärtsscatter (SSC-A) ; X-Achse: Forwärtsscatter, FSC-A) und Histogramme (YAchse: Anzahl der gemessenen Zellen; X-Achse: APC-A bzw. MFI-Wert); Die Zellen wurden fixiert, permeabilisiert, 1x10 ${ }^{6}$ Zellen ausgezählt, in PBS gewaschen, mit AB-Serum blockiert, zentrifugiert, in $100 \mu 1$ PBS mit dem Antikörper bzw. Isotyp gefärbt, und anschließend durchflusszytometrisch analysiert. Die Abbildungen wurden aus der Software (BD FACS Diva) des verwendeten Durchflusszytometers FACS Canto II entnommen.

Die Ergebnisse für die drei Proben ungefärbt, Isotyp und Phospho-Akt sind jeweils in einem Streulicht-Dot-Plot und in einem Histogramm präsentiert. In dem Streulicht-Dot-Plot sind die Größe und Granularität der gemessenen Zellen aufgetragen, wobei jeder Punkt eine Zelle darstellt. Auf der Y-Achse des Histogramm ist die Zellzahl und auf der X-Achse der dazugehörige gemessenen Wert der mittleren Fluoreszenzintensität (MFI-Wert) oder hier spezifisch der $A P C$ - $A$-Wert dargestellt.

\subsubsection{Statistische Auswertung der Daten}

Die Werte wurden in das Statistikprogramm GraphPad Prism V 5 übertragen. Von jeder Zelllinie wurden drei voneinander unabhängige durchflusszytometrische Analysen durchgeführt. Die Ausgabe der Daten erfolgte als Balkendiagramm. Dabei stellt jeder Balken das arithmetische Mittel dreier voneinander unabhängiger Versuche dar. Zusätzlich wurde die 
Standardabweichung angegeben. Signifikante Unterschiede zwischen den verschiedenen Medikamentenkonzentrationen wurden mit einer einfachen Varianzanalyse (ANOVA), gefolgt von einem Bonferroni-post-hoc-Test mit einem Konfidenzintervall von $95 \%$ ermittelt. Die Signifikanzen sind durch Sternchen repräsentiert, wobei ein Sternchen (*) einem $\mathrm{p}<0.05$ entspricht, 2 Sternchen $(* *)$ einem $\mathrm{p}<0.01$ und drei Sternchen $* * *$ einem $\mathrm{p}<0.001$ entsprechen.

\subsubsection{Apoptose-Assay}

Die Apoptosemessungen wurden mit dem „,Cell Death Detection ELISA Plus" von Roche® durchgeführt. Im Unterschied zur Nekrose ist die Apoptose ein aktiver und komplex regulierter Zelltodmechanismus. Sie wird durch äußere oder zellinterne Stimuli initiiert. Aktivierung von Caspasen führt zur Spaltung der DNS (Desoxyribonukleinsäure) in Fragmente aus DNS und Histonen, so genannte Nukleosomen. Mit dem Prinzip eines Sandwich-ELISAs （„Sandwich-Enzyme-linked-immunosorbent-Assay“) können die Nukleosomen als Äquivalent der Apoptose nachgewiesen werden. Der ELISA ist ein Nachweisverfahren mit enzymgekoppelter Immunadsorptions-Analyse. Hierzu wurden die behandelten Zellen lysiert und der Zellüberstand auf eine mit Streptavidin vorbeschichtete Mikroplatte gegeben. Anti-Histon-Biotin- und Anti-DNS-Peroxidase-Antikörper wurden hinzugegeben und inkubiert. Wie in Abbildung 6 gezeigt, werden die Nukleosomen wie in einem Sandwich zwischen den Antikörpern gebunden.

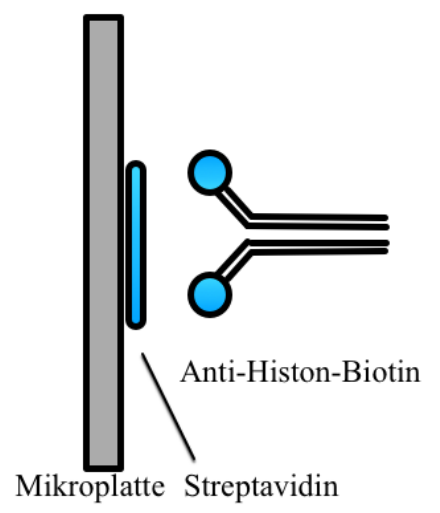

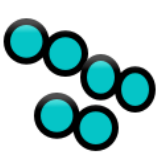

Nukleosomen der Probe

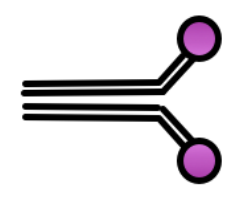

Anti-DNS-Peroxidase (HRP-Peroxidase)

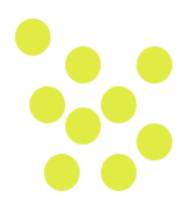

ABTS-Farblösung

\footnotetext{
Abbildung 6: Prinzip des Cell-Death-Detection-ELISA Plus®. Abbildung modifiziert nach Roche 2004. Die in der Zellprobe enthaltenden Nukleosomen binden sowohl an die Anti-Histon-Biotin-Antikörper als auch an den Anti-DNSPeroxidase-Antikörper. Über den Anti-Histon-Biotin-Antikörper wird der Komplex an die Streptavidin beschichtete Platte gebunden. Bei Hinzugabe der ABTS-Farblösung katalysiert die gebundene Peroxidase HRP eine Farbreaktion, die das Vorhandensein von Nukleosomen anzeigt. Die Abbildung wurde mit der Software Pixelmator erstellt.
} 
Der Anti-Histon-Biotin-Antikörper bindet an das Streptavidin einerseits und an den Histonanteil eines Nukleosoms andererseits. Der DNS-Anteil des Nukleosoms wird an den Anti-DNS-Peroxidase-Antikörper gebunden. Gibt man nun etwas ABTS-Farblösung hinzu, katalysiert die Peroxidase HRP eine Farbreaktion. Die Intensität der Farbe korreliert mit der Anzahl der Nukleosomen in der Lösung und kann photometrisch bestimmt werden.

\subsubsection{Zellen aussäen}

Die Zellen wurden auf einer „96-well“-Kulturplatte mit 25.000 Zellen pro „well““ ausgesät. Für den Apoptose-Assay wurde das entsprechende Behandlungsschema wie für die WesternBlot-Analyse und Durchflusszytometrie verwendet. Für jede Zelllinie wurden 15 „wells“ vorbereitet. Ein unbehandelter Ansatz, eine Vehikelkontrolle, und eine Konzentrationsreihe mit BAY 80-6946-behandelten Zellen (10 nM, $50 \mathrm{nM}, 100 \mathrm{nM})$; wobei jeder Ansatz im Triplett pipettiert wurde. Die Platte wurde für die Behandlungszeit von $16 \mathrm{~h}$ in den Inkubator gestellt.

\subsubsection{Zelllyse}

Die 96-Well-Platte wurde bei $400 \mathrm{G}$ für 10 Minuten zentrifugiert und die Überstände vorsichtig abpipettiert. Die Zellen wurden in jeweils $200 \mu 1$ Lysispuffer resuspendiert und anschließend für 30 Minuten bei Raumtemperatur inkubiert. Nach der Inkubation wurde das Zelllysat erneut für 10 Minuten bei $400 \mathrm{G}$ zentrifugiert. In dem Lysatüberstand befanden sich nun die nukleosomalen Spaltprodukte der DNS.

\subsubsection{Inkubation}

Die mit Streptavidin vorbeschichtete Platte aus dem Kit wurde wie folgt belegt: pro „well“ wurden $20 \mu \mathrm{l}$ des Lysatüberstands pipettiert, wobei die verschiedenen Versuchsansätze jeweils im Triplett pipettiert wurden. Zusätzlich wurden die Positiv- und die Negativkontrolle in jeweils 2 Wellen pipettiert. Abschließend wurden in jede Welle $80 \mu$ Immunoreagenz hinzugegeben. Das Immunreagens ist eine im Kit enthaltende Mischung aus Anti-DNS-, AntiHiston-Antikörpern und Inkubationspuffer. Die Platte wurde mit einer Folie abgedeckt und 2 $\mathrm{h}$ auf dem Plattenschüttler (300 rpm) bei Raumtemperatur inkubiert. 


\subsubsection{Farbreaktion}

Um die Farbreaktion zu starten, wurden $100 \mu \mathrm{l}$ der ABTS-Farblösung in jedes „well“ pipettiert. Die Platte wurde auf dem Plattenschüttler (250 rpm) bei Raumtemperatur 10-20 Minuten inkubiert, bis die Farbreaktion sichtbar wurde. Abschließend wurden $100 \mu 1$ der ABTS-Stopplösung in jede Welle gegeben. Die Auswertung erfolgte photometrisch bei einer Absorption von $405 \mathrm{~nm}$ mit dem Mikroplattenlesegerät „,Appliskan “. Um den Hintergrund zu minimieren, wurde zusätzlich bei einer Referenzwellenlänge von 490 nm gemessen.

\subsubsection{Auswertung und statistische Analyse der Ergebnisse}

Die Auswertung der Ergebnisse erfolgte mit dem Programm GraphPad Prism V 5. Um die Hintergrundextinktion heraus zurechnen, wurde die Differenz der Extinktionswerte bei 405nm und 490nm gebildet. Die Apoptoseraten wurden im Verhältnis behandelte Probe zu Vehikelkontrolle bestimmt. Die Ausgabe der Daten erfolgte als Balkendiagramm. Dabei stellt jeder Balken das arithmetische Mittel eines Tripletts einer Probe dar. Zusätzlich wurde die Standardabweichung angegeben. Der Versuch wurde zweimal für jede Zelllinie durchgeführt.

\subsubsection{Proliferations-Assay}

Die Proliferationsmessungen erfolgten mit dem „Cell Titer 96 Non-radioactive Cell Proliferation-Assay“ von Promega®. Dieses Verfahren der Proliferations-Assay-Analyse, nach dem Prinzip eines MTT-Assays, stellt eine kolorimetrische Methode dar Zellviabilität bzw. Proliferation zu ermitteln. Dieses Verfahren wurde erstmals von Mosmann et al beschrieben (Mosmann 1983). Der gelbe wasserlösliche Farbstoff 3-(4,5-Dimethylthiazol-2yl)-2,5-diphenyl-tetrazoliumbromid (MTT) ist ein membrangängiger Stoff, der sich bei Reduktion zu violettfarbenen wasserunlöslichen Formazan-Kristallen verfärbt. Die Reduktion ist abhängig von den mitochondrialen Dehydrogenasen lebender Zellen. Diese FormazanKristalle akkumulieren in proliferierenden Zellen. Anschließend kann der Farbstoff nach Zelllyse und Solubilisierung der Kristalle durch kolorimetrische Messung quantifiziert werden. Dabei ist die Bildung der violettfarbenen Formazan-Kristalle direkt proportional zu der Anzahl an proliferierenden Zellen. Folglich stellt die Farbintensität, die mit Hilfe eines Photometers gemessen werden kann, ein Äquivalent für die Proliferation der Zellen dar.

Der Proliferations-Assay wurde durchgeführt, um die wachstumsinhibierende Wirkung von BAY 80-6946 auf Multiple Myelom-Zellen zu untersuchen. Zu diesem Zweck wurde die 
Wirkung verschiedener Konzentrationen von BAY 80-6946 (10 nM, 50 nM, $100 \mathrm{nM})$ untereinander verglichen.

\subsubsection{Durchführung der Proliferations-Assay-Analyse}

Für die Proliferations-Assay-Analyse wurden 25.000 Zellen pro „,well“ auf einer 96-WellPlatte ausgesät. Es wurde das entsprechende Behandlungsschema wie für die Western-BlotAnalyse, die Durchflusszytometrie und den Apoptose-Assay verwendet: ein unbehandelter Ansatz, eine Vehikelkontrolle, und drei Ansätze einer Konzentrationsreihe mit BAY 80-6946 (10nM, 50nM, 100nM). Jeder Ansatz wurde im Triplett pipettiert. Die Platte wurde für eine Behandlungszeit von $24 \mathrm{~h}$ in den Inkubator gestellt. Nach Ablauf der $24 \mathrm{~h}$ wurden $15 \mu \mathrm{l}$ der MTT haltigen „Dye Solution“ in jede Welle pipettiert. Anschließend wurde die 96-WellPlatte weitere $4 \mathrm{~h}$ in den Inkubator gestellt. Danach wurden in jedes ,well“ $100 \mu \mathrm{der}$ Solubilisationslösung gegeben. Diese führt dazu, dass sich das wasserunlösliche Formazan in der Welle löst. Die 96-Well-Platte wurde weitere $24 \mathrm{~h}$ in den Inkubator gestellt.

Die Auswertung der Proliferations-Assay-Analyse erfolgte photometrisch mit Hilfe des Mikroplattenreaders „,Appliskan“ bei einer Wellenlänge von 570 nm. Um den Hintergrund zu minimieren, erfolgte eine weitere Messung bei der Referenzwellenlänge $630 \mathrm{~nm}$. Da die gemessene Absorption der Menge des gebildeten Formazans entspricht, ist die Absorption direkt proportional zur Anzahl lebender Zellen in der Kultur (Promega 2005).

\subsubsection{Auswertung und statistische Analyse der Ergebnisse}

Die Auswertung der Ergebnisse erfolgte mit dem Programm GraphPad Prism V 5. Um die Hintergrundextinktion heraus zurechnen, wurde die Differenz der Werte bei $570 \mathrm{~nm}$ und 630 nm gebildet. Die Proliferationsraten wurden im Verhältnis behandelte Probe zu Vehikelkontrolle bestimmt. Die Darstellung der Daten erfolgte als Balkendiagramm. Dabei stellt jeder Balken das arithmetische Mittel dreier voneinander unabhängiger Versuche mit jeweils einem Triplett an Proben dar. Zusätzlich wurde die Standardabweichung angegeben. Signifikante Unterschiede zwischen den verschiedenen Konzentrationen von BAY 80-6946 wurden mit einer einfachen Varianzanalyse (ANOVA) gefolgt von einem Bonferroni-posthoc-Test mit einem Konfidenzintervall von $95 \%$ ermittelt. Die Signifikanzen sind durch Sternchen repräsentiert, wobei ein Sternchen $\left(^{*}\right)$ einem $\mathrm{p}<0,05$ entspricht, 2 Sternchen $(* *)$ einem $\mathrm{p}<0,01$ und drei Sternchen $(* * *)$ einem $\mathrm{p}<0,001$ entsprechen. 


\subsubsection{Zellzyklus}

Die Zellzyklusanalyse wurde mit Hilfe der Durchflusszytometrie durchgeführt. Der Zellzyklus wird in die Mitose- (Kernteilungsphase) und die Interphase unterteilt. In der Interphase unterscheidet man zudem die G1-(Präsynthesephase), die S-(Synthesephase), in der die DNS repliziert wird, und die G2-Phase (Postsynthesephase). Desweiteren können sich die Zellen in einer Ruhephase befinden, die auch G0-Phase genannt wird. In dieser Phase teilen sich die Zellen nicht. Die Zellen können jedoch jederzeit wieder über die G1-Phase in die Zellteilung eintreten.

Bei der durchflusszytometrischen Zellzyklusanalyse wird die Tatsache genutzt, dass sich im Verlauf der S-Phase des Zellzyklus der DNS-Gehalt der Zellen verdoppelt. In der G1/G0Phase weisen die Zellen einen haploiden Chromosomensatz auf. Nach der Replikation der DNS in der S-Phase besteht jedes Chromosom aus zwei Chromatiden (diploider Chromosomensatz). In der Mitosephase erfolgen die Trennung der Chromosomen und die Teilung der Zelle in zwei Tochterzellen. Folglich ist der DNS-Gehalt der Zellen in der G2/M (nach der S-Phase)-Phase doppelt so hoch als in der G0/G1-Phase (vor der S-Phase) (Nunez 2001).

Für die durchflusszytometrische Analyse wurden die BAY 80-6946-behandelten Zellen fixiert, permeabilisiert und die DNS mit dem interkalierenden Fluoreszenzfarbstoff Propidiumiodid angefärbt. Da die gemessene Intensität der Fluoreszenz mit dem DNS-Gehalt der Zelle korreliert, lässt sich hierüber die Zyklusphase einer Zelle bestimmen. Aus der durchflusszytometrischen Messung vieler Zellen entsteht das Histogramm des Zellzyklus. Die Abbildung 7 zeigt ein vereinfachtes Schema des Histogramms und ein entsprechendes Zellzyklusschema, das den phasenabhängigen DNS-Gehalt der Zellen verdeutlicht.
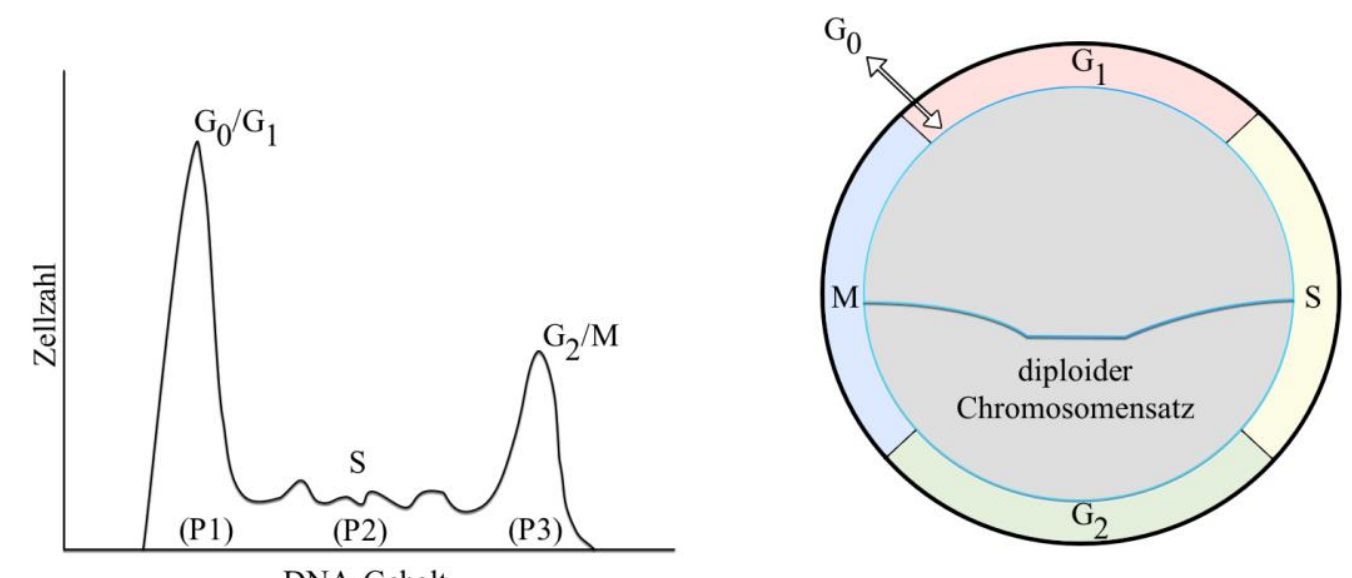

DNA-Gehalt 
Abbildung 7: DNA-Histogramm und Zellzyklusschema. Abbildung modifiziert nach Hagemeier 2012. Das DNAHistogramm (links abgebildet) entsteht bei der durchflusszytometrischen Zellzyklusanalyse aus der Messung einer Vielzahl von Zellen. In diesem vereinfachtem Schema fehlt die Sub-G1- Population, die links des G0/G1-Peaks zu finden ist. Das Zellzyklusschema (rechts abgebildet) zeigt die verschiedenen Phasen des Zellzyklus. In der M- und der S-Phase liegt teilweise, in der G2-Phase vollständig, ein diploider Chromosomensatz vor (Hagemeier 2012). Die Abbildung wurde mit der Software Pixelmator erstellt.

Das erste Signalmaximum („Peak“, P1) stellt die ruhenden oder postmitotischen Zellen in der GO/G1-Phase dar. Im Verlauf der S-Phase verdoppelt sich die chromosomale DNS der Zellen. Somit liegt in dieser Phase in einem Teil der Zellen ein diploider Chromosomensatz vor. Peak P2 zeigt die Zellen, die sich in der S-Phase befinden. In der G2/M-Phase, die in Peak P3 abgebildet ist, liegt in allen Zellen ein diploider Chromosomensatz vor (Hagemeier 2012).

\subsubsection{Zellfärbung}

Die Zellzyklusanalyse der BAY 80-6946-behandelten Zellen wurde für drei verschiedene Behandlungszeiträume durchgeführt: 4, 12 und 24 Stunden. Für diese Behandlungszeiträume wurden jeweils drei verschiedene Konzentrationen von BAY 80-6946 (10 nM, 50 nM, 100 $\mathrm{nM}$ ), eine unbehandelte und eine Vehikelkontrolle angesetzt. Zusätzlich wurde eine Analyse von unbehandelten Zellen gemacht. Ausgesät wurden die Zellen in 6-Well-Platten. Anschließend an den jeweiligen Behandlungszeitraum wurden die Zellen in PBS gewaschen, bei $200 \mathrm{G}$ für 5 Minuten zentrifugiert und das Pellet in jeweils $500 \mathrm{ml}$ PBS aufgenommen. Zur Fixierung und Permeabilisierung wurden pro Probe $3 \mathrm{ml}$ 100-prozentiger Ethanol hinzugegeben. Anschließend wurden die Proben bei $-20{ }^{\circ} \mathrm{C}$ eingefroren. Für die Färbung wurden die Proben zunächst in FACS-Röhrchen überführt, mit PBS gewaschen, bei $200 \mathrm{G} 5$ Minuten zentrifugiert und der Überstand abgenommen. Die Zellpellets wurden in jeweils 425 $\mu 1$ PBS aufgenommen. Hierzu wurden $50 \mu \mathrm{l}$ RNAse $1(1 \mathrm{mg} / \mathrm{ml}$ PBS $)$ und $25 \mu \mathrm{l}$ Propidiumiodid (1 mg/ml PBS) pipettiert. Durch die Zugabe von RNAse 1 werden RNA Bestandteile der Zellen entfernt, da Propidiumiodid auch RNA färben und somit das Ergebnis verfälschen würde. Anschließend wurden die Proben für 30 Minuten bei Raumtemperatur lichtgeschützt inkubiert.

\subsubsection{Durchflusszytometrische Analyse}

Die durchflusszytometrische Analyse des Zellzyklus wurde mit dem FACS-Gerät „, Canto II“ durchgeführt. Zuvor wurde das Gerät mit dem Reinigungsmodus gespült. Einmal wöchentlich 
wurde das Gerät zusätzlich mit der Eichlösung geeicht. Die Proben wurden jeweils direkt vor der Messung auf dem Schüttlergerät durchmischt. Bei niedriger Flussgeschwindigkeit wurden pro Messung 100.000 Zellen jeder Probe ausgezählt. Die Abbildung 8 zeigt exemplarisch ein Histogramm einer Untersuchung der Zelllinie MOLP-8.

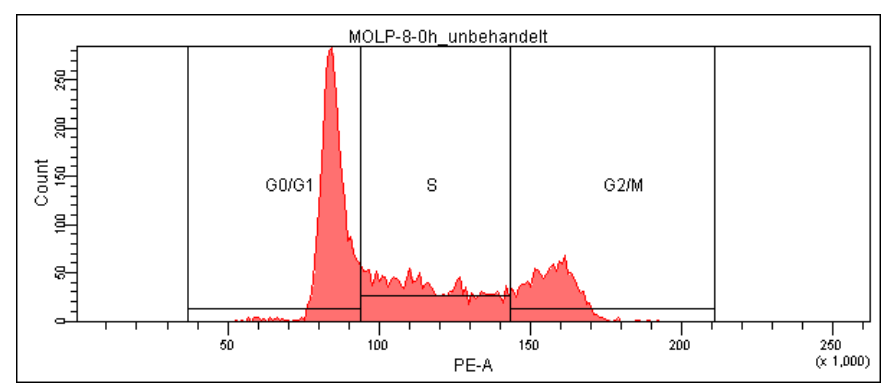

Abbildung 8: Histogramm der Zellzyklusanalyse MOLP-8, unbehandelt; Abbildung mit der Software BD-Facs Diva erstellt. Y-Achse: Count (Anzahl der analysierten Zellen); X-Achse: PE-A= Mittlere Fluoreszenzintensität (MFI)

Auf der X-Achse ist die Intensität der Fluoreszenz und auf der Y-Achse die Anzahl der gemessenen Zellen aufgetragen. Die Intensität der Fluoreszenz korreliert mit dem DNSGehalt der Zellen.

\subsubsection{Mausmodell}

Der vorliegende Versuch im Mausmodell wurde ordnungsgemäß von der zuständigen Kommission der Georg-August-Universität Göttingen genehmigt. Der Tierversuch wurde vom 13. (Maus 1-8) bzw. 14. (Maus 9-18) September bis zum 27. (Maus 1-8) bzw. 28. (Maus 9-18) September 2010 unter der Betreuung und Leitung durch Frau Dr. hum. biol. Margarete Schön durchgeführt.

\subsubsection{Haltungsbedingungen}

Es wurden 19 Nacktmäuse (Stamm (NU/J Foxn1 $\left.{ }^{n u}\right)$ ausschließlich männlichen Geschlechts in die Studie eingeschlossen. Die Nacktmäuse wurden in der Tierversuchsanlage der GeorgAugust-Universität Göttingen gezüchtet und gehalten. Die Tiere wurden in Käfigen, die mit Filterhauben abgedeckt wurden gehalten. Wasser und Einstreu wurden täglich gewechselt. Die Tiere erhielten pelletiertes Futter und Wasser ad libitum. Die Temperatur betrug konstant 
$25^{\circ} \mathrm{C}$ bei einer relativen Luftfeuchtigkeit von $70 \%$. Um möglichst physiologische Bedingungen zu erhalten, erfolgte die Beleuchtung künstlich im 12 h Rhythmus.

\subsubsection{Versuchsablauf}

Zu Beginn des Versuchs waren alle Mäuse klinisch gesund. Die Nacktmäuse wurden in 5 Gruppen aufgeteilt. Gruppe I (Maus 1-4) und II (Maus 5-8) erhielten die Zelllinie AMO-1 intraperitoneal verabreicht. Gruppe III (Maus 9-13) und IV (Maus 14-18) erhielten dagegen die Zellinie MOLP-8 intraperitoneal verabreicht. Dabei wurden jeweils 5 x $10^{6}$ Multiple Myelom-Zellen in PBS injiziert. Um den Zeitaufwand der Versuchsauswertung zu minimieren, wurde der Versuch mit Mäusen, denen die Zelllinie MOLP-8 injiziert wurde, um einen Tag versetzt begonnen und beendet. Die Behandlung der Tiere begann jeweils einen Tag nach der intraperitonealen Zellinjektion. Dabei galt folgender Behandlungsplan.

Tabelle 7: Behandlungsplan Mausversuch; Die Mäuse 1-8 erhielten die Zelllinie AMO-1, die Mäuse 9-18 dagegen erhielten die Zelllinie MOLP-8 intraperitoneal verabreicht. Anschließend wurden die Mäuse 1-4 sowie Mäuse 9-13 als Kontrollgruppen mit dem Vehikel behandelt. Die Mäuse 5-8 sowie 14-18 wurden mit BAY 80-6946 behandelt

\begin{tabular}{|clll|}
\hline$\underline{\text { Zelllinie }}$ & Behandlung & & \\
& Vehikel & BAY 80-6946 & - \\
Amo-1 & Maus 1-4 & Maus 5-8 & \\
MOLP-8 & Maus 9-13 & Maus 14-18 & \\
- & & & Maus 19 \\
\hline
\end{tabular}

Gruppe II und IV erhielten BAY 80-6946 intraperitoneal injiziert (6mg pro kg Körpergewicht) jeweils Montag, Mittwoch und Freitag in den zwei Behandlungswochen (insgesamt sechs Behandlungstage). Gruppe I und Gruppe III erhielten jeweils ausschließlich Vehikelinjektionen der gleichen Konzentration und stellten damit die Kontrollgruppen. Für die intraperitonealen Injektionen wurden die Mäuse jeweils durch Inhalation von Isofluran betäubt. Maus 19 stellte die Negativkontrolle dar. Sie erhielt weder eine intraperitoneale Zellinjektion noch Behandlungen. Nach Ablauf der zwei Behandlungswochen wurde der Versuch beendet. Den internationalen Bestimmungen folgend, wurden die Mäuse mit Inhalation von Isofluran betäubt und durch Genickbruch getötet. Zunächst wurde eine diagnostische peritoneale Spülung mit PBS durchgeführt. Die gewonnene Zellsuspension wurde in Falconröhrchen überführt und auf Eis verwahrt. Anschließend wurden die Tiere seziert. Dabei wurden Proben der folgenden Organe entnommen und jeweils ein Teil in 
Paraffin fixiert und ein Teil in Stickstoff schockgefroren und asserviert: Milz, Leber, Lunge, Femurknochen, abdominale Lymphknoten und Peritoneum.

\subsubsection{Versuchsauswertung}

\subsection{Bauchspülung}

Zunächst wurde die jeweilige Gesamtzellzahl der gewonnenen Zellsuspension bestimmt. Diese enthielt jedoch sowohl die humanen Myelom-Zellen als auch murine Zellen. Um den prozentualen Anteil an humanen Zellen in der Zellsuspension herauszufinden, wurde eine durchflusszytometrische Analyse durchgeführt. Dafür wurden die bei der Bauchspülung gewonnenen Zellen zunächst zweimal mit PBS gewaschen und anschließend jeweils 5 Minuten bei $200 \mathrm{G}$ zentrifugiert.

Für die Färbung wurden pro Probe 100.000 Zellen in jeweils $100 \mu 1$ PBS in FACS-Röhrchen überführt. Von jeder Bauchspülung wurden eine Färbung mit CD 138-Antikörper (20 $\mu 1$ pro Test) und eine Färbung mit MHC Klasse 1-Antikörper (10 $\mu 1$ pro Test) durchgeführt. Beide stellen Oberflächenantigene der Multiplen Myelom-Zellen dar. CD138 (Syndecan-1) ist ein Transmembranprotein und stellt einen bekannten Marker für Plasmazellen dar (Bataille et al. 2006). Der Haupthistokompatibilitätskomplex (Abk. MHC von Major Histocompatibility Complex) bezeichnet eine Genfamilie, die für Proteine kodiert, die sich auf allen humanen kernhaltigen Zellen befinden. Diese sind im Rahmen einer Immunantwort für die Wechselwirkungen zwischen T-Lymphozyten und antigenpräsentierenden Zellen verantwortlich (Choo 2007). Aus diesem Grund spricht man auch vom HLA-System (Human Leucocyte Antigen) (Choo 2007). Als Negativkontrolle wurde auch jeweils eine Probe mit dem passenden Isotyp in der entsprechenden Konzentration gefärbt. Nach einer Inkubationszeit von $1 \mathrm{~h}$ bei $4{ }^{\circ} \mathrm{C}$, wurden die Proben mit PBS gewaschen und 5 Minuten bei $200 \mathrm{G}$ zentrifugiert. Die Zellpellets wurden in jeweils $500 \mu \mathrm{l}$ PBS aufgenommen und mit Hilfe der Durchflusszytometrie analysiert. Anschließend konnte aus den jeweiligen Gesamtzellzahlen der peritonealen Lavage und dem durchflusszytometrisch bestimmten Prozentsatz an Multiplen Myelom-Zellen die absolute Zellzahl an Myelom-Zellen in einer Probe bestimmt werden. 


\subsection{Milz und Femurknochen}

Um eine mögliche Streuung der Myelom-Zellen in den Nacktmäusen nachzuweisen, wurden die Milz und der Femurknochen jeder Maus noch weiter untersucht. Hierzu wurden aus den Femurknochen Spülzytologien gewonnen sowie die Milz zunächst unter Verwendung eines Siebes zerkleinert. Um eine Einzelzellsuspension zu erhalten, wurde mit PBS nachgespült. Anschließend wurden die Zellzahlen der Femurspülzytologie und der Milzzellsuspension mit Hilfe der Neubauer-Zählkammer bestimmt. Von jeder Probe wurden wiederum eine Färbung mit CD 138-Antikörper (20 $\mu$ l pro Test) und eine Färbung mit MHC Klasse 1-Antikörper (10 $\mu 1$ pro Test) durchgeführt.

Für die Färbung wurden jeweils $1 \times 10^{6}$ Zellen in $100 \mu$ 1 PBS pro Probe in FACS-Röhrchen überführt und die Proben für $1 \mathrm{~h}$ bei $4{ }^{\circ} \mathrm{C}$ inkubiert. Anschließend wurden die Proben mit PBS gewaschen, 5 Minuten bei $200 \mathrm{G}$ zentrifugiert und die Zellpellets in $500 \mu \mathrm{l}$ PBS resuspendiert. Abschließend wurden die Proben durchflusszytometrisch analysiert.

\subsection{Auswertung und statistische Analyse der Ergebnisse}

Die Auswertung der Ergebnisse erfolgte mit dem Programm GraphPad Prism V 5. Aus der Zellgesamtzahl einer Bauchspülung und dem durchflusszytometrisch ermittelten prozentualen Anteil an humanen Zellen (Myelom-Zellen) wurde die absolute Zellzahl berechnet und wiederum innerhalb jeder Versuchsgruppe der Mittelwert der absoluten Zellzahl ermittelt. Die Ergebnisse wurden in Form eines Balkendiagramms unter Angabe der Standardabweichung dargestellt. Signifikante Unterschiede der BAY 80-6946-behandelten Tiere zur Vehikelkontrolle wurden mit einer einfachen Varianzanalyse (ANOVA), gefolgt von einem Bonferroni-post-hoc-Test mit einem Konfidenzintervall von $95 \%$ ermittelt. Die Signifikanzen sind durch Sternchen repräsentiert, wobei ein Sternchen $\left(^{*}\right)$ einem $\mathrm{p}<0.05$ entspricht, zwei Sternchen $(* *)$ einem $\mathrm{p}<0.01$ und drei Sternchen $* * *$ einem $\mathrm{p}<0.001$ entsprechen. 


\section{$3 \quad$ Ergebnisse}

\subsection{Der PI3K-Akt-Signalweg ist in Multiplen Myelom-Zellen konstitutiv aktiviert}

Die konstitutive Aktivierung des PI3-Kinase-Akt-Signalweges ist ein häufig beobachtetes Phänomen in Tumoren. Zudem scheint sie eine entscheidende Rolle für die Prognose der Betroffenen zu spielen (Nam et al. 2003; Min et al. 2004; Dai et al. 2005). Auch das Multiple Myelom gehört zu den Tumorerkrankungen, bei denen eine konstitutive Aktivierung des PI3Kinase-Akt-Signalweges ein häufiges Phänomen darstellt (Hsu et al. 2001; Alkan und Izban 2002). Studien konnten zeigen, dass die konstitutive Aktivierung häufig sowohl in Wachstumsfaktor-unabhängigen Zelllinien als auch in Multiplen Myelom-Zellen, die direkt von Patienten gewonnen wurden, auftritt. Dabei konnte die Aktivierung in den nicht malignen hämotopoetischen Zellen der jeweiligen Patienten jedoch nicht nachgewiesen werden (Tu et al. 2000).

Die Höhe der konstitutiven Aktivierung in Multiplen Myelom-Zellen kann jedoch stark variieren. Aus diesem Grund wurde als Grundlage der vorliegenden Arbeit zunächst die konstitutive Aktivierung des PI3-Kinase-Akt-Signalweges in den vier Zelllinien AMO-1, KMS-12-BM, MOLP-8 und U-266 untersucht. Die Aktivierung der Serin-Threonin-Kinase Akt erfordert deren Phosphorylierung am Threoninrest an Position 308 (T308) und zusätzlich die Phosphorylierung am Serinrest an Position 473 (S473) (Vanhaesebroeck und Alessi 2000). In der vorliegenden Arbeit wurde der Nachweis der Phosphorylierung S473 als Marker für die Aktivierung von Akt ausgewählt.

Um die Aktivierung von Akt in den vier Myelom-Zelllinien zu untersuchen, wurde die Methode der Durchflusszytometrie verwendet. Für die FACS-Analysen wurde jeweils eine Probe der vier Zelllinien mit einem fluoreszenzmarkierten Antikörper für S473 nach dem im Abschnitt „Material und Methoden“ erläuterten Protokoll gefärbt und anschließend mit Hilfe des Durchflusszytometers analysiert. Anhand der Leuchtkraft des gebundenen Fluoreszenzfarbstoffes, die als mittlere Fluoreszenzintensität (MFI) angegeben wird, kann man auf den Anteil von aktivierten Zellen rückschließen. 
Als Kontrollen dienten eine ungefärbte Probe, um die Eigenfluoreszenz der Multiplen Myelom-Zellen zu bestimmen und eine mit dem zugehörigen Isotyp gefärbte Probe, um mögliche unspezifische Bindungen des Antikörpers zu erkennen. Diese Messungen wurden für alle vier Zelllinien entsprechend durchgeführt. Tabelle 8 stellt die MFI-Werte einer exemplarischen Messung dar.

Tabelle 8: Mittlere Fluoreszenzintensität (MFI) aller Zelllinien in der durchflusszytometrischen Analyse der konstitutiven Aktivierung von Akt; Die Zellen wurden fixiert, permeabilisiert, $10^{6}$ Zellen ausgezählt, in PBS gewaschen, mit AB-Serum blockiert, zentrifugiert, in $100 \mu 1$ PBS mit dem spezifischen Antikörper oder dem Isotyp-Kontroll-Antikörper gefärbt. Anschließend wurden die MFI-Werte durchflusszytometrisch bestimmt.

\begin{tabular}{|lccc|}
\hline \multicolumn{1}{|c}{ Zelllinie } & $\underline{\text { MFI }}$ & Phospho-Akt \\
Kmo-1 & Kontrolle (ungefärbt) & Kontrolle (Isotyp) & 872 \\
KMS-12-BM & 169 & 279 & 580 \\
MOLP-8 & 188 & 261 & 825 \\
U-266 & 192 & 293 & 702 \\
\hline
\end{tabular}

Die ungefärbten Zellen zeigten eine Eigenfluoreszenz mit MFI-Werten zwischen 169 und 192. In der Isotyp-Kontrollfärbung schwankten die MFI-Werte zwischen 261 und 293. Bei der anti-Phospho-Akt-Färbung zeigten sich zellspezifische Unterschiede. Der bei der Zelllinie AMO-1 gemessene MFI-Wert stellte mit 872 den höchsten Wert dar. Auch bei der Zelllinie MOLP-8 stellte der gemessene MFI-Wert mit 825 einen vergleichsweise hohen Wert dar. Der MFI-Wert, der für die Zelllinie U-266 gemessen wurde, betrug 702. Mit einem MFI-Wert von 580 wurde bei der Zelllinie KMS-12-BM die niedrigste Antikörperbindung nachgewiesen.

Die Abbildung 9 veranschaulicht diese Ergebnisse der Analyse aller 4 Zelllinien, indem jeweils das Histogramm der Isotyp-Färbung und der Phospho-Akt-Färbung in einer Abbildung zusammengefasst wurden. 


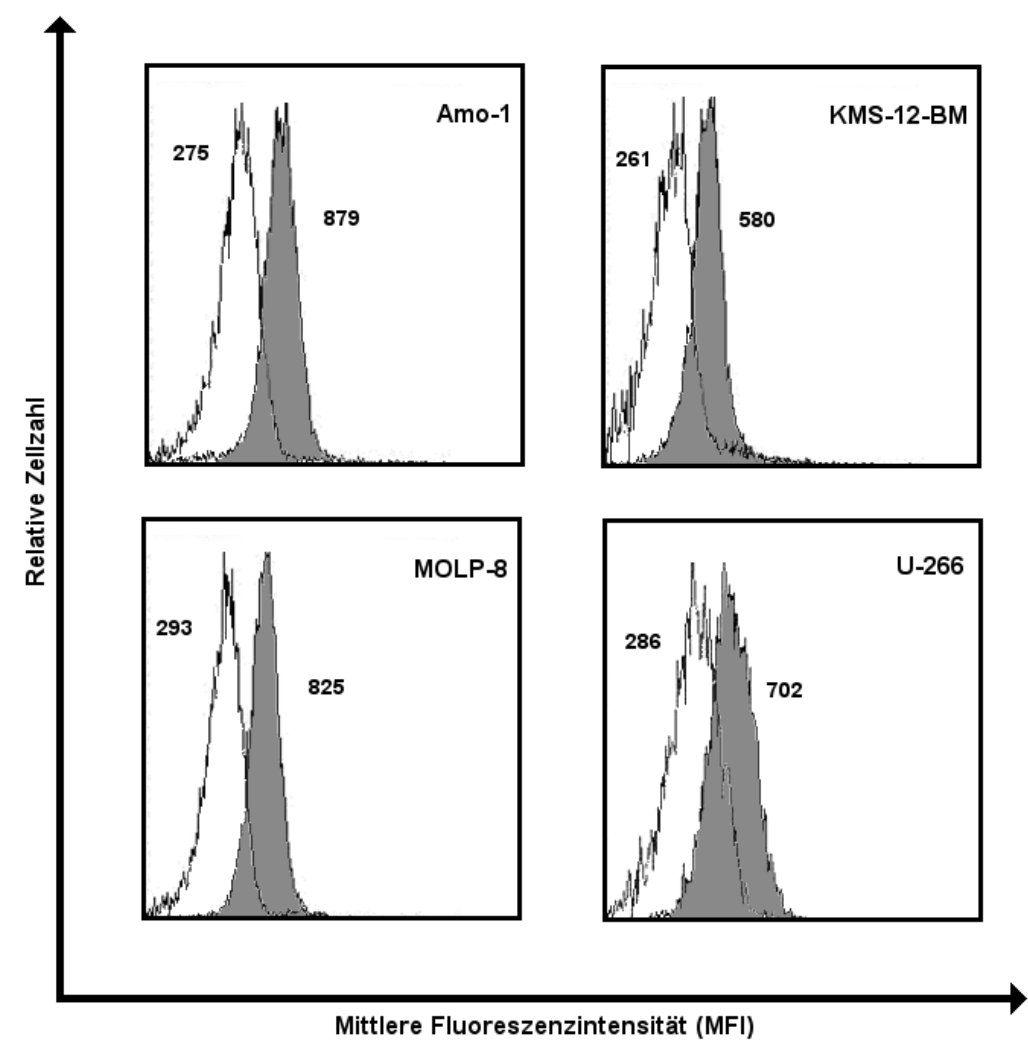

Abbildung 9: Histogramme einer durchflusszytometrischen Analyse der Multiplen Myelom-Zelllinien AMO-1, KMS12-BM, MOLP-8, U-266; Y-Achse: Zellzahl; X-Achse: MFI der jeweiligen Isotypfärbung (linke weiß hinterlegte Kurve) und MFI der Phospho-Akt Färbung (rechte grau hinterlegte Kurve). Die Zellen wurden fixiert, permeabilisiert, $1 \times 10^{6}$ Zellen ausgezählt, in PBS gewaschen, mit AB-Serum blockiert, zentrifugiert, in $100 \mu 1$ PBS mit dem Antikörper bzw. Isotyp gefärbt, und anschließend durchflusszytometrisch analysiert. Die Abbildungen wurden aus der Software (BD FACS Diva) des verwendeten Durchflusszytometers FACS Canto II entnommen.

Zusammenfassend zeigten die durchflusszytometrischen Analysen eine moderate Aktivierung in allen vier Zelllinien, wobei AMO-1 (MFI 879) und MOLP-8 (MFI 825) die höchste konstitutive Aktivierung, U-266 dagegen eine mittlere und KMS-12-BM die niedrigste konstitutive Aktivierung zeigten.

Abbildung 10 zeigt einen Vergleich der verschiedenen Zelllinien übersichtlich in einem Balkendiagramm zusammengefasst. 


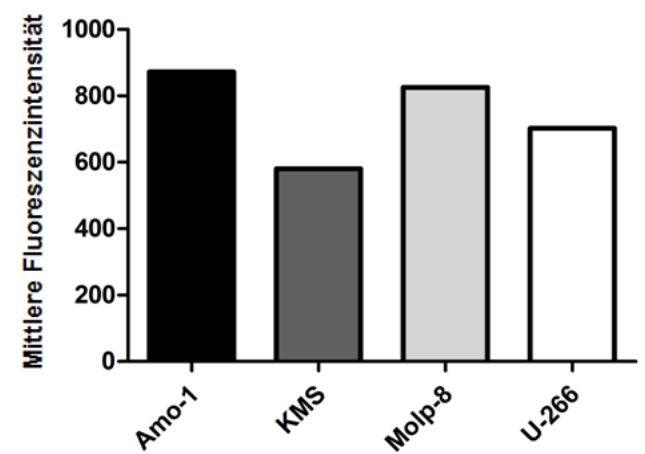

Abbildung 10: Balkendiagramm der konstitutiven Aktivierung von Akt der Zelllinien AMO-1, KMS-12-BM, MOLP-8 und U-266); durchflusszytometrisch ermittelte Daten: Y-Achse: MFI; X-Achse: Zelllinie. Die Zellen wurden fixiert, permeabilisiert, $1 \times 10^{6}$ Zellen ausgezählt, in PBS gewaschen, mit AB-Serum blockiert, zentrifugiert, in $100 \mu 1$ PBS mit dem Antikörper bzw. Isotyp gefärbt, und anschließend durchflusszytometrisch analysiert. Die Abbildung wurde mit Hilfe von GraphPad Prism V 5 erstellt.

\subsection{BAY 80-6946 hemmt die Aktivierung von Akt}

Die durchflusszytometrischen Untersuchungen zeigten eine erhöhte Phosphorylierung von Akt und konnten damit die vermutete konstitutive Aktivierung des PI3-Kinase-AktSignalweges in den vier untersuchten Multiplen Myelom-Zelllinien bestätigten. Im nächsten Schritt sollte getestet werden, ob der neue PI3-Kinase-Inhibitor BAY 80-6946 diese Aktivierung der PI3-Kinase zu hemmen vermag. Hierzu wurden die vier Zelllinien über einen Zeitraum von 16 Stunden mit BAY 80-6946 behandelt. Dabei wurde ein Konzentrationsschema von 0 nM-, 10 nM-, 50 nM- und 100 nM-Lösungen gewählt. Da BAY 80-6946 in einem speziellen Vehikel gelöst vorliegt, wurde eine zusätzliche Zellprobe jeweils ausschließlich mit dem Vehikel behandelt, um auszuschließen, dass dieser ebenfalls die Phosphorylierung von Akt beeinflusst. Von jedem Versuchsansatz wurden wiederum drei Proben angesetzt. Eine Probe blieb jeweils als Kontrolle ungefärbt, eine Probe wurde mit dem Isotyp gefärbt und eine Probe mit dem Phospho-Akt-Antikörper gefärbt. Anschließend wurden alle Proben durchflusszytometrisch analysiert.

Die Abbildung 11 zeigt die Ergebnisse der statistischen Analyse der drei voneinander unabhängigen durchflusszytometrischen Versuche in Form von Balkendiagrammen. 
AMO-1

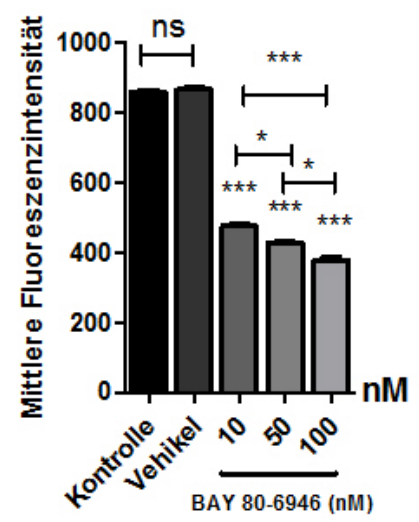

MOLP-8

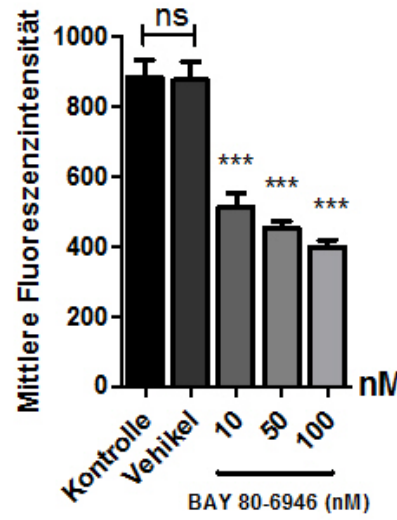

KMS-12-BM

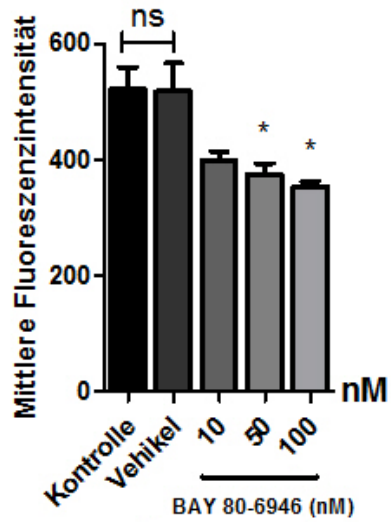

$\mathrm{U}-266$

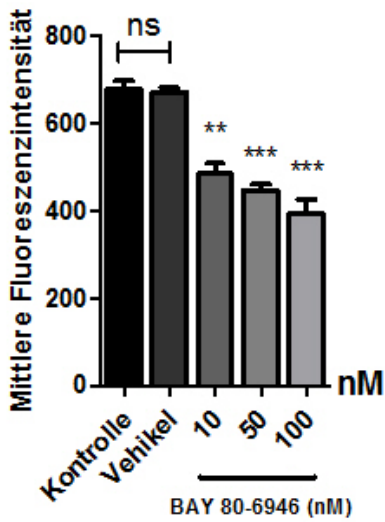

Abbildung 11: Durchflusszytometrische Analyse der Behandlung mit BAY 80-6946; aufgetragen sind die Daten der drei durchflusszytometrischen Analysen (Rohdaten siehe Tabelle 9); Balkendiagramm; Y-Achse: MFI; X-Achse: Probe; Standardabweichung dargestellt. Die Signifikanzen sind durch Sternchen repräsentiert, wobei ein Sternchen $(*)$ einem p $<0.05$ entspricht, zwei Sternchen (**) einem $\mathrm{p}<0.01$ und drei Sternchen $* * *$ einem $\mathrm{p}<0.001$ entsprechen. Die Zellen wurden über 16 Stunden mit BAY 80-6946 behandelt, fixiert, permeabilisiert, 1×106 Zellen ausgezählt, in PBS gewaschen, mit AB-Serum blockiert, zentrifugiert, in $100 \mu 1$ PBS mit dem spezifischen Antikörper oder dem Isotyp-Kontroll-Antikörper gefärbt, und anschließend durchflusszytometrisch analysiert. Die Abbildung wurde mit Hilfe von GraphPad Prism V 5 erstellt.

Die gemessenen MFI-Werte der unbehandelten Proben aller Zelllinien waren vergleichbar mit den Ergebnissen der vorangegangenen durchflusszytometrischen Versuche. So zeigte die Zelllinie AMO-1 Werte zwischen 844 und 872, die Zelllinie MOLP-8 Werte zwischen 825 und 983, die Zelllinie U-266 Werte zwischen 640 und 702 und die Zelllinie KMS-12-BM Werte zwischen 452 und 580 (vergleiche Tabelle 9 im Anhang).

Nach Vehikelzugabe ergaben sich bei allen Zelllinien erwartungsgemäß nur äußerst geringfügige nicht signifikante Veränderungen der MFI-Werte. 
Dagegen zeigte sich eine deutliche Reduktion der MFI-Werte unter Behandlung mit BAY 806946. Die folgenden Werte sind ebenfalls der Tabelle 9 im Anhang zu entnehmen. Die Behandlung der Zelllinie AMO-1, allein mit einer 10 nM-Lösung von BAY 80-6946, äußerte sich in einer deutlichen Reduktion der Akt-Phosphorylierung. Im ersten Versuch sank der gemessene MFI-Wert von 879 (Vehikel behandelte Probe) auf 478. Die zwei weiteren Versuche zeigten ähnliche Ergebnisse. Durchschnittlich ließ sich durch die Behandlung mit einer 10 nM-Lösung von BAY 80-6946 die Phosphorylierung von Akt auf 55,1 \% des Referenzwertes (vehikelbehandelte Proben) senken. Bei der Probe, die mit einer $50 \mathrm{nM}$ Lösung von BAY 80-6946 behandelt wurde, reduzierte sich der MFI-Wert weiter auf 426. Fasst man alle drei Versuche zusammen, konnte eine 50 nM-Lösung von BAY 80-6946 die Phosphorylierung von Akt auf 49,3 \% des Referenzwertes senken. Bei der Probe, die mit einer 100 nM-Lösung von BAY 80-6946 behandelt wurde, ließ sich ein MFI-Wert von 335 ermitteln. Somit konnte die Phosphorylierung von Akt durch Behandlung mit einer $100 \mathrm{nM}$ Lösung von BAY 80-6946 auf durchschnittlich 42,0 \% des Referenzwertes gesenkt werden.

Die Zelllinie MOLP-8 zeigte vergleichbare Ergebnisse. Die Behandlung mit einer $10 \mathrm{nM}$ Lösung von BAY 80-6946 äußerte sich durchschnittlich in einer Reduktion der Phosphorylierung von Akt auf 58,8 \% des Referenzwertes (vehikelbehandelte Proben). Eine 50 nM-Lösung von BAY 80-6946 konnte hier durchschnittlich die Phosphorylierung von Akt auf 51,7\% des Referenzwertes senken. Eine Reduktion der Akt-Phosphorylierung auf 45,7 \% des Referenzwertes ließ sich durch Einsatz einer 100 nM-Lösung von BAY 80-6946 erreichen.

Bei der Zelllinie U-266, die im Vergleich zur Zelllinie AMO-1 und MOLP-8 in den durchflusszytometrischen Analysen eine geringere konstitutive Aktivierung von Akt zeigte, ließ sich die Phosphorylierung von Akt durch Behandlung von BAY 80-6946 ebenfalls deutlich hemmen. Jedoch zeigen sich Unterschiede in der prozentualen Reduktion der AktPhosphorylierung. Die Behandlung mit einer 10 nM-Lösung von BAY 80-6946 äußerte sich durchschnittlich in einer Reduktion der Phosphorylierung von Akt auf $72,2 \%$ des Referenzwertes (vehikelbehandelte Proben). Fasst man alle drei Versuche zusammen, konnte eine 50 nM-Lösung von BAY 80-6946 die Phosphorylierung von Akt auf 66,4 \% des Referenzwertes senken. Unter Behandlung mit einer 100 nM-Lösung, konnte die Phosphorylierung von Akt auf 50,4\% des Referenzwertes gesenkt werden.

Die Zelllinie KMS-12-BM zeigte sowohl in den vorausgehenden durchflusszytometrischen Analysen als auch in diesen Analysen die niedrigste konstitutive Akt-Phosphorylierung aller 
vier Zelllinien. Im ersten Versuch sank der gemessene MFI-Wert von 598 (Vehikel behandelte Probe) auf 417. Die Behandlung mit einer 10 nM-Lösung von BAY 80-6946 äußerte sich durchschnittlich in einer Reduktion der Phosphorylierung von Akt auf 77,4 \% des Referenzwertes (vehikelbehandelte Proben). Eine 50 nM-Lösung von BAY 80-6946 vermochte die Phosphorylierung von Akt auf 72,4 \% des Referenzwertes zu senken. Unter der Behandlung mit einer 100 nM-Lösung von BAY 80-6946 ließ sich die Phosphorylierung von Akt durchschnittlich auf 67,1 \% des Referenzwertes senken. Hiermit zeigte KMS-12-BM zwar eine Reduktion der Akt-Phosphorylierung nach Behandlung mit BAY 80-6946, im Vergleich jedoch die geringste aller vier Zelllinien.

Die Abbildung wurde mit Hilfe des Programms GraphPad Prism V 5 erstellt. Signifikante Unterschiede zwischen den verschiedenen Medikamentenkonzentrationen, wurden mit einer einfachen Varianzanalyse (ANOVA) gefolgt von einem Bonferroni-post-hoc-Test mit einem Konfidenzintervall von $95 \%$ ermittelt. Die statistische Analyse belegt, dass BAY 80-6946 eine signifikante dosisabhängige Hemmung der PI3-Kinase zeigt. Dagegen zeigte sich bei Zugabe des Vehikels erwartungsgemäß keine signifikante Hemmung der AktPhosphorylierung.

\subsection{IGF-1-Stimulation}

Die IGF-1-Stimulation der Multiplen Myelom-Zellen wurde wie im Abschnitt „Material und Methoden“ beschrieben durchgeführt. Die Auswertung der Versuche erfolgte mit Hilfe von durchflusszytometrischen Analysen. Abbildung 12 zeigt exemplarisch die Ergebnisse einer FACS-Analyse der Zelllinien AMO-1 und MOLP-8.

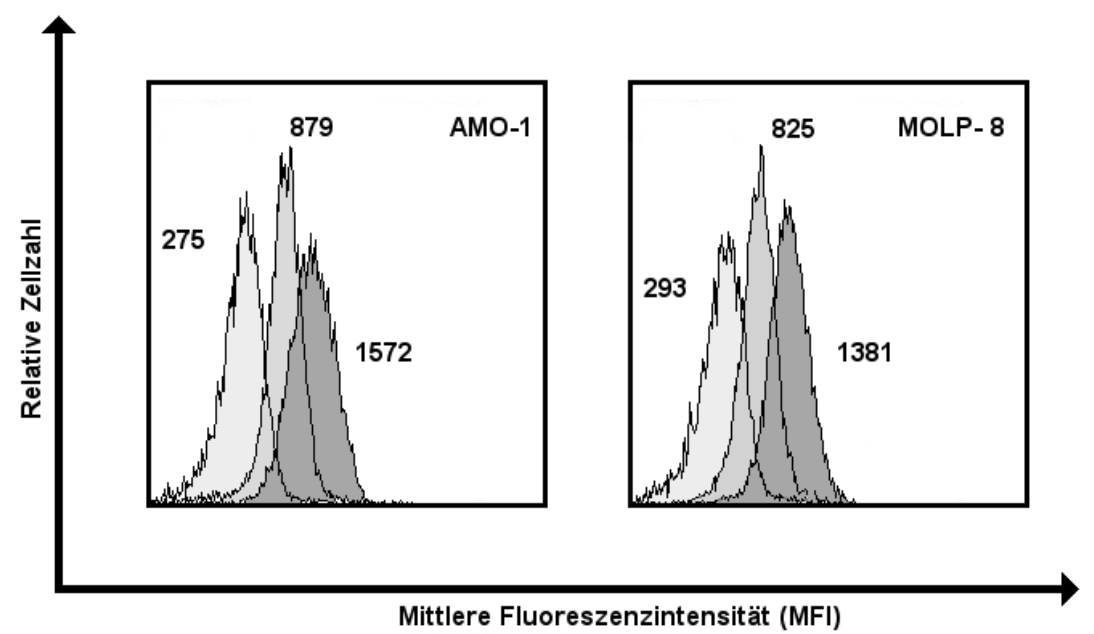


Abbildung 12: Durchflusszytometrische Analyse der IGF-1-Stimulation der Zelllinien AMO-1 und MOLP-8; YAchse: Zellzahl; X-Achse: MFI der jeweiligen Isotyp-Färbung (linke hellgrau hinterlegte Kurve), MFI der unstimulierten Phospho-Akt-Färbung (mittlere grau hinterlegte Kurve) und MFI der IGF-1-stimulierten Phospho-Akt Färbung (rechte grau hinterlegte Kurve). Die angegebenen Zahlenwerte geben die gemessenen MFI-Werte der nebenliegenden Kurve wieder. Die Zellen wurden mit IGF-1 stimuliert, fixiert, permeabilisiert, mit dem fluoreszenzmarkierten Phospho-Akt-Antikörper gefärbt und durchflusszytometrisch analysiert. Abbildungen aus der Software (BD FACS Diva) des verwendeten Durchflusszytometers FACS Canto II entnommen.

Für die Abbildung wurden die Histogramme der verschiedenen Färbungen (Isotyp, unstimulierte sowie IGF-1-stimulierte Phospho-Akt-Färbung) einer Zelllinie übereinandergelegt. Beide Zelllinien zeigten eine deutliche Zunahme der Aktphosphorylierung unter Stimulation mit IGF-1. Bei der Zelllinie AMO-1 wurde bei der Isotypenfärbung eine MFI von 275 ermittelt. Bei der unstimulierten Probe wurde eine MFI von 879 gemessen. Dagegen konnte mit der IGF-1-Stimulation ein MFI-Wert von 1572 erreicht werden. Dies entspricht einer Steigerung um $78 \%$ gegenüber dem Wert der unstimulierten Zellen.

Die Zelllinie MOLP-8 zeigte ganz ähnliche Ergebnisse. Bei der Isotyp-gefärbten Probe wurde eine MFI von 293 ermittelt. Für die unstimulierte Probe wurde eine MFI von 825 gemessen. Unter IGF-1-Stimulation zeigte sich eine MFI von 1381, was einer Steigerung um 67\% gegenüber dem Wert unstimulierter Zellen entspricht.

Zusammenfassend zeigten die Ergebnisse eine moderate konstitutive Aktivierung von Akt beider Zelllinien. Durch Stimulation mit IGF-1 konnte der Grad der Phosphorylierung darüber hinaus deutlich erhöht werden.

Um die Ergebnisse der durchflusszytometrischen Analysen mit einer weiteren Methode zu verifizieren, wurden die Zellen in einem weiteren Versuch erneut mit IGF-1 stimuliert und SDS-Lysate gewonnen, um eine Western-Blot-Analyse durchzuführen. Abbildung 13 zeigt exemplarisch die Ergebnisse einer Western-Blot-Analyse aller vier Zelllinien. Es wurden drei Western-Blot-Gele verwendet und die entsprechenden Membranen mit folgenden Antikörpern inkubiert: Phospho-Akt-Antikörper, Akt-Antikörper und als Ladekontrolle Beta-AktinAntikörper. Dabei sind jeweils die unstimulierte Probe und die IGF-1-stimulierte Probe nebeneinander aufgetragen, um die Unterschiede zu verdeutlichen. 


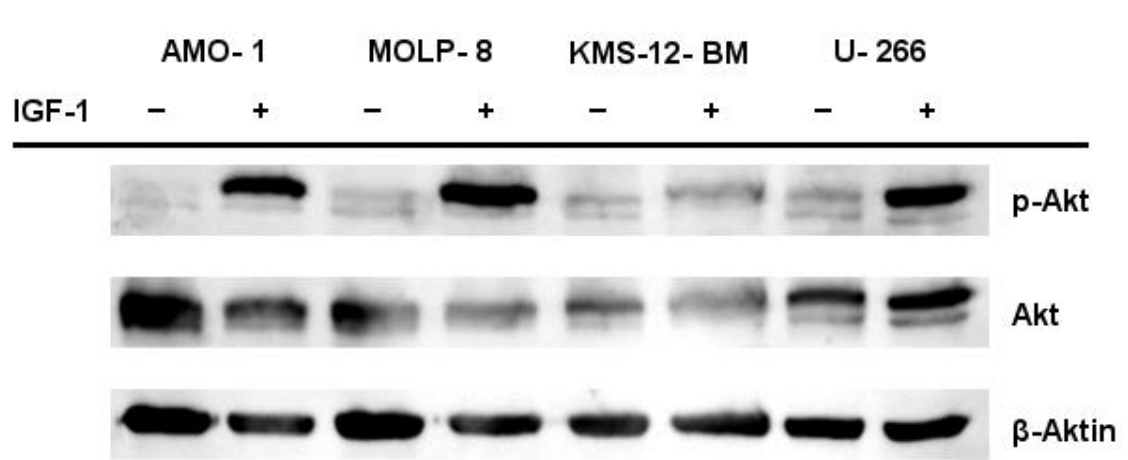

Abbildung 13: Western-Blot-Analyse der IGF-1-Stimulation von AMO-1, MOLP-8, KMS-12-BM, U-266; abgebildet sind die Ergebnisse einer Western-Blot-Analyse aller Zelllinien mit jeweils einer unstimulierten und einer IGF-1-stimulierten Probe. Gewinnung der SDS-Lysate sowie Färbung mit p-Akt-, Akt- sowie Beta-Aktin-Antikörper nach dem Western-BlotAnalyse-Protokoll (siehe Abschnitt „Material und Methoden“). Die Abbildung wurde mit der Image J Software erstellt.

Die Färbung mit dem Beta-Aktin-Antikörper wurde durchgeführt, um eine gleichmäßige Protein-Beladung der Geltaschen zu gewährleisten. In dieser Western-Blot-Analyse zeigte die beta-Aktin-Färbung eine relativ gleichmäßige Protein-Beladung. Bei Betrachtung der mit dem Phospho-Akt-Antikörper markierten Banden der Zelllinien AMO-1, MOLP-8 und U-266 erkennt man einen deutlichen Unterschied der Bandenintensität zwischen der jeweiligen unstimulierten und IGF-1-stimulierten Probe. Dagegen sind beide Banden der Zelllinie KMS12-BM nur schwer mit dem bloßen Auge zu differenzieren. Die mit dem Akt-Antikörper markierten Banden zeigten kein homogenes Bild. Bei den Zelllinien AMO-1 und KMS-12BM nahmen die Intensitäten der Banden durch die IGF-1-Stimulation ab. Dies scheint auch bei der Zelllinie MOLP-8 der Fall zu sein. Die Bandenintensität der Zelllinie U-266 blieb nahezu unverändert.

Um die Auswertung der Western-Blot-Analyse zu objektivieren, wurde eine densiometrischen Auswertung der Western-Blot-Analyse-Banden durchgeführt. Hierzu wurden Integrationsdichtewerte der Western-Blot-Analyse-Banden nach der Anleitung "Analyzing gels and western blots with ImageJ" (Miller 2010) unter Verwendung des Programms ImageJ ermittelt. Die Ergebnisse der densitometrischen Auswertung sind in Abbildung 14 in Form eines Balkendiagramms dargestellt. 


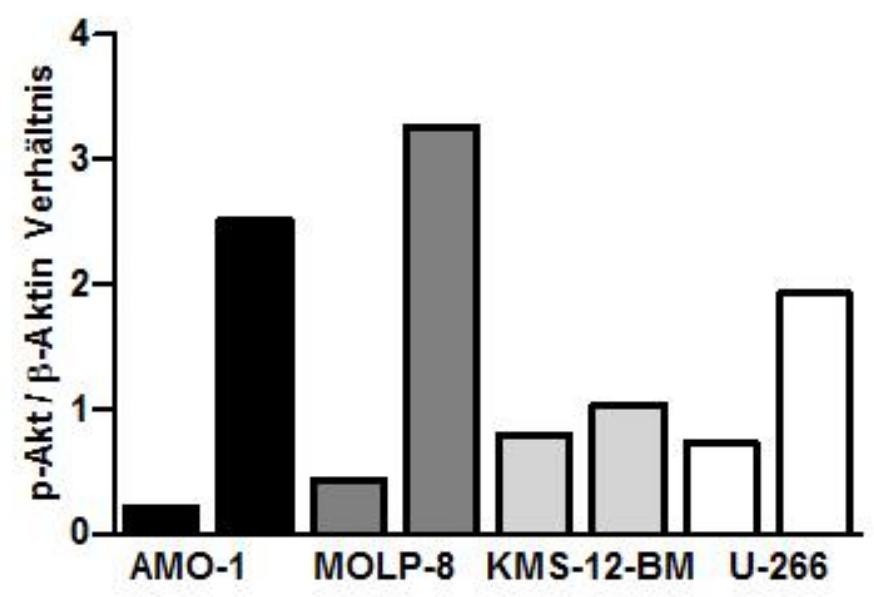

Abbildung 14: Densitometrische Auswertung der Western-Blot-Analyse aus Abbildung 13; Y-Achse: P-Akt/BetaAktin-Quotient; X-Achse Zelllinie; Reihenfolge entspricht der Reihenfolge der Banden in Abbildung 13: AMO-1 unstimuliert, AMO-1 IGF-1 stimuliert, MOLP-8 unstimuliert, MOLP-8 IGF-1 stimuliert, KMS-12-BM unstimuliert, KMS12-BM IGF-1 stimuliert, U-266 unstimuliert, U-266 IGF-1 stimuliert. Die densiometrische Auswertung erfolge mit Hilfe des Programms ImageJ. Die Abbildung wurde mit Hilfe von GraphPad Prism V 5 erstellt.

Die Abbildung veranschaulicht die Ergebnisse der Western-Blot-Analyse. Alle Zelllinien zeigten ein Ansprechen auf die Stimulation mit IGF-1. Bei den Zelllinien AMO-1, MOLP-8 und auch U-266 war ein deutlicher Anstieg der Akt-Phosphorylierung zu verzeichnen. Mit Hilfe der densitometrischen Auswertung wurde auch bei der Zelllinie KMS-12-BM eine geringe Zunahme der Akt-Phosphorylierung sichtbar.

\subsection{BAY 80-6946 hemmt die IGF-1-stimulierte Aktivierung von Akt}

Bis zu diesem Zeitpunkt konnte gezeigt werden, dass Akt in den untersuchten MyelomZelllinien konstitutiv aktiviert ist. Diese Aktivierung ließ sich durch den insulinähnlichen Wachstumsfaktor IGF-1, der auch im Knochenmarkmilieu ausreichend vorhanden ist, deutlich steigern. In der vorliegenden Arbeit konnte gezeigt werden, dass der neue PI3Kinase-Inhibitor BAY 80-6946 in der Lage ist, die konstitutive Aktivierung von Akt zu hemmen. Im nächsten Schritt stellte sich die äußerst relevante Frage, ob BAY 80-6946 auch in der Lage sein würde, die durch IGF-1-stimulierte Aktivierung von Akt zu hemmen.

Um den inhibierenden Effekt von BAY 80-6946 auf die durch IGF-1-stimulierten MyelomZellen zu testen, wurden die Zellen zunächst entsprechend den vorangegangenen Versuchen für 16 Stunden mit BAY 80-6946 behandelt. Dabei wurde erneut das Konzentrationsschema von $0 \mathrm{nM}, 10 \mathrm{nM}, 50 \mathrm{nM}$ und $100 \mathrm{nM}$ gewählt. Als Kontrolle wurde wiederum eine Probe entsprechend mit dem Vehikel behandelt. Anschließend wurden die Zellen über 20 Minuten 
mit IGF-1 in einer Konzentration von $100 \mathrm{ng} / \mathrm{ml}$ stimuliert. Von jedem Versuchsansatzes wurde drei Proben angesetzt. Eine Probe blieb jeweils ungefärbt, eine Probe wurde mit dem Isotyp-Kontroll-Antikörper gefärbt und eine Probe mit dem Phospho-Akt-Antikörper gefärbt. Anschließend wurden alle Proben durchflusszytometrisch analysiert.

In Tabelle 10 im Anhang wurden die MFI-Werte der Phospho-Akt Färbungen übersichtlich zusammengefasst. Die gemessenen MFI-Werte der IGF-1-stimulierten und unbehandelten Zellen waren vergleichbar mit den Ergebnissen der vorangegangenen durchflusszytometrischen Versuche.

So zeigte die Zelllinie AMO-1 Werte zwischen 1414 und 1572. Bei der Zelllinie MOLP-8 konnten Werte zwischen 1224 und 1381 erreicht werden. Nach Vehikelzugabe ergaben sich bei beiden Zelllinien erwartungsgemäß nur äußerst geringfügige Schwankungen der MFIWerte. Die Behandlung der Zelllinie AMO-1 mit einer 10 nM-Lösung von BAY 80-6946 äußerte sich in einer deutlichen Reduktion der MFI-Werte. Im ersten Versuch sank der gemessene MFI-Wert von 1572 (Vehikel behandelte Probe) auf 1046 Der zweite Versuche zeigte ähnliche Ergebnisse. Durchschnittlich ließ sich durch Behandlung mit einer $10 \mathrm{nM}$ Lösung von BAY 80-6946 die Phosphorylierung von Akt auf 66,5 \% des Referenzwertes (vehikelbehandelte Proben) senken. Bei der Probe, die mit einer 50 nM-Lösung von BAY 806946 behandelt wurden, reduzierte sich der MFI-Wert weiter auf 479. Fasst man beide Versuche zusammen, konnte eine 50 nM-Lösung von BAY 80-6946 die Phosphorylierung von Akt auf $33 \%$ des Referenzwertes senken. In der Probe, die mit 100 nM-Lösung von BAY 80-6946 behandelt wurde, konnte ein MFI-Wert von 398 ermittelt werden. Somit ließ sich die Phosphorylierung von Akt durch Behandlung mit einer 100 nM-Lösung von BAY 80-6946 auf $27,3 \%$ des Referenzwertes senken.

Die Zelllinie MOLP-8 zeigte der Zelllinie AMO-1 ähnliche Ergebnisse. Im ersten Versuch sank der gemessene MFI-Wert von 1381 (Vehikel behandelte Probe) auf 714. Die Behandlung mit einer 10 nM-Lösung von BAY 80-6946 äußerte sich durchschnittlich in einer Reduktion der Phosphorylierung von Akt auf 59,3\% des Referenzwertes (vehikelbehandelte Proben). Bei der Probe, die mit einer 50 nM-Lösung von BAY 80-6946 behandelt wurde, reduzierte sich der MFI-Wert weiter auf 495. Fasst man beide Versuche zusammen, konnte eine 50 nM-Lösung von BAY 80-6946 die Phosphorylierung von Akt auf 38,2 \% des Referenzwertes senken. Für die Probe, die mit einer 100 nM-Lösung von BAY 80-6946 behandelt wurde, konnte ein MFI-Wert von 370 gemessen werden. Somit ließ sich die 
Phosphorylierung von Akt durch Behandlung mit einer 100 nM-Lösung von BAY 80-6946 auf $38,3 \%$ des Referenzwertes senken.

Die MFI-Werte der Proben, die mit einer 100 nM-Lösung von BAY 80-6946 behandelt wurden, waren vergleichbar mit den Werten, die bei den Versuchen mit unstimulierten Zellen gewonnen wurden. BAY 80-6946 gelang somit eine nahezu komplette Hemmung der stimulierten und konstitutiven Akt Aktivierung.

Die Abbildung 15 zeigt die Ergebnisse der beiden voneinander unabhängig durchgeführten durchflusszytometrischen Versuche noch einmal übersichtlich in Form von Balkendiagrammen unter Angabe der Standardabweichung. Sie wurden mit Hilfe des Programms GraphPad Prism V 5 erstellt.

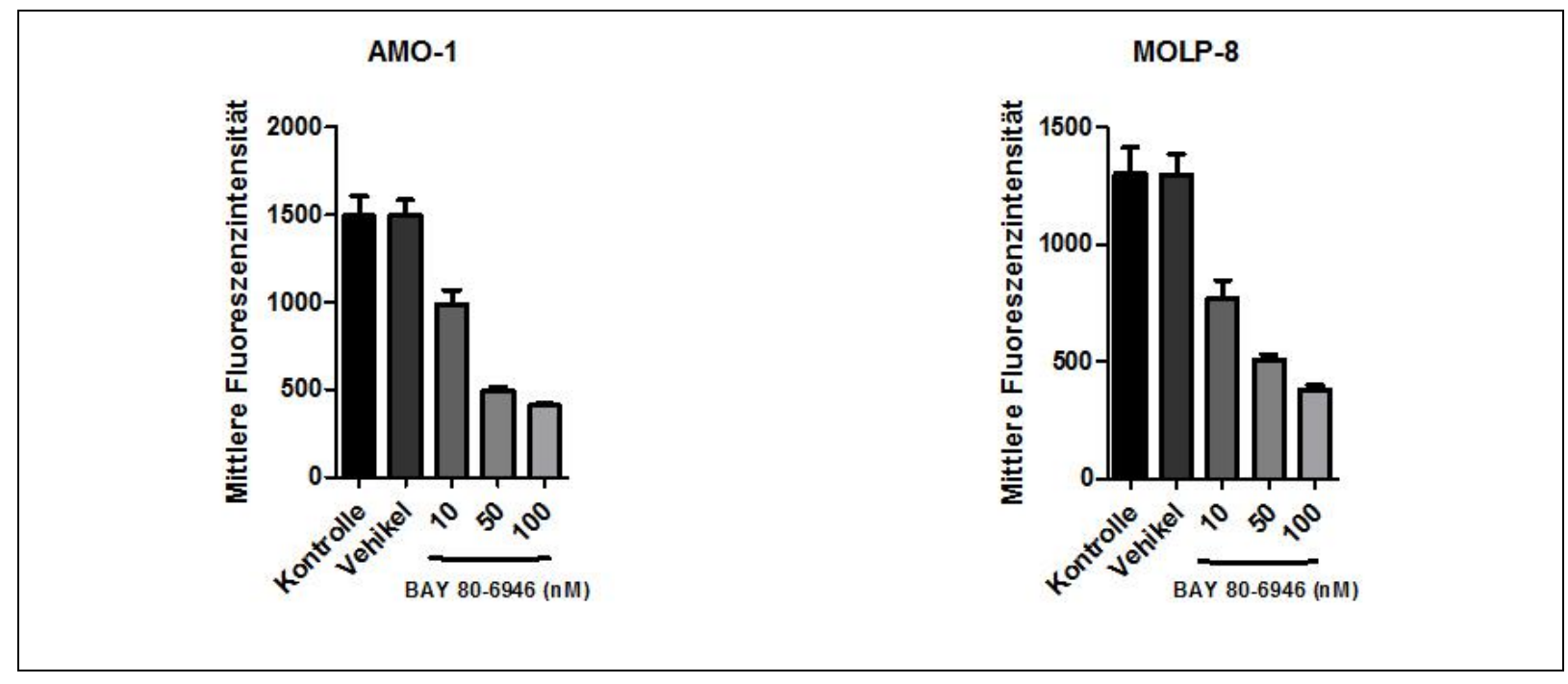

Abbildung 15: Hemmung der IGF-1-stimulierten Zelllinien AMO-1 und MOLP-8 durch BAY 80-6946; Balkendiagramm der durchflusszytometrisch ermittelten MFI-Werte von jeweils zwei unabhängigen Versuchen; Y-Achse: MFI; X-Achse: Probe; Standardabweichung dargestellt. Die Abbildung wurde mit Hilfe von GraphPad Prism V 5 erstellt.

Die beiden dargestellten Balkendiagramme veranschaulichen die deutliche Hemmung der Aktphosphorylierung, die BAY 80-6946 auf die IGF-1-stimulierten Zellen ausübte. Dagegen zeigte die Vehikelzugabe erwartungsgemäß keine signifikante Hemmung.

Um die Ergebnisse der durchflusszytometrischen Analysen zu prüfen, wurden anschließend erneut Zellen mit IGF-1 stimuliert und anschließend mit BAY 80-6946 behandelt sowie SDSLysate gewonnen. Diese wurden anschließend für Western-Blot-Analysen verwendet. Dabei wurde eine Membran für die Phospho-Akt-Färbung verwendet, diese anschließend gestrippt (Verfahren siehe Abschnitt Material und Methoden) und erneut für die Beta-Aktin-Färbung verwendet. Abbildung 16 zeigt exemplarisch das Ergebnis einer Western-Blot-Analyse der 
Zelllinie AMO-1. Insgesamt wurde diese Western-Blot-Analyse dreimal nach dem „,WesternBreeze“-Verfahren durchgeführt.

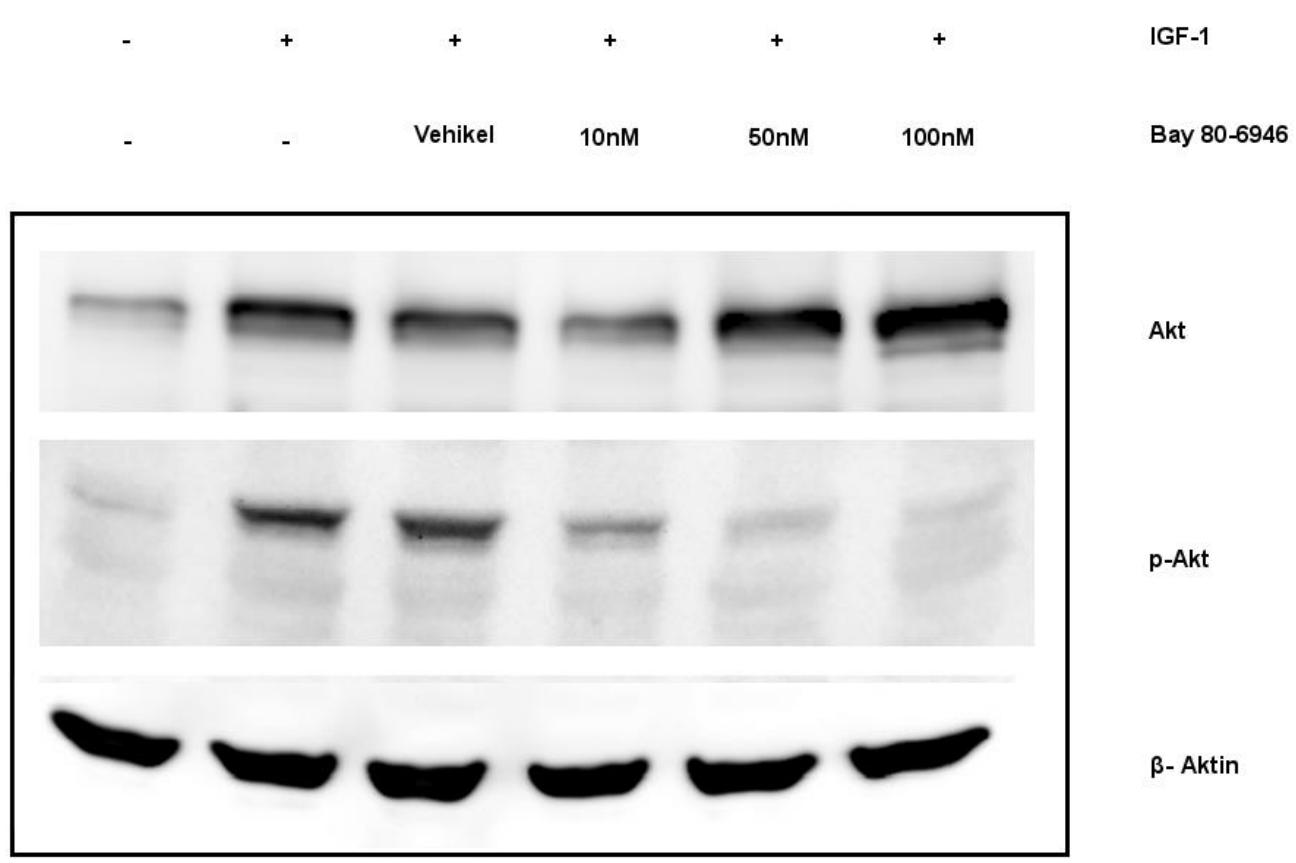

Abbildung 16: Western-Blot-Analyse, Hemmung der IGF-1-stimulierten Aktivierung von Akt (Zelllinie AMO-1); Die Abbildung zeigt drei Antikörperfärbungen: Akt-Antikörper, Phospho-Akt-Antikörper, Beta-Aktin-Antikörper. Reihenfolge der Proben: 1: unstimuliert und unbehandelt, 2: IGF-1 stimuliert und unbehandelt, 3: IGF-1 stimuliert und Vehikel, 4: IGF-1 stimuliert und $10 \mathrm{nM}$ BAY 80-6946, 5: IGF-1 stimuliert und $50 \mathrm{nM}$ BAY 80-6946, 6: IGF-1 stimuliert und $100 \mathrm{nM}$ BAY 80 6946. Die Abbildung wurde mit Image J Software erstellt.

Abgebildet sind die Ergebnisse von drei Antikörperfärbungen. In der obersten Reihe ist die Akt-Antikörper-Färbung, in der Mitte die Phospho-Akt-Antikörper-Färbung und zuunterst die Beta-Aktin-Antikörper-Färbung abgebildet. Bei jeder Färbung wurden jeweils die Proteinproben in folgender Reihenfolge von links nach rechts aufgetragen: 1: unstimuliert; unbehandelt, 2: IGF-1 stimuliert, unbehandelt, 3: IGF-1 stimuliert, Vehikelkontrolle, 4: IGF-1 stimuliert, BAY 80-6946 $10 \mathrm{~nm}$, 5: IGF-1 stimuliert, BAY 80-6946 $50 \mathrm{~nm}, 6$ : IGF-1 stimuliert, BAY 80-6946 $100 \mathrm{~nm}$.

Die Beta-Aktin-Färbung zeigte eine gleichmäßige Proteinverteilung in den Gelkammern. Im Vergleich der Banden 1 und 2 wird die Zunahme der Akt-Konzentration mit der IGF-1Stimulation der Zellen deutlich. Die Bande der mit 10 nM-Lösung von BAY 80-6946behandelten Probe nahm im Vergleich ab. In den höheren BAY 80-6946Konzentrationsbereichen nahm die Bandenstärke dagegen deutlich zu. 
Die Phospho-Akt Bande der unstimulierten Probe 1 ist mit dem Auge schwer zu erkennen. Dagegen ist die Bande der IGF-1-stimulierten und unbehandelten Probe 2 deutlich zu erkennen. Die Vehikel-Zugabe hatte auch im Westen-Blot keinen Einfluss auf die PhosphoAkt-Konzentration der AMO-1 Zellen (Probe 3). Die Behandlung der Zellen mit einer $10 \mathrm{nM}$ Lösung von BAY 80-6946 führte jedoch schon zu einer deutlichen Abnahme der Bandenstärke (Probe 4). Die Banden der Proben, die mit 50 nM oder 100 nM-Lösung von BAY 80-6946 behandelt wurden (Proben 5 und 6), sind schwer mit dem Auge zu diskriminieren. Um diese Unterschiede erkenntlich $\mathrm{zu}$ machen, wurden die Integrationsdichtewerte der Western-Blot-Analyse-Banden mit Hilfe der Image J Software ermittelt und der Quotient zum Integrationsdichtewert der jeweiligen B-Aktin-Kontrolle gebildet. Die Ergebnisse dieser densitometrischen Analyse sind als Balkendiagramm in Abbildung 17 dargestellt.

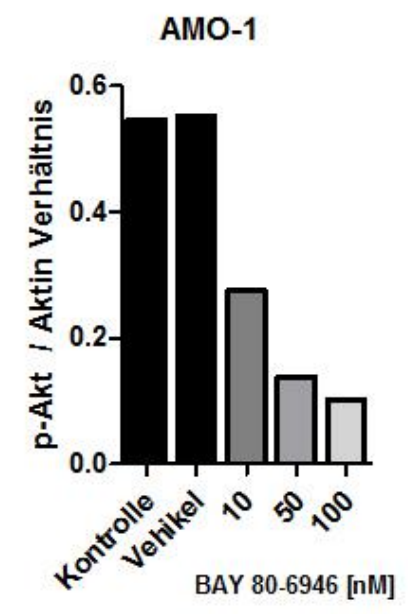

Abbildung 17: Densiometrische Auswertung der Western-Blot-Analyse aus Abbildung 16, Zelllinie AMO-1, Y-Achse: Quotient der Integrationsdichtewerte p-Akt-Proteinbande zu B-Aktin-Proteinbande, X-Achse: Probe. Die Abbildung wurde mit Hilfe von GraphPad Prism V 5 erstellt.

Das Balkendiagramm zeigt deutlich die konzentrationsabhängige Hemmung der AktPhosphorylierung von Akt, die auch schon mit Hilfe der Durchflusszytometrie veranschaulicht werden konnte. Allein die Behandlung der AMO-1 Zellen mit einer $10 \mathrm{nM}$ Lösung von BAY 80-6946 halbierte die Akt-Phosphorylierung nahezu. Die Behandlungen mit einer $50 \mathrm{nM}$ und $100 \mathrm{nM}$-Lösung hemmten die Aktivierung von Akt weiterhin. Die Vehikelzugabe zeigte erwartungsgemäß keinen Einfluss auf den Phospho-Akt-Status der Zellen. 
Um diese Ergebnisse zu überprüfen wurde der Versuch mit einer weiteren Zelllinie entsprechend ebenfalls dreimal durchgeführt. Zellen der Zelllinie MOLP-8 wurden mit IGF-1 stimuliert und mit BAY 80-6946 behandelt. Die anschließend gewonnenen SDS-Lysate wurden ebenfalls für Western-Blot-Analysen nach dem „WesternBreeze“-Verfahren verwendet. Dabei wurde ebenfalls eine Membran für die Phospho-Akt-Färbung, diese anschließend gestrippt (Verfahren siehe Abschnitt Material und Methoden) und erneut für die Beta-Aktin-Färbung verwendet. Die Abbildung 18 zeigt das Ergebnis einer Western-BlotAnalyse der Zelllinie MOLP-8.

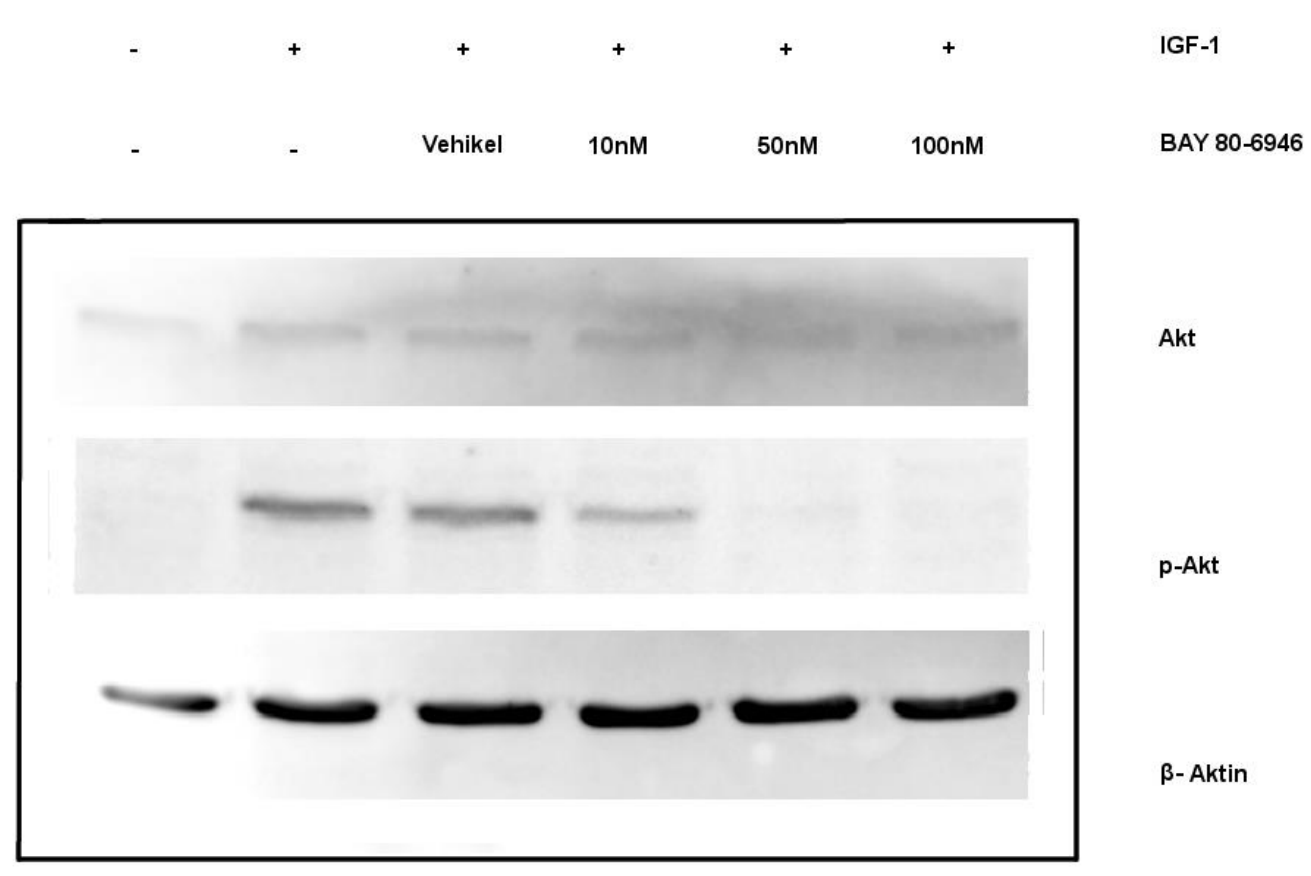

Abbildung 18: Western-Blot-Analyse, Hemmung der IGF-1-stimulierten Aktivierung von Akt (Zellinie MOLP-8) Die Abbildung wurde mit Image J Software erstellt.

Abgebildet sind ebenfalls die Ergebnisse der drei Antikörperfärbungen. In der obersten Reihe ist die Akt-Antikörper-Färbung, in der Mitte die Phospho-Akt-Antikörper-Färbung und zuunterst die Beta-Aktin-Antikörper-Färbung abgebildet. Beim Auftragen der Proben wurde auf die gleiche Reihenfolge wie bei den vorherigen Western-Blot-Analysen der Zellreihe AMO-1 geachtet.

Die beta-Aktin-Färbung zeigt eine gleichmäßige Proteinverteilung in den Gelkammern. Soweit die mit dem Akt-Antikörper gefärbten Banden durch die Verunreinigungen noch zu interpretieren sind, zeigt sich keine eindeutige Zunahme oder Abnahme der Bandenintensität durch die Behandlung mit BAY 80-6946. Die Phospho-Akt-Bande der unstimulierten Probe 1 
ist wie bei der Zelllinie AMO-1 mit dem Auge schwer zu erkennen. Dagegen ist die Bande der IGF-1-stimulierten und unbehandelten Probe 2 deutlich zu erkennen. Die Vehikel-Zugabe hat auch im Westen-Blot keinen Einfluss auf die Phospho-Akt-Konzentration der AMO-1 Zellen (Probe 3). Die Behandlung der Zellen mit einer 10 nM-Lösung von BAY 80-6946 führte jedoch schon zu einer deutlichen Abnahme der Bandenstärke (Probe 4). Die Banden der Proben, die mit 50 nM oder 100 nM-Lösung von BAY 80-6946 behandelt wurden (Proben 5 und 6), sind wie bei der Zelllinie AMO-1 schwer mit dem Auge zu diskriminieren. Um diese Unterschiede erkenntlich zu machen, wurden die Integrationsdichtewerte der WesternBlot-Analyse-Banden mit Hilfe der Image J Software ermittelt und der Quotient zum Integrationsdichtewert der jeweiligen Beta-Aktin-Kontrolle gebildet. Die Ergebnisse dieser densiometrischen Analyse sind als Balkendiagramm in Abbildung 19 dargestellt.

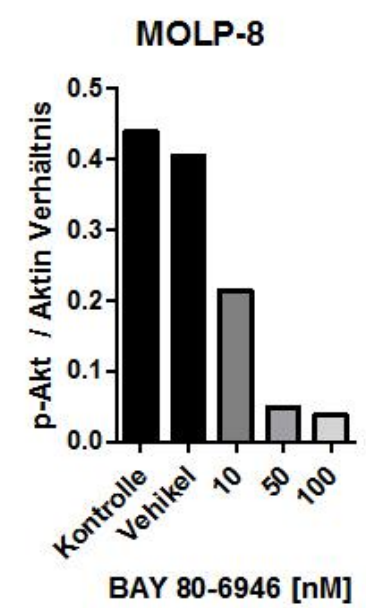

Abbildung 19: Densiometrische Auswertung der Western-Blot-Analyse aus Abbildung 18, Zelllinie MOLP-8, YAchse: Quotient der Integrationsdichtewerte p-Akt-Proteinbande zu ß-Aktin-Proteinbande, X-Achse: Probe. Die Abbildung wurde mit Hilfe von GraphPad Prism V 5 erstellt.

Das Balkendiagramm zeigt eine deutliche konzentrationsabhängige Hemmung der Phosphorylierung von Akt entsprechend den Ergebnissen der Zelllinie AMO-1. Auch bei der Zelllinie MOLP-8 halbierte die Behandlung der Zellen mit einer 10 nM-Lösung von BAY 806946 die Akt-Phosphorylierung nahezu. Im Unterschied zur Zelllinie AMO-1 hatte die Behandlung der Zellen mit einer 50 nM-Lösung von BAY 80-6946 einen darüber hinaus gehenden Effekt auf den Phospho-Akt-Status der Zellen. Der Unterschied zwischen einer 50 nM-Lösung und einer 100 nM-Lösung war allerdings auch hier nur minimal. Die Vehikelzugabe zeigte erwartungsgemäß keinen Einfluss auf den Phospho-Akt-Status der Zellen. 
Zusammenfassend haben diese Versuche gezeigt, dass BAY 80-6946 nicht nur die konstitutive Aktivierung von Akt zu vermindern vermag, sondern ebenso die IGF-1stimulierte Aktivierung. Unter Einfluss der Hemmung von BAY 80-6946 zeigten die durch IGF-1-stimulierten Zellen ebenso eine deutliche dosisabhängige Inhibition der AktPhosphorylierung.

\subsection{Die Hemmung der PI3K erhöht die Apoptoseraten in Myelom-Zellen}

Nachdem die Untersuchung der Wirkung des neuen PI3-Kinase-Inhibitors BAY 80-6946 auf humane Multiple Myelom-Zellen eine viel versprechende Hemmung der Akt-Aktivierung gezeigt hatte, stellte sich die Frage, inwieweit diese mit einem funktionellen Einfluss auf Apoptose und Proliferation der Zellen einhergeht. Die Phosphorylierung von Akt führt zur Aktivierung zahlreicher nachgeschalteter Signalkaskaden mit apoptosehemmendem Effekt (Franke et al. 2003). Dabei ist der PI3-Kinase-Akt-Signalweg sowohl direkt über die Phosphorylierung des pro-apoptotischen Proteins BAD (Datta et al. 1997) als auch indirekt über seinen Einfluss auf die beiden zentralen Regulatoren des Zelltodes $N F-\kappa B$ und p53 (Scheid und Woodgett 2001; Downward 2004) an der Apoptoseregulation beteiligt.

Um den Einfluss des PI3-Kinase-Inhibitors BAY 80-6946 auf die Apoptoseraten der MyelomZellen zu untersuchen, wurde ein ELISA (Enzyme Linked Immunosorbent Assay), das ein Nachweisverfahren mit enzymgekoppelter Immunadsorptions-Analyse darstellt, durchgeführt. Hierfür wurde der „Cell Death Detection Elisa“ der Firma Roche verwendet. Dieses Verfahren wurde ausführlich im Abschnitt Material und Methoden erläutert. Der Versuch wurde mit allen vier Zelllinien dem Protokoll entsprechend durchgeführt und einmal wiederholt. Jeder Versuchsansatz wurde im Triplett angelegt. Zusätzlich wurden jeweils eine Positiv- und eine Negativkontrolle (im Assay enthalten) verwendet.

Nach der photometrischen Messung der Extinktion bei einer Wellenlänge von $405 \mathrm{~nm}$, wurde der Versuch mit Hilfe des Programms GraphPad Prism V 5 ausgewertet. Der photometrisch gemessene Extinktionswert ist linear abhängig von der jeweiligen NukleosomenKonzentration in der Zellprobe. Diese stellt wiederum das Äquivalent der Apoptose dar. Aus den gemessenen Extinktionswerten eines Proben-Tripletts wurde jeweils das arithmetische Mittel gebildet und der Betrag des Extinktionswertes der Negativkontrolle abgezogen. Die Apoptoseraten wurden im Verhältnis behandelte Probe zu Vehikelkontrolle bestimmt. Signifikante Unterschiede zwischen den verschiedenen Medikamentenkonzentrationen 
wurden mit einer einfachen Varianzanalyse (ANOVA), gefolgt von einem Bonferroni-posthoc-Test mit einem Konfidenzintervall von $95 \%$ ermittelt.

Die Abbildung 20 zeigt die Ergebnisse aller vier Zelllinien eines Versuches in Form von Balkendiagrammen.

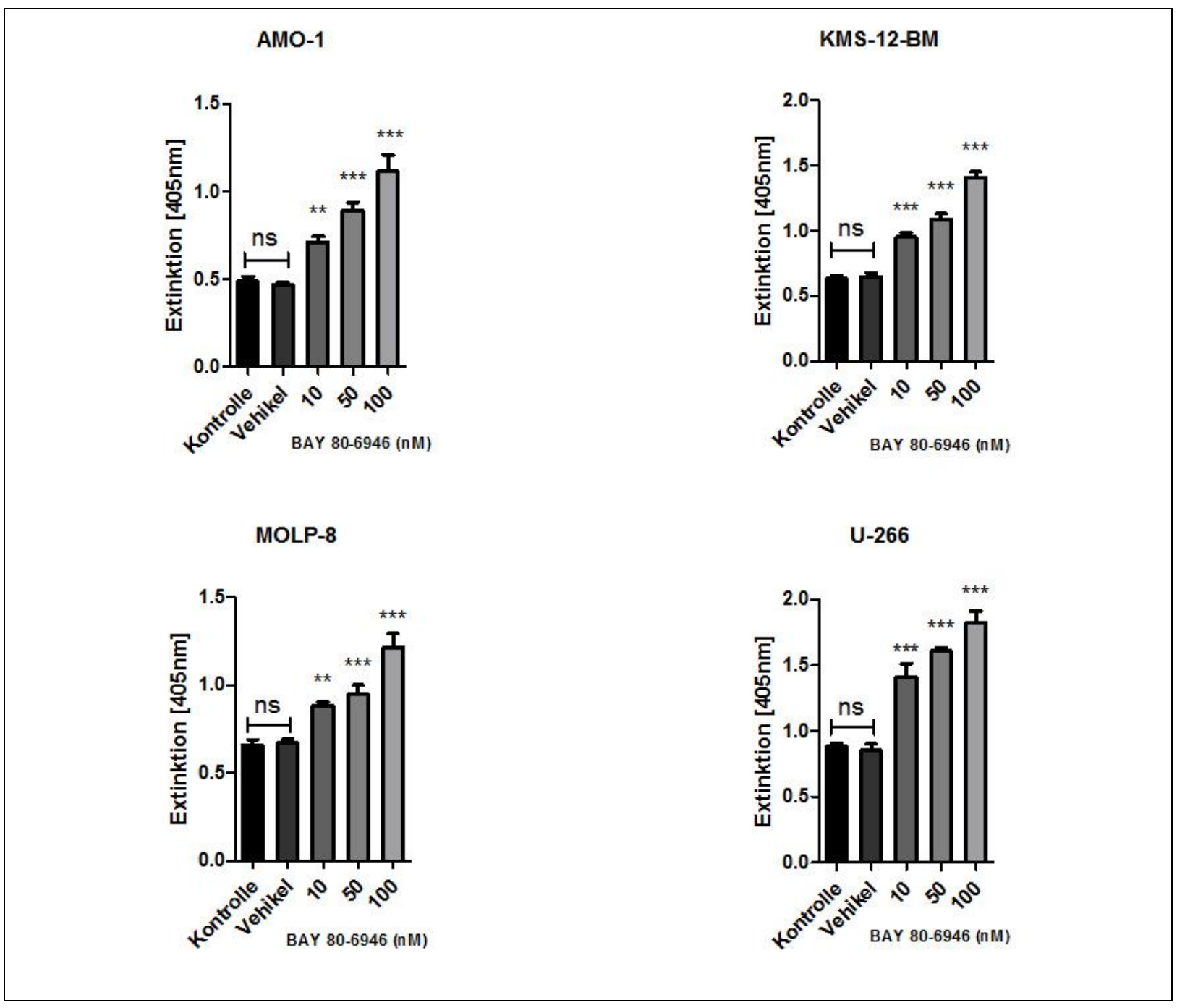

Abbildung 20: Balkendiagramm, Auswertung des Apoptose-Assays „Cell Death Detection Elisa“, Y-Achse; Extinktion bei $405 \mathrm{~nm}$, X-Achse: Probe. Die Signifikanzen sind durch Sternchen repräsentiert, wobei ein Sternchen $(*)$ einem $\mathrm{p}<0.05$ entspricht, zwei Sternchen (**) einem $\mathrm{p}<0.01$ und drei Sternchen $* * *$ einem $\mathrm{p}<0.001$ entsprechen. Die Abbildung wurde mit Hilfe von GraphPad Prism V 5 erstellt.

Die Ergebnisse aller vier Zelllinien zeigten eine deutliche konzentrationsabhängige Erhöhung der Apoptoseraten unter Hemmung mit BAY 80-6946. Dagegen ließ sich in der Probe mit Vehikelzugabe erwartungsgemäß keine signifikante Veränderung der Apoptoseraten feststellen. In Tabelle $11 \mathrm{im}$ Anhang sind alle Ergebnisse der Apoptose-Assay-Untersuchung aufgeführt. Im Folgenden sollen exemplarisch die Ergebnisse eines Versuches der Zelllinie AMO-1 erläutert werden. In der 10 nM BAY 80-6946-Lösung erhöhte sich der gemessene 
Extinktionswert von 0,402 auf 0,646. Dies entspricht einer Erhöhung der Apoptoserate auf das 1.61-fache des Ausgangswertes. In der 50 nM BAY 80-6946-Lösung zeigte sich eine Erhöhung des Extinktionswertes auf einen Wert von 0,827, was einer Apoptosenratensteigerung auf das 2,06-fache des Ausgangswertes entspricht. Nach Behandlung mit einer 100 nM BAY 80-6946-Lösung zeigte sich wiederum eine Steigerung des Extinktionswertes auf einen Wert von 1.049, was eine Erhöhung der Apoptoserate auf das 2,61-fache des Ausgangswertes darstellt. Der zweite analog durchgeführte Versuch zeigte vergleichbare Ergebnisse. Auch bei den anderen Zelllinien waren ähnliche konzentrationsabhängige Steigerungen der Apoptoseraten zu beobachten. Den höchsten apoptosesteigernden Effekt erreichte BAY 80-6946 bei der Zelllinie U-266. Schon in einer 10 nM-Lösung stieg die Apoptoserate im ersten Versuch auf mehr als das 1,5 (1,696) fache an. In der 100 nM-Lösung war diese sogar mehr als verdreifacht $(3,12)$. Bei den anderen Zelllinien erreichte eine 100 nM-Lösung von BAY 80-6946 durchschnittlich eine Verdopplung der Apoptoseraten (AMO-1: 2,61 und 1,93; KMS-12-BM: 1,99 und 2,22: MOLP-8: 2,39 und 1,84).

\subsection{BAY 80-6946 hemmt die Proliferation von Myelom-Zellen}

Die Ergebnisse der Apoptose-Untersuchungen konnten einen funktionellen Einfluss des PI3Kinase-Inhibitors BAY 80-6946 auf die Apoptoseraten von humanen Multiplen MyelomZellen zeigen. Es ist bekannt, dass Akt über die apoptosehemmende Wirkung hinaus, einen proliferations- und wachstumsfördernden Effekt auf Multiple Myelom-Zellen ausübt (Diehl et al. 1998). Über seinen indirekten Einfluss auf Cyclin D1 und folglich auf dessen beschleunigende Funktion in der G1-/S-Phasen-Progression, ist die Proteinkinase Akt an der Regulation des Zellzyklus beteiligt. Dieser Einfluss begründet sich auf folgendem Mechanismus: Durch Phosphorylierung hemmt Akt die Glycogen-Synthase-Kinase-3 (GSK3), die selber die Expression von Cyclin D1 senkt. Folglich führt die Aktivierung von Akt indirekt zu einer Beschleunigung der Zellzyklus-Progression (Diehl et al. 1998).

Zusätzlich vermag Akt die Serin-Threonin-Kinase mTOR zu aktivieren. Diese ist mit verantwortlich für die nährstoffabhängige Regulation der Proteinsynthese. Somit vermag Akt hier einen indirekt verstärkenden Einfluss auf die Translation von Proteinen wahrzunehmen (Pene et al. 2002; Younes et al. 2007). 
In der vorliegenden Arbeit wurde die Wirkung von BAY 80-6946 auf die Proliferation der Multiplen Myelom-Zellen mit Hilfe einer kolorimetrischen Proliferations-Assay-Analyse untersucht.

Die kolorimetrische Proliferations-Assay-Analyse wurde mit Hilfe des „,Cell Titer 96 Nonradioactive Cell Proliferation Assay “ der Firma Promega durchgeführt. Dieser beruht auf dem Prinzip eines MTT-Assays. Die Funktion und Durchführung sind ausführlich im Abschnitt Material und Methoden erläutert.

Die Abbildung 21 zeigt die statistische Auswertung der durchgeführten Proliferations-AssayAnalysen in Form von Balkendiagrammen. Die Standardabweichungen sowie die Signifikanzen sind ebenfalls in den Diagrammen angegeben. Die Auswertung ergab fast ausschließlich hoch signifikante Ergebnisse mit Ausnahme der Ergebnisse der Zelllinie U266. Die Zugabe der Vehikellösung zeigte keine signifikante Beeinflussung der Proliferation.

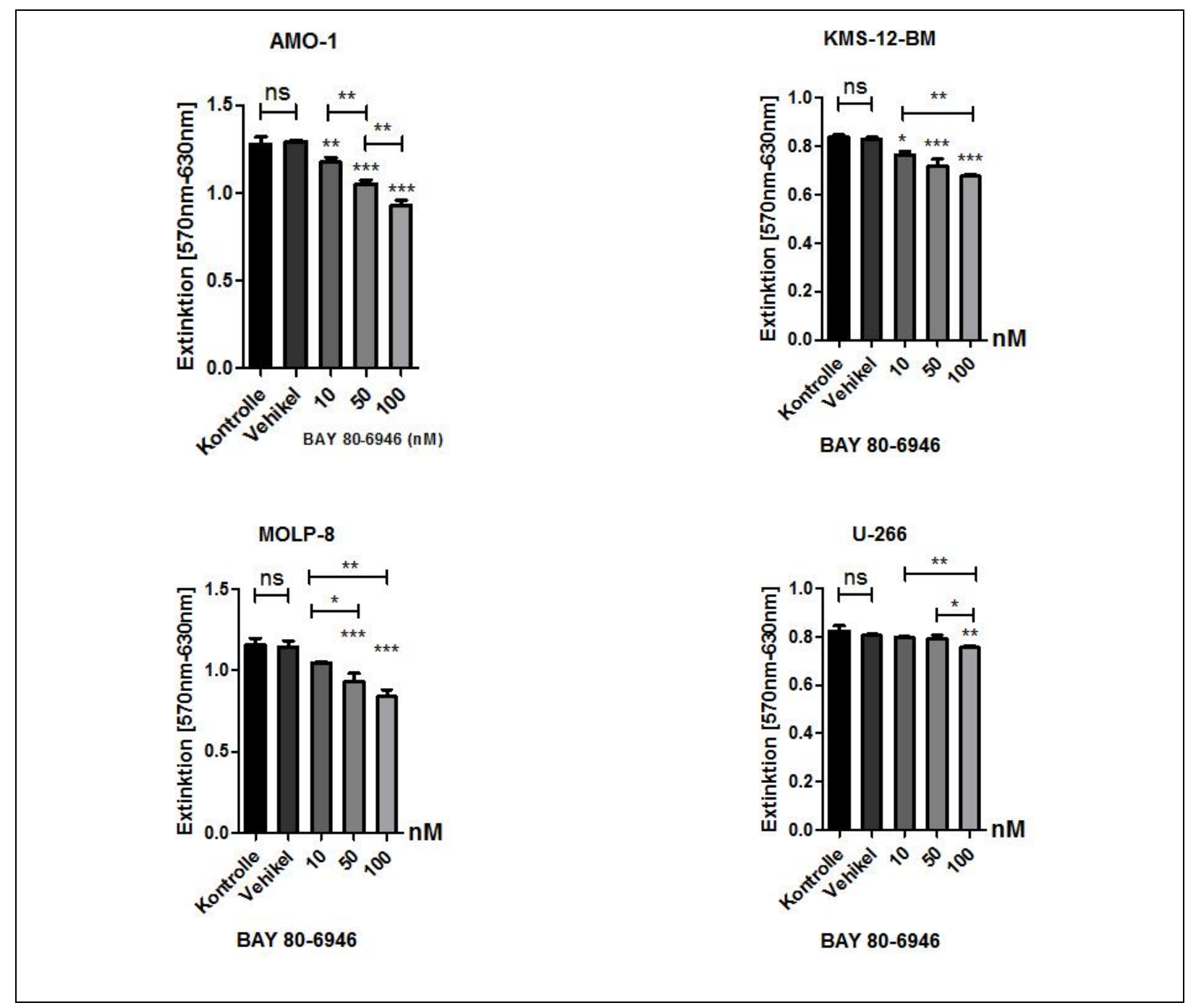


Abbildung 21: Proliferations-Assay-Analyse der Zelllinien AMO-1, KMS-12-BM, MOLP-8, U-266; Jeder Balken stellt das arithmetische Mittel dreier unabhängiger Versuche mit jeweils einem Triplett an Proben dar. Die Standardabweichung ist angegeben. Signifikante Unterschiede wurden mit einer einfachen Varianzanalyse (ANOVA) gefolgt von einem Bonferronipost-hoc-Test mit einem Konfidenzintervall von 95\% ermittelt. Die Signifikanzen sind durch Sternchen repräsentiert, wobei ein Sternchen $(*)$ einem p $<0,05$ entspricht, zwei Sternchen $(* *)$ einem $p<0,01$ und drei Sternchen $(* * *)$ einem $p<0,001$ entsprechen. Die Abbildung wurde mit Hilfe von GraphPad Prism V 5 erstellt.

Die Ergebnisse zeigen eine moderate konzentrationsabhängige Hemmung der Proliferation durch BAY 80-6946. Indessen blieben die Proliferationsraten in den Proben mit Vehikelzugabe ebenso unverändert wie in den vorangegangenen Versuchen.

In Tabelle 12 im Anhang sind alle Ergebnisse der Proliferations-Assay-Analysen übersichtlich zusammengestellt. Im Folgenden sollen exemplarisch die Ergebnisse eines Versuches der Zelllinie AMO-1 erläutert werden. In der 10 nM BAY 80-6946-Lösung sank der gemessene Extinktionswert von 1,294 auf 1,174. Dies entspricht einer Reduktion der Proliferationsrate auf ein 0,907-faches des Ausgangswertes. In der 50 nM BAY 80-6946Lösung zeigte sich eine Senkung des Extinktionswertes auf einen Wert von 1,051, was eine Verminderung der Proliferationsrate auf das 0,812-fache des Ausgangswertes bedeutet. In der 100 nM BAY 80-6946-Lösung zeigte sich wiederum eine Minderung des Extinktionswertes auf einen Wert von 0,926, was eine Proliferationsratensenkung auf das 0,716-fache des Ausgangswertes darstellt. Der zweite analog durchgeführte Versuch zeigte vergleichbare Ergebnisse. Auch bei den anderen Zelllinien zeigten sich sehr ähnliche konzentrationsabhängige Senkungen der Proliferationsraten. Eine 100 nM-Lösung von BAY 80-6946 erreichte durchschnittlich eine moderate Reduktion der Proliferationsraten auf 7080\% des Ausgangswertes (AMO-1: 0,716, 0,74 und 0,727; KMS-12-BM: 0,835, 0,815 und 0,864; MOLP-8: 0,779, 0,732 und 0,801). Bei der Zelllinie U-266 jedoch, die noch den größten Anstieg der Apoptoseraten gezeigt hatte, konnte BAY 80-6946 im Gegenzug nur einen geringen proliferationshemmenden Effekt erreichen (U-266: 0,886, 0,827, 0,938).

\subsection{BAY 80-6946 beeinflusst den Zellzyklus von Myelom-Zellen}

Der Zellzyklus bezeichnet den periodischen Ablauf zwischen zwei Zellteilungen. Grundsätzlich steht die Progression einer Zelle im Zellzyklus unter strenger Kontrolle, insbesondere durch Cycline und Cyclin-abhängige Kinasen (CDKs) (Nigg 1995). Zu diesen Regulationsmechanismen gehören Prozesse wie die Entdeckung und Reparatur von DNS- 
Schäden und die Verhinderung unkontrollierter Zellteilungen. In Tumorzellen sind viele dieser Regulationsmechanismen häufig gestört (Knudson 2001). Ziel der Zellzyklusuntersuchung war es, zu untersuchen, inwiefern BAY 80-6946 den Zellzyklus der Multiplen Myelom-Zellen beeinflussen kann.

Die vorangegangenen Untersuchungen hatten gezeigt, dass der PI3-Kinase-Inhibitor BAY 806946 einen proliferationshemmenden Einfluss auf humane Multiple Myelom-Zellen hat. Vor dem Hintergrund, dass die PI3-Kinase unter anderem über ihren indirekten Einfluss auf den Zellzyklus die Proliferation der Zellen zu stimulieren vermag, wurde anschließend die Auswirkungen der Behandlung mit BAY 80-6946 auf den Zellzyklus der Myelom-Zelllinien untersucht. Die PI3-Kinase vermag den Abbau des progressionsfördernden Cyclin D1 zu verhindern und führt somit zu einem beschleunigten Übergang von der G0/G1 in die S-Phase (Cross et al. 1995; Diehl et al. 1998). Somit würde man bei Hemmung der PI3-Kinase eine Erhöhung der Zellzahl in der G0/G1-Phase erwarten. Diese These sollte mit Hilfe von durchflusszytometrischen Analysen bestätigt werden.

Es wurden Zellzyklusanalysen der Zelllinie AMO-1 und MOLP-8 durchgeführt. Die Analysen der mit BAY 80-6946-behandelten Zellen wurden für jeweils drei verschiedene Behandlungszeiträume durchgeführt: 4, 12 und 24 Stunden. Für diese Behandlungszeiträume wurden jeweils drei verschiedene Konzentrationen von BAY 80-6946 (10 nM, 50 nM, 100 $\mathrm{nM}$ ), eine unbehandelte und eine Vehikel-Kontrolle angesetzt. Zusätzlich wurde eine Analyse von unbehandelten Zellen gemacht. Nach der Behandlung wurden die Zellproben mit Propidiumiodid gefärbt und durchflusszytometrisch analysiert.

Tabelle 13 im Anhang zeigt exemplarisch die Ergebnisse einer Zellzyklusanalyse der Zelllinie MOLP-8. Dabei bezieht sich der angegebene prozentuale Anteil der Zellen in der jeweiligen Zellzyklusphase auf die Gesamtzahl der Zellen der jeweiligen Probe. In den Zellproben, die 4 Stunden oder 12 Stunden mit BAY 80-6946 behandelt wurden, zeigten sich keine signifikanten Änderungen der Verteilung der Zellen auf die Zellzyklusphasen. Es war lediglich folgende Tendenz zu erkennen: Mit steigender Konzentration von BAY 80-6946 stieg der prozentuale Anteil der Zellen in der G0/1-Phase (41,3\% bzw. 47,4\% unbehandelt zu 49,8 \% bzw. 55 \% bei 100 nM BAY 80-6946-Lösung). Dagegen sank der Anteil der Zellen in der G2/M-Phase ab (17,2\% bzw. $22 \%$ unbehandelt zu 6,1 bzw. 15,7 \% bei 100 nM BAY 80-6946-Lösung). Der prozentuale Anteil der Zellen in der S-Phase stieg nach 4h leicht an (41,5 \% unbehandelt zu 44,1 \% bei 100 nM BAY 80-6946-Lösung). Nach 12 h Behandlung dagegen sank der Anteil wiederum ab (30,5\% unbehandelt zu 29,3\% bei 100 nM BAY 80- 
6946-Lösung). Ebenso war zu erkennen, dass mit steigender Behandlungszeit auch in der unbehandelten Probe der prozentuale Anteil der Zellen, die sich in der G0/1-Phase befinden, leicht anstieg (0h: $45 \%$; 4h: 41,3; 12h: 47,4\%; 24h: 52,7\%).

Nach der 24-stündigen Behandlungen hingegen war eine deutliche prozentuale Zunahme der Zellen in der G0/1-Phase zu verzeichnen (52,7 \% unbehandelt zu 68,0 \% bei $100 \mathrm{nM}$ BAY 80-6946-Lösung). Entsprechend fiel der Anteil der Zellen in der S-Phase (33,8 \% unbehandelt zu 20,0 \% bei 100 nM BAY 80-6946-Lösung) deutlich ab. Die Zellzahl in der G2/M-Phase blieb dabei nahezu unverändert (13,5\% unbehandelt zu $12.0 \%$ bei 100 nM BAY 80-6946Lösung).

Die weiteren durchflusszytometrischen Analysen der Zelllinie MOLP-8 sowie die entsprechend durchgeführten Analysen der Zelllinie AMO-1 zeigten vergleichbare Ergebnisse. Abbildung 22 und 23 veranschaulichen die Ergebnisse in ihrer Gesamtheit. Dargestellt sind jeweils die Ergebnisse eines Versuchs nach 24-stündiger Behandlung mit BAY 80-6946. Dabei ist auf der X-Achse die Konzentration von BAY 80-6946 aufgetragen. Die Y-Achse gibt die prozentuale Anzahl der Zellen an, die sich in der G0/G1-Phase befinden. Die sekundäre Y-Achse stellt den Prozentsatz der Zellen in der S-Phase dar.

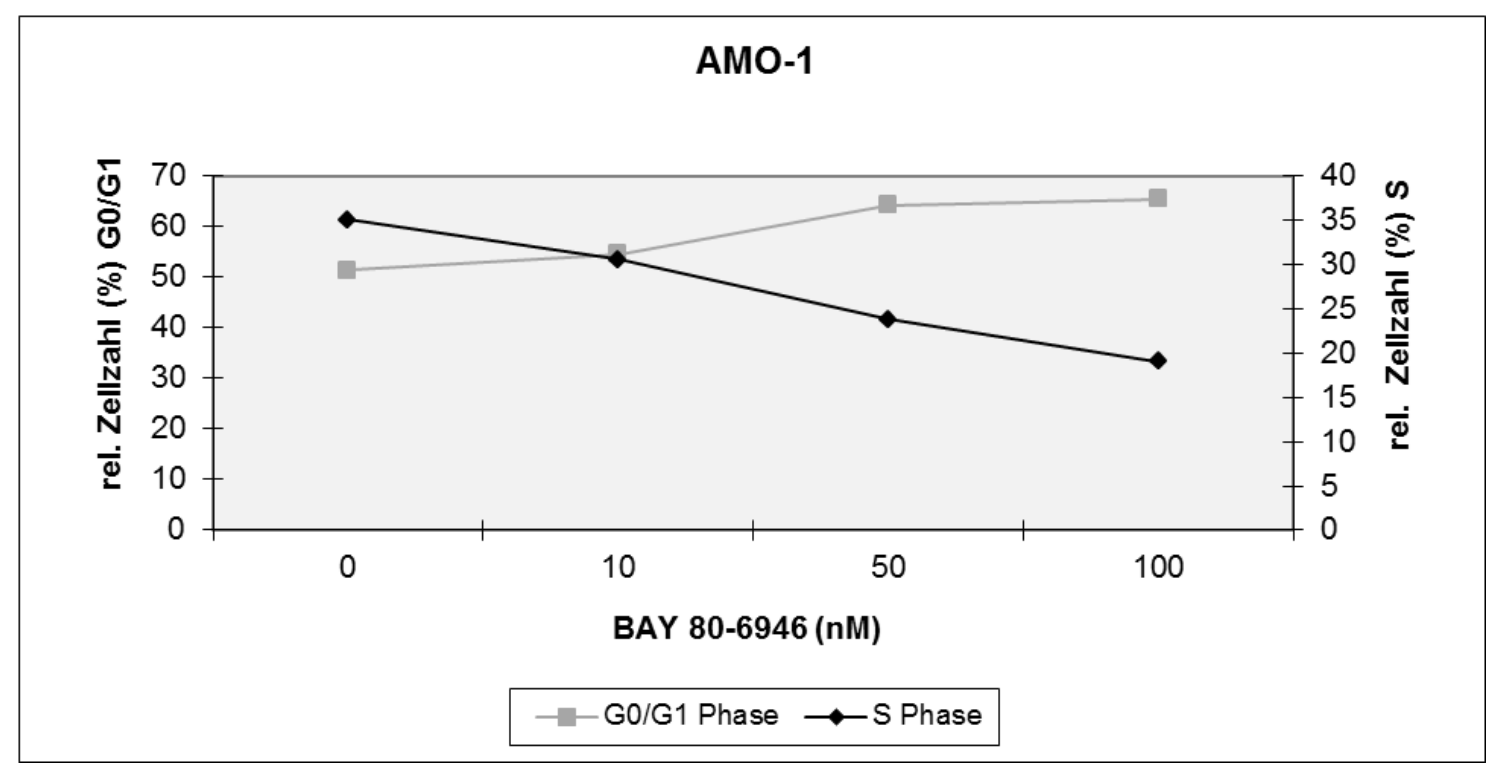

Abbildung 22: Zellzyklusanalyse der Zelllinie AMO-1 nach 24 h Behandlung mit BAY 80-6946. Die Abbildung wurde mit Microsoft Excel® erstellt. 


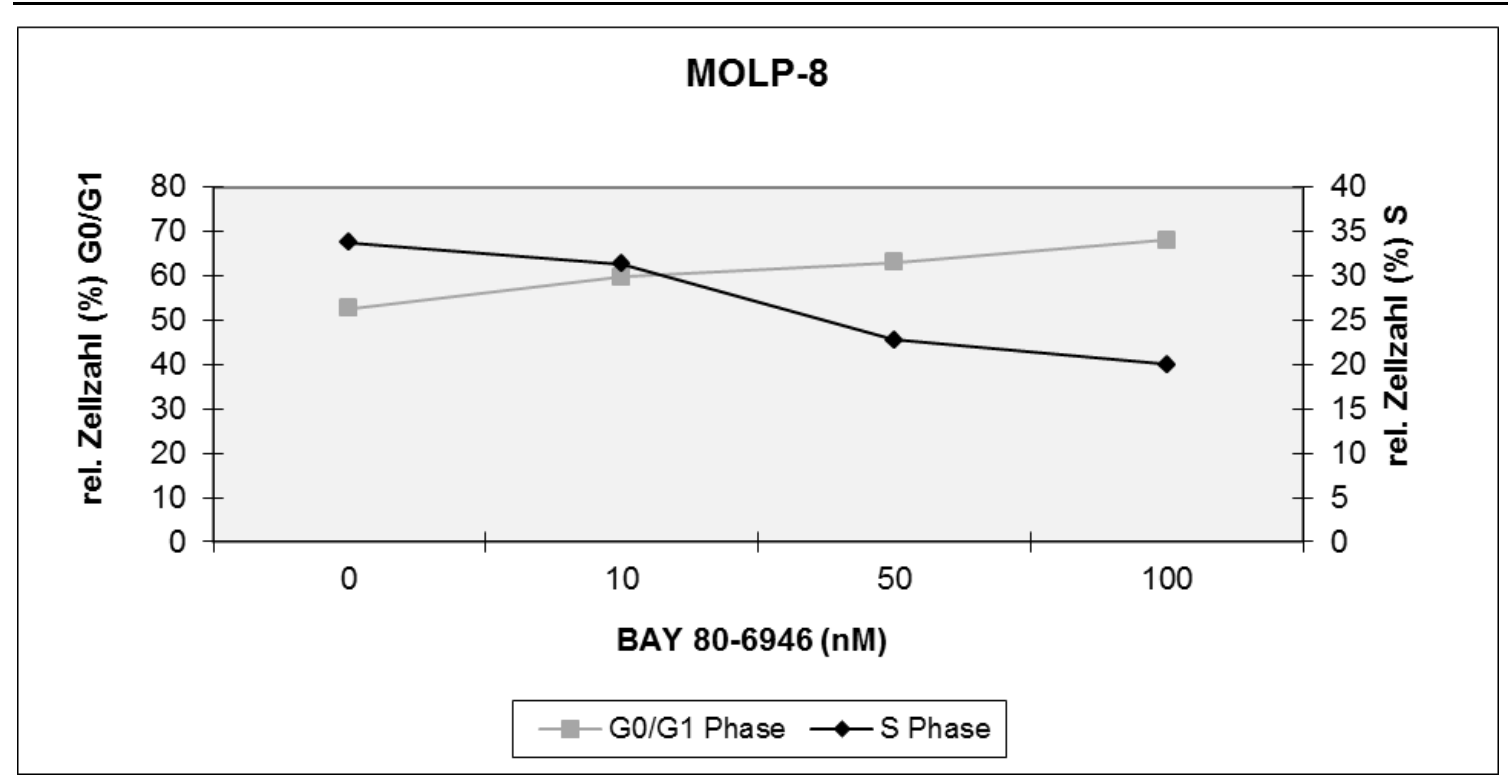

Abbildung 23: Zellzyklusanalyse der Zelllinie MOLP-8 nach 24 h Behandlung mit BAY 80-6946. Die Abbildung wurde mit Microsoft Excel® erstellt.

Die Abbildungen verdeutlichen den Anstieg der prozentualen Zellzahl in der G0/1-Phase unter steigender Konzentration von BAY 80-6946. Damit einher geht der entsprechende Abfall des Prozentsatzes an Zellen, die sich in der S-Phase befinden.

\subsection{Mausmodell}

Um die Multiplen Myelom-Zellen, die sich nach Beendigung des Versuches noch im Peritoneum der Mäuse befanden, zählen zu können, musste ein Verfahren entwickelt werden diese zweifelsfrei identifizieren zu können. Zu diesem Zweck wurde eine Färbung mit zwei fluoreszenzgekoppelten Antikörpern, die jeweils gegen spezifische Oberflächenantigene der Multiplen Myelom-Zellen gerichtet sind, durchgeführt. Die Antikörper waren gegen HLA$A B C$ und gegen CD138 gerichtet. $H L A-A B C$ stellt ein Oberflächenantigen dar, das sich auf allen kernhaltigen humanen Zellen befindet (Choo 2007). Das humane Oberflächenantigen CD138 ist ein etablierter Zellmarker für Plasmazellen (Bataille et al. 2006). Dagegen besitzen die murinen Zellen keine humanen Zelloberflächenmarker.

In einem Vorversuch wurde die Bindefähigkeit dieser beiden Antikörper an die Zellen der Zelllinien AMO-1 und MOLP-8 durchflusszytometrisch überprüft. Die Abbildung 24 zeigt exemplarisch die Ergebnisse des Versuches mit dem gegen das Zelloberflächenantigen HLA$A B C$ gerichteten Antikörper in Form eines Histogramms. 


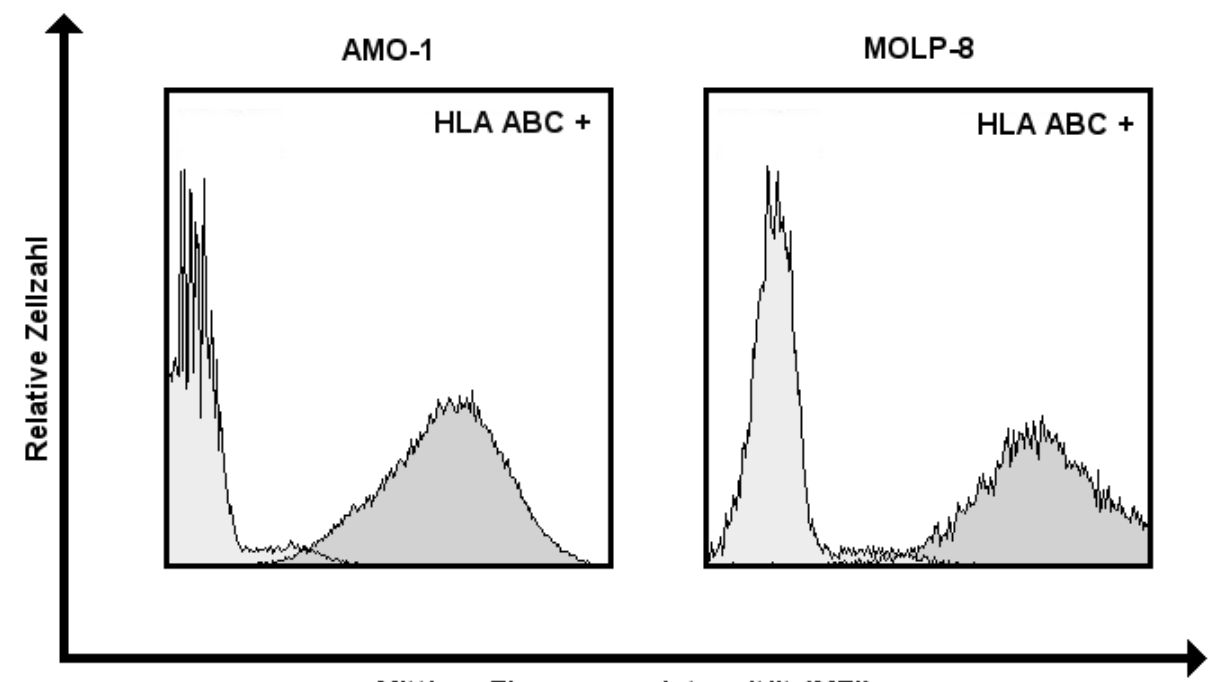

Mittlere Fluoreszenzintensität (MFI)

Abbildung 24: Die Multiplen Myelom-Zelllinien AMO-1 und MOLP-8 exprimieren das Zelloberflächenprotein HLAABC. Histogramm der durchflusszytometrischen Analyse. Die Zellen wurden jeweils in $100 \mu$ l PBS überführt, für eine Stunde bei $4{ }^{\circ} \mathrm{C}$ mit $10 \mu \mathrm{L}$ HLA-ABC- Antikörper pro Test inkubiert, gewaschen, zentrifugiert, in $500 \mu$ l PBS aufgenommen und anschließend durchflusszytometrisch analysiert. Als Negativkontrolle wurde jeweils eine Probe mit dem passenden Isotyp gefärbt. Die linke Kurve zeigt dabei jeweils die Isotypenkontrolle; die rechte Kurve die HLA-ABC-AntikörperFärbung. Abbildungen aus der Software (BD FACS Diva) des verwendeten Durchflusszytometers FACS Canto II entnommen.

In den beiden Histogrammen sind jeweils die Isotyp-Kontrolle und die mit HLA-ABCAntikörper gefärbte Probe in einer Abbildung übereinandergelegt worden. Dabei zeigen die mit HLA-ABC-Antikörper gefärbten Proben (jeweils die rechte Kurve) beider Zelllinien eine hohe Mittlere Fluoreszenzintensität (MFI). Somit konnte gezeigt werden, dass die beiden Multiple Myelom- Zelllinien AMO-1 und MOLP-8 HLA-ABC als Oberflächenantigen tragen. Der Versuch wurde entsprechend mit dem gegen das Zelloberflächenantigen CD138 gerichteten Antikörper durchgeführt. Auch hier zeigte sich eine ausreichende Expression (ohne Abbildung).

\subsubsection{Peritoneallavage}

Der Tierversuch wurde wie im Abschnitt „Material und Methoden“ erläutert durchgeführt und mit der peritonealen Lavage beendet. Abbildung 25 zeigt beispielhaft die Histogramme der FACS-Analysen der Proben der Peritoneallavage von vier verschiedenen Mäusen im Vergleich. Dabei wurden jeweils die Kurven der Isotyp gefärbten Probe und der $H L A-A B C$ gefärbten Probe übereinander gelegt. 


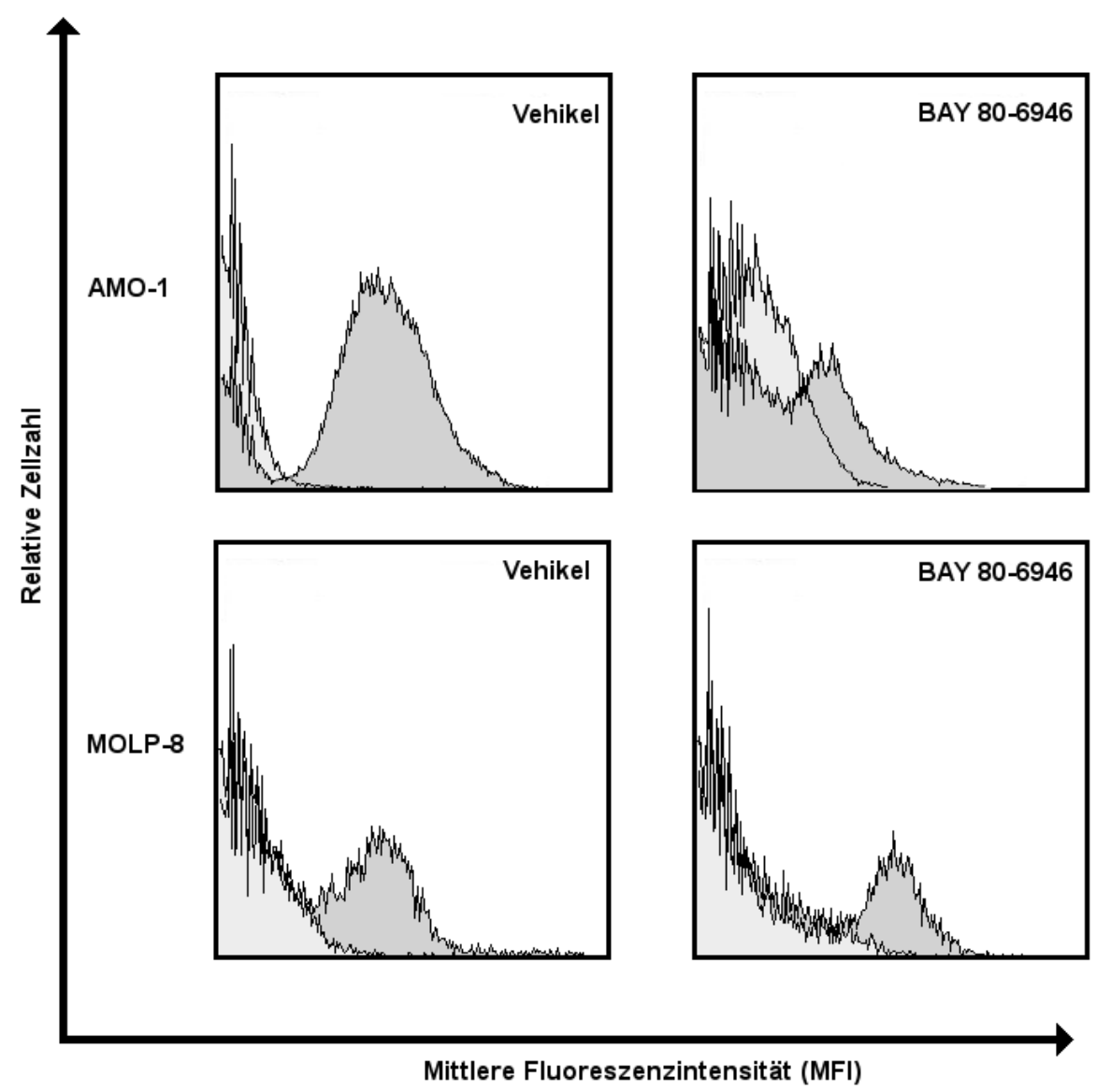

Abbildung 25: Durchflusszytometrische Auswertung der peritonealen Lavage von Maus 2, 7, 11, 16. Histogramm der durchflusszytometrischen Analyse. Die Zellproben wurden jeweils zweifach mit PBS gewaschen und bei 200 G zentrifugiert. Für die Färbung wurden 100.000 Zellen pro Probe in $100 \mu$ l PBS überführt, Antikörper hinzupipettiert und für eine Stunde bei $4{ }^{\circ} \mathrm{C}$ inkubiert, gewaschen, zentrifugiert, in $500 \mu \mathrm{l}$ PBS aufgenommen und anschließend durchflusszytometrisch analysiert. Als Negativkontrolle wurde jeweils eine Probe mit dem passenden Isotyp gefärbt. Die linke Kurve zeigt dabei jeweils die Isotypenkontrolle, die rechte Kurve die HLA-ABC-Antikörper-Färbung. Abbildungen aus der Software (BD FACS Diva) des verwendeten Durchflusszytometers FACS Canto II entnommen.

Die linke Abbildung in der oberen Reihe zeigt die Histogramme der Zellprobe, die bei der peritonealen Lavage von Maus 2 gewonnen wurde. Maus 2 wurden Zellen der Zelllinie AMO-1 injiziert. Sie gehörte der Kontrollgruppe, die mit dem Vehikel behandelt wurde, an. Der Großteil der Zellprobe zeigt sich $H L A-A B C$-positiv und ist somit als Multiple MyelomPopulation zu identifizieren. Die rechte Abbildung in der oberen Reihe zeigt die Histogramme der Isotyp und der $H L A-A B C$ gefärbten Zellprobe, die bei der peritonealen Lavage von Maus 7 gewonnen wurde. Maus 7 wurde ebenfalls die Zelllinie AMO-1 injiziert. Allerdings gehörte sie der Gruppe an, die mit BAY 80-6946 behandelt wurde. Vergleicht man die Histogramme von Maus 2 und 7, sieht man deutlich, dass die Anzahl der $H L A-A B C$-positiven Zellen, sprich der Multiplen Myelom-Zellen, mit der Behandlung von BAY 80-6946 deutlich abnimmt. In 
der unteren Reihe sind die Histogramme der Zellproben, die bei der peritonealen Lavage von Maus 11 und Maus 16 gewonnen wurden, abgebildet. Beiden Mäusen wurde die Zelllinie MOLP-8 injiziert. Maus 11 gehörte der Kontrollgruppe an, Maus 16 dagegen der Gruppe, die mit BAY 80-6946 behandelt wurde. Auch hier kann man im Vergleich der beiden Histogramme eine Abnahme der Anzahl der $H L A-A B C$-positiven Zellen erkennen, auch wenn diese deutlich geringer ausfällt.

Die Abbildung 26 zeigt die Ergebnisse der peritonealen Lavage der Zelllinie AMO-1 zusammenfassend in Form eines Balkendiagramms.

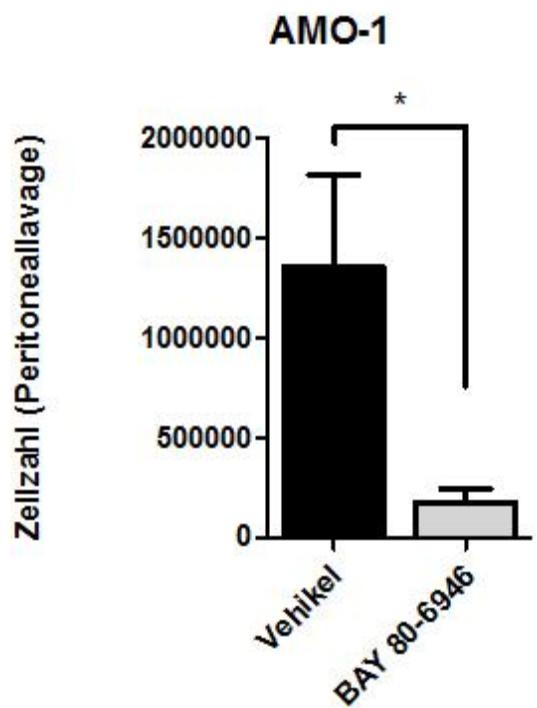

\begin{abstract}
Abbildung 26: Balkendiagramm der Ergebnisse der peritonealen Lavage (Zelllinie AMO-1). Durchflusszytometrisch ermittelte Daten: Y-Achse: Zellzahl; X-Achse: Behandlungsart. Innerhalb der Versuchsgruppe wurde der Mittelwert der absoluten Zellzahl ermittelt und als Balkendiagramm unter Angabe der Standardabweichung dargestellt. Signifikante Unterschiede der BAY 80-6946-behandelten Tiere zur Vehikelkontrolle, wurden mit einer einfachen Varianzanalyse (ANOVA) gefolgt von einem Bonferroni-post-hoc-Test mit einem Konfidenzintervall von 95\% ermittelt. Die Signifikanzen sind als Sternchen repräsentiert, wobei ein Sternchen $(*)$ einem p $<0.05$ entspricht, zwei Sternchen $(* *)$ einem $\mathrm{p}<0.01$ und drei Sternchen $* * *$ einem $\mathrm{p}<0.001$ entsprechen. Die Abbildung wurde mit Hilfe von GraphPad Prism V 5 erstellt.
\end{abstract}

Hierfür wurden zunächst die absoluten Zellzahlen aus der jeweiligen Gesamtzellzahl einer peritonealen Lavage und dem durchflusszytometrisch ermittelten prozentualen Anteil an Myelom-Zellen errechnet. In Abbildung 26 ist jeweils der Mittelwert der absoluten Zellzahlen aller Versuchstiere einer Gruppe dargestellt. Es zeigt sich eine statistisch signifikante $(\mathrm{p}<$ 0,05) Reduzierung der absoluten Zellzahl um 86,9 \% gegenüber dem Ausgangsmittelwert.

Die Abbildung 27 zeigt die entsprechenden Ergebnisse der Zellreihe MOLP-8. 


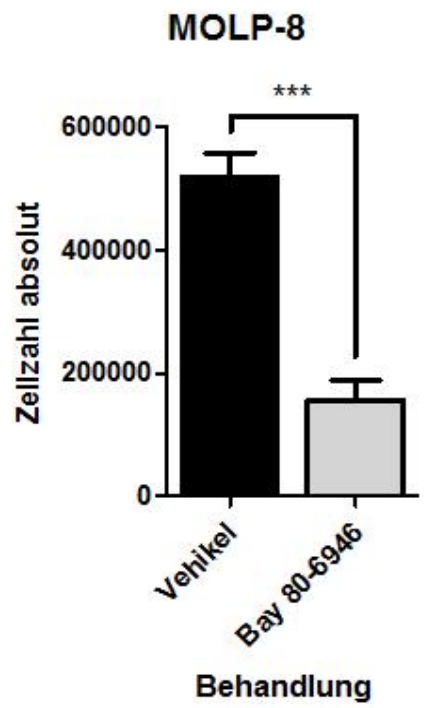

\begin{abstract}
Abbildung 27: Balkendiagramm der Ergebnisse der peritonealen Lavage (Zellinie MOLP-8). Durchflusszytometrisch ermittelte Daten: Y-Achse: Zellzahl; X-Achse: Behandlungsart. Innerhalb der Versuchsgruppe wurde der Mittelwert der absoluten Zellzahl ermittelt und als Balkendiagramm unter Angabe der Standardabweichung dargestellt. Signifikante Unterschiede der BAY 80-6946-behandelten Tiere zur Vehikelkontrolle, wurden mit einer einfachen Varianzanalyse (ANOVA) gefolgt von einem Bonferroni-post-hoc-Test mit einem Konfidenzintervall von 95\% ermittelt. Die Signifikanzen sind als Sternchen repräsentiert, wobei ein Sternchen $(*)$ einem $\mathrm{p}<0.05$ entspricht, zwei Sternchen (**) einem $\mathrm{p}<0.01$ und drei Sternchen *** einem p<0.001 entsprechen. Die Abbildung wurde mit Hilfe von GraphPad Prism V 5 erstellt.
\end{abstract}

Bei den Versuchstieren, denen die Zelllinie MOLP-8 injiziert worden war, konnte eine statistisch signifikante ( $\mathrm{p}<0,001$ ) Reduzierung der absoluten Zellzahl auf 69,3\% gegenüber dem Ausgangswert erreicht werden.

In der Auswertung der Färbungen mit dem gegen CD 138 gerichteten Antikörper (Daten nicht gezeigt) zeigte sich dagegen kein entsprechend konsistentes Ergebnis. Die als Kontrolle mit gefärbten AMO-1 Zellen zeigten erwartungsgemäß eine hohe Mittlere Fluoreszenzintensität (MFI). Dagegen zeigten die Zellproben, die bei der peritonealen Lavage gewonnen wurden, unabhängig davon welcher Versuchsgruppe sie angehörten, eine nur geringe MFI.

\title{
3.8.2 Milz und Femurknochen
}

Die Milzzellen wurden, wie im Abschnitt „Material und Methoden“ erläutert, isoliert. Anschließend wurde der prozentuale Anteil an Multiplen Myelom-Zellen durchflusszytometrisch bestimmt. Abbildung 28 zeigt beispielhaft die Histogramme der FACS-Analysen der Milzzellen von vier verschiedenen Mäusen im Vergleich. Dabei wurden 
jeweils die Kurven der Isotyp gefärbten Probe und der $H L A-A B C$ gefärbten Probe übereinander gelegt.

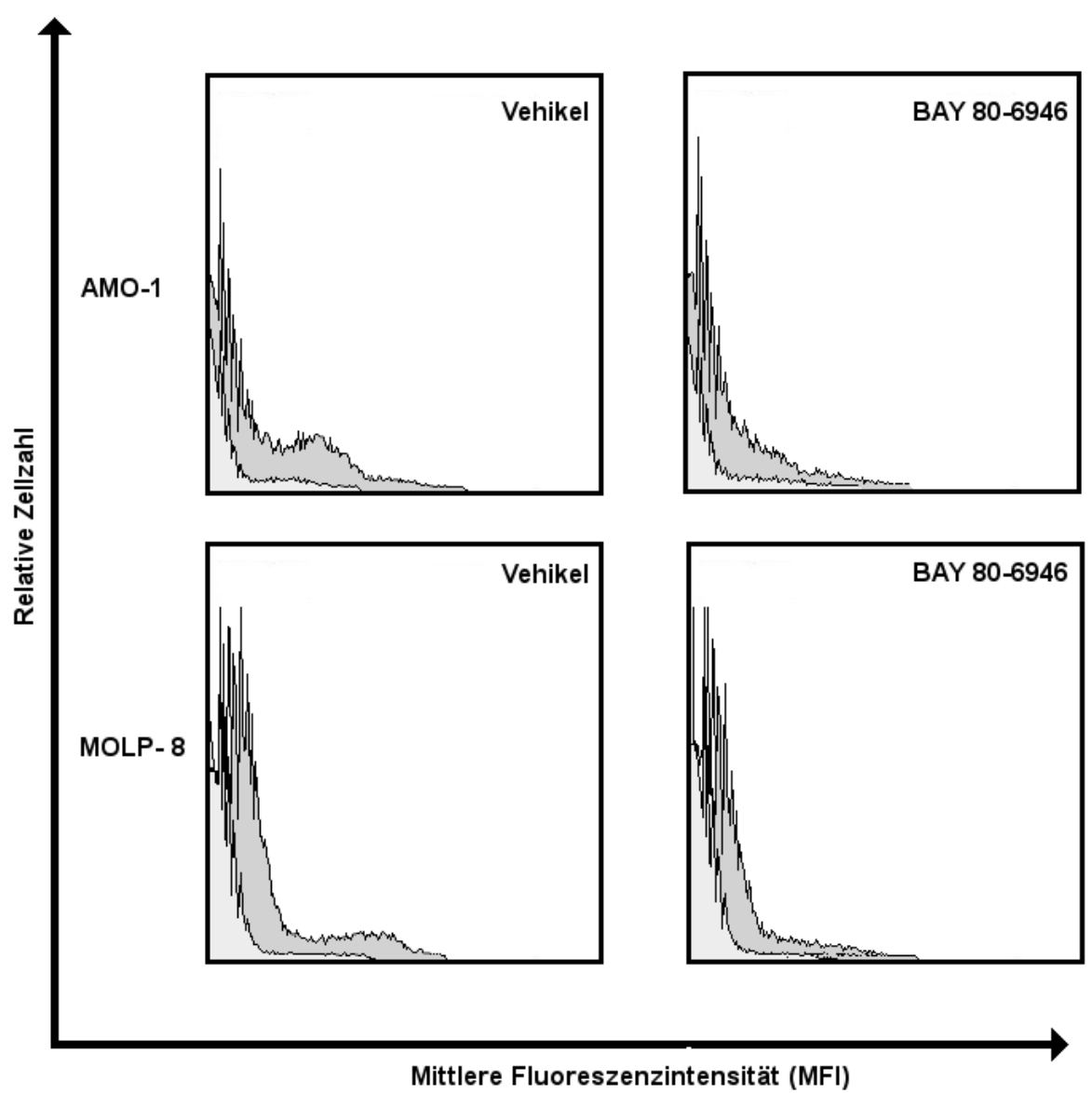

\begin{abstract}
Abbildung 28: Durchflusszytometrische Analyse der Milzzellen von Maus 3 , 13,14. Histogramm der durchflusszytometrischen Analyse. Die Zellproben wurden jeweils zweifach mit PBS gewaschen und bei $200 \mathrm{G}$ zentrifugiert. Für die Färbung wurden 100.000 Zellen pro Probe in $100 \mu$ PBS überführt, Antikörper hinzupipettiert und für eine Stunde bei $4{ }^{\circ} \mathrm{C}$ inkubiert, gewaschen, zentrifugiert, in $500 \mu \mathrm{l}$ PBS aufgenommen und anschließend durchflusszytometrisch analysiert. Als Negativkontrolle wurde jeweils eine Probe mit dem passenden Isotyp gefärbt. Die linke Kurve zeigt dabei jeweils die Isotypenkontrolle; die rechte Kurve die HLA-ABC-Antikörper-Färbung. Abbildungen aus der Software $(B D$ FACS Diva) des verwendeten Durchflusszytometers FACS Canto II entnommen.
\end{abstract}

Die linke Abbildung in der oberen Reihe zeigt das Histogramm der Zellprobe, die bei der peritonealen Lavage von Maus 3 gewonnen wurde. Maus 3 wurden Zellen der Zelllinie AMO-1 injiziert. Sie gehörte der Kontrollgruppe, die mit dem Vehikel behandelt wurde, an. Die rechte Abbildung in der oberen Reihe zeigt die Histogramme der Isotyp und der HLA$A B C$ gefärbten Zellprobe, die bei der peritonealen Lavage von Maus 7 gewonnen wurde. Maus 7 wurde ebenfalls die Zelllinie AMO-1 injiziert. Allerdings gehörte sie der Gruppe an, die mit BAY 80-6946 behandelt wurde. Vergleicht man die Histogramme von Maus 3 und 7, 
zeigen sich zwar in beiden Proben eine relativ geringe Anzahl von HLA-positiven Zellen, jedoch in der vehikelbehandelten Probe eindeutig mehr.

In der unteren Reihe sind die Histogramme der Zellproben, die bei der peritonealen Lavage von Maus 13 und Maus 14 gewonnen wurden, abgebildet. Beiden Mäusen wurde die Zelllinie MOLP-8 injiziert. Maus 13 gehörte der Kontrollgruppe an, Maus 14 dagegen der Gruppe, die mit BAY 80-6946 behandelt wurde. Bei diesen Tieren ist der Unterschied nicht mehr eindeutig mit dem Auge auszumachen, auch wenn man ein wenig mehr HLA-positive Zellen in der vehikelbehandelten Probe erahnen kann. Jedoch sind die Unterschiede allenfalls marginal.

Die folgenden beiden Abbildungen zeigen die Ergebnisse aller Versuchstiere der Zelllinien AMO-1 (Abbildung 29) und MOLP-8 (Abbildung 30) zusammenfassend in Form eines Balkendiagramms.

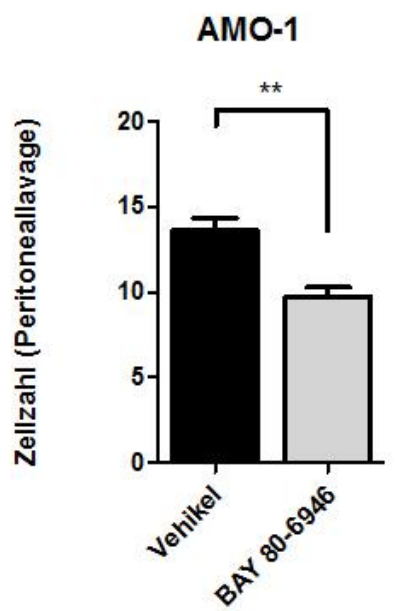

\footnotetext{
Abbildung 29: Balkendiagramm der Ergebnisse der Milzuntersuchung (Zelllinie AMO-1). Durchflusszytometrisch ermittelte Daten: Y-Achse: Zellzahl; X-Achse: Behandlungsart. Innerhalb der Versuchsgruppe wurde der Mittelwert der absoluten Zellzahl ermittelt und als Balkendiagramm unter Angabe der Standardabweichung dargestellt. Signifikante Unterschiede der BAY 80-6946-behandelten Tiere zur Vehikelkontrolle, wurden mit einer einfachen Varianzanalyse (ANOVA) gefolgt von einem Bonferroni-post-hoc-Test mit einem Konfidenzintervall von 95\% ermittelt. Die Signifikanzen sind als Sternchen repräsentiert, wobei ein Sternchen $\left(^{*}\right)$ einem $\mathrm{p}<0.05$ entspricht, zwei Sternchen $(* *)$ einem $\mathrm{p}<0.01$ und drei Sternchen *** einem p $<0.001$ entsprechen. Die Abbildung wurde mit Hilfe von GraphPad Prism V 5 erstellt.
} 
MOLP-8

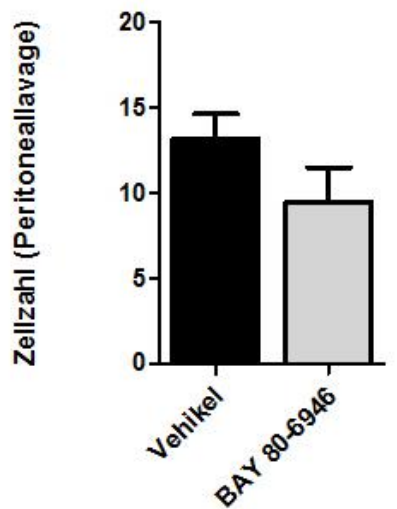

Abbildung 30: Balkendiagramm der Ergebnisse der Milzuntersuchung (Zelllinie MOLP-8). Durchflusszytometrisch ermittelte Daten: Y-Achse: Zellzahl; X-Achse: Behandlungsart. Innerhalb der Versuchsgruppe wurde der Mittelwert der absoluten Zellzahl ermittelt und als Balkendiagramm unter Angabe der Standardabweichung dargestellt. Signifikante Unterschiede der BAY 80-6946-behandelten Tiere zur Vehikelkontrolle, wurden mit einer einfachen Varianzanalyse (ANOVA) gefolgt von einem Bonferroni-post-hoc-Test mit einem Konfidenzintervall von 95\% ermittelt. Die Signifikanzen sind als Sternchen repräsentiert, wobei ein Sternchen $\left(^{*}\right)$ einem $\mathrm{p}<0.05$ entspricht, zwei Sternchen $(* *)$ einem $\mathrm{p}<0.01$ und drei Sternchen *** einem p $<0.001$ entsprechen. Die Abbildung wurde mit Hilfe von GraphPad Prism V 5 erstellt.

Für die Zelllinie AMO-1 zeigte sich ein signifikanter Unterschied in der Anzahl Multipler Myelom-Zellen in der Milz zwischen Vehikel und BAY 80-6946-behandelten Tieren. So zeigten die Vehikel-behandelten Mäuse im Durchschnitt 13,4 \% Myelom-Zellen und die BAY 80-6946-behandelten Tiere 9,6 \% Myelom-Zellen in der Milz. Im Unterschied dazu waren die Unterschiede in der Untersuchung mit der Zelllinie MOLP-8 nicht signifikant.

Die Zellen der Femurknochen wurden wie im Abschnitt „Material und Methoden“ beschrieben mit Hilfe einer Spülzytologie isoliert. In den anschließenden durchflusszytometrischen Analysen konnten keine Multiplen Myelom-Zellen nachgewiesen werden (Daten nicht gezeigt). 


\section{$4 \quad$ Diskussion}

\subsection{Konstitutive Aktivierung von Akt in Multiplen Myelom-Zellen}

Die Aktivierung (Phosphorylierung) der Proteinkinase Akt in Multiplen Myelom-Zellen korreliert mit einer schlechten Prognose sowie einer verkürzten Überlebenszeit der Betroffenen (Saal et al. 2007). Die Aktivierung stellt noch dazu ein häufiges Phänomen in Multiplen Myelom-Zellen dar (Hsu et al. 2001; Alkan und Izban 2002). Dagegen weisen die nicht malignen hämatologischen Zellen der Patienten keine übermäßige Aktivierung auf (Tu et al. 2000). Diese Tatsache unterstützt die Vermutung, dass die konstitutive Aktivierung von Akt eine wichtige Rolle in der Pathogenese des Multiplen Myeloms spielt.

Mechanismen, die eine konstitutive Aktivierung von Akt induzieren, sind insbesondere Mutationen des Tumorsuppressors PTEN, Amplifikationen oder Mutationen der PI3-Kinase sowie Mutationen der Wachstumsfaktor-Rezeptoren (Shaw und Cantley 2006; Maehama 2007). Allen gemeinsam ist eine konsekutiv erhöhte und Wachstumsfaktor-unabhängige Aktivität des PI3K-Akt-Signalweges. Diese resultiert letztendlich in einer folgenschweren relativen Apoptose-Resistenz der Multiplen Myelom-Zellen (Downward 2004; Hideshima et al. 2005; Maehama 2007; Vogt et al. 2010).

Folglich nimmt die übermäßige Aktivität des PI3K-Akt-Signalwegs eine zentrale Rolle in der Resistenzentwicklung gegenüber den eingesetzten Therapeutika ein (Mitsiades et al. 2006; Hideshima et al. 2007; Anderson und Carrasco 2011). Über seinen Apoptose-hemmenden Effekt hinaus hat der PI3K-Akt-Signalweg auch Einfluss auf andere Schlüsselfunktionen der Multiplen Myelom-Zellen. So wird die über Zytokine wie VEGF induzierte Migration der Multiplen Myelom-Zellen ebenfalls über den PI3-Kinase-Signalweg vermittelt. Dagegen scheint sie unabhängig vom MAP-Kinase-Signalweg zu sein (Podar et al. 2001).

Resistenzentwicklungen gegenüber den eingesetzten Therapeutika stellen eine der größten Herausforderungen in der Therapie von Krebserkrankungen im Allgemeinen dar. Dies gilt jedoch ganz im Besonderen für das Multiple Myelom. Bis heute verhindert die Apoptoseresistenz eine kurative Therapie dieser Erkrankung. Das Mikromilieu im Knochenmark bietet den Multiplen Myelom-Zellen einen umfassenden Schutz vor den Angriffen der Therapeutika (Anderson et al. 2000; Hideshima und Anderson 2002; Hideshima et al. 2004). Ungeachtet der therapeutischen Fortschritte, die mit der Entwicklung von 
Substanzen wie Thalidomid, Bortezomib und Lenalidomid erziehlt werden konnten, verhindert das Auftreten von Medikamentenresistenzen bis heute eine kurative Therapie (Hideshima et al. 2007; Anderson et al. 2011). Zudem spricht nur eine Minderheit (25-35\%) der Patienten auf diese Therapie mit den neuen Substanzen an (Hideshima und Anderson 2002; Richardson et al. 2003; Ghobrial et al. 2007).

Somit können die Forderungen nach neuen Therapiestrategien weiterhin aufrecht erhalten werden. Untersuchungen der Signalkaskaden, die in der Pathogenes des Multiplen Myeloms eine wichtige Rolle einnehmen, könnten den Rahmen für die Entwicklung neuer Therapiestrategien liefern (Richardson et al. 2004). Der PI3K-Akt-Signalweg mit seiner herausragenden Rolle in der Ausbildung von Apoptoseresistenz sowie Zellzyklusregulation des Multiplen Myeloms, stellt unter diesen Signalkaskaden ein äußerst erfolgsversprechendes Angriffsziel dar (Tu et al. 2000; Goekjian und Jirousek 2001; Younes et al. 2007). Dies konnten auch vorangegangene Studien bestätigen (Hideshima et al. 2006; Neri et al. 2008; Richardson et al. 2011b).

Darüber hinaus konnten zahlreiche Studien zeigen, dass der Einsatz von Dexamethason, Doxorubicin oder Bortezomib die Aktivierung von Akt zusätzlich induzieren kann und folglich wiederum Medikamentenresistenzen hervorruft (Hideshima et al. 2006; Hideshima et al. 2001b; Mitsiades et al. 2002). Vor diesem Hintergrund, erscheint die zusätzliche Gabe einer Substanz, die spezifisch den PI3K-Akt-Signalweg angreift, eine sinnvolle Ergänzung der Therapiestrategie darzustellen.

Diese Erkenntnis bildete die Grundlage für die vorliegende Dissertation mit dem Ziel, die anti-tumorale Wirkung von BAY 80-6946, einem neuen pan-Klasse-I-PI3-Kinase-Inhibitor, auf molekularer und zellulärer Ebene in vitro sowie in einem Xenotransplantationsmodell in vivo zu untersuchen. Im Gegensatz zu bisherigen Studien, beispielsweise mit BEZ-235, einem kombinierten PI3K/mTOR-Inhibitor (Maira et al. 2008), ist BAY 80-6946 ein selektiver Klasse-I/PI3-Kinase-Inhibitor. In Hinsicht auf eventuelle Nebenwirkungen könnte sich diese Selektivität von Vorteil erweisen.

\subsection{BAY 80-6946 hemmt die Aktivierung von Akt}

Der neue spezifische PI3K-Inhibitor BAY 80-6946 konnte die Akt-Aktivierung in allen vier untersuchten Multiplen Myelom-Zelllinien deutlich senken. Dabei zeigte die Behandlung mit der geringsten eingesetzten Konzentration $(10 \mathrm{nM})$ bereits den stärksten Einfluss auf den 
Phospho-Akt Spiegel. Unter der Behandlung mit einer 10 nM-Lösung ließ sich durchschnittlich eine Reduktion der MFI auf nahezu 70 bis $55 \%$ des Ausgangswertes erreichen. Zusammenfassend lässt sich sagen, dass die Zelllinien unter dem hemmenden Einfluss von BAY 80-6946 eine deutliche dosisabhängige Inhibierung der Aktphosphorylierung zeigten. BAY 80-6946 zeigt sich somit als potenter PI3-KinaseInhibitor. Die Frage, ob sich diese Ergebnisse auch auf andere Myelom-Zelllinien oder andere Tumorzellen übertragen lassen, müssen zukünftige Studien beantworten.

\subsection{Der Einfluss von BAY 80-6946 auf Apoptose, Proliferation und Zellzyklus}

Die Behandlung der Multiplen Myelom-Zelllinien mit BAY 80-6946 führte zu einer nennenswerten Induktion der Apoptose, Hemmung der Zellzyklus-Progression sowie zu einer moderaten Senkung der Proliferationsraten.

In den Apoptose-Assay-Untersuchungen erreichte BAY 80-6946 in der 100 nM-Lösung durchschnittlich eine Verdopplung der Apoptoseraten gegenüber den mit Vehikel-behandelten Zellen. Vor dem Hintergrund, dass der PI3K-Akt-Signalweg eine Schlüsselfunktion in der Regulation der Apoptose der Multiplen Myelom-Zellen einnimmt, erscheint diese umfassende proapoptotische Wirkung von BAY 80-6946 durchaus plausibel. Innerhalb des Mikromilieus des Knochenmarks übt die PI3K direkt über die Aktivierung zahlreicher Mitglieder der in die Apoptose-Regulation involvierten Proteinfamilien wie BAD (Datta et al. 1997), der proapoptotischen Caspase 9 (Franke et al. 2003; Downward 2004) oder FKHR, einem Mitglied der Forkhead-Box-Protein-Familie (Ghobrial et al. 2005), großen Einfluss aus. Zudem ist die PI3K auch indirekt involviert in die Regulation der beiden zentralen Regulatoren des Zelltodes NF- $\kappa B$ und p53 (Scheid und Woodgett 2001; Downward 2004).

In den Zellzyklusanalysen konnte durch BAY 80-6946 eine moderate Hemmung der Zellzyklusprogression erreicht werden. Die Verschiebung des Verhältnisses der G0/G1-Phase zu S-Phase in Richtung G0/G1-Phase machte diese deutlich. Nach der 24-stündigen Behandlung zeigte sich im Gegensatz zu der 4- und 12-stündigen Behandlungszeit eine deutliche Zunahme der Zellen in der G0/1-Phase. Der Prozentsatz der Zellen, der sich in der G2/M-Phase befand, blieb dabei nahezu unverändert. Diese Wirkung von BAY 80-6946 erscheint ebenfalls plausibel, wenn man den Einfluss des PI3K-Akt-Signalwegs auf die Regulation des Zellzyklus betrachtet. Akt ist über seine Fähigkeit die Glycogen-SynthaseKinase-3 (GSK-3) zu hemmen in die Zellzyklusregulation involviert. Da die GSK-3 selber die 
Expression von Cyclin D1 zu senken vermag, führt Akt indirekt zu einer beschleunigten Progression des Zellzyklus (Diehl et al. 1998). Somit führt die Hemmung des PI3K-AktSignalweges über BAY 80-6946 erwartungsgemäß zu einer Hemmung der Zellzyklusprogression. Aus vorangegangenen Studien weiß man, dass die Überexpression von Cyclin D1 (Translokation $\mathrm{t}(11,14)$ ) in 15-20 \% der Erkrankungen auftritt. Somit scheint Cyclin D1 bei bis zu einem Viertel der Patienten eine bedeutende Funktion in der Pathogenese des Multiplen Myeloms einzunehmen (Bergsagel et al. 2005; Hideshima et al. 2007).

In Proliferations-Untersuchungen konnte in Zellen, die mit BAY 80-6946 behandelt wurden, eine moderate, aber reproduzierbare und signifikante konzentrationsabhängige Inhibition der Proliferation festgestellt werden. Unter der Behandlung mit einer 100 nM-Lösung konnte durchschnittlich, mit Ausnahme der Zelllinie U-266, eine Reduktion der Proliferationsraten auf das 0,7 bis 0,8 fache des Ausgangswertes erreicht werden. Es gibt derzeit keine einfache Erklärung dafür, dass alle vier Zelllinien eine Abnahme der Akt-Phosphorylierung sowie Zunahme der Apoptoseraten zeigten, jedoch keine einheitliche Proliferationshemmung zu erzielen war, wobei man selbstverständlich allgemein über andere Signalwege spekulieren kann, welche kompensatorisch zelluläre Funktionen der Tumor-Progression ausfüllen könnten. Genaue Untersuchungen der Wechselwirkung des PI3K-Akt-Signalweges mit anderen Signalkaskaden sowie die (indirekte) Beeinflussung dieser Signalwege durch BAY 80-6946 stehen noch aus. U-266 zeigte unter Behandlung mit BAY 80-6946 den deutlichsten Anstieg der Apoptoserate. Dagegen war die proliferationshemmende Wirkung in dieser Zelllinie am geringsten ausgeprägt. Es lässt sich nur mutmaßen, dass U-266 über weitere proliferationsfördernde Signalwege verfügen muss, die unter Therapie mit BAY 80-6946 eine kompensierende Funktion einnehmen.

In Zusammenschau aller Ergebnisse kann man davon ausgehen, dass sich die funktionellen Einflüsse von Bay 80-6946 auf die Proliferation, den Zellzyklus sowie die Apoptose zu einem deutlichen anti-tumoralen Gesamteffekt aufsummieren. Zudem bleibt festzuhalten, dass die apoptosesteigernde Wirkung wahrscheinlich den größten Anteil von diesem einnimmt. Vor dem Hintergrund, dass der Erwerb einer relativen Apoptoseresistenz eines der bedeutendsten Charakteristika der Medikamentenresistenz bei Multiplen Myelom-Zellen darstellt (Van de Donk et al. 2005), ist es denkbar, dass BAY 80-6946 dazu beitragen könnte diese zu überwinden. 


\subsection{BAY 80-6946 hemmt die IGF-1-stimulierte Aktivierung von Akt}

In den für diese Arbeit durchgeführten Experimenten gelang es, durch BAY 80-6946 nicht nur die konstitutive Aktivierung von Akt, sondern darüber hinaus auch die IGF-1-stimulierte Aktivierung von Akt nahezu vollständig zu blockieren. Dieses Ergebnis lässt die Vermutung zu, dass es BAY 80-6946 gelingen könnte, die schützende Wirkung von IGF-1 im Mikromilieu des Knochenmarks zu überwinden.

IGF-1 stellt einen der bedeutendsten Wachstumsfaktoren für Multiple Myelom-Zellen im Mikromilieu des Knochenmarks dar (Sprynski et al. 2009). Über die Aktivierung des PI3KAkt-Signalweges bietet IGF-1 den Zellen vor Ort einen umfassenden Schutz vor Glukokortikoid-induzierter Apoptose (Sprynski et al. 2009). Darüber hinaus kommt IGF-1 nicht nur im Mikromilieu des Knochenmarks vor, sondern wird auch in der Leber synthetisiert und befindet sich somit ubiquitär im Organismus (Qiang et al. 2002). Folglich sind die Multiplen Myelom-Zellen konstant der Stimulation durch IGF-1 ausgesetzt.

Vorangegangene Studien gaben eindeutige Hinweise darauf, dass IGF-1 sowohl in vitro als auch in vivo eine bedeutsame Rolle im Verlauf der Erkrankung des Multiplen Myeloms spielt (Ferlin et al. 2000; Qiang et al. 2002). Es konnten zwei verschiedene Signalwege identifiziert werden, die über IGF-1 aktiviert werden. Zum einen handelt es sich dabei um den PI3K-AktSignalweg. Daneben kann IGF-1 über die Aktivierung von Ras auch die Aktivierung des MAPK-Signalwegs initiieren (Qiang et al. 2002). Versuche, in denen jeweils spezifische Inhibitoren der beiden Signalwege eingesetzt wurden, zeigten dass die Hemmung der MAPK im Gegensatz zur PI3K keinen Einfluss auf die Phosphorylierung wichtiger Zielstrukturen wie Akt oder Forkhead hatte. Zudem konnte gezeigt werden, dass die Hemmung der PI3K mit dem Inhibitor LY294002 ebenfalls zu einer Hemmung der Phosphorylierung von p44/42, einer Zielstruktur der MAPK, führte.

Aus diesen Versuchsergebnissen lässt sich schlussfolgern, dass die PI3K indirekten Einfluss auf die Regulation der MAPK besitzen könnte (Qiang et al. 2002). Vor dem Hintergrund, dass die MAPK ebenso wie die PI3K in die Regulation vieler Prozesse, die für die Proliferation und das Überleben einer Tumorzelle verantwortlich sind, eingreifen kann, wäre in diesem Fall von einer zusätzlichen anti-tumoralen Wirkung eines PI3K-Inhibitors auszugehen. Ob BAY 80-6946 jedoch auch die entsprechende Fähigkeit besitzt, müssten weitere Studien noch zeigen. 
Aufgrund seines umfassenden proliferations- und überlebensfördernden Effekts, kann man sich jedoch allein von der Hemmung der von IGF-1 ausgehenden Stimulation einen guten antiproliferativen Effekt versprechen. So wurden schon Versuche unternommen, die wichtige Funktion von IGF-1 in der Pathogenese des Multiplen Myeloms als neue Therapiestrategie zu nutzen (Mitsiades et al. 2004; Pollak 2012).

\subsection{Einsatz von BAY 80-6946 im murinen Xenotransplantations-Modell}

Neben der überzeugenden anti-tumoralen in vitro Wirkung zeigte BAY 80-6946 ebenso einen antiproliferativen Effekt auf die Multiplen Myelom-Zellen in einem Xenograft-Mausmodell.

Trotz intensiver Forschung existiert bis zum heutigen Zeitpunkt noch kein Tiermodell, welches sämtliche Aspekte des humanen Multiplen Myeloms widerspiegelt. Viele Studien griffen daher auf die Methode zurück, humane Zellen subkutan in Mäuse zu injizieren und anschließend das lokale Tumorwachstum zu messen (Hideshima et al. 2006; Podar et al. 2007). Auf der einen Seite bietet dieses Studienmodell eine einfache und direkte Möglichkeit, das lokale Tumorwachstum zu verfolgen. Auf der anderen Seite bietet diese Methode jedoch nur eingeschränkte Möglichkeiten, die gesamte Tumormasse mit verschiedenen Zellarten in den Tumorknoten sowie systemische Auswirkungen der Myelom-Erkrankung zu untersuchen. Hinzu kommt das generelle Problem, dass dieser Methode wie auch allen Modellen die Einbeziehung des Mikromilieus im Knochenmark fehlt. Dabei ist es gerade dieses spezifische Umfeld, das eine der bedeutendsten Rollen im Entwicklungsprozess von Medikamentenresistenzen spielt.

Vor diesem Hintergrund wurden erste Versuche unternommen, experimentelle Modelle zu entwickeln, die das Mikromilieu im Knochenmark einbeziehen (Urashima et al. 1997; Ikeda et al. 2010). Die Arbeitsgruppe um Hiroshi Ikeda nutzte ein kompliziertes Modell, in dem die Multiplen Myelom-Zellen in einen Knochenspan, der den Versuchsmäusen subkutan implantiert worden war, injiziert wurden (Ikeda et al. 2010). Trotz dieser Bemühungen sind weitere Studien in diesem Bereich notwendig, um ein möglichst einfach umzusetzendes Modell, das das Mikromilieu im Knochenmark möglichst realistisch nachempfindet, zu entwickeln.

Für die vorliegende Arbeit wurde ein neues, einfach durchzuführendes Studienmodell entwickelt. Dabei handelt es sich um ein Xenograft-Mausmodell, in dem die Multiplen Myelom-Zellen Nacktmäusen (Stamm (NU/J Foxn1 ${ }^{\text {nu}}$ ) intraperitoneal verabreicht wurden. 
Auch dieses Modell weist Einschränkungen auf, insbesondere da es das Mikromilieu im Knochenmark nicht einbezieht. Es stellt allerdings insofern eine Annäherung an die klinische Situation der Myelom-Patienten dar, als es zumindest auch einige systemische Wirkungen untersuchen lässt.

Die in-vivo-Versuche wurden über einen Zeitraum von zwei Wochen durchgeführt. Die Mäuse wurden in zwei Gruppen aufgeteilt, wovon eine dreimal wöchentlich mit BAY 806946 in einer Dosierung von $6 \mathrm{mg}$ pro Kilogramm Körpergewicht und die andere entsprechend mit Vehikellösung als Kontrolle behandelt wurde.

Die Differenzierung der Multiplen Myelom-Zellen von den murinen Zellen wurde mittels Färbung eines Antikörpers, der gegen den Haupthistokompatibilitätskomplex Klasse I (MHC I) gerichtet ist, und eines Antikörpers, der gegen CD138 gerichtet ist, vorgenommen. Anschließend wurden durchflusszytometrische Analysen durchgeführt. Die Auswertung zeigte eine eindeutige Reduzierung der absoluten Zellzahl von 86,9 \% der Zelllinie AMO-1 und 69,3\% der Zelllinie MOLP-8.

Im Gegensatz zu den Färbungen mit dem gegen $H L A-A B C$ gerichteten Antikörper zeigten die Färbungen mit dem gegen CD138 gerichteten Antikörper kein entsprechend konsistentes Ergebnis. Die zur Kontrolle mitgefärbten AMO-1 Zellen zeigten erwartungsgemäß eine hohe Mittlere Fluoreszenzintensität (MFI). Dagegen zeigten die Zellproben, die bei der peritonealen Lavage gewonnen wurden, unabhängig davon, welcher Versuchsgruppe sie angehörten, eine nur geringe MFI. Grundsätzlich muss man natürlich nach methodischen Fehlern bei der Messung suchen. Eine weitere Erklärung für die diskrepanten Fluoreszenzintensitäten könnte sein, dass die Myelom-Zellen den Oberflächenmarker CD138 im Laufe des Experimentes verlieren oder von ihrer Oberfläche abspalten. Es ist bekannt, dass sowohl normale als auch maligne Plasmazellen CD138 als Oberflächenmarker besitzen (Bataille et al. 2006). Darüber hinaus haben vorangegangene Studien gezeigt, dass apoptotische normale und maligne Plasmazellen CD138 als Oberflächenmarker verlieren können (Bataille et al. 2006).

Zudem konnte BAY 80-6946 auch das systemische Fortschreiten der Erkrankung der Multiplen Myelom-Zellen reduzieren, wie die durchflusszytometrischen Analysen der Milzen der untersuchten Mäuse zeigten. Hierfür wurden die aus den Milzen gewonnenen Zellsuspensionen ebenfalls mit dem gegen $H L A-A B C$ gerichteten Antikörper gefärbt. Durch die Durchflusszytometrie konnten jeweils kleine Populationen von mutmaßlich gestreuten humanen Myelom-Zellen in den Milzen der Mäuse nachgewiesen werden. Selbstverständlich 
besitzt die hier durchgeführte experimentelle Strategie Einschränkungen hinsichtlich ihrer Aussagekraft. Insbesondere war die Zahl der „gestreuten“ humanen Myelom-Zellen vergleichsweise klein. Außerdem waren die in Myelom-Patienten häufig involvierten Kompartimente nicht befallen, wie die durchflusszytometrischen Analysen der KnochenSpülzytologien, in denen keine humanen Myelom-Zellen nachgewiesen werden konnten, nahelegten.

Es wäre auch denkbar, dass BAY 80-6946 die Streuung der Zellen in die Milz, das Knochenmark und andere Kompartimente inhibieren konnte. Diese Hypothese ist insbesondere deshalb von Interesse, da extramedulläre Manifestationen des Multiplen Myeloms zwar häufig auftreten, die Mechanismen der systemischen Ausbreitung der Erkrankung jedoch noch nicht vollständig geklärt werden konnten (Varettoni et al. 2010).

\subsection{Ausblick und Fazit}

Vor dem Hintergrund der nahezu regelhaft auftretenden Resistenzentwicklungen gegenüber den Standard-Therapeutika ist die Nachfrage nach neuen Therapiestrategien in der Behandlung des Multiplen Myeloms hoch. Ein häufiges Phänomen in der Pathogenese des Multiplen Myeloms stellt die Aktivierung von Akt dar (Hsu et al. 2001; Alkan und Izban 2002). Die konsekutiv erhöhte Aktivität des PI3K-Akt-Signalwegs spielt insbesondere durch die Förderung einer relativen Apoptose-Resistenz der Multiplen Myelom-Zellen (Downward 2004; Hideshima et al. 2005; Maehama 2007; Vogt et al. 2010) eine zentrale Rolle in der Resistenzentwicklung (Mitsiades et al. 2006; Hideshima et al. 2007; Anderson und Carrasco 2011). Darüber hinaus konnten zahlreiche Studien zeigen, dass der Einsatz von Dexamethason, Doxorubicin oder Bortezomib ebenso die Aktivierung von Akt induzieren kann und somit zu Medikamentenresistenzen beiträgt (Hideshima et al. 2006; Hideshima et al. 2001b; Mitsiades et al. 2002). Folglich könnten spezifische Inhibitoren des PI3K-AktSignalwegs eine sinnvolle Ergänzung der gegenwärtigen Therapiestrategien darstellen.

Insgesamt legen die Ergebnisse dieser Arbeit nahe, dass der neue spezifische pan-Klasse IPI3K-Inhibitor BAY 80-6946 das Potenzial in sich trägt, das Wachstum Multipler MyelomZellen sowohl in vitro als auch in vivo erfolgreich zu hemmen.

Allerdings muss bedacht werden, dass die „natürliche“ Umgebung im Knochenmark, in der sich die Multiplen Myelom-Zellen befinden, äußerst komplex ist. Die Bindung der Multiplen Myelom-Zellen an die ortsständigen Zellen induziert nicht nur die Aktivierung des PI3K-Akt- 
Signalweges, sondern ebenso viele weitere Signalkaskaden, beispielsweise den NF-кB-, den MAPK- oder den JAK-STAT-Signalweg (Lentzsch et al. 2004; van de Donk et al. 2005). All diese Signalkaskaden tragen zu erhöhter Proliferation, Resistenzentwicklung und Migration der Tumorzellen bei (Hideshima und Anderson 2002). Die Untersuchungen dieser Signalkaskaden im Mikromilieu des Knochenmarks haben nicht nur zu einem besseren Verständnis der Pathogenes des Multiplen Myeloms geführt, sondern könnten auch in Zukunft den Rahmen für die Entwicklung neuer Therapiestrategien erweitern (Richardson et al. 2004). Insbesondere die Kombination von Therapeutika, die verschiedene Mechanismen des Mikromilieus im Knochenmark angreifen, könnte eine vielversprechende Möglichkeit darstellen Medikamentenresistenz zu unterbinden und Therapieerfolge bei Patienten mit refraktärem Krankheitsverlauf zu erzielen (Richardson et al. 2011b).

In einigen Studien wurde bereits nachgwiesen, dass die Kombinationstherapie mit AktInhibitoren einen vielversprechenden Therapieansatz darstellt. Der Proteasomeninhibitor Bortezomib wurde bereits in Studien mit dem Akt-Inhibitor Perifosin kombiniert (Hideshima et al. 2007). In vitro wirkt Bortezomib wachstumsinhibierend über Hemmung des MAPKSignalweges. Zudem hemmt Bortezomib die Migration über Inhibierung des PI3KSignalweges sowie das Überleben der Multiplen Myelomzelle über Hemmung des JAKSTAT-Signalweges (Hideshima et al. 2007). Allerdings konnte auch gezeigt werden, dass Bortezomib gleichzeitig zur Aktivierung von Akt führt (Podar et al. 2007; Hideshima et al. 2007).

Die Kombinationstherapie von Bortezomib mit dem Akt-Inhibitor Perifosin konnte diese Aktivierung unterbinden und führte somit $\mathrm{zu}$ einem synergistischen zytotoxischen Effekt (Hideshima et al. 2006). Es wäre denkbar, dass BAY 80-6946 als spezifischer PI3K-Inhibitor, der vom Mechanismus eine Stufe höher in der Signalkaskade angreift und folglich neben Akt noch weitere Zielstrukturen der PI3K hemmt, einen noch größeren Effekt aufweist.

Vor dem Hintergrund, dass die PI3K nahezu ubiquitär in sämtlichen eukaryotischen Zellen exprimiert wird (Vanhaesebroeck et al. 1997), muss man auch die Frage nach potentiellen Nebenwirkungen stellen (Crabbe et al. 2007; Ghobrial et al. 2007). Die Klasse I der PI3Kinasen, die nach heutigen Studienergebnissen diejenige mit der größten Relevanz bei Krebserkrankungen ist (Yuan und Cantley 2008; Courtney et al. 2010), ist ebenso in viele physiologische Prozesse der Zellen involviert (Crabbe et al. 2007). Unter anderem stellt die PI3K einen zentralen Regulator der Insulinwirkung im Zellmetabolismus dar (Courtney et al. 2010). Studien zufolge ist der Diabetes mellitus Typ 2, der sich durch Insulinresistenz 
auszeichnet, mit einer verminderten Aktivität der PI3K auf das Insulinsignal hin assoziiert (Courtney et al. 2010). Folglich könnte die therapeutische Hemmung der PI3K ebenfalls eine Insulinresistenz verursachen oder fördern. In der Tat wurde die Insulinresistenz in Phase-1Studien als Nebenwirkung der Therapie mit PI3K-Inhibitoren beobachtet, jedoch ohne Auftreten einer dosislimitierenden Toxizität. Im Tierversuch konnte die aufgetretene Hyperglykämie bei reduzierter Glukosetoleranz mit Hilfe oraler Antidiabetika erfolgreich behandelt werden (Courtney et al. 2010).

Die bisherigen Erkenntnisse in der Verwendung von PI3K-Inhibitoren zeigen, dass diese Therapie insgesamt gut toleriert wird und die Progression der Erkrankung verhindert werden kann, ohne eine klinisch relevante Insulinresistenz auszulösen (Brachmann et al. 2009). Zudem gibt es Überlegungen, die induzierte Hyperglykämie als messbaren pharmakodynamischen Parameter zu nutzen, um Aussagen darüber treffen zu können, ob der therapeutisch eingesetzte PI3K-Inhibitor einen Effekt aufweist (Pollak 2012).

Bedenkt man, dass konstitutive und IGF-1-induzierte Aktivierung von Akt eine charakterisierende Eigenschaft von Multiplen Myelom-Zellen ist, scheint es ebenso denkbar, dass spezifische pan-Klasse-I/PI3-Kinase-Inhibitoren wie BAY 80-6946 bevorzugt Einfluss auf Tumorzellen und weniger auf nicht maligne Zellen nehmen werden. Diese Hypothese müsste jedoch in weiteren umfassenden Studien überprüft werden.

Neben dem Multiplen Myelom konnte die Aktivierung von Akt auch in vielen weiteren Tumorentitäten nachgewiesen und therapeutisch genutzt werden (Zhao und Vogt 2008; Yuan und Cantley 2008) (Dean et al. 1996). Es ist deshalb durchaus denkbar, dass BAY 80-6946 auch in der Behandlung weiterer Tumorerkrankungen Erfolge erzielen könnte. 


\section{$5 \quad$ Zusammenfassung}

Trotz umfassender Forschungen ist das Multiple Myelom gegenwärtig noch eine unheilbare Erkrankung. In erster Linie sind hierfür die regelhaft auftretenden Medikamentenresistenzen verantwortlich. Konstitutive sowie induzierte Aktivierung der PI3-Kinase im Mikromilieu des Knochenmarks steht in engem Zusammenhang mit Wachstum, Überleben, Migration sowie Resistenzbildung der Myelom-Zellen, wobei insbesondere Apoptoseresistenz eine herausragende Rolle spielt. Frühere Studien konnten zeigen, dass Inhibition der PI3K zur Apoptose der Myelom-Zellen führen kann. Folglich stellt die PI3K ein neues, vielversprechendes therapeutisches Angriffsziel dar.

In der vorliegenden Arbeit wurde die Wirkung des neuen hoch selektiven pan-Klasse I PI3Kinase-Inhibitors BAY 80-6946 ( $\mathrm{IC}_{50}=0,5 \mathrm{nM}$ gegenüber PI3K- $\alpha$ ) auf vier verschiedene humane Myelom-Zelllinien (AMO-1, KMS-12-BM, MOLP-8, U-266) untersucht. Tatsächlich konnte durch das neue Pharmakon die Induktion einer signifikanten dosisabhängigen Zytotoxizität in den Myelom-Zellen, die mit einer klaren Reduktion der Akt-Aktivierung (Phosphorylierung) einherging, erreicht werden. Die Behandlung mit BAY 80-6946 führte in den Myelom-Zellen zu signifikanter Erhöhung der Apoptoseraten, Reduktion der Proliferationsraten sowie Hemmung der Zellzyklus-Progression (jeweils $p<0.001$ gegenüber den mit Vehikel-behandelten Zellen). Darüber hinaus konnte BAY 80-6946 die pathogenetisch wichtige IGF-1-induzierte Akt-Stimulation in Myelom-Zellen überwinden. Schließlich zeigte BAY 80-6946 eine überzeugende anti-tumorale in-vivo-Wirkung gegenüber den Zelllinien AMO-1 und MOLP-8 in einem murinen Xenograft-Modell. Nach zweiwöchiger Behandlung mit BAY 80-6946 (6 mg/kg KG jeden 2. Tag) konnte die Zahl der Myelom-Zellen in den Empfängertieren um 86,9 \% (AMO-1) beziehungsweise 69,3 \% (MOLP-8) reduziert werden, ohne dass Anzeichen einer Toxizität beobachtet wurden.

Vor dem Hintergrund dieser Ergebnisse, erscheint es durchaus denkbar, dass PI3KInhibitoren wie BAY 80-6946 in Zukunft eine Ergänzung zu den bisher in der Behandlung des Multiplen Myelom angewandten Therapiestrategien werden, insbesondere wenn bereits Resistenzen gegenüber anderen Chemotherapeutika aufgetreten sind. 


\section{$6 \quad$ Anhang}

\subsection{Verzeichnis der Abbildungen}

\begin{tabular}{|c|c|c|}
\hline Abbildungsnummer & Bezeichnung & Seite \\
\hline 1 & Die Pathogenese des Multiplen Myeloms & 5 \\
\hline 2 & Die Familie der PI3-Kinasen & 13 \\
\hline \multirow[t]{2}{*}{3} & Aktivierungsmechanismus der & 15 \\
\hline & Klasse I PI3-Kinasen & \\
\hline 4 & Strukturformel BAY 80-6946 & 19 \\
\hline \multirow[t]{2}{*}{5} & Durchflusszytometrische Analyse der konstitutiven & 44 \\
\hline & Aktivierung von Akt (Zelllinie Amo-1) & \\
\hline 6 & Prinzip des Cell-Death-Detection-ELISA Plus & 46 \\
\hline 7 & DNA Histogramm und Zellzyklusschema & 50 \\
\hline \multirow[t]{2}{*}{8} & Histogramm der Zellzyklusanalyse MOLP-8 & 52 \\
\hline & unbehandelt & \\
\hline \multirow[t]{3}{*}{9} & Histogramme einer durchflusszytometrischen & 58 \\
\hline & Analyse der Multiplen Myelom-Zelllinien AMO-1, & \\
\hline & KMS-12-BM, MOLP-8, U-266 & \\
\hline \multirow[t]{3}{*}{10} & Balkendiagramm der konstitutiven Aktivierung von & 59 \\
\hline & Akt der Zelllinien AMO-1, KMS-12-BM, MOLP-8 & \\
\hline & und U-266) & \\
\hline \multirow[t]{2}{*}{11} & Durchflusszytometrische Analyse der Behandlung & 60 \\
\hline & mit BAY 80-6946 & \\
\hline \multirow[t]{2}{*}{12} & Durchflusszytometrische Analyse der IGF-1- & 62 \\
\hline & Stimulation der Zelllinien AMO-1 und MOLP-8 & \\
\hline \multirow[t]{2}{*}{13} & Western-Blot-Analyse der IGF-1-Stimulation von & 64 \\
\hline & AMO-1, MOLP-8, KMS-12-BM, U-266 & \\
\hline
\end{tabular}


Analyse aus Abbildung 13

Hemmung der IGF-1-stimulierten Zelllinien

AMO-1 und MOLP-8 durch BAY 80-6946

Western-Blot-Analyse, Hemmung der IGF-1-

stimulierten Aktivierung von Akt

(Zelllinie AMO-1)

Densiometrische Auswertung der Western-Blot-

Analyse aus Abbildung 16, Zelllinie AMO-1

Western-Blot-Analyse, Hemmung der IGF-1-

stimulierten Aktivierung von Akt

(Zelllinie MOLP-8)

Densiometrische Auswertung der Western-Blot-

Analyse aus Abbildung 18, Zelllinie MOLP-8

Balkendiagramm, Auswertung des Apoptose-Assay

\section{„Cell Death Detection Elisa“}

AMO-1, KMS-12-BM, MOLP-8, U-266;

\section{Balkendiagramm}

nach 24h Behandlung mit BAY 80-6946

nach 24h Behandlung mit BAY 80-6946

MOLP-8 exprimieren das Zelloberflächenprotein

\section{HLA-ABC}

Durchflusszytometrische Auswertung der peritonealen Lavage von Maus 2, 7, 11, 16 


\begin{tabular}{|clc|}
\hline 27 & $\begin{array}{l}\text { Balkendiagramm der Ergebnisse der peritonealen } \\
\text { Lavage (Zelllinie MOLP-8) }\end{array}$ & 83 \\
28 & $\begin{array}{l}\text { Durchflusszytometrische Analyse der Milzzellen } \\
\text { von Maus } 3,7,13,14\end{array}$ & 85 \\
& Balkendiagramm der Ergebnisse der \\
& Milzuntersuchung (Zelllinie AMO-1) \\
& Balkendiagramm der Ergebnisse der & 86 \\
& Milzuntersuchung (Zellinie MOLP-8) & \\
\hline
\end{tabular}

\subsection{Verzeichnis der Tabellen}

\section{Tabellennummer}

\section{Bezeichnung}

Seite

1

Stadieneinteilung des Multiplen Myeloms: Durie-Salmon-

4

Kriterien und ISS-Kriterien

2

Biochemische Aktivität von BAY 80-6946;

Ergebnisse eines Kinase-Assays

Behandlungschema BAY 80-6946 unstimuliert

Behandlungsschema BAY 80-6946, IGF-1-stimuliert

Pipettierschema Bradford Protein-Assay

Antikörperkonzentrationen Western-Blot-Analyse

Behandlungsplan Mausversuch

Mittlere Fluoreszenzintensität (MFI) aller Zelllinien in der

durchflusszytometrischen Analyse der konstitutiven

Aktivierung von Aktf 


\begin{tabular}{|clc|}
\hline 12 & Proliferations-Assay-Analyse & 108 \\
13 & $\begin{array}{l}\text { durchflusszytometrische Zellzyklusanalyse; } \\
\text { Zelllinie MOLP-8 }\end{array}$ & 109 \\
14 & Peritoneallavage Zellinie AMO-1 & 110 \\
15 & Peritoneallavage Zellinie MOLP-8 & 111 \\
\hline
\end{tabular}

\subsection{Verzeichnis der Abkürzungen}

\begin{tabular}{|ll|}
\hline Abkürzung & Bedeutung \\
AB-Serum & antikörperfreies humanes Serum der \\
Akt & Blutgruppe AB \\
BAD & Gen der Proteinkinase B \\
BCL-X & Bcl-2-Antagonist of Cell Death \\
Bim, auch BCL2L11 & B-cell lymphoma-extra large \\
BMSC & Bcl-2 interacting mediator of cell death \\
bone marrow stromal cell, \\
Knochenmarkstromazelle \\
cell-adhesion-mediated drug resistance, \\
zelladhäsionsvermittelte Medikamenten- \\
resistenz \\
CBAB \\
Triphenylmethanfarbstoff Coomassie- \\
Brilliant-Blau G-250 \\
cyclin-dependent kinases, \\
Cyclin-abhängige Kinasen \\
zelluläres Myelocytomatose-Onkogen \\
hypercalcemia, renal insufficiency, anemia \\
und bone lesions; Hyperkalzämie, \\
Niereninsuffizienz, Anämie,
\end{tabular}




\begin{tabular}{|c|c|}
\hline & Knochenläsionen \\
\hline CXCR4 & CXC-Motiv-Chemokinrezeptor 4 \\
\hline \multirow[t]{2}{*}{ DGHO } & Deutsche Gesellschaft für Hämatologie und \\
\hline & Onkologie \\
\hline DNS & Desoxyribonukleinsäure \\
\hline \multirow[t]{2}{*}{ ELISA } & enzyme linked immunosorbent assay, \\
\hline & enzymgekoppelter Immunabsorptions-Test \\
\hline Fas-Ligand & CD95- Ligand \\
\hline \multirow[t]{2}{*}{ FACS } & fluorescence activated cell sorting, \\
\hline & Durchflusszytometrie \\
\hline \multirow[t]{2}{*}{ FCS } & fetal calf serum, \\
\hline & fetales Kälberserum \\
\hline \multirow[t]{2}{*}{ FGFR3 } & fibroblast growth factor receptor 3 , \\
\hline & Fibroblasten- Wachstumsfaktor-Rezeptor 3 \\
\hline \multirow[t]{3}{*}{ FKHR } & forkhead related transcription factor auch \\
\hline & foxo 1 a, Mitglied der Forkhead-Box-Protein \\
\hline & Familie \\
\hline \multirow[t]{2}{*}{ GSK-3 } & glycogen-synthase-kinase-3, \\
\hline & Glykogen-Synthase-Kinase-3 \\
\hline \multirow[t]{2}{*}{ HRP } & horseradish peroxidase, \\
\hline & Meerrettichperoxidase \\
\hline \multirow[t]{2}{*}{ Hsp90 } & heat shock protein 90 \\
\hline & Hitzeshock Protein 90 \\
\hline \multirow[t]{2}{*}{ IGF-1 } & insulin-like-growth-factor-1, insulinähnlicher \\
\hline & Wachstumsfaktor 1 \\
\hline IL-6 & Interleukin-6 \\
\hline \multirow[t]{2}{*}{ IMiDs $®$} & immunmodulatory drugs; \\
\hline & immunmodulatorische Medikamente \\
\hline
\end{tabular}




\begin{tabular}{|c|c|}
\hline IMWG & international myeloma working group \\
\hline ISS & international-staging system \\
\hline \multirow[t]{4}{*}{ JAK-STAT-Kinase } & januskinase-signal transducers and \\
\hline & activators of transcription-kinase, \\
\hline & Januskinase-Signalüberträger und \\
\hline & Aktivatoren der Transkription-Kinase \\
\hline \multirow[t]{2}{*}{ JPEG } & joint photographic experts group, \\
\hline & Begriff für ein Bildformat \\
\hline \multirow[t]{2}{*}{ MAP-Kinase } & mitogen-activated-protein-kinase, \\
\hline & mitogenaktivierte Proteinkinase \\
\hline \multirow[t]{2}{*}{ MCL-1 } & Myeloid cell leukemia sequence 1, Myeloide \\
\hline & Leukämie Sequenz 1 \\
\hline \multirow[t]{2}{*}{ MFI } & mean fluorescence intensity, mittlere \\
\hline & Fluoreszenzintensität \\
\hline \multirow[t]{2}{*}{ MGUS } & Monoklonale Gammopathie unklarer \\
\hline & Signifikanz \\
\hline \multirow[t]{2}{*}{ MHC } & major histocompatibility complex, \\
\hline & Haupthistokompatibilitätskomplex \\
\hline MMSET & multiple myeloma SET Domain \\
\hline mTOR & mammalian target of rapamycin \\
\hline mTORC2 & mTOR Komplex 2 \\
\hline \multirow[t]{2}{*}{ MTT } & 3-(4,5-Dimethylthiazol-2-yl)-2,5- \\
\hline & diphenyltetrazoliumbromid \\
\hline \multirow[t]{3}{*}{$\mathrm{NF}-\kappa \mathrm{B}$} & nuclear factor 'kappa-light-chain-enhancer' \\
\hline & of activated B-cells, \\
\hline & Kernfaktor-kappa von aktivierten B-Zellen \\
\hline OPG & Osteoprotegerin \\
\hline \multirow[t]{2}{*}{ PBS } & phosphate buffered saline; \\
\hline & phosphatgepufferte Salzlösung \\
\hline
\end{tabular}




\begin{tabular}{|c|c|}
\hline PDK1 & phosphoinositide-dependent kinase 1, \\
\hline & phosphoinositid-abhängige Kinase 1 \\
\hline PFA & Paraformaldehyd \\
\hline PH-Domäne & "Pleckstrin-Homologie"-Domäne \\
\hline PI & Phosphatidylinositol \\
\hline PI-3,4,5-P3 bzw. PIP3 & Phosphatidylinositol-3,4,5-trisphosphat \\
\hline PI3K & Phosphoinositid-3-Kinase \\
\hline PI-4,5-P2 bzw. PIP2 & Phosphatidylinositol-4,5-bisphosphat \\
\hline PI-4-P & Phosphatidylinositol-4-phosphat \\
\hline $\mathrm{PKC}$ & Proteinkinase $\mathrm{C}$ \\
\hline PTEN & phosphatase and tensin homolog \\
\hline RANKL & receptor activator of $N F-\kappa B$ Ligand, Rezeptor \\
\hline & Aktivator des NF- $\kappa B$ Liganden \\
\hline SDF1 $\alpha$ & stromal derived factor $1 \alpha$, Faktor stromaler \\
\hline & Herkunft $1 \alpha$ \\
\hline SDS & Natriumdodecylsulfat \\
\hline $\mathrm{TNF} \alpha$ & Tumornekrosefaktor $\alpha$ \\
\hline VEGF & $\begin{array}{l}\text { vascular endothelial growth factor, vaskulär- } \\
\text { endothelialer Wachstumsfaktor }\end{array}$ \\
\hline
\end{tabular}

\subsection{Verzeichnis der Einheiten}

\begin{tabular}{|ll|}
\hline Einheit & Bedeutung \\
$\mu 1$ & Mikroliter \\
${ }^{\circ} \mathrm{C}$ & Grad Celsius \\
\hline
\end{tabular}




\begin{tabular}{|ll|}
\hline G & G-Faktor: $\frac{\text { Beschleunigung }}{\text { Erdbeschleunigung }}=\frac{a}{g}$ \\
$\mathrm{~g}$ & Gramm \\
Min. & Stunde(n) \\
$\mathrm{ml}$ & Minuten \\
$\mathrm{nm}$ & Milliliter \\
$\mathrm{nM}$ & $10^{-9}$ Meter; Einheit der Wellenlänge \\
$\mathrm{nM}$ & Nanomol \\
$\mathrm{rpm}$ & nanomolar: $10^{-9}$ mol/L \\
$\mathrm{V}$ & revolutions per minute; Umdrehungen pro \\
& Minute \\
\hline
\end{tabular}

\subsection{Tabellen der Ergebnisse}

Tabelle 9: Hemmung der Aktivierung von Akt mit BAY 80-6946; MFI-Werte der durchflusszytometrischen Untersuchung (Phospho-Akt Färbung); alle Zellproben wurden mit BAY 80-6946 nach dem Konzentrationsschema 10 $\mathrm{nM}, 50 \mathrm{nM}$ und $100 \mathrm{nM}$ behandelt, anschließend fixiert, permeabilisiert, mit dem fluoreszenzmarkierten Phospho-AktAntikörper gefärbt und durchflusszytometrisch analysiert.

\begin{tabular}{|c|c|c|c|c|c|}
\hline \multicolumn{6}{|c|}{ MFI Phospho-Akt AMO-1 } \\
\hline & \multirow[t]{2}{*}{ Unbehandelt } & \multirow[t]{2}{*}{ Vehikel } & \multicolumn{3}{|c|}{ BAY 80-6946 } \\
\hline & & & $10 \mathrm{nM}$ & $50 \mathrm{nM}$ & $100 \mathrm{nM}$ \\
\hline 1 & 872 & 879 & 478 & 426 & 335 \\
\hline 2 & 844 & 850 & 491 & 437 & 360 \\
\hline 3 & 857 & 869 & 462 & 420 & 398 \\
\hline $1-3$ & Vergleich zur & Ikontrolle & $55,1 \%$ & $49,3 \%$ & $42,0 \%$ \\
\hline
\end{tabular}




\begin{tabular}{|c|c|c|c|c|c|}
\hline \multicolumn{6}{|c|}{ MFI Phospho-Akt KMS-12-BM } \\
\hline & \multirow[t]{2}{*}{ Unbehandelt } & \multirow[t]{2}{*}{ Vehikel } & \multicolumn{3}{|c|}{ BAY 80-6946 } \\
\hline & & & $10 \mathrm{nM}$ & $50 \mathrm{nM}$ & $100 \mathrm{nM}$ \\
\hline 1 & 580 & 598 & 417 & 383 & 357 \\
\hline 2 & 452 & 430 & 371 & 339 & 335 \\
\hline 3 & 533 & 525 & 412 & 403 & 369 \\
\hline \multirow[t]{4}{*}{$1-3$} & \multicolumn{2}{|c|}{ Vergleich zur Vehikelkontrolle } & 77,4 & 72,5 & 67,1 \\
\hline & \multicolumn{4}{|c|}{ MFI Phospho-Akt MOLP-8 } & \\
\hline & \multirow[t]{2}{*}{ Unbehandelt } & \multirow[t]{2}{*}{ Vehikel } & \multicolumn{3}{|c|}{ BAY 80-6946 } \\
\hline & & & $10 \mathrm{nM}$ & $50 \mathrm{nM}$ & $100 \mathrm{nM}$ \\
\hline 1 & 844 & 841 & 447 & 422 & 388 \\
\hline 2 & 983 & 979 & 573 & 491 & 437 \\
\hline 3 & 825 & 808 & 526 & 447 & 376 \\
\hline \multirow[t]{4}{*}{$1-3$} & \multicolumn{2}{|c|}{ Vergleich zur Vehikelkontrolle } & $\mathbf{5 8 , 8} \%$ & $51,7 \%$ & $45,7 \%$ \\
\hline & \multicolumn{4}{|c|}{ MFI Phospho-Akt U-266 } & \\
\hline & \multirow[t]{2}{*}{ Unbehandelt } & \multirow[t]{2}{*}{ Vehikel } & \multicolumn{3}{|c|}{ BAY 80-6946 } \\
\hline & & & $10 \mathrm{nM}$ & $50 \mathrm{nM}$ & $100 \mathrm{nM}$ \\
\hline 1 & 640 & 651 & 460 & 451 & 425 \\
\hline 2 & 691 & 684 & 533 & 470 & 427 \\
\hline 3 & 702 & 680 & 463 & 418 & 328 \\
\hline $1-3$ & \multicolumn{2}{|c|}{ Vergleich zur Vehikelkontrolle } & $72,2 \%$ & $66,4 \%$ & $\mathbf{5 0 , 4 \%}$ \\
\hline
\end{tabular}

Tabelle 10: Hemmung der IGF-1-stimulierten Aktivierung von Akt mit BAY 80-6946; MFI-Werte der durchflusszytometrischen Untersuchung (Phospho-Akt Färbung) von IGF-1-stimulierten AMO-1 und MOLP-8 Zellen. Die Zellen wurden mit BAY 80-6946 in FCS freiem Medium für 16 Stunden behandelt, anschließend mit 100ng/ml IGF-1 für 20 Minuten stimuliert, fixiert, permeabilisiert, $1 \times 10^{6}$ Zellen ausgezählt, in PBS gewaschen, mit AB-Serum blockiert, zentrifugiert, in $100 \mu \mathrm{l}$ PBS mit dem Antikörper bzw. Isotyp gefärbt. Anschließend wurden die MFI-Werte durchflusszytometrisch bestimmt. 


\begin{tabular}{|c|c|c|c|c|c|}
\hline \multicolumn{6}{|c|}{ MFI Phospho-Akt AMO-1 } \\
\hline \multirow[t]{2}{*}{ Versuch } & IGF-1-stim. & IGF-1-stim. & \multicolumn{3}{|c|}{ IGF-1-stim. +BAY 80-6946 } \\
\hline & unbehandelt & Vehikel & $10 \mathrm{nM}$ & $50 \mathrm{nM}$ & $100 \mathrm{nM}$ \\
\hline 1 & 1572 & 1556 & 1046 & 479 & 398 \\
\hline 2 & 1414 & 1433 & 931 & 507 & 419 \\
\hline $1+2$ & im Vergleich zt & hikelkontrolle & $66,5 \%$ & $33 \%$ & $27,3 \%$ \\
\hline \multicolumn{6}{|c|}{ MFI Phospho-Akt MOLP-8 } \\
\hline \multirow[t]{2}{*}{ Versuch } & IGF-1-stim. & IGF-1-stim. & \multicolumn{3}{|c|}{ IGF-1-stim. +BAY 80-6946 } \\
\hline & unbehandelt & Vehikel & $10 \mathrm{nM}$ & $50 \mathrm{nM}$ & $100 \mathrm{nM}$ \\
\hline 1 & 1381 & 1359 & 714 & 495 & 370 \\
\hline 2 & 1224 & 1232 & 823 & 494 & 364 \\
\hline $1+2$ & \multicolumn{2}{|c|}{ im Vergleich zur Vehikelkontrolle } & $59,3 \%$ & $38,2 \%$ & 28,3 \\
\hline
\end{tabular}

Tabelle 11: Apoptose-Assay mit dem „Cell Death Detection ELISA Plus“ von Roche®. Die Zellen wurden auf einer 96Well-Platte mit 25.000 Zellen pro Kulturgefäß ausgesät, mit BAY 80-6946 behandelt, lysiert, der Zellüberstand auf eine mit Streptavidin vorbeschichtete Mikroplatte gegeben. Anti-Histon-Biotin und Anti-DNS-Peroxidase-Antikörper hinzugegeben und $2 \mathrm{~h}$ inkubiert. Anschließend $100 \mu \mathrm{l}$ ABTS-Farblösung hinzupipettiert, 10-20 Minuten inkubiert, $100 \mu \mathrm{l}$ ABTSStopplösung hinzugegeben. Die Auswertung erfolgte photometrisch bei einer Absorption von $405 \mathrm{~nm}$ mit dem Mikroplattenlesegerät „Appliskan“. Um den Hintergrund zu minimieren, wurde zusätzlich bei einer Referenzwellenlänge von 490nm gemessen.

\begin{tabular}{|c|c|c|c|c|c|c|}
\hline \multirow[t]{2}{*}{ AMO-1 } & \multirow[t]{2}{*}{ Versuch } & \multirow[t]{2}{*}{ unbeh. } & \multirow[t]{2}{*}{ Vehikel } & \multicolumn{3}{|c|}{ BAY 80-6946 } \\
\hline & & & & $10 \mathrm{nM}$ & $50 \mathrm{nM}$ & $100 \mathrm{nM}$ \\
\hline Extinktionswerte bei & 1 & 0,422 & 0,402 & 0,646 & 0,827 & 1,049 \\
\hline $405 \mathrm{~nm}$ & 2 & 0,578 & 0,588 & 0,749 & 0,911 & 1,134 \\
\hline \multirow[t]{2}{*}{ Apoptoseraten } & 1 & - & 1,0 & 1,61 & 2,06 & 2,61 \\
\hline & 2 & - & 1,0 & 1,28 & 1,55 & 1,93 \\
\hline \multirow[t]{2}{*}{$\underline{\text { KMS-12-BM }}$} & Versuch & unbeh. & Vehikel & \multicolumn{3}{|c|}{ BAY 80-6946 } \\
\hline & & & & $10 \mathrm{nM}$ & $50 \mathrm{nM}$ & $100 \mathrm{nM}$ \\
\hline Extinktionswerte & 1 & 0,588 & 0,57 & 0,779 & 0,955 & 1,131 \\
\hline bei $405 \mathrm{~nm}$ & 2 & 0,61 & 0,624 & 0,929 & 1,063 & 1,387 \\
\hline Apoptoseraten & 1 & - & 1,0 & 1,37 & 1,68 & 1,99 \\
\hline
\end{tabular}




\begin{tabular}{|c|c|c|c|c|c|c|}
\hline \multirow{3}{*}{ MOLP-8 } & 2 & - & 1,0 & 1,49 & 1,7 & 2,22 \\
\hline & Versuch & unbeh. & Vehikel & \multicolumn{3}{|c|}{ BAY 80-6946 } \\
\hline & & & & $10 \mathrm{nM}$ & $50 \mathrm{nM}$ & $100 \mathrm{nM}$ \\
\hline \multirow{2}{*}{$\begin{array}{l}\text { Extinktionswerte } \\
\text { bei } 405 \mathrm{~nm}\end{array}$} & 1 & 0,52 & 0,43 & 0,81 & 0,85 & 1,03 \\
\hline & 2 & 0,634 & 0,648 & 0,864 & 0,926 & 1,189 \\
\hline \multirow[t]{2}{*}{ Apoptoseraten } & 1 & - & 1,0 & 1,879 & 1,971 & 2,390 \\
\hline & 2 & - & 1,0 & 1,334 & 1,43 & 1,84 \\
\hline \multirow[t]{2}{*}{$\underline{\mathrm{U}-266}$} & Versuch & unbeh. & Vehikel & \multicolumn{3}{|c|}{ BAY 80-6946 } \\
\hline & & & & $10 \mathrm{nM}$ & $50 \mathrm{nM}$ & $100 \mathrm{nM}$ \\
\hline \multirow{2}{*}{$\begin{array}{l}\text { Extinktionswerte } \\
\text { bei } 405 \mathrm{~nm}\end{array}$} & 1 & 0,818 & 0,79 & 1,34 & 1,54 & 1,77 \\
\hline & 2 & 0,752 & 0,706 & 0,954 & 1,070 & 2,199 \\
\hline \multirow[t]{2}{*}{ Apoptoseraten } & 1 & - & 1,0 & 1,696 & 1,95 & 2,24 \\
\hline & 2 & - & 1,0 & 1,35 & 1,52 & 3,12 \\
\hline
\end{tabular}

Tabelle 12: Proliferations-Assay-Analyse mit dem „Cell Titer 96 Non-radioactive Cell Proliferation-Assay“ von Promega ${ }^{\circledR}$. Die Zellen wurden mit 25.000 Zellen pro Kulturgefäß auf einer 96-Well-Platte ausgesät, BAY 80-6946 in entsprechender Konzentration hinzugegeben, 24 Stunden in den Inkubator gestellt, $15 \mu 1$ „Dye Solution“ hinzupipettiert und für weitere vier Stunden inkubiert. Danach wurden $100 \mu$ l Solubilisationslösung hinzugegeben und die 96-Well-Platte erneut für 24 Stunden inkubiert. Die Auswertung der Proliferations-Assay-Analyse erfolgte photometrisch mit Hilfe des Mikroplattenreaders „Appliskan“ bei einer Wellenlänge von $570 \mathrm{~nm}$. Um den Hintergrund zu minimieren, erfolgte eine weitere Messung bei der Referenzwellenlänge $630 \mathrm{~nm}$.

\begin{tabular}{|c|c|c|c|c|c|c|}
\hline \multirow[t]{2}{*}{$\underline{\text { AMO-1 }}$} & \multirow[t]{2}{*}{ Versuch } & \multirow[t]{2}{*}{ unbeh. } & \multirow[t]{2}{*}{ Vehikel } & \multicolumn{3}{|c|}{ BAY 80-6946 } \\
\hline & & & & $10 \mathrm{nM}$ & $50 \mathrm{nM}$ & $100 \mathrm{nM}$ \\
\hline & 1 & 1,277 & 1,294 & 1,174 & 1,051 & 0,926 \\
\hline \multirow{3}{*}{$\begin{array}{l}\text { Extinktionswerte } \\
\text { bei } 570 \mathrm{~nm}\end{array}$} & 2 & 1,397 & 1,341 & 1,248 & 1,100 & 0,988 \\
\hline & 3 & 1,350 & 1,368 & 1,271 & 1,109 & 0,994 \\
\hline & 1 & - & 1,0 & 0,907 & 0,812 & 0,716 \\
\hline \multirow[t]{2}{*}{ Proliferationsraten } & 2 & - & 1,0 & 0,931 & 0,82 & 0,74 \\
\hline & 3 & - & 1,0 & 0,929 & 0,811 & 0,727 \\
\hline \multirow[t]{3}{*}{$\underline{\text { KMS-12-BM }}$} & Versuch & unbeh. & Vehikel & \multicolumn{3}{|c|}{ BAY 80-6946 } \\
\hline & & & & $10 \mathrm{nM}$ & $50 \mathrm{nM}$ & $100 \mathrm{nM}$ \\
\hline & 1 & 0,892 & 0,877 & 0,796 & 0,772 & 0,732 \\
\hline
\end{tabular}




\begin{tabular}{|c|c|c|c|c|c|c|}
\hline Extinktionswerte & 2 & 0,836 & 0,829 & 0,764 & 0,718 & 0,676 \\
\hline \multirow[t]{2}{*}{ bei $570 \mathrm{~nm}$} & 3 & 0,844 & 0,839 & 0,784 & 0,741 & 0,725 \\
\hline & 1 & - & 1,0 & 0,908 & 0,880 & 0,835 \\
\hline \multirow[t]{2}{*}{ Proliferationsraten } & 2 & - & 1,0 & 0,922 & 0,866 & 0,815 \\
\hline & 3 & - & 1,0 & 0,934 & 0,883 & 0,864 \\
\hline \multirow[t]{3}{*}{ MOLP-8 } & Versuch & unbeh. & Vehikel & \multicolumn{3}{|c|}{ BAY 80-6946 } \\
\hline & & & & $10 \mathrm{nM}$ & $50 \mathrm{nM}$ & $100 \mathrm{nM}$ \\
\hline & 1 & 1,137 & 1,074 & 1,04 & 0,913 & 0,837 \\
\hline \multirow{3}{*}{$\begin{array}{c}\text { Extinktionswerte } \\
\text { bei } 570 \mathrm{~nm}\end{array}$} & 2 & 1,158 & 1,145 & 1,044 & 0,932 & 0,838 \\
\hline & 3 & 1,172 & 1,166 & 1,046 & 0,941 & 0,864 \\
\hline & 1 & - & 1,0 & 0,968 & 0,850 & 0,779 \\
\hline \multirow[t]{2}{*}{ Proliferationsraten } & 2 & - & 1,0 & 0,912 & 0,814 & 0,732 \\
\hline & 3 & - & 1,0 & 0,897 & 0,807 & 0,801 \\
\hline \multirow[t]{3}{*}{$\underline{\mathrm{U}-266}$} & Versuch & unbeh. & Vehikel & \multicolumn{3}{|c|}{ BAY 80-6946 } \\
\hline & & & & $10 \mathrm{nM}$ & $50 \mathrm{nM}$ & $100 \mathrm{nM}$ \\
\hline & 1 & 0,714 & 0,702 & 0,664 & 0,660 & 0,622 \\
\hline \multirow{3}{*}{$\begin{array}{l}\text { Extinktionswerte } \\
\text { bei } 570 \mathrm{~nm}\end{array}$} & 2 & 0,782 & 0,796 & 0,747 & 0,759 & 0,658 \\
\hline & 3 & 0,824 & 0,805 & 0,797 & 0,789 & 0,755 \\
\hline & 1 & - & 1,0 & 0,946 & 0,940 & 0,886 \\
\hline \multirow[t]{2}{*}{ Proliferationsraten } & 2 & - & 1,0 & 0,938 & 0,954 & 0,827 \\
\hline & 3 & - & 1,0 & 0,990 & 0,980 & 0,938 \\
\hline
\end{tabular}

Tabelle 13: Durchflusszytometrische Zellzyklusanalyse; Zelllinie MOLP-8. Für die durchflusszytometrische Analyse wurden die Zellen in 6-Well-Platten mit BAY 80-6946 behandelt, mit Ethanol fixiert und permeabilisiert und bei $-20{ }^{\circ} \mathrm{C}$ eingefroren. Für die Färbung wurden $50 \mu \mathrm{l}$ RNAse $1(1 \mathrm{mg} / \mathrm{ml}$ PBS) und $25 \mu 1$ Propidiumiodid (1 mg/ml PBS) hinzupipettiert, 30 Minuten bei Raumtemperatur lichtgeschützt inkubiert und bei niedriger Flussgeschwindigkeit durchflusszytometrisch analysiert. 


\begin{tabular}{|c|c|c|c|c|}
\hline \multirow[t]{2}{*}{ Behandlungszeit } & \multirow[t]{2}{*}{ Konzentration BAY 80-6946 } & \multicolumn{3}{|c|}{ Zellzyklusphase (Zellzahl in \%) } \\
\hline & & $\mathrm{G} 0 / 1$ & $S$ & $\mathrm{G} 2 / \mathrm{M}$ \\
\hline $\mathrm{Oh}$ & unbehandelt & 45 & 32,9 & 22,1 \\
\hline \multirow[t]{4}{*}{$4 \mathrm{~h}$} & unbehandelt & 41,3 & 41,50 & 17,20 \\
\hline & $10 \mathrm{nM}$ & 42,3 & 40,70 & 17,00 \\
\hline & $50 \mathrm{nM}$ & 46,9 & 42,20 & 10,90 \\
\hline & $100 \mathrm{nM}$ & 49,80 & 44,10 & 6,10 \\
\hline \multirow[t]{4}{*}{$12 \mathrm{~h}$} & unbehandelt & 47,40 & 30,50 & 22,00 \\
\hline & $10 \mathrm{nM}$ & 51,10 & 32,20 & 16,80 \\
\hline & $50 \mathrm{nM}$ & 51,20 & 31,40 & 17,40 \\
\hline & $100 \mathrm{nM}$ & 55,00 & 29,30 & 15,70 \\
\hline \multirow[t]{4}{*}{$24 \mathrm{~h}$} & unbehandelt & 52,70 & 33,80 & 13,50 \\
\hline & $10 \mathrm{nM}$ & 59,70 & 31,30 & 9,00 \\
\hline & $50 \mathrm{nM}$ & 63,00 & 22,80 & 14,20 \\
\hline & $100 \mathrm{nM}$ & 68,00 & 20,00 & 12,00 \\
\hline
\end{tabular}

Tabelle 14: Peritoneallavage Zelllinie AMO-1. Die Zellproben wurden zunächst ausgezählt, um die Gesamtzellzahl zu ermitteln. Um den Prozentsatz an humanen Myelom-Zellen zu ermitteln, wurde eine Färbung einem gegen $H L A-A B C$ gerichteten Antikörper durchgeführt und diese durchflusszytometrisch analysiert. Für die Färbung wurden 100.000 Zellen pro Probe in $100 \mu \mathrm{l}$ PBS überführt, Antikörper hinzupipettiert und für eine Stunde bei $4{ }^{\circ} \mathrm{C}$ inkubiert, gewaschen, zentrifugiert, in $500 \mu \mathrm{PBS}$ aufgenommen und anschließend durchflusszytometrisch analysiert. Als Negativkontrolle wurde jeweils eine Probe mit dem passenden Isotyp gefärbt. Abschließend konnte aus der Gesamtzellzahl und dem Prozentsatz an $H L A-A B C$ positiven Zellen die absolute Zellzahl der Myelom-Zellen ermittelt werden.

\section{Peritoneallavage Zelllinie AMO-1}

$\begin{array}{ccccc}\text { Maus Behandlung } & \begin{array}{l}\text { Gesamtzellzahl } \\ \text { Peritoneallavage }\end{array} & \begin{array}{l}H L A \text { - } A B C \text {-positiv } \\ \text { (in \%) }\end{array} & \begin{array}{l}\text { Myelom-Zellen } \\ \text { Peritoneallavage }\end{array} \\ 1 & \text { Vehikel } & 3390000 & 66,9 & 2267910\end{array}$




\begin{tabular}{|c|c|c|c|c|}
\hline 2 & & 1640000 & 61,5 & 1008600 \\
\hline 3 & & \multicolumn{3}{|c|}{ Kein Ergebnis } \\
\hline 4 & & 1500000 & 52,5 & 787500 \\
\hline 5 & BAY 80-6946 & 510000 & 67,3 & 343230 \\
\hline 6 & & 840000 & 29,6 & 248640 \\
\hline 7 & & 765000 & 7,5 & 57375 \\
\hline 8 & & 600000 & $9,3 \%$ & 55800 \\
\hline
\end{tabular}

Tabelle 15: Peritoneallavage Zelllinie MOLP-8. Die Zellproben wurden zunächst ausgezählt, um die Gesamtzellzahl zu ermitteln. Um den Prozentsatz an humanen Myelom-Zellen zu ermitteln, wurde eine Färbung einem gegen $H L A-A B C$ gerichteten Antikörper durchgeführt und diese durchflusszytometrisch analysiert. Für die Färbung wurden 100.000 Zellen pro Probe in $100 \mu \mathrm{l}$ PBS überführt, Antikörper hinzupipettiert und für eine Stunde bei $4{ }^{\circ} \mathrm{C}$ inkubiert, gewaschen, zentrifugiert, in $500 \mu 1$ PBS aufgenommen und anschließend durchflusszytometrisch analysiert. Als Negativkontrolle wurde jeweils eine Probe mit dem passenden Isotyp gefärbt. Abschließend konnte aus der Gesamtzellzahl und dem Prozentsatz an $H L A-A B C$ positiven Zellen die absolute Zellzahl der Myelom-Zellen ermittelt werden.

\begin{tabular}{|c|c|c|c|c|}
\hline \multicolumn{5}{|c|}{ Peritoneallavage Zelllinie MOLP-8 } \\
\hline Maus & Behandlung & $\begin{array}{l}\text { Gesamtzellzahl } \\
\text { Peritoneallavage }\end{array}$ & $\begin{array}{l}H L A-A B C \text {-positiv } \\
\text { (in \%) }\end{array}$ & $\begin{array}{l}\text { Myelom-Zellen } \\
\text { Peritoneallavage }\end{array}$ \\
\hline 9 & Vehikel & 1290000 & 32,5 & 419250 \\
\hline 10 & & 1390000 & 33,8 & 469820 \\
\hline 11 & & 1800000 & 30,1 & 541800 \\
\hline 12 & & 2670000 & 24,7 & 659490 \\
\hline 13 & & 1770000 & 28,3 & 500910 \\
\hline Maus & Behandlung & $\begin{array}{l}\text { Gesamtzellzahl } \\
\text { Peritoneallavage }\end{array}$ & $\begin{array}{l}H L A-A B C \text {-positiv } \\
\text { (in \%) }\end{array}$ & $\begin{array}{l}\text { Myelom-Zellen } \\
\text { Peritoneallavage }\end{array}$ \\
\hline 14 & BAY 80-6946 & 1170000 & 23,5 & 274950 \\
\hline 15 & & 1000000 & 16,5 & 165000 \\
\hline 16 & & 545000 & 18,4 & 100280 \\
\hline 17 & & 300000 & 36,4 & 109200 \\
\hline 18 & & 610000 & 22,5 & 137250 \\
\hline 19 & Kontrolle & 300000 & 0 & 0 \\
\hline
\end{tabular}




\section{$7 \quad$ Literaturverzeichnis}

Alkan S, Izban KF (2002): Immunohistochemical localization of phosphorylated AKT in multiple myeloma. Blood 99, 2278-2279

Anderson KC, Kyle RA, Dalton WS, Landowski T, Shain K, Jove R, Hazlehurst L, Berenson J (2000): Multiple Myeloma: New Insights and Therapeutic Approaches. Hematology Am Soc Hematol Educ Program 147-165

Anderson KE, Jackson SP (2003): Class I phosphoinositide 3-kinases. Int J Biochem Cell Biol $\underline{35}, 1028-1033$

Anderson KC, Carrasco RD (2011): Pathogenesis of myeloma. Annu Rev Pathol $\underline{6}$, 249-274 Anderson KC, Alsina M, Bensinger W, Biermann JS, Chanan-Khan A, Cohen AD, Devine S, Djulbegovic B, Faber EA Jr, Gasparetto C, Huff CA, Kassim A, Medeiros BC, Meredith R, Raje N, Schriber J, Singhal S, Somlo G, Stockerl-Goldstein K, Treon SP, Tricot G, Weber

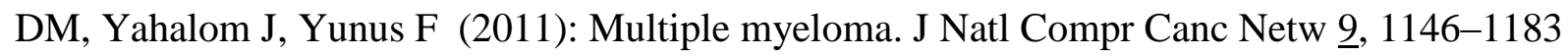
Attal M, Harousseau JL, Stoppa AM, Sotto JJ, Fuzibet JG, Rossi JF, Casassus P, Maisonneuve H, Facon T, Ifrah N, Payen C, Bataille R (1996): A prospective, randomized trial of autologous bone marrow transplantation and chemotherapy in multiple myeloma. Intergroupe Français du Myélome. N Engl J Med 335, 91-97

Bader AG, Kang S, Vogt PK (2006): Cancer-specific mutations in PIK3CA are oncogenic in vivo. Proc Natl Acad Sci USA $\underline{103}, 1475-1479$

Badros AZ (2010): In the age of novel therapies, what defines high-risk multiple myeloma? J Natl Compr Canc Netw 8 Suppl 1, S28-34

Bataille R, Jégo G, Robillard N, Barillé-Nion S, Harousseau J-L, Moreau P, Amiot M, PellatDeceunynck C (2006): The phenotype of normal, reactive and malignant plasma cells. Identification of „many and multiple myelomas“ and of new targets for myeloma therapy. Haematologica 91, 1234-1240

Bergsagel PL, Kuehl WM, Zhan F, Sawyer J, Barlogie B, Shaughnessy J Jr (2005): Cyclin D dysregulation: an early and unifying pathogenic event in multiple myeloma. Blood 106, 296303 
Bio-Rad Instruction Manual, Bio-Rad Protein Assay.

Brachmann S, Fritsch C, Maira S-M, García-Echeverría C (2009): PI3K and mTORInhibitors: a new generation of targeted anticancer agents. Curr Opin Cell Biol 21, 194-198

Bradford MM (1976): A rapid and sensitive method for the quantitation of microgram quantities of protein utilizing the principle of protein-dye binding. Anal Biochem $\underline{72}, 248-254$

Brenner H, Gondos A, Pulte D (2008): Recent major improvement in long-term survival of younger patients with multiple myeloma. Blood $\underline{111}$, 2521-2526

Burnette WN (1981): „Western blotting“: electrophoretic transfer of proteins from sodium dodecyl sulfate--polyacrylamide gels to unmodified nitrocellulose and radiographic detection with antibody and radioiodinated protein A. Anal Biochem 112, 195-203

Carpenter CL, Duckworth BC, Auger KR, Cohen B, Schaffhausen BS, Cantley LC (1990): Purification and characterization of phosphoinositide 3-kinase from rat liver. J Biol Chem $\underline{265}, 19704-19711$

Carpenter CL, Auger KR, Chanudhuri M, Yoakim M, Schaffhausen B, Shoelson S, Cantley LC (1993): Phosphoinositide 3-kinase is activated by phosphopeptides that bind to the SH2 domains of the 85-kDa subunit. J Biol Chem $\underline{268}, 9478-9483$

Cell Signaling Technology® (2009): Flow Cytometry Protocol. URL: http://www.cellsignal.com/support/protocols/Flow.html

Choo SY (2007): The HLA System: Genetics, Immunology, Clinical Testing, and Clinical Implications. Yonsei Med J $\underline{48}, 11-23$

Courtney KD, Corcoran RB, Engelman JA (2010): The PI3K pathway as drug target in human cancer. J Clin Oncol 28, 1075-1083

Covelli A (1999): Modulation of multidrug resistance (MDR) in hematological malignancies. Ann Oncol 10 Suppl 6, 53-59

Crabbe T, Welham MJ, Ward SG (2007): The PI3K inhibitor arsenal: choose your weapon! Trends Biochem Sci $\underline{32}, 450-456$

Cross DA, Alessi DR, Cohen P, Andjelkovich M, Hemmings BA (1995): Inhibition of glycogen synthase kinase- 3 by insulin mediated by protein kinase B. Nature $\underline{378}, 785-789$ Dahia PL (2000): PTEN, a unique tumor suppressor gene. Endocr Relat Cancer 7, 115-129 
Dai DL, Martinka M, Li G (2005): Prognostic significance of activated Akt expression in melanoma: a clinicopathologic study of 292 cases. J Clin Oncol $\underline{23}$, 1473-1482

Dankbar B, Padró T, Leo R, Feldmann B, Kropff M, Mesters RM, Serve H, Berdel WE, Kienast J (2000): Vascular endothelial growth factor and interleukin-6 in paracrine tumorstromal cell interactions in multiple myeloma. Blood 95, 2630-2636

Datta SR, Dudek H, Tao X, Masters S, Fu H, Gotoh Y, Greenberg ME (1997): Akt phosphorylation of BAD couples survival signals to the cell-intrinsic death machinery. Cell 91, 231-241

Datta SR, Brunet A, Greenberg ME (1999): Cellular survival: a play in three Akts. Genes Dev $\underline{13}, 2905-2927$

Dean N, McKay R, Miraglia L, Howard R, Cooper S, Giddings J, Nicklin P, Meister L, Ziel R, Geiger T, Muller M, Fabbro D (1996): Inhibition of growth of human tumor cell lines in nude mice by an antisense of oligonucleotide inhibitor of protein kinase C-alpha expression. Cancer Res $\underline{56}, 3499-3507$

Diehl JA, Cheng M, Roussel MF, Sherr CJ (1998): Glycogen synthase kinase-3beta regulates cyclin D1 proteolysis and subcellular localization. Genes Dev 12, 3499-3511

Donk NWCJ van de, Lokhorst HM, Bloem AC (2005): Growth factors and antiapoptotic signaling pathways in multiple myeloma. Leukemia 19, 2177-2185

Donk NWCJ van de, Lokhorst HM, Dimopoulos M, Cavo M, Morgan G, Einsele H, Kropff M, Schey S, Avet-Loiseau H, Ludwig H, Goldschmidt H, Sonneveld P, Johnsen HE, Bladé J, San-Miguel JF, Palumbo A (2011): Treatment of relapsed and refractory multiple myeloma in the era of novel agents. Cancer Treat Rev $\underline{37}, 266-283$

Downward J (2004): PI 3-kinase, Akt and cell survival. Semin Cell Dev Biol 15, 177-182

Durie BG, Salmon SE (1975): A clinical staging system for multiple myeloma. Correlation of measured myeloma cell mass with presenting clinical features, response to treatment, and survival. Cancer $\underline{36}, 842-854$

Eleutherakis-Papaiakovou V, Bamias A, Gika D, Simeonidis A, Pouli A, Anagnostopoulos A, Michali E, Economopoulos T, Zervas K, Dimopoulos MA (2007): Renal failure in multiple myeloma: incidence, correlations, and prognostic significance. Leuk Lymphoma $\underline{48}$, 337-341 
Facon T, Mary JY, Hulin C, Benboubker L, Attal M, Pegourie B, Renaud M, Harousseau JL, Guillerm G, Chaleteix C, Dib M, Voillat L, Maisonneuve H, Troncy J, Dorvaux V, Monconduit M, Martin C, Casassus P, Jaubert J, Jardel H, Doyen C, Kolb B, Anglaret B, Grosbois B, Yakoub-Agha I, Mathiot C, Avet-Loiseau H (2007): Melphalan and prednisone plus thalidomide versus melphalan and prednisone alone or reduced-intensity autologous stem cell transplantation in elderly patients with multiple myeloma (IFM 99-06): a randomised trial. Lancet $\underline{370}, 1209-1218$

Ferlin M, Noraz N, Hertogh C, Brochier J, Taylor N, Klein B (2000): Insulin-like growth factor induces the survival and proliferation of myeloma cells through an interleukin-6independent transduction pathway. Br J Haematol 111, 626-634

Franke TF, Hornik CP, Segev L, Shostak GA, Sugimoto C (2003): PI3K-Akt and apoptosis: size matters. Oncogene 22, 8983-8998

Geering B, Cutillas PR, Nock G, Gharbi SI, Vanhaesebroeck B (2007): Class IA phosphoinositide 3-kinases are obligate p85-p1 10 heterodimers. Proc Natl Acad Sci USA 104, 7809-7814

Ghobrial IM, Witzig TE, Adjei AA (2005): Targeting apoptosis pathways in cancer therapy. CA Cancer J Clin $\underline{55}, 178-194$

Ghobrial IM, Leleu X, Hatjiharissi E, Hideshima T, Mitsiades C, Schlossman R, Anderson KC, Richardson P (2007): Emerging drugs in multiple myeloma. Expert Opin Emerg Drugs $\underline{12}, 155-163$

Ghosh N, Matsui W (2009): Cancer stem cells in multiple myeloma. Cancer Lett $\underline{277}, 1-7$ Glauer J, Pletz N, Schön M, Schneider P, Liu N, Ziegelbauer K, Emmert S, Wulf GG, Schön MP (2013: A novel selective small-molecule PI3K inhibitor is effective against human multiple myeloma in vitro and in vivo. Blood Cancer J.

Goekjian PG, Jirousek MR (2001): Protein kinase C inhibitors as novel anticancer drugs. Expert Opin Investig Drugs $\underline{10}, 2117-2140$

Greipp PR, San Miguel J, Durie BGM, Crowley JJ, Barlogie B, Bladé J, Boccadoro M, Child JA, Avet-Loiseau H, Harousseau J-L, Kyle RA, Lahuerta JJ, Ludwig H, Morgan G, Powles R, Shimizu K, Shustik C, Sonneveld P, Tosi P, Turesson I, Westin J (2005): International staging system for multiple myeloma. J Clin Oncol $\underline{23}, 3412-3420$ 
Hagemeier H: Molekulare Wirkmechanismen des IGF-1-Rezeptor-Antagonisten NVPAEW541 beim Multiplen Myelom, Med. Diss. Ludwig-Maximilian-Universität München 2012.

Harousseau J-L, Attal M, Avet-Loiseau H, Marit G, Caillot D, Mohty M, Lenain P, Hulin C, Facon T, Casassus P, Michallet M, Maisonneuve H, Benboubker L, Maloisel F, Petillon M-O, Webb I, Mathiot C, Moreau P (2010): Bortezomib plus dexamethasone is superior to vincristine plus doxorubicin plus dexamethasone as induction treatment prior to autologous stem-cell transplantation in newly diagnosed multiple myeloma: results of the IFM 2005-01 phase III trial. J Clin Oncol 28, 4621-4629

Hazlehurst LA, Damiano JS, Buyuksal I, Pledger WJ, Dalton WS (2000): Adhesion to fibronectin via beta1 integrins regulates p27kip1 levels and contributes to cell adhesion mediated drug resistance (CAM-DR). Oncogene 19, 4319-4327

Hideshima T, Anderson KC (2002): Molecular mechanisms of novel therapeutic approaches for multiple myeloma. Nat Rev Cancer 2, 927-937

Hideshima T, Chauhan D, Schlossman R, Richardson P, Anderson KC (2001a): The role of tumor necrosis factor alpha in the pathophysiology of human multiple myeloma: therapeutic applications. Oncogene 20, 4519-4527

Hideshima T, Nakamura N, Chauhan D, Anderson KC (2001b): Biologic sequelae of interleukin-6 induced PI3-K/Akt signaling in multiple myeloma. Oncogene 20, 5991-6000

Hideshima T, Bergsagel PL, Kuehl WM, Anderson KC (2004): Advances in biology of multiple myeloma: clinical applications. Blood 104, 607-618

Hideshima T, Chauhan D, Richardson P, Anderson KC (2005): Identification and validation of novel therapeutic targets for multiple myeloma. J Clin Oncol $\underline{23}$, 6345-6350

Hideshima T, Catley L, Yasui H, Ishitsuka K, Raje N, Mitsiades C, Podar K, Munshi NC, Chauhan D, Richardson PG, Anderson KC (2006): Perifosine, an oral bioactive novel alkylphospholipid, inhibits Akt and induces in vitro and in vivo cytotoxicity in human multiple myeloma cells. Blood 107, 4053-4062

Hideshima T, Mitsiades C, Tonon G, Richardson PG, Anderson KC (2007): Understanding multiple myeloma pathogenesis in the bone marrow to identify new therapeutic targets. Nat Rev Cancer 7, 585-598 
Howard A, Pelc SR (1986): Synthesis of Desoxyribonucleic Acid in Normal and Irradiated Cells and Its Relation to Chromosome Breakage. Int J Rad Biol 499, 207-218

Howlander N, Noone A, Krapcho M, Neyman N, Aminou R, Waldron W, Altekruse, Kosary C, Ruhl J, Tatalovich Z, Cho H, Mariotto A, Eisner M, Lewis D, Chen H, Feuer E, Cronin K, Edwards B (2011): SEER Cancer Statistics Review, 1975-2008, National Cancer Institute. Bethesda, MD. http://seer.cancer.gov/csr/1975_2008/

Hsu J, Shi Y, Krajewski S, Renner S, Fisher M, Reed JC, Franke TF, Lichtenstein A (2001): The AKT kinase is activated in multiple myeloma tumor cells. Blood 98, 2853-2855

Ikeda H, Hideshima T, Fulciniti M, Perrone G, Miura N, Yasui H, Okawa Y, Kiziltepe T, Santo L, Vallet S, Cristea D, Calabrese E, Gorgun G, Raje NS, Richardson P, Munshi NC, Lannutti BJ, Puri KD, Giese NA, Anderson KC (2010): PI3K/p110\{delta $\}$ is a novel therapeutic target in multiple myeloma. Blood $\underline{116}, 1460-1468$

Invitrogen (2003): Instruction Manual WesternBreeze $®$ Chromogenic Western Blot Immunodetection Kit; Catalog nos. WB7103, WB7105, WB 7107.

Jagannath S (2008): Pathophysiological underpinnings of multiple myeloma progression. J Manag Care Pharm 14, 7-11

Jantunen E, Kuittinen T, Penttilä K, Lehtonen P, Mahlamäki E, Nousiainen T (2006): Highdose melphalan $(200 \mathrm{mg} / \mathrm{m} 2)$ supported by autologous stem cell transplantation is safe and effective in elderly (>or=65 years) myeloma patients: comparison with younger patients treated on the same protocol. Bone Marrow Transplant 37, 917-922

Jimenez C, Jones DR, Rodríguez-Viciana P, Gonzalez-García A, Leonardo E, Wennström S, Kobbe C von, Toran JL, R-Borlado L, Calvo V, Copin SG, Albar JP, Gaspar ML, Diez E, Marcos MA, Downward J, Martinez-A C, Mérida I, Carrera AC (1998): Identification and characterization of a new oncogene derived from the regulatory subunit of phosphoinositide 3-kinase. EMBO J 17, 743-753

Jourdan M, Tarte K, Legouffe E, Brochier J, Rossi JF, Klein B (1999): Tumor necrosis factor is a survival and proliferation factor for human myeloma cells. Eur Cytokine Netw $\underline{10}, 65-70$ Kandel ES, Hay N (1999): The regulation and activities of the multifunctional serine/threonine kinase Akt/PKB. Exp Cell Res 253, 210-229

Kastritis E, Zervas K, Symeonidis A, Terpos E, Delimbassi S, Anagnostopoulos N, Michali E, Zomas A, Katodritou E, Gika D, Pouli A, Christoulas D, Roussou M, Kartasis Z, 
Economopoulos T, Dimopoulos MA (2009): Improved survival of patients with multiple myeloma after the introduction of novel agents and the applicability of the International Staging System (ISS): an analysis of the Greek Myeloma Study Group (GMSG). Leukemia $\underline{23}, 1152-1157$

Knudson A (2001): Two genetic hits (more or less) to cancer. Nat Rev Cancer 1 , 157-162 Kortüm M, Einsele H, Naumann R, Peest D, Liebisch P, Goldschmidt H (2010): Leitlinie Multiples Myelom der Deutschen Gesellschaft für Hämatologie und Onkologie.

Kuehl WM, Bergsagel PL (2002): Multiple myeloma: evolving genetic events and host interactions. Nat Rev Cancer $\underline{2}, 175-187$

Kumar SK, Rajkumar SV, Dispenzieri A, Lacy MQ, Hayman SR, Buadi FK, Zeldenrust SR, Dingli D, Russell SJ, Lust JA, Greipp PR, Kyle RA, Gertz MA (2008): Improved survival in multiple myeloma and the impact of novel therapies. Blood $\underline{111}, 2516-2520$

Kumar A, Galeb S, Djulbegovic B (2011): Treatment of patients with multiple myeloma: an overview of systematic reviews. Acta Haematol $\underline{125}, 8-22$

Kyle RA, Gertz MA, Witzig TE, Lust JA, Lacy MQ, Dispenzieri A, Fonseca R, Rajkumar SV, Offord JR, Larson DR, Plevak ME, Therneau TM, Greipp PR (2003): Review of 1027 patients with newly diagnosed multiple myeloma. Mayo Clin Proc $\underline{78}, 21-33$

Kyle RA, Rajkumar SV (2007): Monoclonal gammopathy of undetermined significance and smouldering multiple myeloma: emphasis on risk factors for progression. Br J Haematol $\underline{139}$, $730-743$

Kyle RA, Rajkumar SV (2009): Criteria for diagnosis, staging, risk stratification and response assessment of multiple myeloma. Leukemia $\underline{23}, 3-9$

Landgren O, Kyle RA, Pfeiffer RM, Katzmann JA, Caporaso NE, Hayes RB, Dispenzieri A, Kumar S, Clark RJ, Baris D, Hoover R, Rajkumar SV (2009): Monoclonal gammopathy of undetermined significance (MGUS) consistently precedes multiple myeloma: a prospective study. Blood $\underline{113}, 5412-5417$

Landowski TH, Olashaw NE, Agrawal D, Dalton WS (2003): Cell adhesion-mediated drug resistance (CAM-DR) is associated with activation of NF-kappa B (RelB/p50) in myeloma cells. Oncogene 22, 2417-2421 
Laviola L, Natalicchio A, Giorgino F (2007): The IGF-I signaling pathway. Curr Pharm Des $\underline{13}, 663-669$

Lentzsch S, Chatterjee M, Gries M, Bommert K, Gollasch H, Dörken B, Bargou RC (2004): PI3-K/AKT/FKHR and MAPK signaling cascades are redundantly stimulated by a variety of cytokines and contribute independently to proliferation and survival of multiple myeloma cells. Leukemia $\underline{18}, 1883-1890$

Li J, Yen C, Liaw D, Podsypanina K, Bose S, Wang SI, Puc J, Miliaresis C, Rodgers L, McCombie R, Bigner SH, Giovanella BC, Ittmann M, Tycko B, Hibshoosh H, Wigler MH, Parsons R (1997): PTEN, a putative protein tyrosine phosphatase gene mutated in human brain, breast, and prostate cancer. Science 275, 1943-1947

Liu N, Ziegelbauer K (nicht veröffentlicht): Biochemische Aktivität von BAY 80-6946; Kinase-Assay. BayerHealthCare, Wuppertal, Deutschland

Luo J, Manning BD, Cantley LC (2003): Targeting the PI3K-Akt pathway in human cancer: rationale and promise. Cancer Cell $\underline{4}, 257-262$

Maehama T, Dixon JE (1998): The tumor suppressor, PTEN/MMAC1, dephosphorylates the lipid second messenger, phosphatidylinositol 3,4,5-trisphosphate. J Biol Chem 273 , 1337513378

Maehama T (2007): PTEN: its deregulation and tumorigenesis. Biol Pharm Bull $\underline{30}$, 16241627

Maira S-M, Stauffer F, Brueggen J, Furet P, Schnell C, Fritsch C, Brachmann S, Chène P, Pover A De, Schoemaker K, Fabbro D, Gabriel D, Simonen M, Murphy L, Finan P, Sellers W, García-Echeverría C (2008): Identification and characterization of NVP-BEZ235, a new orally available dual phosphatidylinositol 3-kinase/mammalian target of rapamycin inhibitor with potent in vivo antitumor activity. Mol Cancer Ther $\underline{7}, 1851-1863$

Matsuo Y, Drexler HG, Harashima A, Okochi A, Hasegawa A, Kojima K, Orita K (2004): Induction of CD28 on the new myeloma cell line MOLP-8 with $\mathrm{t}(11 ; 14)(\mathrm{q} 13 ; \mathrm{q} 32)$ expressing delta/lambda type immunoglobulin. Leuk Res $\underline{28}, 869-877$

Miller L (2010): Analyzing gels and western blots with ImageJ.

Min YH, Cheong J-W, Kim JY, Eom JI, Lee ST, Hahn JS, Ko YW, Lee MH (2004):

Cytoplasmic mislocalization of $\mathrm{p} 27 \mathrm{Kip} 1$ protein is associated with constitutive 
phosphorylation of Akt or protein kinase B and poor prognosis in acute myelogenous leukemia. Cancer Res $\underline{64}$, 5225-5231

Mitsiades CS, Mitsiades N, Poulaki V, Schlossman R, Akiyama M, Chauhan D, Hideshima T, Treon SP, Munshi NC, Richardson PG, Anderson KC (2002): Activation of NF-kappaB and upregulation of intracellular anti-apoptotic proteins via the IGF-1/Akt signaling in human multiple myeloma cells: therapeutic implications. Oncogene 21, 5673-5683

Mitsiades CS, Mitsiades NS, McMullan CJ, Poulaki V, Shringarpure R, Akiyama M, Hideshima T, Chauhan D, Joseph M, Libermann TA, García-Echeverría C, Pearson MA, Hofmann F, Anderson KC, Kung AL (2004): Inhibition of the insulin-like growth factor receptor-1 tyrosine kinase activity as a therapeutic strategy for multiple myeloma, other hematologic malignancies, and solid tumors. Cancer Cell 5, 221-230

Mitsiades CS, Mitsiades NS, Munshi NC, Richardson PG, Anderson KC (2006): The role of the bone microenvironment in the pathophysiology and therapeutic management of multiple myeloma: interplay of growth factors, their receptors and stromal interactions. Eur J Cancer $\underline{42}, 1564-1573$

Moreau A-S, Jia X, Ngo HT, Leleu X, O’Sullivan G, Alsayed Y, Leontovich A, Podar K, Kutok J, Daley J, Lazo-Kallanian S, Hatjiharissi E, Raab MS, Xu L, Treon SP, Hideshima T, Anderson KC, Ghobrial IM (2007): Protein kinase C inhibitor enzastaurin induces in vitro and in vivo antitumor activity in Waldenstrom macroglobulinemia. Blood 109, 4964-4972 Mosmann T (1983): Rapid colorimetric assay for cellular growth and survival: application to proliferation and cytotoxicity assays. J Immunol Methods $\underline{65}$, 55-63

Nam SY, Lee HS, Jung G-A, Choi J, Cho SJ, Kim MK, Kim WH, Lee BL (2003): Akt/PKB activation in gastric carcinomas correlates with clinicopathologic variables and prognosis. APMIS $\underline{111}, 1105-1113$

Neri A, Marmiroli S, Tassone P, Lombardi L, Nobili L, Verdelli D, Civallero M, Cosenza M, Bertacchini J, Federico M, Pol A De, Deliliers GL, Sacchi S (2008): The oral protein-kinase C beta inhibitor enzastaurin (LY317615) suppresses signalling through the AKT pathway, inhibits proliferation and induces apoptosis in multiple myeloma cell lines. Leuk Lymphoma $\underline{49}, 1374-1383$

Nigg EA (1995): Cyclin-dependent protein kinases: key regulators of the eukaryotic cell cycle. Bioessays $\underline{17}, 471-480$ 
Nucci M, Anaissie E (2009): Infections in Patients with Multiple Myeloma in the Era of High-Dose Therapy and Novel Agents. Clin Infect Dis $\underline{49}, 1211-1225$

Nunez R (2001): DNA measurement and cell cycle analysis by flow cytometry. Curr Issues Mol Biol $\underline{3}, 67-70$

O'Brian C, Vogel VG, Singletary SE, Ward NE (1989): Elevated protein kinase C expression in human breast tumor biopsies relative to normal breast tissue. Cancer Res $\underline{49}$, 3215-3217

Ohtsuki T, Yawata Y, Wada H, Sugihara T, Mori M, Namba M (1989): Two human myeloma cell lines, amylase-producing KMS-12-PE and amylase-non-producing KMS-12$\mathrm{BM}$, were established from a patient, having the same chromosome marker, $\mathrm{t}(11 ; 14)(\mathrm{q} 13 ; \mathrm{q} 32)$. Br J Haematol 73, 199-204

Orlowski RZ (2006): Initial therapy of multiple myeloma patients who are not candidates for stem cell transplantation. Hematology Am Soc Hematol Educ Program, 338-347

Palumbo A, Anderson K (2011): Multiple myeloma. N Engl J Med 364, 1046-1060

Pene F, Claessens Y-E, Muller O, Viguié F, Mayeux P, Dreyfus F, Lacombe C, Bouscary D (2002): Role of the phosphatidylinositol 3-kinase/Akt and mTOR/P70S6-kinase pathways in the proliferation and apoptosis in multiple myeloma. Oncogene 21, 6587-6597

Philp AJ, Campbell IG, Leet C, Vincan E, Rockman SP, Whitehead RH, Thomas RJ, Phillips WA (2001): The phosphatidylinositol 3'-kinase p85alpha gene is an oncogene in human ovarian and colon tumors. Cancer Res $\underline{61}, 7426-7429$

Podar K, Tai YT, Davies FE, Lentzsch S, Sattler M, Hideshima T, Lin BK, Gupta D, Shima Y, Chauhan D, Mitsiades C, Raje N, Richardson P, Anderson KC (2001): Vascular endothelial growth factor triggers signaling cascades mediating multiple myeloma cell growth and migration. Blood $\underline{98}, 428-435$

Podar K, Raab MS, Zhang J, McMillin D, Breitkreutz I, Tai Y-T, Lin BK, Munshi N, Hideshima T, Chauhan D, Anderson KC (2007): Targeting PKC in multiple myeloma: in vitro and in vivo effects of the novel, orally available small-molecule inhibitor enzastaurin (LY317615.HCl). Blood 109, 1669-1677

Pollak M (2012): The insulin and insulin-like growth factor receptor family in neoplasia: an update. Nat Rev Cancer 12, 159-169 
Promega (2005): Technical Bulletin: CellTiter 96®AQueous Non-Radioactive Cell ProliferationAssay. INSTRUCTIONS FOR USE OF PRODUCTS G5421, G5430, G5440, G1111 AND G1112.

Qiang Y-W, Kopantzev E, Rudikoff S (2002): Insulinlike growth factor-I signaling in multiple myeloma: downstream elements, functional correlates, and pathway cross-talk. Blood 99, 4138-4146

Raab MS, Podar K, Breitkreutz I, Richardson PG, Anderson KC (2009): Multiple myeloma. Lancet $\underline{374}, 324-339$

Rajkumar SV (2012): Multiple myeloma: 2012 update on diagnosis, risk-stratification, and management. Am J Hematol $\underline{87}, 78-88$

Rajkumar SV, Buadi F (2007): Multiple myeloma: new staging systems for diagnosis, prognosis and response evaluation. Best Pract Res Clin Haematol 20, 665-680

Rajkumar SV, Kyle RA, Buadi FK (2010): Advances in the diagnosis, classification, risk stratification, and management of monoclonal gammopathy of undetermined significance: implications for recategorizing disease entities in the presence of evolving scientific evidence. Mayo Clin Proc 모, 945-948

Richardson PG, Barlogie B, Berenson J, Singhal S, Jagannath S, Irwin D, Rajkumar SV, Srkalovic G, Alsina M, Alexanian R, Siegel D, Orlowski RZ, Kuter D, Limentani SA, Lee S, Hideshima T, Esseltine D-L, Kauffman M, Adams J, Schenkein DP, Anderson KC (2003): A phase 2 study of bortezomib in relapsed, refractory myeloma. N Engl J Med 348, 2609-2617 Richardson P, Hideshima T, Anderson KC (2004): An update of novel therapeutic approaches for multiple myeloma. Curr Treat Options Oncol ㅁ, 227-238

Richardson PG, Hideshima T, Mitsiades C, Anderson KC (2007): The emerging role of novel therapies for the treatment of relapsed myeloma. J Natl Compr Canc Netw $\underline{5}, 149-162$ Richardson PG, Laubach JP, Schlossman RL, Ghobrial IM, Mitsiades CS, Rosenblatt J, Mahindra A, Raje N, Munshi N, Anderson KC (2011a): The Medical Research Council Myeloma IX Trial: The Impact on Treatment Paradigms(*). European Journal of Haematology

Richardson PG, Wolf J, Jakubowiak A, Zonder J, Lonial S, Irwin D, Densmore J, Krishnan A, Raje N, Bar M, Martin T, Schlossman R, Ghobrial IM, Munshi N, Laubach J, Allerton J, Hideshima T, Colson K, Poradosu E, Gardner L, Sportelli P, Anderson KC (2011b): 
Perifosine plus bortezomib and dexamethasone in patients with relapsed/refractory multiple myeloma previously treated with bortezomib: results of a multicenter phase I/II trial. J Clin Oncol 29, 4243-4249

Roche AS (2004): Prinzip des Cell Death Detection Elisa Plus. URL: https://www.rocheapplied-science.com/US/ProdInfo/images/oid_10750654.jpg (08062012)

Roodman GD (2010): Pathogenesis of myeloma bone disease. J Cell Biochem 109, 283-291

Roy HK, Olusola BF, Clemens DL, Karolski WJ, Ratashak A, Lynch HT, Smyrk TC (2002): AKT proto-oncogene overexpression is an early event during sporadic colon carcinogenesis. Carcinogenesis $\underline{23}, 201-205$

Russell SJ, Rajkumar SV (2011): Multiple myeloma and the road to personalised medicine. Lancet Oncol 12, 617-619

Saal LH, Johansson P, Holm K, Gruvberger-Saal SK, She Q-B, Maurer M, Koujak S, Ferrando AA, Malmström P, Memeo L, Isola J, Bendahl P-O, Rosen N, Hibshoosh H, Ringnér M, Borg A, Parsons R (2007): Poor prognosis in carcinoma is associated with a gene expression signature of aberrant PTEN tumor suppressor pathway activity. Proc Natl Acad Sci USA $\underline{104}, 7564-7569$

Salmon SE, Dalton WS, Grogan TM, Plezia P, Lehnert M, Roe DJ, Miller TP (1991):

Multidrug-resistant myeloma: laboratory and clinical effects of verapamil as a chemosensitizer. Blood $\underline{78}, 44-50$

Samuels Y, Velculescu VE (2004): Oncogenic mutations of PIK3CA in human cancers. Cell Cycle $\underline{3}, 1221-1224$

Scheid MP, Woodgett JR (2001): PKB/AKT: functional insights from genetic models. Nat Rev Mol Cell Biol 2, 760-768

Schwab G, Siegall CB, Aarden LA, Neckers LM, Nordan RP (1991): Characterization of an interleukin-6-mediated autocrine growth loop in the human multiple myeloma cell line, U266. Blood $\underline{77}$, 587-593

Schwarzenbach H (2002): Expression of MDR1/P-glycoprotein, the multidrug resistance protein MRP, and the lung-resistance protein LRP in multiple myeloma. Med Oncol $\underline{19}$, 87104 
Shaw RJ, Cantley LC (2006): Ras, PI(3)K and mTOR signalling controls tumour cell growth. Nature $\underline{441}, 424-430$

Shimizu S, Takiguchi T, Fukutoku M, Yoshioka R, Hirose Y, Fukuhara S, Ohno H, Isobe Y, Konda S (1993): Establishment of a CD4-positive plasmacytoma cell line (AMO1).

Leukemia $\underline{7}, 274-280$

Sirohi B, Powles R (2004): Multiple myeloma. The Lancet 363, 875-887

Sprynski AC, Hose D, Caillot L, Réme T, Shaughnessy JD, Barlogie B, Seckinger A, Moreaux J, Hundemer M, Jourdan M, Meissner T, Jauch A, Mahtouk K, Kassambara A, Bertsch U, Rossi JF, Goldschmidt H, Klein B (2009): The role of IGF-1 as a major growth factor for myeloma cell lines and the prognostic relevance of the expression of its receptor. Blood $\underline{113}, 4614-4626$

Stein RC, Waterfield MD (2000): PI3-kinase inhibition: a target for drug development? Mol Med Today $\underline{6}, 347-357$

Tai Y-T, Podar K, Catley L, Tseng Y-H, Akiyama M, Shringarpure R, Burger R, Hideshima T, Chauhan D, Mitsiades N, Richardson P, Munshi NC, Kahn CR, Mitsiades C, Anderson KC (2003): Insulin-like growth factor-1 induces adhesion and migration in human multiple myeloma cells via activation of beta1-integrin and phosphatidylinositol 3'-kinase/AKT signaling. Cancer Res $\underline{63}$, 5850-5858

The International Myeloma Working Group (2003): Criteria for the classification of monoclonal gammopathies, multiple myeloma and related disorders: a report of the International Myeloma Working Group. Br J Haematol 121, 749-757

Thundimadathil J (2012): Cancer treatment using peptides: current therapies and future prospects. J Amino Acids 2012, 967347

Toker A, Cantley LC (1997): Signalling through the lipid products of phosphoinositide-3-OH kinase. Nature $\underline{387}, 673-676$

Towbin H, Staehelin T, Gordon J (1979): Electrophoretic transfer of proteins from polyacrylamide gels to nitrocellulose sheets: procedure and some applications. Proc Natl Acad Sci USA $\underline{76}, 4350-4354$

Tu Y, Gardner A, Lichtenstein A (2000): The phosphatidylinositol 3-kinase/AKT kinase pathway in multiple myeloma plasma cells: roles in cytokine-dependent survival and proliferative responses. Cancer Res $\underline{60}$, 6763-6770 
Urashima M, Chen BP, Chen S, Pinkus GS, Bronson RT, Dedera DA, Hoshi Y, Teoh G, Ogata A, Treon SP, Chauhan D, Anderson KC (1997): The development of a model for the homing of multiple myeloma cells to human bone marrow. Blood 90, 754-765

Vanhaesebroeck B, Leevers SJ, Panayotou G, Waterfield MD (1997): Phosphoinositide 3kinases: a conserved family of signal transducers. Trends Biochem Sci $\underline{22}, 267-272$

Vanhaesebroeck B, Alessi DR (2000): The PI3K-PDK1 connection: more than just a road to PKB. Biochem J $\underline{346 ~ P t ~} 3,561-576$

Vanhaesebroeck B, Leevers SJ, Ahmadi K, Timms J, Katso R, Driscoll PC, Woscholski R, Parker PJ, Waterfield MD (2001): Synthesis and function of 3-phosphorylated inositol lipids. Annu Rev Biochem 70, 535-602

Varettoni M, Corso A, Pica G, Mangiacavalli S, Pascutto C, Lazzarino M (2010): Incidence, presenting features and outcome of extramedullary disease in multiple myeloma: a longitudinal study on 1003 consecutive patients. Ann Oncol 21, 325 -330 Venon M-D, Roccaro AM, Gay J, Moreau A-S, Dulery R, Facon T, Ghobrial IM, Leleu X (2009): Front line treatment of elderly multiple myeloma in the era of novel agents. Biologics $\underline{3}, 99-109$

Vivanco I, Sawyers CL (2002): The phosphatidylinositol 3-Kinase AKT pathway in human cancer. Nat Rev Cancer 2 , 489-501

Vogt PK, Hart JR, Gymnopoulos M, Jiang H, Kang S, Bader AG, Zhao L, Denley A (2010): Phosphatidylinositol 3-kinase: the oncoprotein. Curr Top Microbiol Immunol 347, 79-104 Walker EH, Perisic O, Ried C, Stephens L, Williams RL (1999): Structural insights into phosphoinositide 3-kinase catalysis and signalling. Nature $\underline{402}, 313-320$

Younes H, Leleu X, Hatjiharissi E, Moreau A-S, Hideshima T, Richardson P, Anderson KC, Ghobrial IM (2007): Targeting the phosphatidylinositol 3-kinase pathway in multiple myeloma. Clin Cancer Res $\underline{13}$, 3771-3775

Yuan TL, Cantley LC (2008): PI3K pathway alterations in cancer: variations on a theme. Oncogene 27, 5497-5510

Zhang XG, Bataille R, Widjenes J, Klein B (1992): Interleukin-6 dependence of advanced malignant plasma cell dyscrasias. Cancer $\underline{69}, 1373-1376$ 
Zhao L, Vogt PK (2008): Class I PI3K in oncogenic cellular transformation. Oncogene 27, $5486-549$ 
